\title{
CLOTH NAPKIN SINGULATION SYSTEM
}

\author{
By \\ SHUVRA BANIK \\ Bachelor of Science in Mechanical Engineering \\ Bangladesh University of Engineering \& Technology \\ Dhaka, Bangladesh \\ 2011
}

Submitted to the Faculty of the

Graduate College of the

Oklahoma State University

in partial fulfillment of

the requirements for

the Degree of

MASTER OF SCIENCE

December, 2013 


\section{CLOTH NAPKIN SINGULATION SYSTEM}

Thesis Approved:

Dr. Lawrence L. Hoberock

Thesis Adviser

Dr. Gary E. Young

Dr. Martin T. Hagan 


\section{ACKNOWLEDGEMENTS}

I would like to express my deepest gratitude to my thesis adviser, Dr. Lawrence L. Hoberock, for his advice, encouragement, constant support, understanding, flexibility and many hours of guidance throughout my graduate program. My sincere appreciation extends to Dr. Gary E. Young and Dr. Martin T. Hagan for serving on my thesis committee.

I would like to extend my thanks to Mr. John T. Gage, DML Manager, other employees and teaching assistants at DML, and Mr. Gary D. Thacker, CEAT support services, for their cordial assistance. I would also like to extend my thanks to my past and present colleagues at Robotics Laboratory, Mr. Daman Bareiss, Mr. Rajashekar R. Chitaveli, Mr. Sai V. G. Lolla, Mr. Trung H. Duong, Mr. Mohsen Emami, Mr. Mehran Andalibi, Mr. Ali A. Sadabad and Mr. Hossein Mohamadipanah for their friendship and support. I would like to express my special thanks to my friends, Mr. Md Abu Hasan, Mr. Md Farhadul Haque, Mr. Md Montashirur Rahman and Mr. Maruful Hasan for helping me

when needed. My thanks go to all of my other friends for their encouragement and support. My sincere gratitude also goes to School of Mechanical and Aerospace Engineering for providing me with teaching assistantships throughout my graduate study.

Finally I would like to express my heartiest thanks and appreciation to my parents and sister for their unfailing support and encouragement through the entire duration of this research work and all other endeavors in my life. 
Name: SHUVRA BANIK

Date of Degree: DECEMBER, 2013

Title of Study: CLOTH NAPKIN SINGULATION SYSTEM

Major Field: MECHANICAL AND AEROSPACE ENGINEERING

\begin{abstract}
:
Scope and Method of Study:

Food service establishments serve food to many customers daily reusing a small inventory of silverware pieces. These silverware pieces are washed after each use and sets of pieces (e.g., a spoon, a soup spoon, a fork, and a knife per set) are often wrapped in napkins for using during further food serving. Upscale restaurants generally use cloth napkins, while others use paper napkins. Whether it is a cloth napkin or paper napkin, manual wrapping of silverware pieces in napkins is repetitive, tedious, and laborintensive. Hence automation of wrapping of silverware pieces is highly desirable. One major component of an automated silverware wrapping system is a napkin singulator to feed the wrapping system with singulated napkins to be used for wrapping. This study investigates the design and construction of a cloth napkin singulation system, capable of singulating cloth napkins from a given stack of napkins without human interaction. The method of this study has been primarily experimental.
\end{abstract}

Findings and Conclusions:

A reliable cloth napkin singulation system with high accuracy has been designed, developed, constructed and evaluated. The system utilizes an adhesive tape to pick a napkin from a stack of napkins and a mechanism utilizing a linear actuator to remove the picked napkin from the adhesive tape near an upstream conveyor end. Then the removed napkin is passed along the moving conveyor to be fed to a silverware wrapping system, and the cycle is repeated until all napkins in the feed stack have been singulated. Results of evaluation demonstrate development of a cloth napkin singulation system with a high average singulation efficiency of $96 \%$, which is a $14 \%$ increase over the earlier version of this mechanism. Also the system developed in this study is completely automated, unlike the earlier one. The average singulation time for each napkin cycle achieved by this system is 1.34 minutes, but this time can easily be decreased by employing higher speed carriage drive motors. 


\section{TABLE OF CONTENTS}

Chapter

Page

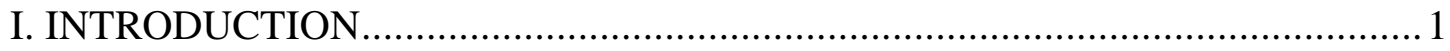

1.1 Automation of Silverware Handling ........................................................ 1

1.2 Literature Review of Preceding Work at Oklahoma State University ............. 3

1.2.1 Silverware Singulation ............................................................... 4

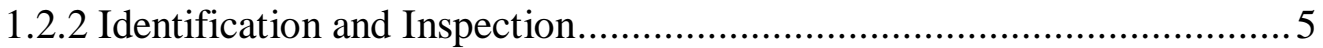

1.2.3 Silverware Sorting ................................................................... 7

1.2.4 Silverware Grouping ......................................................... 8

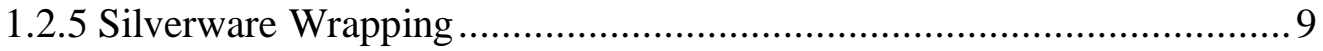

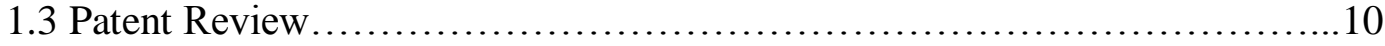

1.4 Previous Cloth Napkin Singulation Work - Jeyapalan (2005)............... 14

1.5 Objective.........................................................21

II. DESIGN OF CLOTH NAPKIN SINGULATION SYSTEM..............................23

2.1 Previous State of Design......................................................................23

2.1.1 Problems Identified with Existing Setup.........................25

2.2 Design Considerations................................................27

2.2.1 Design of Napkin Picking System................................29

2.2.2 Design of System to Move a Picked Napkin to a Conveyor....................32

2.2.3 Design of Napkin Removal System....................................35

2.2.4 Design of System to Engage a Napkin on the Moving Conveyor...........41

2.2.5 Design of System to Return Carriage to Resting Position......................48

2.2.6 Design of Napkin Tray Lifting System...............................................49

2.2.7 Design of Adhesive Tape Renewal System.........................................53

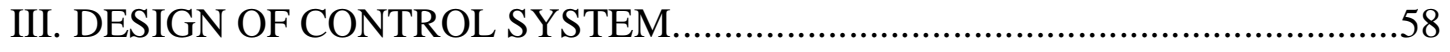

3.1 Interface between Actuators, Sensors and Controllers ..............................58

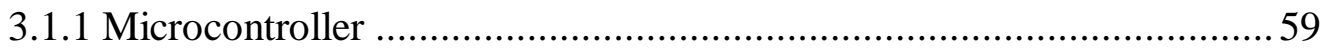

3.1.2 Control System for Carriage Slider-Crank Mechanism ......................60 60

3.1.3 Control System for Carriage Rack-and-Pinion Mechanism .................. 63

3.1.4 Control System for Napkin Removing and Napkin Engaging Linear Actuator 
3.1.5 Control System for Conveyor.....................................69

3.1.6 Control System for Napkin Tray Lifting Mechanism...................70

3.1.7 Control System for Adhesive Tape Renewal System.................. 72

3.1.8 Power Supply Units...............................................73

3.2 Program for Cloth Napkin Singulation System.............................76

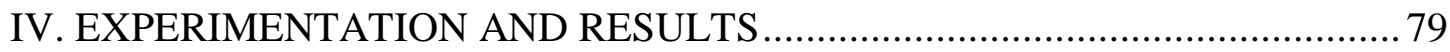

4.1 Factors Considered for Experimentations …………..................................... 79

4.1.1 Performance of Napkin Picking Mechanism ....................................... 80

4.1.2 Performance of Napkin Removing Mechanism..................................... 81

4.1.3 Performance of Mechanism to Engage Napkin on Conveyor ................8 83

4.2 Tabulation of Performance of Cloth Napkin Singulation System .................. 84

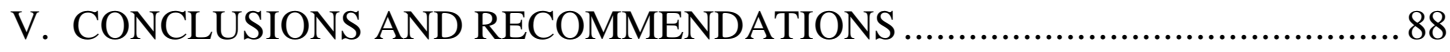

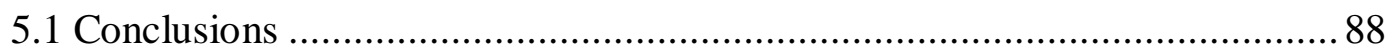

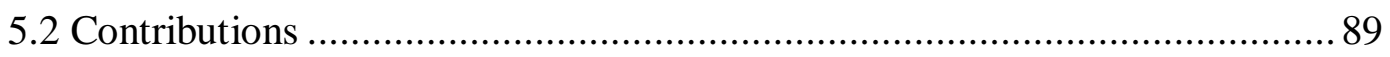

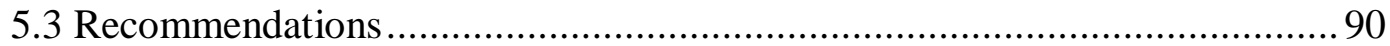

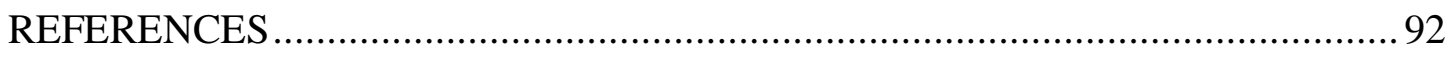

APPENDICES

Appendix A - Abstracts of Patents.................................................................... 96

Appendix B - Detailed and Dimensioned Photographs of Cloth Napkin

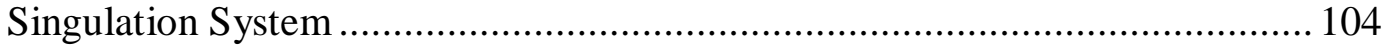

Appendix C - Datasheet for Microcontroller and Detailed Prototyping Board

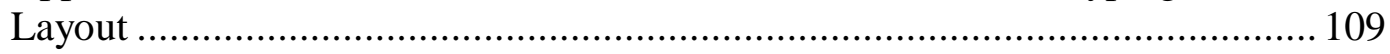

Appendix D - Datasheet for Carriage Slider-Crank and Conveyor Motors ........ 113

Appendix E - Datasheet for Bidirectional PWM Motor Speed Controller for

Carriage Slider-Crank Mechanism ............................................................... 115

Appendix F - Datasheet for Top, Front, Middle and Rear Infrared Sensor

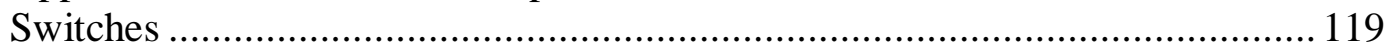

Appendix G - Datasheet for Carriage Stepper Motors....................................... 123

Appendix H - Datasheet for Micro Stepping Drivers for Carriage

Rack-and-Pinion Mechanism .................................................................... 126

Appendix I - Datasheet for Linear Actuators for Napkin Removing and

Napkin Engaging Mechanisms .................................................................... 130

Appendix J - Datasheet for Linear Actuator Control Boards for Napkin

Removing and Napkin Engaging Mechanisms 
Appendix K - Datasheet for DC to Pulse Width Modulator for Conveyor and Adhesive Tape Renewal Mechanism ...................................................... 137

Appendix L - Datasheet for Napkin Tray Lead Screw Stepper Motor ...

Appendix M - Datasheet for Bipolar Stepper Motor Driver for Napkin Tray Lifting Mechanism......................................................................... 148

Appendix N - Datasheet for Adhesive Tape Renewal Motor.......................... 151

Appendix O - Datasheets for Power Supply Units ......................................... 153

Appendix P - Source Code for Cloth Napkin Singulation Program 


\section{LIST OF TABLES}

Table $\quad$ Page

4.1 Performance of Cloth Napkin Singulation System......................... 84

4.2 Time taken by Cloth Napkin Singulation System.......................... 86 


\section{LIST OF FIGURES}

Figure $\quad$ Page

1.1 Flow Diagram of Automation of Post-dishwashing Silverware Handling ..........2

1.2 Position of a Roller on a Stack of Cloth Napkins (Jeyapalan, 2005)................ 16

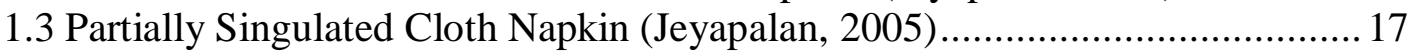

1.4 Final Design for the Napkin Singulator (Jeyapalan, 2005) ............................ 18

1.5 Napkin Tray Lifting Mechanism (Jeyapalan, 2005) ................................... 20

2.1 Flow Diagram of Cloth Napkin Singulation System ..................................28

2.2 Carriage Slider-Crank Configuration (Perspective View) .............................29

2.3 Schematic Diagram of Napkin Picking Mechanism (Front View)................... 31

2.4 Carriage Rack-and-Pinion Configuration (Perspective View) .......................... 33

2.5 Schematic Diagram of Napkin Moving Mechanism (Angled View from $45^{\circ}$

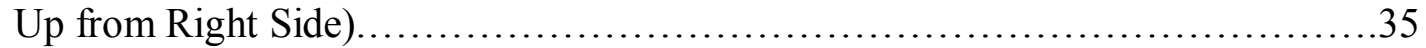

2.6 Napkin Removal Configuration (Perspective View) ................................... 36

2.7 Previous Attempts for Napkin Removal (Perspective View) ........................... 38

2.8 Schematic Diagram of Napkin Removal (Perspective View) ......................... 40

2.9 Previous Four-Bar Configuration (Side View) ....................................... 42

2.10 Napkin Engaging Configuration (Perspective View) ............................... 43

2.11 Conveyor Configuration (Perspective View) ........................................... 44

2.12 Take-Up Roller (Side View) ........................................................ 45

2.13 Schematic Diagram of Napkin Engagement on Moving Conveyor ................ 47

2.14 Schematic Diagram of Carriage Return (Angled View from $45^{\circ} \mathrm{Up}$ from

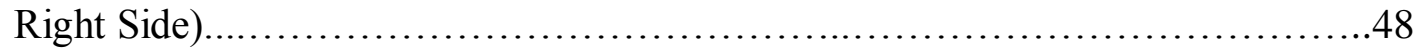

2.15 Previous Napkin Tray Lifting Configuration (Side View) ............................50

2.16 Napkin Tray Lifting Configuration (Perspective View) ...............................51

2.17 Schematic Diagram of Napkin Tray Lifting (Side View) .............................53

2.18 Tape Roll Configuration (Perspective View) ........................................ 54

2.19 Schematic Diagram of Adhesive Tape Renewal (Front View) ......................56

2.20 Cloth Napkin Singulation System (Perspective View) .................................5 57

3.1 Schematic Diagram of Pin Configuration of PIC18F4520 Prototyping Board .. 60

3.2 Schematic Connection Diagram for Carriage Slider-Crank Control System..... 61

3.3 Schematic Connection Diagram for Top Infrared Sensor Switch ....................62

3.4 Schematic Connection Diagram for Carriage Rack-and-Pinion Control

System.....

3.5 Schematic Connection Diagrams for Front, Middle, and Rear Infrared Sensor

Switches........................................................66 
3.6 Schematic Connection Diagrams for Napkin Removing and Napkin Engaging Linear Actuators Control Systems......................................................................68

3.7 Schematic Connection Diagram for Conveyor Control System........................69

3.8 Schematic Connection Diagram for Napkin Tray Lifting Control System......... 71

3.9 Schematic Connection Diagram for Adhesive Tape Renewal Control System.72

3.10 Schematic Diagram of Pin Configuration of Power Supply Units .................. 74

3.11 Schematic Connection Diagram of Complete Control System .........................75

3.12 Flowchart for Cloth Napkin Singulation Algorithm....................................... 77

4.1 Picking of Multiple Napkins at a time by Adhesive Tape ……......................... 80

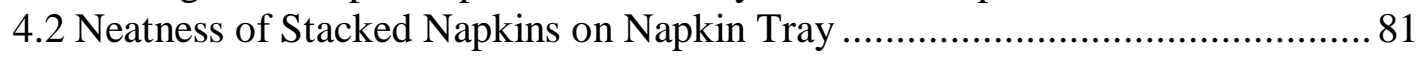

4.3 Partially Extended Napkin Removing Linear Actuator ................................... 82

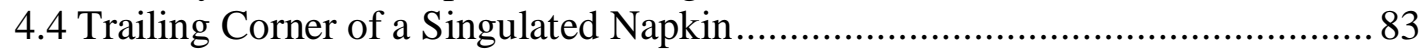

B1 Detailed Perspective View of Cloth Napkin Singulation System Setup .......... 105

B2 Dimensioned Front View of Cloth Napkin Singulation System Setup ............. 106

B3 Dimensioned Side View of Cloth Napkin Singulation System Setup .............. 107

B4 Dimensioned Top View of Cloth Napkin Singulation System Setup................108 


\section{CHAPTER I}

\section{INTRODUCTION}

\subsection{Automation of Silverware Handling}

Large commercial food service establishments, such as large chain restaurants and kitchens of hospitals, cruise lines, hotels and resorts, and other large professional catering and dining services prepare and serve large amounts of food to feed hundreds, or thousands of people on a regular basis, generating substantial amounts of dirty dishes and silverware pieces. These are often washed in large commercial dishwashing machines. Post-dishwashing processing of silverware pieces includes a series of operations, namely: segregating individual pieces from the clean, wet, entangled cluster of silverware pieces exiting the dishwasher, identifying the types and orientations of the silverware pieces, inspecting the pieces for cleanliness, sorting the identified, oriented and clean silverware pieces into different groups based on their types (e.g., spoon, soup spoon, fork and knife), separating individual silverware pieces from these groups to produce one set of different silverware pieces to be rolled in a napkin, singulating individual napkins from a stack of napkins, and finally wrapping each silverware set in a napkin to be used during serving of food. Most of these operations are repetitive, tedious and labor-intensive process, performed manually in hot, moist environments with unpleasant working conditions for long durations, making these an ideal candidate for automation. 
Automation of the handling of silverware pieces in such commercial establishments holds promise for reduced labor, minimized operating costs, faster operations, and increased productivity, such that an efficient automated process is highly desirable. A conceptual flow diagram of the overall automation of a silverware handling process is given in Figure 1.1, where arrows indicate the direction of silverware flow. Unclean and unidentified silverware pieces are returned to dishwasher and silverware singulation system, respectively.

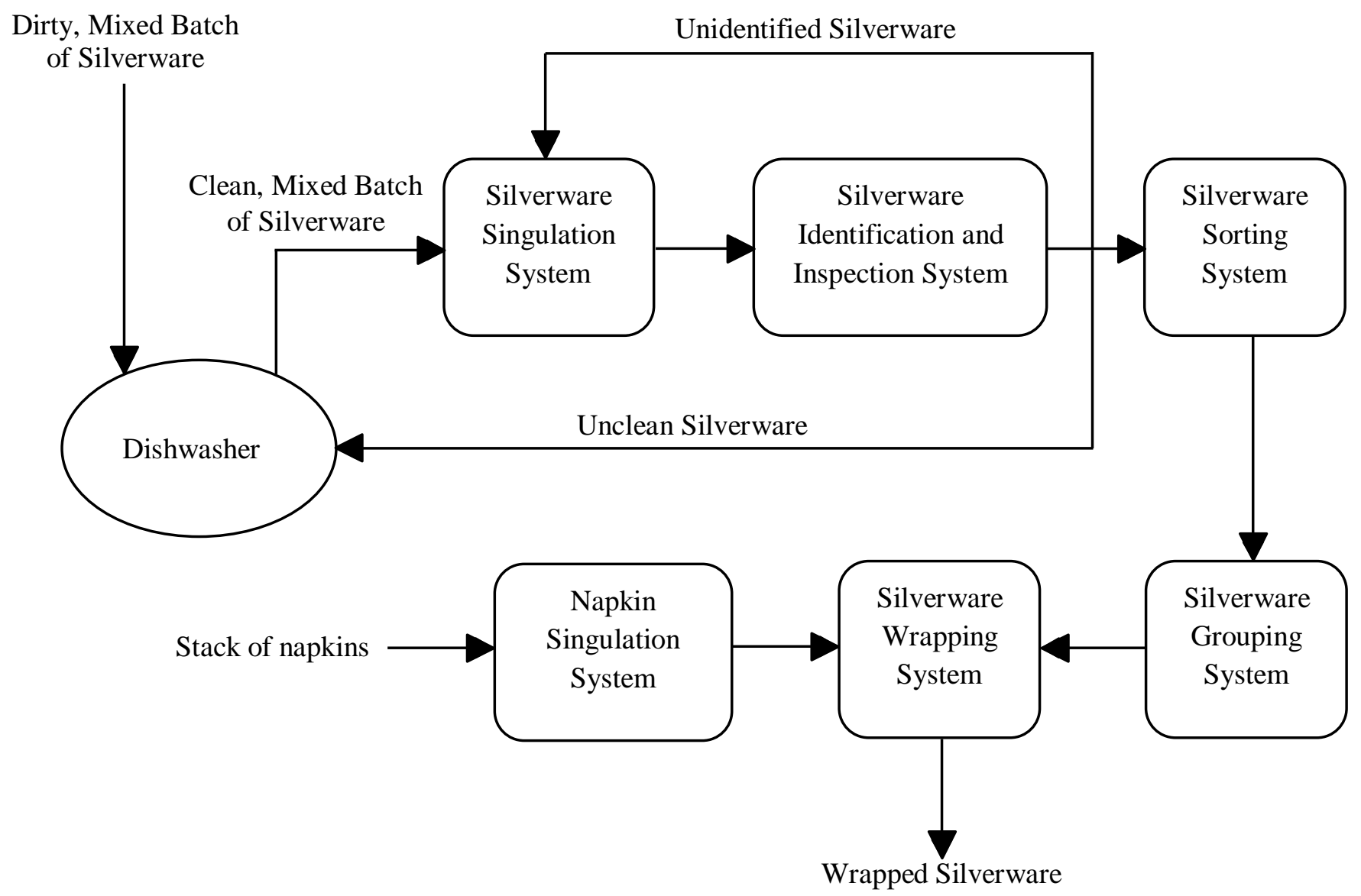

Figure 1.1: Flow Diagram of Automation of Post-dishwashing Silverware Handling 
The study herein has been motivated by a typical commercial dishwashing operation in a privately held 700-bed hospital in the Midwestern U.S. which operates 3 two-hour dishwashing shifts daily, each processing up to 700 trays of dishes (Hashimoto, 1995; Yeri, 2003; Nagaraj, 2003; Peddi, 2005; Akella, 2008; Chitaveli, 2011). Each tray typically consists of four silverware pieces, a spoon, a soup spoon, a fork and a knife, amounting to 2800 silverware pieces a shift, or 8400 pieces a day. Due to space and time limitations involved in pre-scrubbing and silverware loading operations at the upstream end of the process, these pieces are not sorted before washing. Typically, all silverware pieces are mixed together in a container and fed into the dishwasher for batch-wash. Thus, after the washing shift has been completed, one or two workers must inspect up to 2800 pieces of silverware for cleanliness and sort them in different groups based on their types in less than two hours. Additional operations may require grouping four different silverware pieces together to produce a set, singulating individual napkins from a stack of napkins and wrapping each silverware set in a napkin to be used in food serving. Thus this manual, repetitive, tedious and labor-intensive handling of silverware pieces leaves a good option for a fast, adaptable, efficient and also cost-effective automation.

\subsection{Literature Review of Preceding Work at Oklahoma State University}

Prior to this work, a significant amount of work to automate the post-dishwashing handling of silverware pieces was attempted at Oklahoma State University. Below is a brief description of all of the various approaches developed, their functions, and their limitations, which led to this project. 


\subsubsection{Silverware Singulation}

Hashimoto (1995) designed a prototype silverware singulating machine to separate single pieces of silverware from an assortment of silverware pieces containing four kinds of silverware: spoon, soup spoon, fork and knife. She utilized a vertically oriented multi-paneled vibrating feed hopper, into which the mixed batch was fed, together with a magnetic conveyor that pulled the separated and aligned single pieces discharged from the bottom of the hopper. The vibrating feed hopper exerted vibration to the batched silverware inside at an appropriate frequency and amplitude to prevent silverware pieces from jamming. Different panel openings in the feeder metered the number of silverware pieces on their way to the feeder exit located at the bottom of the feeder, which again metered individual pieces onto the conveyor. The magnets of the conveyor attracted the individual pieces and conveyed them securely to the conveyor discharge. She used two different batches of randomly mixed silverware pieces, small and large, each containing 33 and 66 pieces, respectively, for experimentation and achieved a separation accuracy of $41 \%$ and an alignment accuracy of $14.9 \%$. Though her constructed prototype had limited capability, it served as a great starting point for developing an effective silverware singulator.

Akella(2008) improved on Hashimoto's singulation device by using a horizontally oriented vibrating bin containing the mixed batch of cleaned silverware, which served as the feeding device. This was followed by a downward sloping plane, an inclined metering bin, and a singulating trough made of duck cloth with a magnetic conveyor underneath. A crank pin mechanism applied an in-line vibration pattern to the large silverware batch feed bin, which helped dispense silverware pieces in comparatively small batches onto the sloping plane. Two controlled electromagnets beneath the sloping plane worked as non-intrusive gates, which controlled the number of silverware pieces sliding down the incline. Silverware pieces then reached a vibrating metering bin, actuated by a solenoid plunger, where they were delivered onto the singulating trough. Three comb-circuit conducting copper strip sensors were installed at 
different locations on the inclined plane to provide the electromagnets and the solenoid with correct feedback of the presence of silverware pieces. Finally the silverware pieces were conveyed to the discharge along the singulating trough by the magnetic force delivered from magnetic buttons on a moving conveyor beneath the trough. Akella used a large batch of 400 silverware pieces for experimentation and obtained an average singulation efficiency of $92.9 \%$ and an average throughput of 28.41 pieces/min.

Chitaveli (2011) fine-tuned Akella's singulating device by addressing several imperfections. He resolved non-uniform dispensing from the feed bin to the downward sloping plane by replacing the feed bin with a slowly moving, lengthy conveyor. Instead of using Akella's copper strip sensors (which were prone to failure due to wear from the sliding silverware), he used noncontact inductive proximity sensors to detect the presence of silverware pieces. He also reduced surface wear on the singulating trough by replacing Akella's duck cloth with a combination of thin plastic sheet and teflon sheet. Like Akella, he also tested a batch of 400 silverware pieces and achieved an average singulation efficiency of $94.40 \%$ and an average throughput of 35.70 pieces/min which was a $1.5 \%$ increase in average singulation efficiency and a $25.66 \%$ increase in average throughput over Aklella's macine.

\subsubsection{Identification and Inspection}

Yeri (2003) employed machine vision to identify the types and find the orientation of singulated silverware pieces delivered from a silverware singulating machine. His device consisted of a suspended dome shaped lighting enclosure, a digital line scale camera with a lens and a polarizer mounted at the top of the dome, two linear polarizers for reducing specular reflections, four quartz halogen lamps for illumination, a frame grabber for computer interfacing, and a magnetic conveyor which carried the silverware pieces in and out of the dome. In order to isolate the 
efficiency of the vision system from that of the singulating machine, silverware pieces were fed into the system by manually placing them onto the conveyor. A combination of a photoelectric transmitter-emitter pair and a delay circuit was used to trigger the camera exactly when the silverware piece was below the camera center-line. Images captured in gray scale were then converted into binary images and further processing was done to generate three properties, namely area, length and width of the silverware piece. Comparison of these properties with preset values of the silverware pieces yielded types and orientation of the silverware pieces on the conveyor. Tests were conducted with a fixed batch of 25 silverware pieces in each trial at different conveyor speeds and $100 \%$ orientation detection efficiency was obtained along with identification efficiencies that ranged from $86 \%$ at $35 \%$ of maximum conveyor speed to $91.6 \%$ at $60 \%$ of maximum conveyor speed. His device could process silverware pieces at a rate of 105 pieces/min.

Lolla (2005) enhanced Yeri's identification system by adding inspection of silverware pieces for cleanliness. He used a modified version of Yeri's lighting setup by adding curtains, removing diffusers, and replacing previous AC light sources with DC lamps, which resulted in better lighted regions with less noise in the captured images. The reliability of the identification algorithm was improved by measuring area moment of inertia and perimeter, in addition to area during image processing. Edge detection was employed to distinguish dirty silverware pieces from the clean ones. His system achieved $100 \%$ identification efficiency, with an average accuracy of $87 \%$ in classifying clean silverware pieces and an average accuracy of $91 \%$ in classifying dirty silverware pieces. The maximum processing rate for his setup was approximately 55 pieces/min. 


\subsubsection{Silverware Sorting}

Nagaraj (2003) constructed a silverware sorting machine that could receive signals from a silverware identification device, and based on such signals, sort the silverware pieces into different bins. The silverware pieces were scraped off a magnetic conveyor of the silverware identification device by using a solenoid controlled wooden flap which could be moved up and down. Then the silverware pieces were passed through a stepper motor controlled diverter, which oriented all the silverware pieces in the same direction, either handle up or handle down. After that the silverware pieces entered a stepper motor controlled rotating chute, which directed them into specific guideways according to their types through a plastic arm. The guideways then led the pieces into respective collection bins. The entire setup was placed on an inclined wooden slide board, which helped the silverware pieces move by gravity. Infrared switches were used to get feedback of the positions of the stepper motors. Her machine had an at an optimum process rate of 34 pieces/minute, with an efficiency of $98.13 \%$.

Peddi (2005) implemented robust techniques to construct a compact, faster and more effective silverware sorting and orienting device, which was able to avoid shortcomings of Nagaraj's device. He redesigned the magnetic conveyor by introducing slotted plastic blocks mounted on the top of magnets to support silverware pieces, which eliminated silverware vibration during conveying. Solenoid actuated lifting systems consisting of fingers on hinged metal plates were designed to mesh into the slots of the plastic blocks to remove the silverware pieces from the plastic blocks. Removed silverware pieces were then stored and oriented into different bins based on their types and cleanliness. He used batches of 25 randomly mixed silverware pieces for testing purpose and achieved an integrated sorting and orienting accuracy above $98 \%$ at a processing rate of 55 pieces/min. 


\subsubsection{Silverware Grouping}

Sabpipatana (2010) developed a silverware grouping mechanism that could singulate a single piece of silverware from each grouping of identical, aligned spoons, soup spoons, forks and knives from the output of Peddi's sorting device and produce a set of 4 different silverware pieces to deliver to a wrapping device to be wrapped in a napkin. His device consisted of four inclined bins, each capable of accommodating 15 silverware pieces, a bin shaking mechanism to minimize entanglement of silverware pieces in the bins, a conveyor and an electromagnetic silverware picking mechanism. The picking mechanism picked up silverware pieces from the bins and released them on the conveyor. Picking and releasing of the silverware pieces were operated by controlling the current supply to the electromagnets. When a complete set of silverware was placed on the conveyor, the conveyor was activated to carry the set off the conveyor. His device could produce sets of silverware pieces at a rate of 5.40 sets/min and was $100 \%$ successful in forming complete silverware sets.

Sadabad (2011) integrated silverware identification, orientation detection, sorting and grouping into a single device and thus eliminated complexity. Instead of using magnetic susceptibility of the silverware materials, he incorporated a vision-based identification system, which made the identification process independent of the material of which the pieces were made. Silverware pieces on a horizontal conveyor at the entrance were identified using a vision system consisting of a camera, a light box, an image acquisition board and a program written in MATLAB and installed on a computer. Images captured by the camera were converted into digital format by the image acquisition board and sent to the computer. Further processing was done by the software and properties such as major axis length, minor axis length, center location and centroid location were calculated and compared with pre-set values, which led to the decisions regarding types and orientations of the silverware pieces. After a decision was made, a pneumatic powered sweeper mechanism pushed the silverware pieces off the conveyor into appropriate bins, either based on 
their types and orientation, or based on grouping into a set of 4 different pieces to be delivered to a silverware wrapping machine. The integrated (hardware and software) accuracy of his system was $88.75 \%$; software accuracy was $88.75 \%$ and $99.37 \%$ in identifying types and direction, respectively. Mechanical sorting efficiency of his device was $90.63 \%$.

\subsubsection{Silverware Wrapping}

Jeyapalan (2005) designed and constructed a device to wrap a set of silverware pieces in a cloth napkin. The wrapping process was split into three sub-processes: singulating one cloth napkin from a stack of cloth napkins, dropping a silverware set onto the singulated cloth napkin and folding the silverware set in the napkin. A powered roller attempted to singulate the topmost napkin from the napkin stack by pressing vertically downward onto the stack. The napkin stack was placed on a tray powered by thee lead screw motors to maintain proper contact between the stack and the powered roller. An unpowered roller fixed on a powered rotating arm placed and released the singulated napkin on a belt running over a static cylindrical quadrant. The belt then carried the napkin to the horizontal portion of a conveyor. After that a solenoid-powered silverware drop mechanism placed a set of silverware pieces on one of the diagonal portions of the napkin. Then a sequence of continuous folds or rolls was made by three folding mechanisms. Finally, the rolled napkin was conveyed out of the system and dropped into a collecting bin. During experimentation, Jeyapalan found that the sliding friction between the top two napkins of the stack was much higher than expected, such that napkin singulation was not possible. To overcome this, he interleaved the napkins in the stack with vellum papers of the same size as the napkins. The sheets of paper in the napkin stack were manually removed after each napkin was conveyed to the silverware drop mechanism. This left the process un-automated, but helped to test the feasibility of the other components. Despite this modification, the unified processing 
efficiency of his device was only $68 \%$. To address reasons for low efficiency, Jeyapalan conducted tests by manually feeding the napkins to the device and achieved $100 \%$ processing efficiency. This indicated large need for improvement in the cloth napkin singulation system. The area addressed in the work herein is cloth napkin singulation. A patent search, a detailed description of work by Jeyapalan in cloth napkin singulation and a thesis objective will be presented in what follows.

\subsection{Patent Review}

A patent search through the database of the United States Patent and Trademark Office was conducted to find patents related to cloth napkin singulation. Initial searches using keywords including "Napkin singulation", "Napkin separation", "Napkin removal', "Picking up napkin" etc. did not return any patents specifically related to napkin singulation adapted for silverware wrapping. Further searches were then conducted using a variety of keywords including "Silverware wrapping", "Silverware rolling", "Flatware wrapping", "Flatware Rolling", "Eating utensils wrapping", "Eating utensils rolling" etc., which resulted in several pertinent patents. After careful scrutinization, wrapping systems without a napkin singulation system have been discarded from the scope of this discussion. A brief summary of the patents related to napkin singulation for a silverware wrapping device is presented in what follows. Abstracts of these patents are given in Appendix A.

U.S. Patent 6,023,908 "Method and apparatus for folding a napkin around an eating utensil", February 15, 2000, describes a silverware wrapping device with a napkin singulation system. A stack of napkins is placed diagonally on a spring loaded platform. A napkin selector belt containing a plurality of Velcro® patches or similar attachment means on its upper surface picks a napkin from the stack and delivers it to a folding mechanism. The patent does not provide any 
information on the material of the napkin, i.e. paper or cloth, which is important for properly picking up the napkin using the attachment means on the selector belt. Release of the picked napkin is mentioned to be performed by a disconnect rod, which does not appear very practical. Moreover, the singulation process is not automated, needing significant manual labor to drive a hand-crank to move the napkin selector belt.

U.S. Patent 6,023,913 "Apparatus and method for wrapping silverware within a napkin", February 15, 2000, mentions a silverware wrapping device with an automatic napkin singulation system. The napkin pick-up system comprises a pick-up head and transport means. The pick-up head has a pair of rollers which can be turned in opposite directions simultaneously. To pick up a napkin, the pick-up head is lowered upon a stack of paper napkins using the transport means, and the rollers are rotated in opposite directions such that the top napkin of the stack gets pinched between the rollers. Then the pick-up head and the napkin are transported to the work table using the transport means. There the rollers are rotated in opposite directions to disengage the napkin on the work table. The entire system is driven by an air-powered actuator. The napkin singulation system uses paper napkins, presumably owing to the fact that the napkin must have some rigidity to get properly pinched between the rollers. Therefore this system may not work with cloth napkins. Again, the pinch might wrinkle the paper napkins which would decrease the quality and esthetic appeal of the wraps.

U.S. Patent 6,837,028 “Automated flatware and napkin assembling apparatus", January 4, 2005, represents a napkin singulation device which is suitable only for disposable paper napkins available in rolled form. A napkin stream from a roll of rolled paper napkins is fed to the wrapping system by an indexing roller arrangement. The rollers are powered by stepper motors, and the motors are controlled by a logic controller such as a Programmable Logic Controller (PLC) or a basic stamp module. This device would not be appropriate for cloth napkins, because 
cloth napkins usually are not available in rolled form. Also the indexing rollers may not work properly with cloth napkins.

U.S. Patent 6,918,226 “Automatic utensil wrapping machine”, July 19, 2005, gives an outline of a utensil wrapping machine with an automatic napkin singulation system. The napkin singulation unit consists of a napkin lifting station which supports a stack of napkins and a napkin transfer station which transfers the napkins to a wrapping station. The napkin transfer station uses a number of suction devices to releasably engage a napkin from the top of the napkin stack and then this napkin on to the wrapping station. After a predetermined number of napkins are removed from the napkin stack, the napkin lifting station raises the napkin stack to accommodate the decreased stack height. Air cylinders are used to power the singulation process, which may make the device overly bulky to fit in a small work space. Moreover, the patent claims that the machine works with any types of napkins, i.e. paper or cloth, which is doubtful because the performance of the suction devices to engage a napkin is not likely to be the same on different types of napkins. Moreover, earlier experiments in our work showed that suction devices on cloth napkins were ineffective due to high permeability of the cloth.

U.S. Patent 7,210,279 "Device for wrapping a napkin about silverware and associated method", May 1, 2007, proposes a model of silverware wrapping mechanism which includes an automatic napkin singulation system. A horizontally moving vacuum head, connected to a conveyor belt assembly picks up a napkin from a stack of napkins and carries it to the wrapping mechanism and disengages. The napkin stack is placed on a platform connected to a vertically oriented pulley assembly, which helps to maintain a specific vertical distance between the vacuum head and the top napkin of the stack. The patent does not provide any information on the material of the napkin. Again, vacuum pick-up on our cloth napkins was ineffective. Also there is a possibility of misalignment of the released napkins at the wrapping section because of jittery movement of the vacuum head caused by the conveyor belt. 
U.S. Patent 7,322,172 "Utensil wrapping apparatus and method", January 29, 2008, delivers an idea of a silverware wrapping device with an automated napkin delivery mechanism. The napkin delivery system has a transfer arm that rotates about a pivot point. The transfer arm is proposed to include grippers, robotic fingers or other mechanisms like vacuum lifting portion to lift up one napkin from a stack of napkins and deliver that to the wrapping area. The patent also suggests an alternative mechanism of napkin delivery similar to paper feed mechanism of a computer printer which might work with paper napkins but will most likely fail with cloth napkins (Jeyapalan, 2005). Furthermore, the design of the transfer arm would most likely fail to deliver a napkin in a spread condition to the wrapping mechanism, which is required to produce good quality wraps.

U.S. Patent 7,412,808 "Food service set assembly system", August 19, 2008, presents a system to deliver wrapped silverware, which also houses an automatic napkin singulation unit. The napkin singulation unit consists of a napkin magazine and a transfer assembly. The napkin magazine has a spring-loaded plate on which a stack of napkins is placed and a lift rod which picks up napkins from the stack. The transfer mechanism includes a clip and mechanism that receives a single napkin from the magazine and delivers the napkin to the wrapping mechanism. Another mechanism consisting of a vacuum chuck powered by an air compressor and tank is also suggested for picking up napkins from the stack. However none of these operations are explained in detail, which raises doubt about effectiveness. Similarly, the patent claims the invention will work with any type of napkin is doubtful.

U.S. Patent 7,513,089 "Device for holding and dispensing utensils for wrapping apparatus", April 7, 2009, portrays a napkin singulation method designed for a silverware wrapping mechanism. A stack of napkins is placed on a platform whose height can be adjusted using a motorized, pneumatic or mechanical mechanism. To pick up the top napkin of the stack, the platform is lifted upward until a vacuum pick up head makes contact with the top napkin. After the napkin is picked up by the vacuum pick up head, the platform is lowered. When the platform returns to its 
original position, clamps are used to hold the top napkin. The clamps then release the napkin to a wrapping mechanism. Though the patent claims that the invention works with any types of napkins, our experience shows that vacuum pick-up is ineffective for cloth napkins.

It is evident from these patents that a significant amount of ingenuity has been dedicated to solving the napkin singulation problem to deliver singulated napkins to a silverware wrapping device. However, we are not aware of any commercial success of these patents because of several shortcomings, including inability to singulate cloth napkins properly, failure in producing good wraps with a professional appeal, complication in design and implementation, high production cost, unsatisfactory throughput, and requirement of significant manual labor. Thus significant room is left to develop a cloth napkin singulation system that could properly and effectively deliver singulated cloth napkins to a silverware wrapping device.

\subsection{Previous Cloth Napkin Singulation Work - Jeyapalan (2005)}

Arul Selvam Simon Jeyapalan, as a part of his Master's thesis, "Automated wrapping of silverware in a napkin" (Jeyapalan, 2005), designed a cloth napkin singulation system. His silverware wrapping device comprised three subsystems, namely, cloth napkin singulation system, silverware dropping mechanism and silverware wrapping mechanism. The task of the cloth napkin singulation system was to pick a single cloth napkin from a stack of cloth napkins and place it on a conveyor to move it to the silverware dropping mechanism. When the singulated napkin on the conveyor reached the silverware dropping mechanism, a set of silverware pieces, namely, a spoon, a soup spoon, a fork, and a knife were dropped upon the napkin. Then the wrapping mechanism made a sequence of folds or rolls to completely wrap the silverware pieces in the napkin. Finally the wrapped silverware pieces were transported into a collecting bin by the conveyor. 
Before starting his project, Jeyapalan conducted an analysis of various methods used to wrap silverware pieces in a cloth napkin. It turned out that the general practice to wrap silverware pieces in a cloth napkin was to place a silverware set along one of the diagonals of the napkin and wrap it. Accordingly he attempted to make a cloth napkin singulation system that could singulate a cloth napkin from a stack and deliver it in a diagonal position on a conveyor. The napkins he used in his device were square cotton dinner napkins measuring 20 " in length per side and were neatly stacked in a pile. The napkin stack was placed in a diagonal position with respect to the conveyor so that the napkin singulation mechanism could pick up and place one single napkin at a time on the conveyor.

To singulate the napkins from the napkin stack, Jeyapalan used a mechanism similar to the one used in desktop laser printers to singulate sheets of paper from a stack to feed the printer. The mechanism is shown in Figure 1.2. A roller pressed vertically onto the stack of napkins to pull a single napkin from the top of the napkin stack. The underlying idea behind was that when the friction between the topmost napkin and roller was greater than the friction between the top two napkins in the napkin stack, the napkin on the top would be singled out from the napkin stack. 


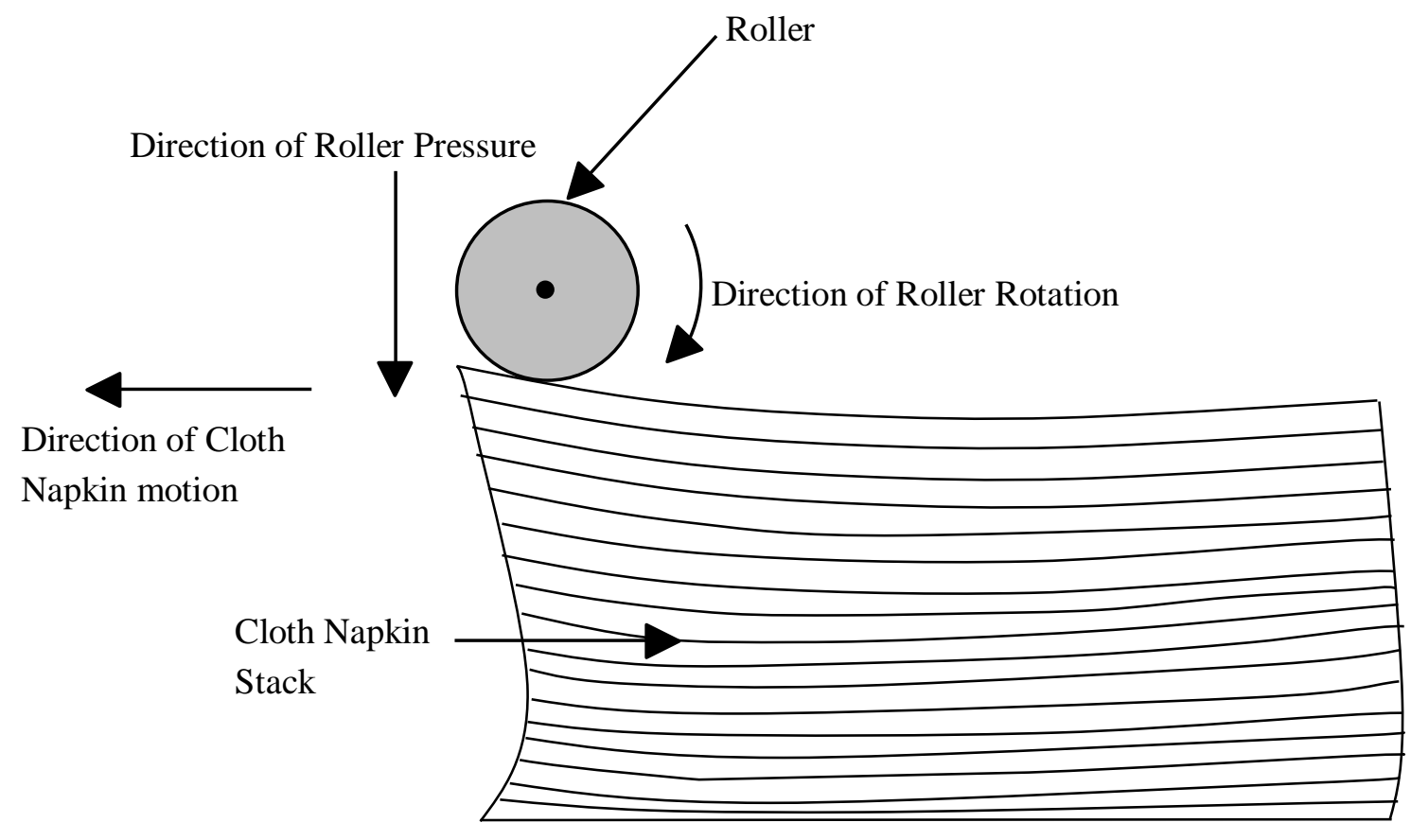

Figure 1.2: Position of a Roller on a Stack of Cloth Napkins (Jeyapalan, 2005)

After the roller had partially singulated the topmost napkin of the stack, one end of the partially singulated napkin extended from the stack, as shown in Figure 1.3. A pick-up device was then used to pull the partially singulated napkin out of the napkin stack and place it on a conveyor to be taken to the silverware drop mechanism. 


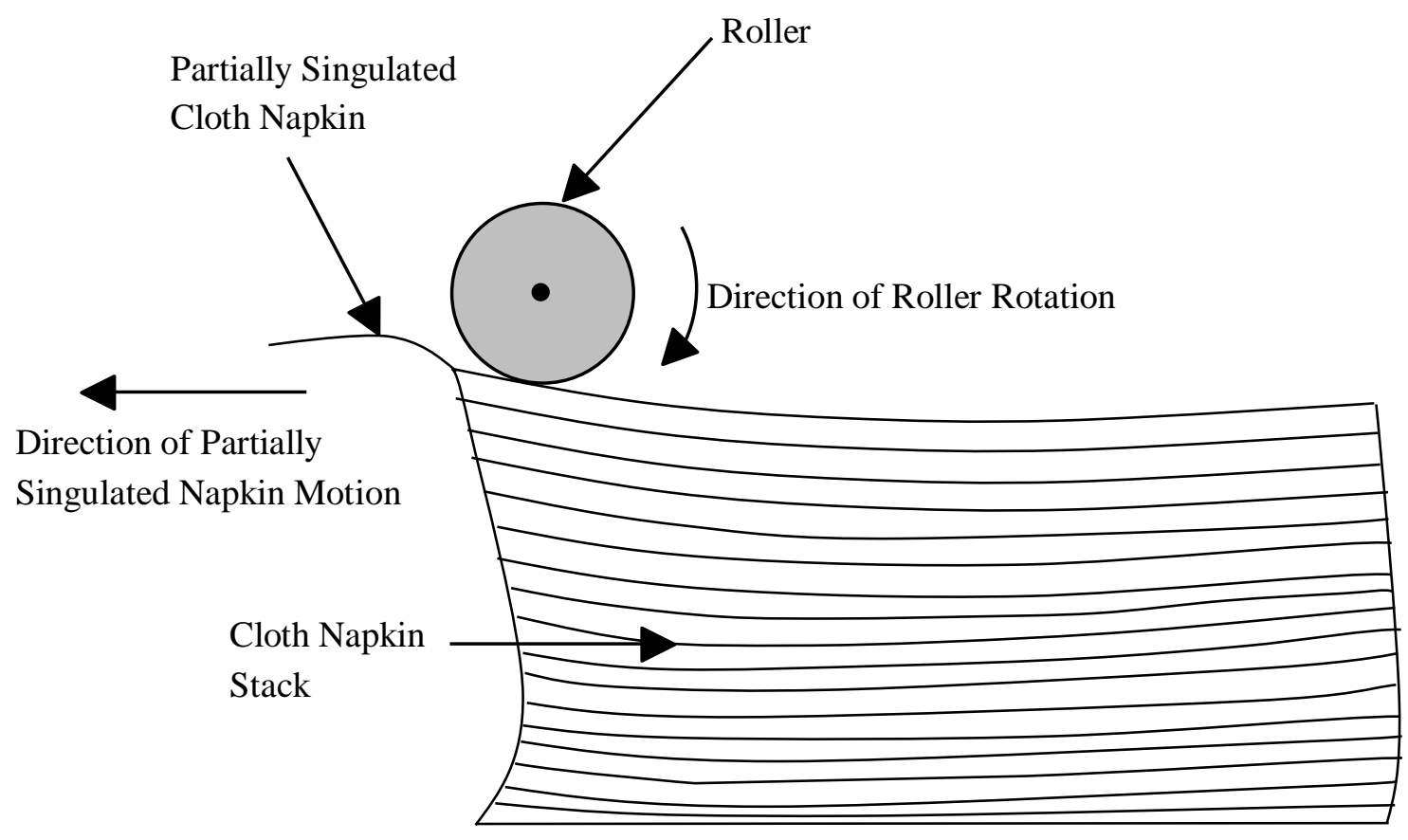

Figure 1.3: Partially Singulated Cloth Napkin (Jeyapalan, 2005)

Various methods were considered to pick up the partially singulated napkin from the napkin stack and place it on the conveyor. One approach was to place the napkin stack adjacent to the conveyor system to allow the napkin drop directly on the conveyor after partial singulation. However this design made the overall length of the singulation unit too long to fit in a small work place, and thereby was abandoned. Another design was considered by placing the napkin stack beneath the conveyor. The partially singulated napkin was secured between two rollers and placed on the conveyor by using motorized rotating arms. This design made the device compact, but the overall singulation process became complicated with additional drives, and therefore was not implemented in the end.

The final design that was integrated to the silverware dropping mechanism and silverware wrapping mechanism was a modified version of the second design. This design also placed the 
napkin stack beneath the conveyor. In addition, the new design included a static quadrant of a cylinder with one edge of the cylinder quadrant at one end of the napkin stack and the other edge near the starting point of the horizontal portion of the conveyor as shown in Figure 1.4.

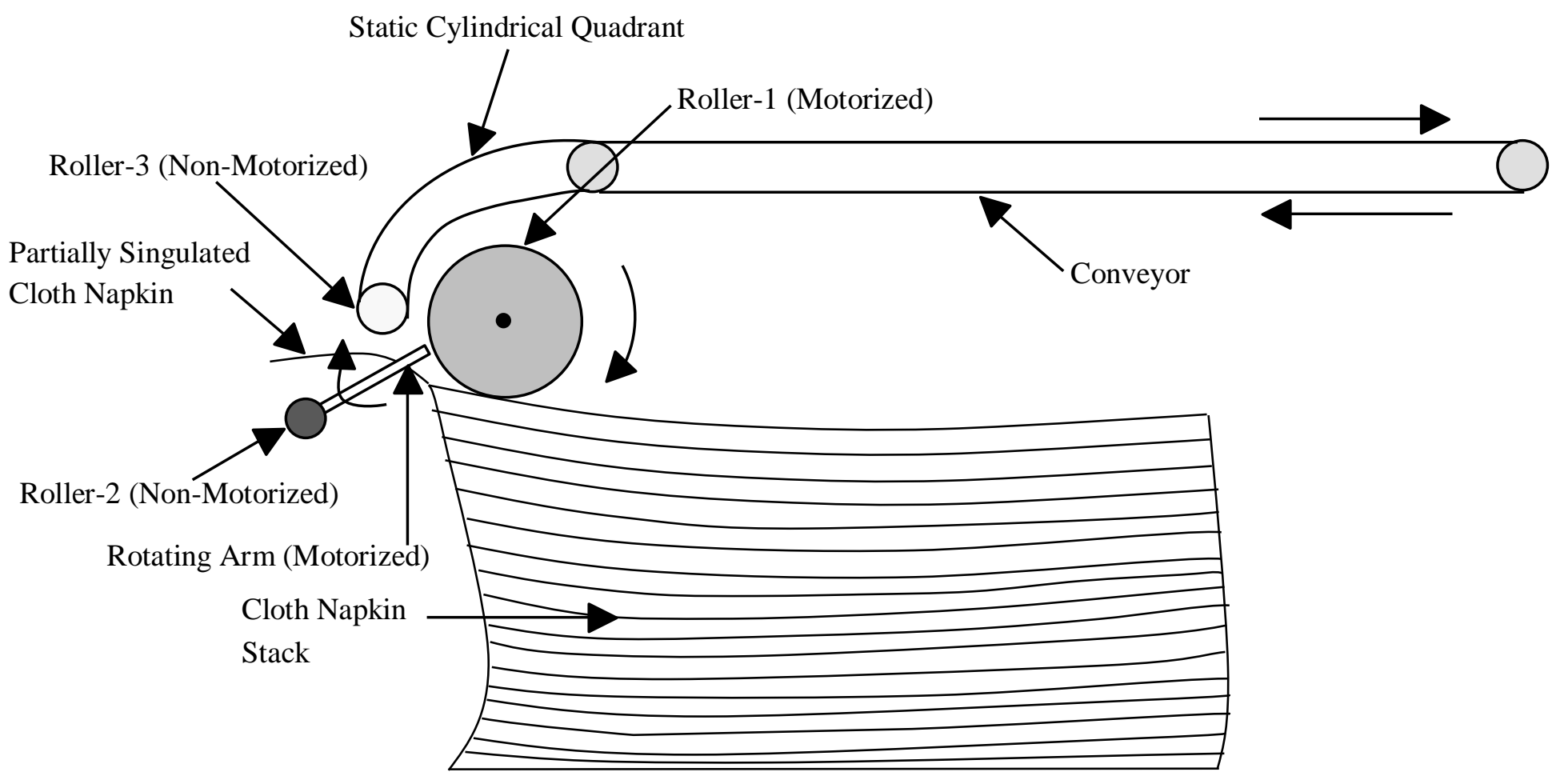

Figure 1.4: Final Design for the Napkin Singulator (Jeyapalan, 2005)

An unpowered roller (Roller-2) was fixed on a powered rotating arm which could travel along the curved surface of the quadrant of the cylinder. The conveyor belt ran over the static cylindrical quadrant by using an additional unpowered end roller (Roller-3). Once the tip of the topmost napkin of the napkin stack was partially singulated by Roller-1, Roller-2 on the powered rotating arm secured the napkin between the roller and the belt running over the static cylindrical 
quadrant, with the napkin between the roller and the belt running over the static cylindrical quadrant. Once the napkin had cleared Roller-2, the arm rotated it back to its initial position and waited for the next cycle.

Maintaining sufficient contact between Roller-1 and the topmost napkin of the napkin stack was mandatory for this singulating mechanism to work properly. To accommodate the decreased stack height, the napkin stack was placed on a tray which could be moved vertically up or down using three lead screw motors. The lead screws of the motors were threaded through three flanged nuts and the nuts were fixed on the tray holding the napkin stack. A schematic diagram of this setup is illustrated in Figure 1.5. After a predetermined number of napkins were removed from the stack, all three motors were actuated synchronously to move the napkin stack upwards to maintain good contact and pressure between Roller-1 and the topmost napkin. When all the napkins were removed from the stack, the tray was brought back to its initial position by reversing the motors. 


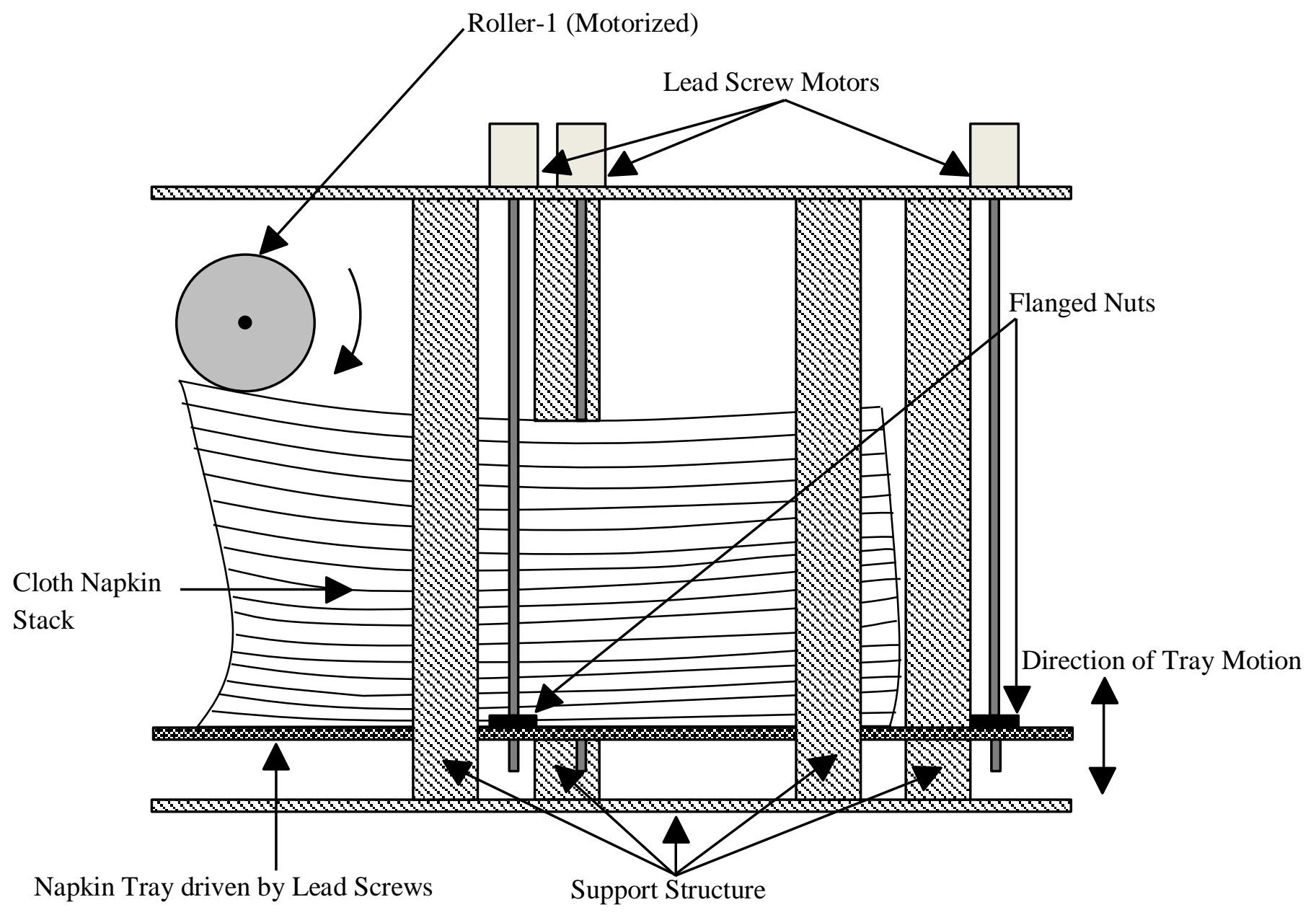

Figure 1.5: Napkin Tray Lifting Mechanism (Jeyapalan, 2005)

As the mechanism to partially singulate a cloth napkin from the cloth napkin stack was inspired from the paper sheet singulation mechanism of desktop laser printers, Jeyapalan found that in order for the cloth napkin singulation mechanism work properly, the cloth napkins should have been relatively stiff and smooth, like printer paper. To increase the stiffness of the cloth napkins, Jeyapalan added laundry starch to the cloth napkins in different amounts. It was found that the more the cloth napkin was starched, the stiffer it became and in turn exhibited less friction 
between the top two napkins of the stack. However, even for the most highly starched napkins, he found that the frictional force between the top two napkins was higher than the frictional force between the topmost napkin and Roller-1. Also, the added stiffness made it difficult for the wrapping mechanism to fold and roll the napkin. Accordingly, the idea of starching the cloth napkins was dropped.

Failure of the cloth napkin singulation system forced Jeyapalan to come up with a workaround, consisting of inserting a sheet of vellum paper of the same size as the napkin between each two consecutive napkins of the stack. This resulted in a reduced friction between the top two members of the stack, namely the topmost napkin and the vellum paper sheet beneath it, which helped the napkin singulation system work. Each sheet of paper in the stack was manually removed after the immediate top napkin was conveyed to the silverware drop mechanism. This made the process un-automated and artificial, but helped Jeyapalan conduct tests on the feasibility of the rest components of his device. However, the unified efficiency he achieved was only $68 \%$. In order to pinpoint the reason behind that low efficiency, Jeyapalan conducted tests by manually feeding the napkins to the device and achieved a processing efficiency of $100 \%$. This suggests a large need of improvement in the cloth napkin singulation system. The work herein is to design and construct an automated cloth napkin singulation system to replace Jeyaplan's cloth napkin singulation unit and thereby allow completion of the silverware wrapping device.

\subsection{Objective}

Napkins are an essential aspect in any food service establishments. Whether it is a fine dining restaurant or an average one, it is often customary to provide customers with silverware pieces wrapped in napkins during food serving. Upscale restaurants generally use cloth napkins, while others use paper napkins. This enhances the table decor and provides a convenient way to prepare 
the tables prior to customer arrival. Automation of the process of wrapping silverware pieces in napkins would decrease the significant manual labor and associated costs. Also it would minimize the risk of contamination and transmission of diseases from the restaurant employees during manual wrapping. This thesis concentrates on designing and constructing an automated cloth napkin singulation system, a major subsystem of any high-quality automated silverware wrapping device. The objective of this thesis is to modify, design, construct and test an efficient mechanism to singulate cloth napkins from a cloth napkin stack and place the napkins on a conveyor so that this singulation device can feed a silverware wrapping system, such as that described by Jeyapalan.

The design of the hardware for the cloth napkin singulation system is thoroughly discussed in Chapter II. The control system design is presented in Chapter III, and experimental results and analyses are given in Chapter IV. Conclusions and contributions of the developed singulation device are presented in Chapter V, together with recommendations for future work. 


\section{CHAPTER II}

\section{DESIGN OF CLOTH NAPKIN SINGULATION SYSTEM}

\subsection{Previous State of Design}

Because the cloth napkin singulator of Jeyapalan's (2005) silverware wrapping device was not successful, a new project was started by Kelli (Nee Briley) Ford, an M.S.M.E. student in the OSU School of MAE, who came up with a new concept for picking napkins from a stack using an adhesive manufactured by 3-M Corporation. She designed and constructed the majority of the device used in the work herein, but left the graduate program in Spring 2010 with the work unfinished and with no written documentation. Bareiss (2011) took up the system where BrileyFord had left off and slightly improved it by adding several modifications, such as fixing the broken connections of the electrical systems, re-wiring some of the controllers for better operation, adding several infrared sensors to create closed-loop control for many of the mechanical subsystems, milling down flat surfaces on shafts for set screws to prevent slippage, and moving a few mechanical parts around to prevent hindrance during motion. Below is a brief description of the state of the singulation system before the segment of work described herein began.

A combination of several mechanical and electrical subsystems were utilized to design and construct a cloth napkin singulation system that could remove the topmost napkin from a stack of cloth napkins and pass it on to a conveyor to be delivered to a silverware wrapping mechanism. 
The system employed a slider-crank mechanism that lowered a support structure that contained a roll of adhesive tape, with a small surface of this tape contacting the top napkin in a stack. The structure with tape and adhered napkin was then raised back up, effectively picking the topmost napkin from the stack. Upon completion of a full cycle, an electronic sensor mounted on the top of a carriage, carrying this structure, signaled the slider-crank mechanism to stop, holding the napkin at the highest limit of travel. A motor-driven rack-and-pinion mechanism then pulled the picked napkin toward a conveyor until an electronic sensor mounted aside one of the racks signaled to stop the motion. At this point, a linear actuator with a needle on the end attempted to detach the napkin from the adhesive surface. Once the napkin was removed, the rack-and-pinion mechanism returned the carriage toward the starting position so as not to obstruct the remaining process of the machine. Another electronic sensor mounted near the front of the machine signaled to halt when the carriage reached the starting position. After that, a four-bar mechanism attempted to position a wheel to hold the napkin on the conveyor as the conveyor carried the singulated napkin away from the stack. An electronic sensor mounted near the four-bar signaled to halt the mechanism after the wheel had been positioned on the napkin and then returned to its resting position. The napkin tray was then indexed upward to expose the next napkin in the stack on the tray by using three lead screw motors. After a predetermined number of napkins were passed along the conveyor, the adhesive surface collected dust and other debris and eventually lost its ability to adhere to the napkins. Accordingly a mechanism was designed and constructed to replace the used area of the adhesive tape roll with using an assembly of a powered winding roller, two idler rollers and an unwinding roller. 


\subsubsection{Problems Identified with Existing Setup}

Though a major portion of the mechanical system had been designed and constructed before the present thesis work started, many of the major subsystems were not functional, along with several other imperfections. These shortcomings are described in what follows.

- The slider-crank mechanism employed to pick napkins from the stack used two connecting rods of unequal lengths, which caused jerky and unreliable motion during operation. The mechanism also used two cranks which slipped on their respective pulley shafts. This slippage resulted in occasional tilting of the entire assembly to the left during motion, which in turn bound up the assembly, preventing the mechanism from picking napkins properly.

- The pinion gears of the rack-and-pinion mechanism slipped on the driving stepper motor shafts which caused noise and jittery motion of the configuration during travel to and from the conveyor. The vertical distance between the racks, together with the linear guide rails disposed parallel to the racks to hold the weight of the configuration, were not well aligned. This created excessive pressure on the racks by the mating pinion gears, leading to high pitch noise, vibration and stoppage of motion. Also the horizontal distance between the racks in the path of travel varied throughout, which resulted in noise and occasional derailment of the pinion gears from the racks, stopping motion abruptly during travel.

- The linear actuator with a needle on the end, which attempted to push a picked napkin off the adhesive surface near one of the conveyor ends, failed to remove the napkin completely, leaving the napkin removal process unsuccessful. Also this method of disengagement would deposit the napkin on the conveyor with its corner folded over, which was undesirable. 
- The driving motor of the four-bar mechanism often could not provide enough torque to create pressure on the napkin when it contacted the conveyor to successfully pass napkins along the conveyor. The feedback signal from a single electronic sensor was not sufficient to place the wheel on the napkin perfectly. This also caused failure of the wheel to return to its resting position, which later caused interference of the four-bar assembly with the rack-and-pinion configuration during the succeeding cycle of the singulation process.

- The conveyor was composed of two separate belts in parallel, which moved apart from each other over time, leaving a gap in-between. This wrinkled the napkins laying on the conveyor belts and caused the four-bar mechanism to provide insufficient pressure of the wheel on the napkins such that the conveyor could pass them along. The belts were under-tensioned, leading to slippage on their rollers, which hindered the smooth running of the conveyor. The conveyor rollers were not perfectly aligned, resulting in creeping of the belts to one side after a period of time. The conveyor drive motor coupler often slipped on the drive roller shaft, causing unexpected termination of conveyor motion. The conveyor ran continuously during the whole singulation process, which was neither energy-efficient nor safe, because the conveyor motor could burn out if stalled.

- The lead screw motors for the napkin stack tray, which were actuated synchronously to lift the napkin tray, did not turn equally because of different loading conditions that prevailed at the flanged nuts that supported the tray during motion along the lead screws. This tilted and eventually bound up the tray, restricting further vertical motion.

- The powered tape winding roller, idler rollers and the unwinding roller to renew the adhesive strip were not aligned. This caused the adhesive strip to creep to one side under the resting idler rollers, reducing the effective adhesive surface area to adhere to napkins 
during the singulation process. Also, the driving motor to power the winding roller was nonfunctional due to a broken soldered tab from fatigue and needed to be replaced.

These shortcomings kept the singulation system from functioning as an integrated unit and needed further research and improvements. Detailed description of these shortcomings and our design and construction approaches to solving them are discussed in the following sections.

\subsection{Design Considerations}

Despite the cloth napkin singulation system, primarily designed and constructed by Kelli (Nee Briley) Ford, and later partially improved by Bareiss (2011), having several shortcomings, leaving the system nonoperational altogether, we elected to proceed with the core concept of this design, because it held significant promise for improvements. The napkins used in this singulation system are commercial-grade, square cotton dinner napkins, each measuring 19" in length, per side. Napkins are neatly stacked in a pile and are diagonally positioned, for the singulation system to pick a single napkin at a time and place it diagonally on a conveyor in a fully open condition, to be conveyed to a silverware wrapping system. It is then intended that the wrapping system designed by Jeyapalan (2005) drop silverware pieces on the napkin and perform wrapping. The process is then repeated as necessary. The entire singulation process is split into several steps, each utilizing different mechanical and electrical systems to accomplish a particular task to reach the ultimate singulation goal. A flow diagram of the singulation process comprising these steps is shown in Figure 2.1. 


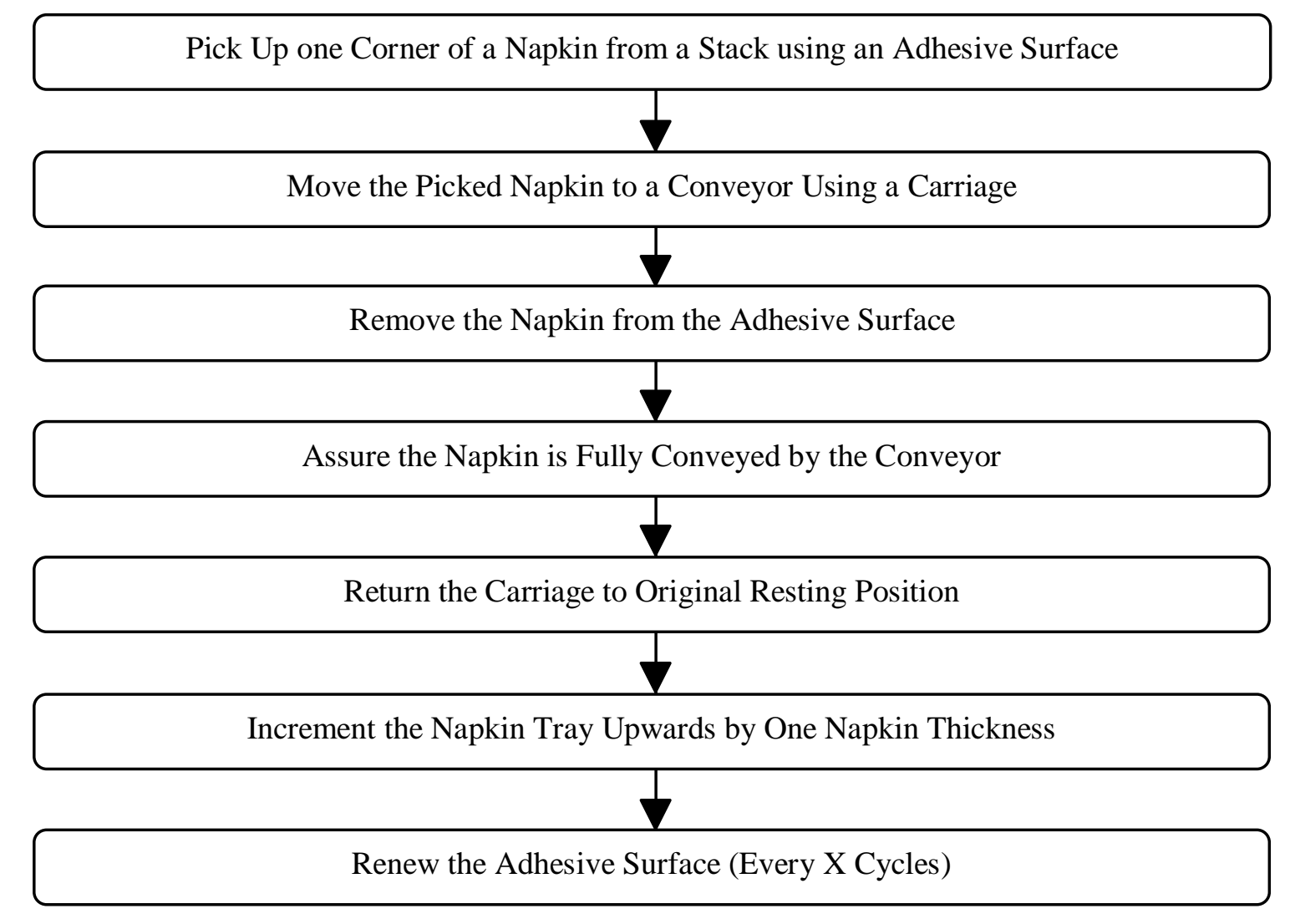

Figure 2.1: Flow Diagram of Cloth Napkin Singulation System

In the following sections, we present more details about each of these steps, along with different methods we investigated, approaches we explored, techniques we employed, and mechanisms we developed to design and construct a successful cloth napkin singulation system. Relevant drawings are included for ease of discussion. These drawings, however, serve only for illustration purposes and are not drawn to scale. A complete set of detailed and dimensioned photographs of the actual setup are given in Appendix B. 


\subsubsection{Design of Napkin Picking System}

The napkin picking system employs a slider-crank mechanism to pick a napkin from a napkin stack. The mechanism is housed on a carriage and is driven by a $12 \mathrm{~V}$ motor, which is linked to two timing pulleys through timing belts to rotate two cranks. Two connecting rods are pivoted to the cranks by crankpins on one end and to a wooden sliding plate by wrist pins on the other end. The rotary motion from the motor is converted to linear sliding motion by the mechanism, which helps lower and raise the sliding plate, held on linear bearings, moving along two vertically mounted linear guide rails. The configuration is shown in Figure 2.2.

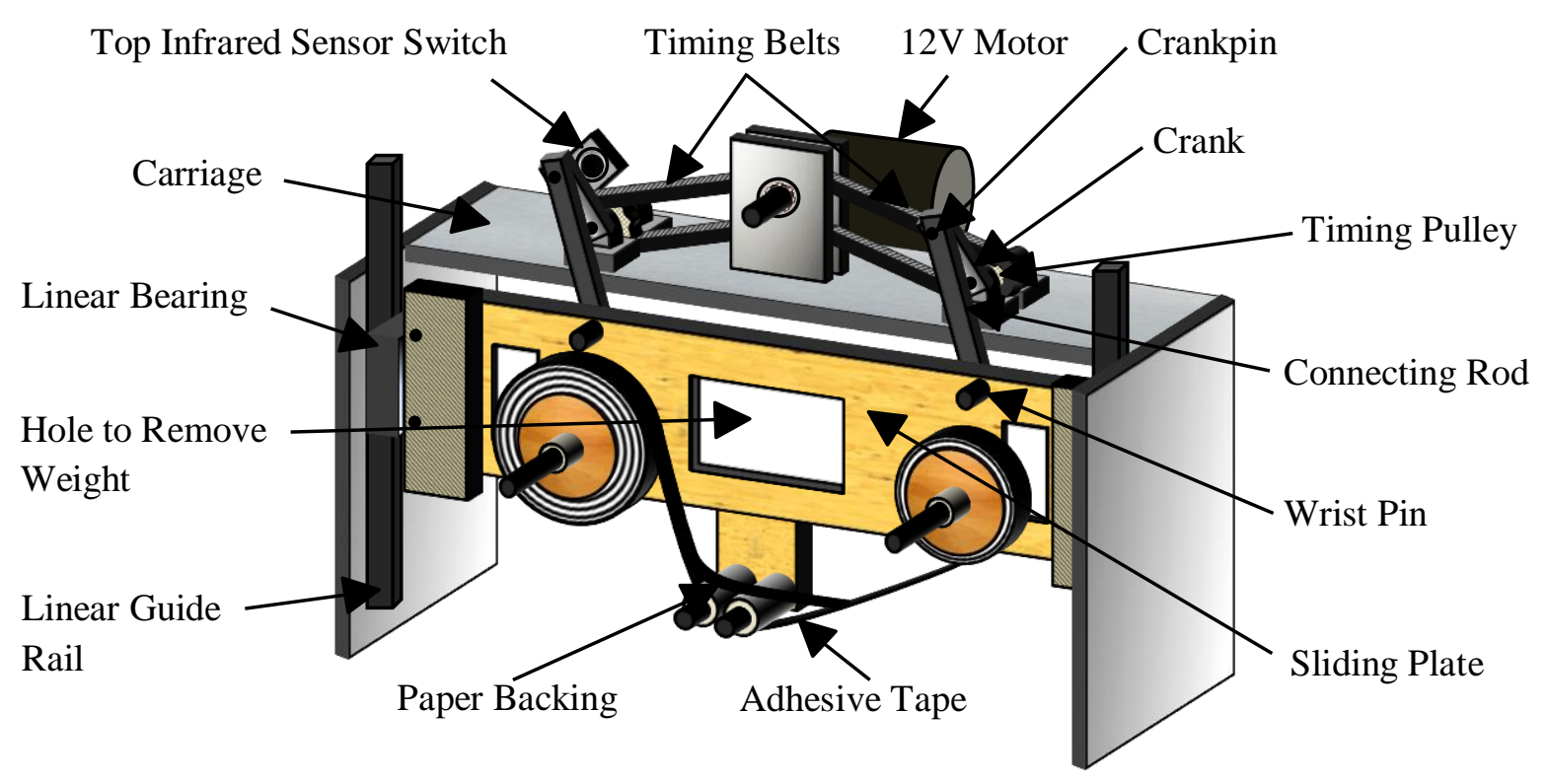

Figure 2.2: Carriage Slider-Crank Configuration (Perspective View)

An infrared sensor switch located at the top of the carriage signals to halt the mechanism when one complete cycle of rotation is completed. The sliding plate has a roll of special adhesive tape 
(manufactured by 3-M Corporation) mounted on it, which helps lift one corner of a napkin from a napkin stack placed beneath the sliding plate, when the plate is lowered by the mechanism (Details of the tape roll system are given later on in this chapter). The plate has several holes cut into it, to remove weight, which facilitates ease of plate movement.

Initial testing identified several problems with the existing carriage slider-crank system that hampered seamless operation of the mechanism. One of them was jerky movement of the configuration during motion. Investigation determined that the connecting rods used in the system were not of equal length, causing the jerking. After one of the connecting rods was replaced with one of equal length, the problem was resolved.

Another problem was slippage of the cranks on their respective timing pulley shafts when excessive torque was applied. This occasionally tilted the sliding plate to left and eventually jammed it, restraining further motion. We discovered the set screws which were supposed to lock the cranks in place on the milled flat segments of the shafts, were worn out or stripped and could no longer remain tight. This was fixed by replacing the old set screws with new ones. Additional set screws were also installed for better fastening of the cranks to the shafts.

After the problems of carriage slider-crank configuration were resolved, the mechanism could reliably pick napkins from a stack. In Figure 2.3, a schematic diagram of the napkin picking mechanism is shown. The napkin stack is diagonally positioned on a napkin tray in such a way that when the carriage is at its resting position, the sliding plate holding the adhesive tape is right above one corner of the napkin stack. To pick a napkin, the sliding plate is lowered by rotating the cranks counterclockwise using the driving motor. When the cranks reach the lowest point of travel, the sliding plate presses the adhesive tape on the proximate corner of the napkin stack, as shown in Figure 2.3(a). 


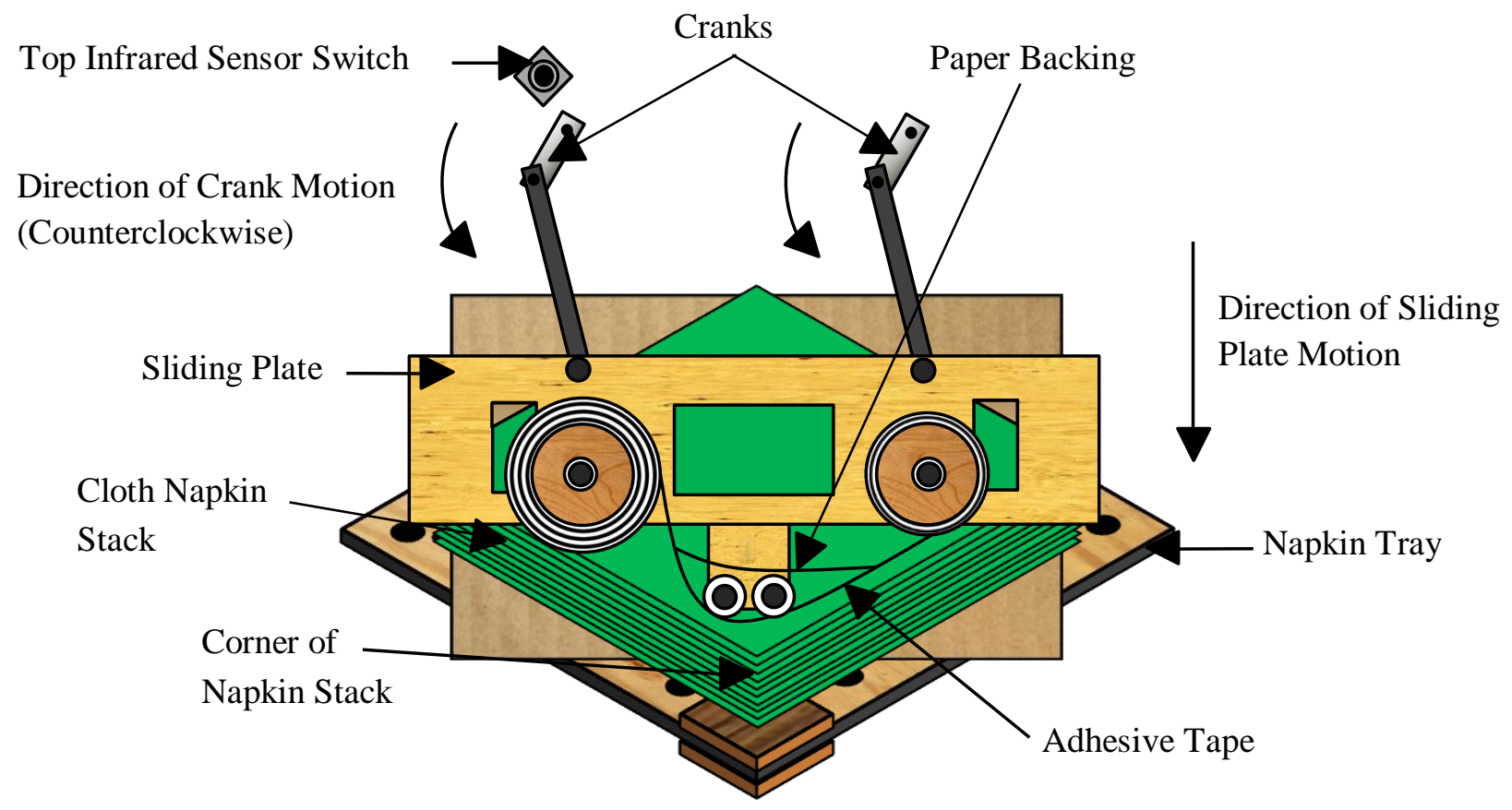

(a) Before Picking Napkin

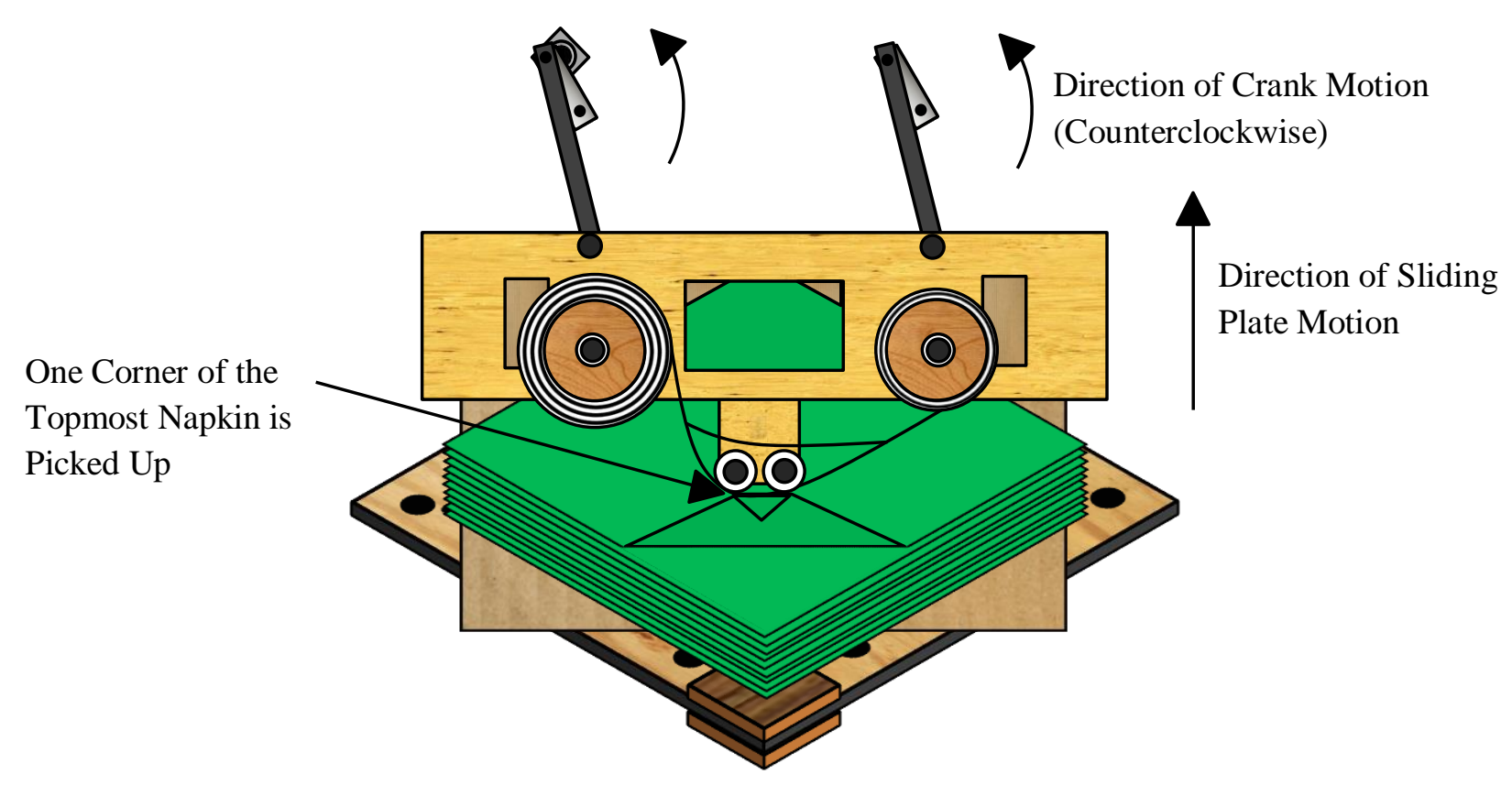

(b) After Picking Napkin

Figure 2.3: Schematic Diagram of Napkin Picking Mechanism (Front View) 
As a result, one corner of the topmost napkin adheres to the adhesive tape. When the cranks return to their highest limit of travel, the top infrared sensor switch signals to stop motion, and the sliding plate has risen back up with the napkin attached, as shown in Figure 2.3(b). Thus one napkin is partially singulated from rest of the napkins in the stack.

\subsubsection{Design of System to Move a Picked Napkin to a Conveyor}

As shown in Figure 2.4, the sliding plate with attached napkin is mounted on a transverse-moving carriage driven by a rack-and-pinion mechanism. After a napkin is picked up, the rack-and-pinion mechanism moves the napkin to a conveyor. The mechanism utilizes two stepper motors, which are mounted on both sides of the carriage with pinion gears attached to their shafts. Rack gears, supported on the static frame, are installed on each side of the carriage such that the engaged pinion gears can roll along the lengths of the racks. The weight of the carriage is held by linear bearings attached to both sides of the carriage, which slide along two linear guide rails mounted

on the static frame. Several infrared sensor switches are installed along the path of travel of the carriage, on one side of the static frame, to detect position of the carriage during motion. 


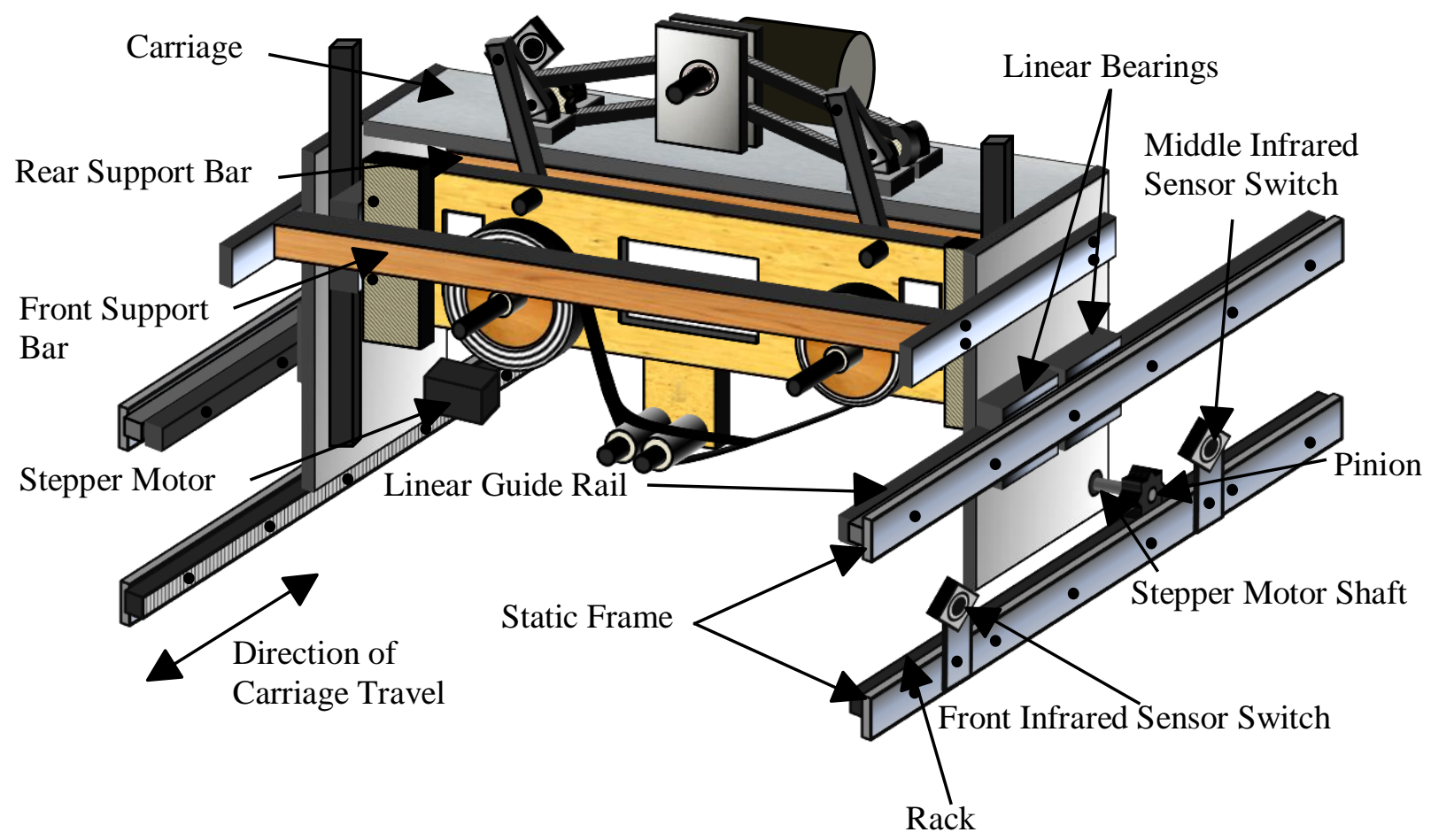

Figure 2.4: Carriage Rack-and-Pinion Configuration (Perspective View)

When first tested, several problems were discovered with the rack-and-pinion system. One was slippage of the pinion gears on their driving motor shafts, which created noise, vibration, and unreliable motion. To solve this, we first replaced the old worn out set screws which held the pinion gears on the milled flat surfaces of the motor shafts. While this initially solved the problem, after a few cycles of operation, the set screws became loose and the pinion gears began slipping again. After investigation, we found that some of the threads on the pinion shafts were stripped out such that the new set screws could no longer fasten the pinions tightly to the motor shafts. After drilling holes through the motor shafts and the pinion hubs, we used through pins to lock the pinion gears to the motor shafts, which stopped the slippage. 
Another problem was high contact pressure exerted by the pinion gears on their meshing racks, which resulted in high pitch noise, vibration and sudden stoppage of carriage motion. After investigation, we found that the vertical distance between the linear guide rails and racks disposed in parallel to them were unequal throughout the path of travel of the carriage. As a result, the guide rails could not hold the full load of the carriage during travel, as was intended. This resulted in extremely high contact pressure between pinions and racks, causing the pinions to bind temporarily on the racks together with noise and vibration. After adjustment of the vertical distance between the guide rails and racks, the problem was solved.

A further problem was then discovered, namely that, the racks were not parallelly aligned lengthwise, which caused occasional disengagement of the pinions from the mating racks. By using washers as spacers at different locations between the racks and corresponding static frame we aligned the racks to eliminate this problem. We also added two wooden support bars at the front and back of the carriage, as shown in Figure 2.4, which provided additional support to maintain the pinions on the racks during travel.

After fixing these problems with carriage rack-and-pinion, the system could move a picked napkin toward a conveyor without interruption. A schematic view of this operation is shown in Figure 2.5. After the adhesive tape of the sliding plate picks a napkin and reaches back up to its top position, as described in the previous section, the carriage stepper motors begin driving the pinion gears to move the carriage along the mating racks toward the Conveyor. Three infrared sensor switches are mounted on the static frame to determine position of the carriage during travel. When the carriage interrupts rear infrared sensor switch, shown in Figure 2.5, the switch sends signal to the control unit and the carriage is stopped (The purposes of the other two sensor switches are discussed in the following sections). The rear infrared sensor switch is judicially placed slightly ahead of the conveyor end position, adjacent to the napkin tray, such that the carriage pulls a significant portion of the picked napkin onto the conveyor. This allows other 
mechanisms, described below, to easily disengage the napkin and assure that the conveyor transports it. In this way a singulated napkin is moved to a conveyor from the napkin stack.

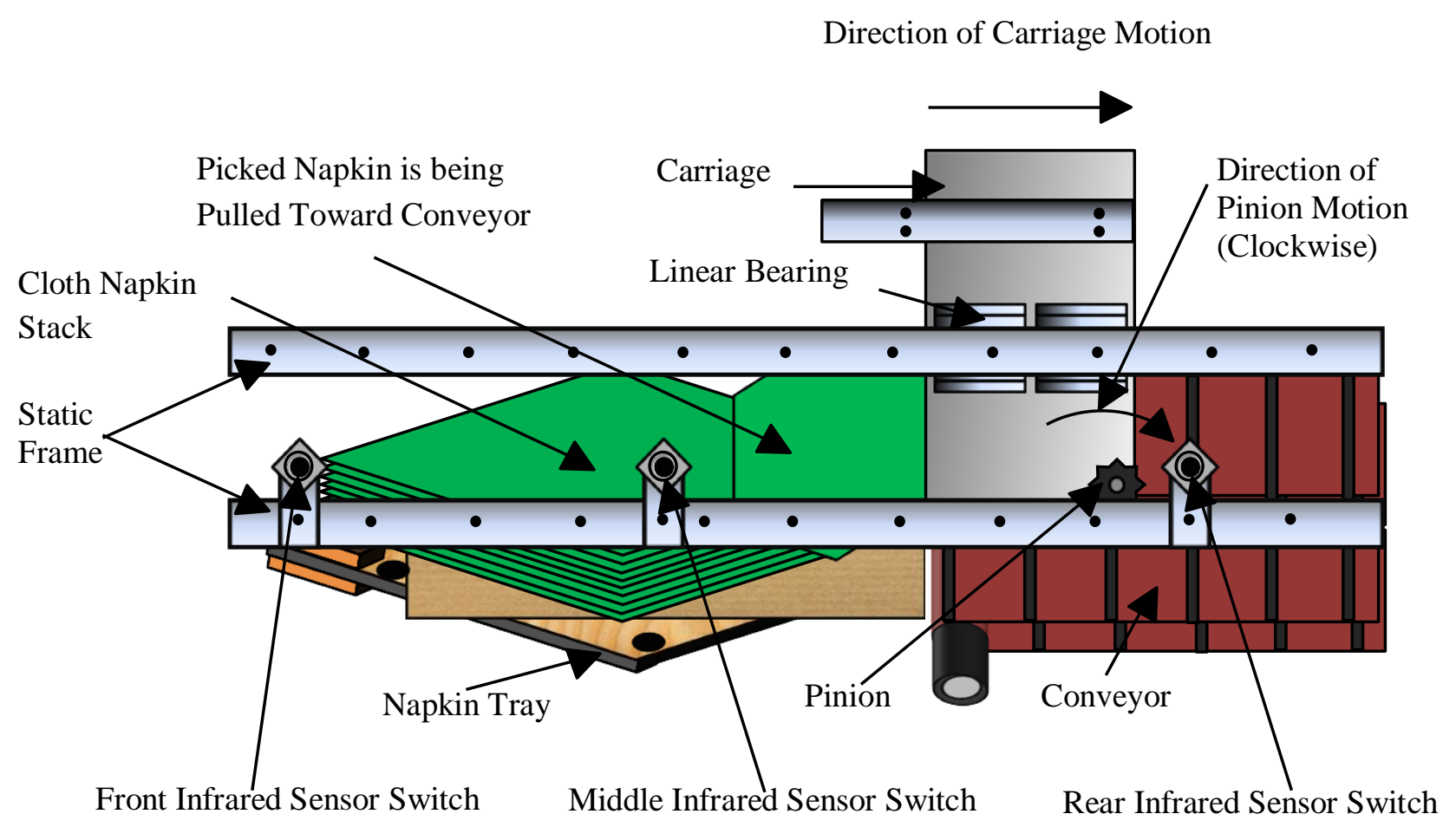

Figure 2.5: Schematic Diagram of Napkin Moving Mechanism (Angled View from $45^{\circ} \mathrm{Up}$ from Right Side)

\subsubsection{Design of Napkin Removal System}

After the carriage moves a picked napkin to the upstream conveyor end, a napkin removal mechanism is employed to remove the napkin from the adhesive surface and place it on the conveyor. This configuration utilizes a $12 \mathrm{~V}$ DC linear actuator, with a stroke length of $100 \mathrm{~mm}$, 
and a gear ratio of 63:1, which is firmly mounted on the front support bar, in front of the sliding plate, with an overhead support from the carriage. A horizontally disposed, 4" long x $13 / 8$ " wide $\mathrm{x} 1 / 2$ " thick aluminum block is attached on the clevis rod end of the actuator, at the bottom, using mounting brackets, bolts and nuts. The actuator works in conjunction with the slider-crank mechanism driving the sliding plate, to successfully remove a napkin from the adhesive tape. When fully extended, the actuator presses and holds down the aluminum bar on the napkin laying on the conveyor, while the sliding plate then moves upward, detaching the adhesive tape from the napkin. This configuration is shown in Figure 2.6.

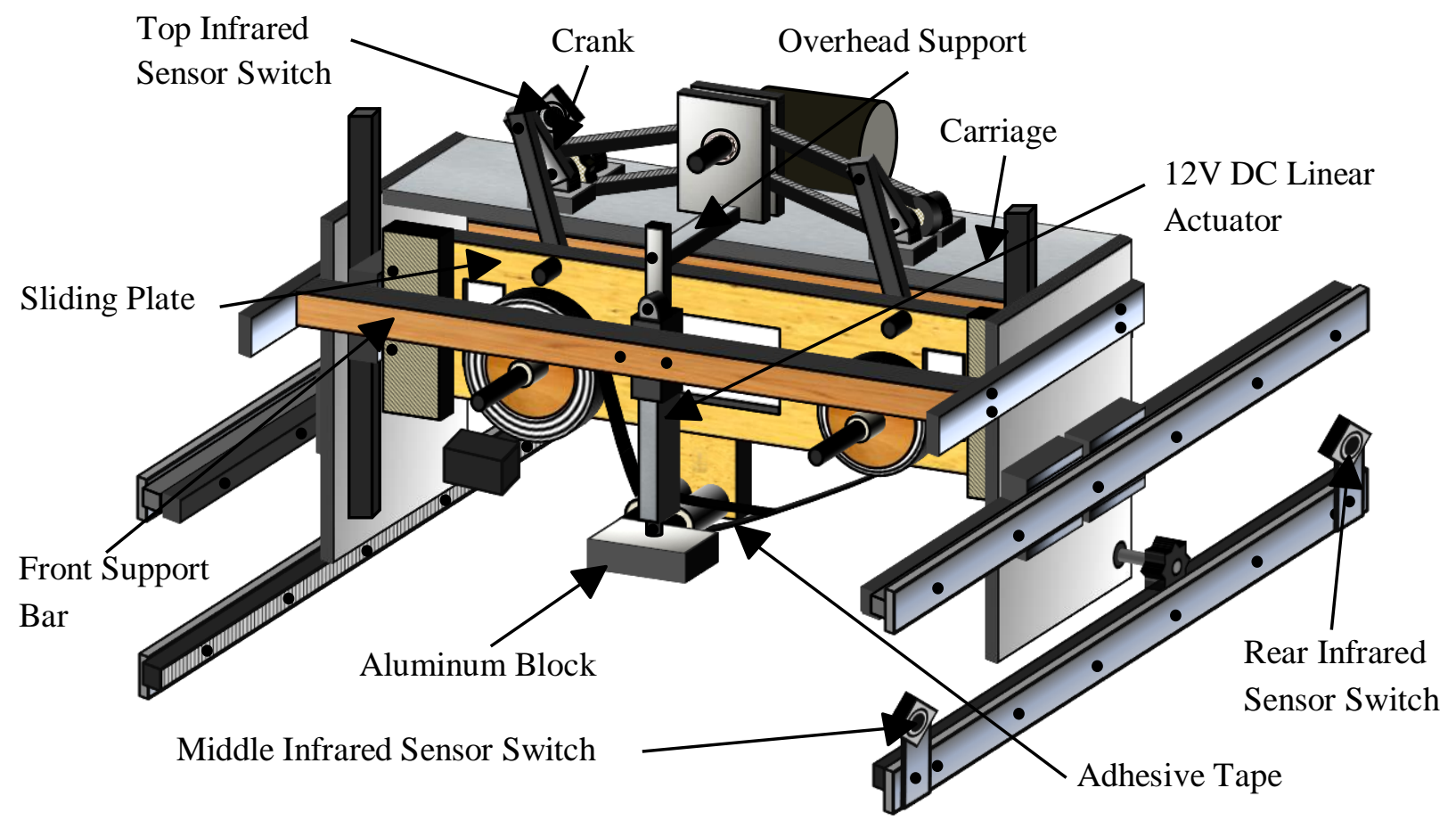

Figure 2.6: Napkin Removal Configuration (Perspective View) 
In the previous design by Briley-Ford, a linear actuator of $50 \mathrm{~mm}$ stroke length, with a needle attached to the end, attempted to remove a napkin from the adhesive tape fixture, but was unsuccessful. This configuration is shown in Figure 2.7(a). After preliminary investigation, it appeared that the stroke length of the actuator was not sufficient to reach down enough to push the napkin completely off the tape. As an experiment, we replaced the old linear actuator with a new one having a stroke length of $100 \mathrm{~mm}$ and a gear ratio of $63: 1$, hoping that a higher stroke length would help remove the napkin successfully. However, we found that napkin removal remained unsuccessful. The needle could partially disengage the napkin corner held to the tape near the needle, but could not disengage the napkin completely. Also this method required a napkin to be held by the adhesive tape at some distance from the napkin corner during pick-up, so that the needle could penetrate the napkin corner hanging over the conveyor and push it off during the removal process. This placed the napkin on the conveyor with its corner folded over, which was not acceptable, because for later silverware wrapping, the napkin needed to be completely flat. Considering these drawbacks, we concluded that napkin removal using a needle was not a viable approach, and we proceeded to investigate other alternatives.

Our initial attempt was replacing the needle with a thin metal bar with two equidistant fingers projecting horizontally from the ends of the bar, as shown in Figure 2.7(b). This showed slightly better performance over the needle, since the horizontally disposed fingers could reach entirely across both sides of the tape fixture that held the napkin, when the needle could only reach the front portion. 
Linear Actuator

(Stroke Length $100 \mathrm{~mm}$ )

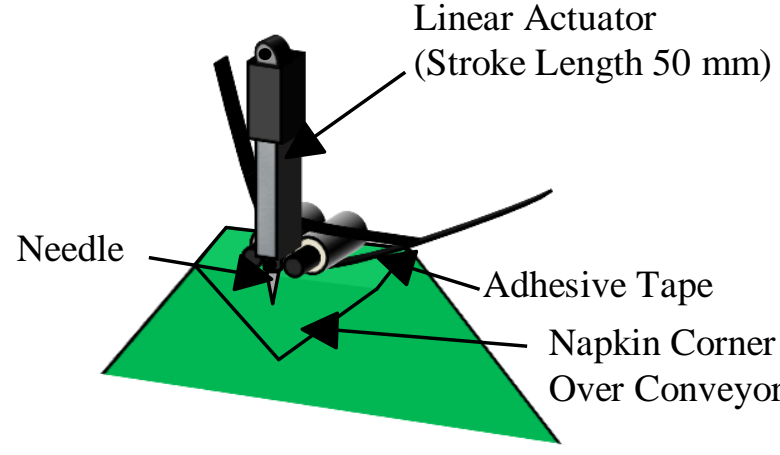

(a) Napkin Removal Using Needle

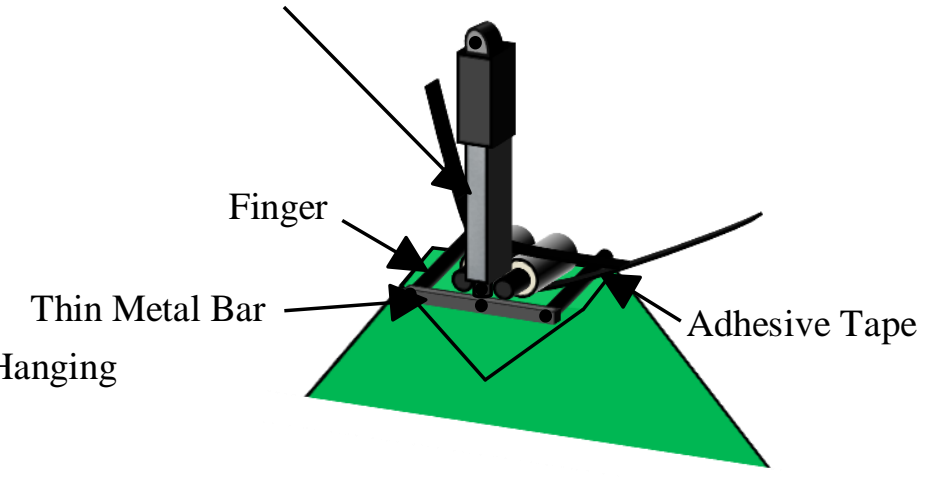

(b) Napkin Removal Using Thin Metal Bar with Fingers

Figure 2.7: Previous Attempts for Napkin Removal (Perspective View)

To successfully remove a napkin, the fingers should to be in close proximity to the adhesive area contacting the napkin so that the fingers could push the entire adhered napkin area off the tape. However this would cause interference of the fingers with tape roll configuration during napkin pick-up process when the sliding plate containing the tape roll is lowered. This left us with options of either changing the tape roll configuration to accommodate the fingers or finding a better alternative to the bar with fingers. As the tape roll system was already in a working state, and also there was a possibility that the bar with fingers might place the napkin on the conveyor with its corner folded over, we abandoned the napkin removal concept using the bar with fingers.

Finally we employed a linear actuator with a horizontally oriented aluminum block attached on the end, synchronized with the carriage slider-crank mechanism, and found success in removing a napkin from the adhesive tape. The thickness of the aluminum bar was judicially selected so as to press and hold down the napkin corner firmly on the conveyor when the slider-crank mechanism 
disengages the adhesive surface from the napkin. A simplified view of this mechanism is shown in Figure 2.8. After the carriage stops at the conveyor upstream end, the carriage slider-crank mechanism rotates the cranks counterclockwise until the sliding plate travels all the way down with the napkin attached, as shown in Figure 2.8(a). Then the linear actuator is extended. When the actuator fully extends, the aluminum block on its end presses and holds down the napkin securely on the conveyor, while the sliding plate is raised back up, as illustrated in Figure 2.8(b). This disengages the napkin from the adhesive tape and places the picked corner of the napkin on the conveyor. Also the corner unfolds itself upon release, since the tape was moved to engage the napkin closer to the corner during pick-up. After the napkin is released, the actuator retracts and returns the aluminum block to its resting position. We found that this process reliably removes the picked napkin from the adhesive tape and properly lands it on the conveyor end. 


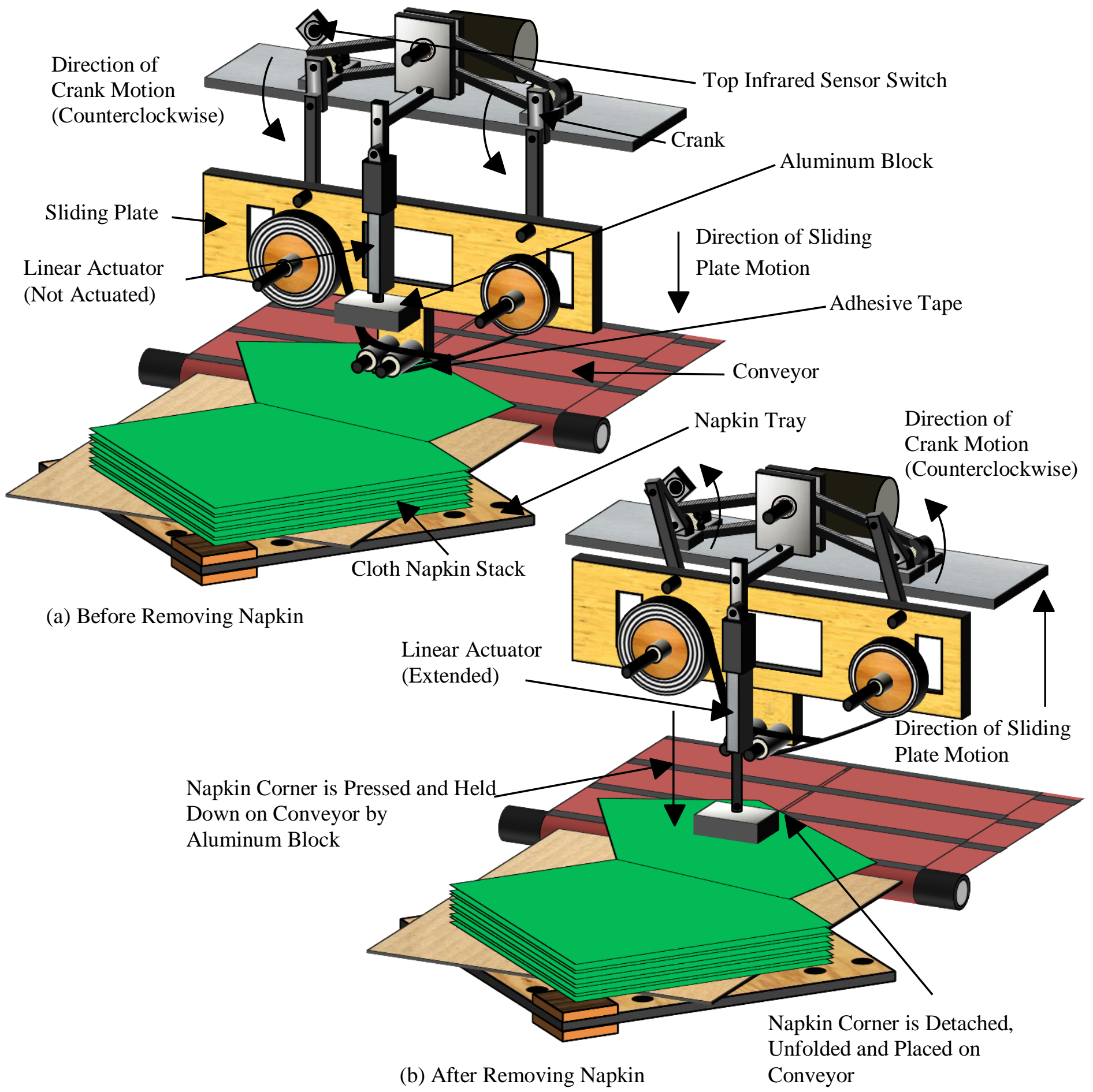

Figure 2.8: Schematic Diagram of Napkin Removal (Perspective View) 


\subsubsection{Design of System to Engage a Napkin on the Moving Conveyor}

After a napkin is removed from the adhesive tape and a corner of the napkin has been placed on the upstream conveyor end, a mechanism is needed to create necessary hold-down pressure for the conveyor to fully engage the napkin and pull it off the stack. In the device inherited from Briley-Ford, a four-bar mechanism was used to drive a wheel, which when contacting the napkin end on the conveyor, was intended to provide the needed hold-down pressure. This configuration, shown in Figure 2.9, initially consisted of four links; later one extension link was added to place the wheel further toward the upstream conveyor end. The mechanism used a $12 \mathrm{~V}$ motor which rotated in a single direction to lower the wheel onto the conveyor to press down on a napkin. After that, the wheel was to return to its resting position without reversing the direction of the driving motor. An infrared sensor switch positioned beside the motor monitored the position of Coupler-1 of the four-bar mechanism and attempted to utilize that data to halt the mechanism when necessary. After initial testing, we found several major problems with this approach. First, the motor often could not provide sufficient torque to press down the wheel firmly on the napkin to provide necessary hold-down friction. Previously, lightening holes had been added to the links to reduce the weight of the configuration to solve this problem, but the problem remained. Moreover, position feedback from one infrared sensor switch was not sufficient for the control unit to precisely control the position of the wheel. As a result the mechanism occasionally failed to properly position the wheel on the napkins laying on the conveyor. This also resulted in stoppage of the four-bar motion at unexpected positions as the wheel was returning to its resting position. This in turn caused interference of the four-bar system with the carriage rack-and-pinion system during the next cycle of operation. After review and experimentation, we concluded that the four-bar mechanism was not a plausible solution for engaging napkins with the conveyor. Therefore we explored different approaches. 


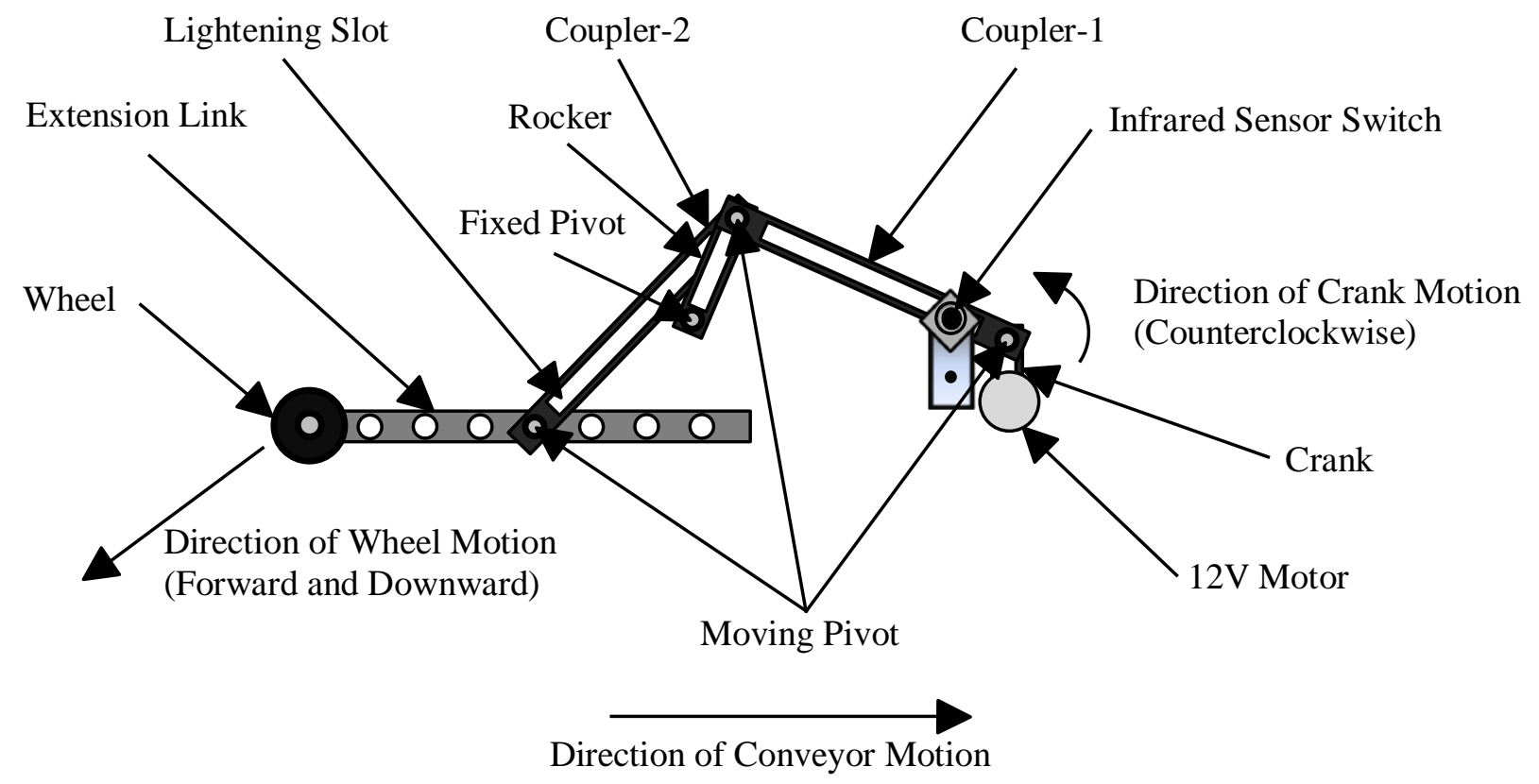

Figure 2.9: Previous Four-Bar Configuration (Side View)

We elected to try an unpowered $31 / 2$ " diameter roller, attached to the end of a $12 \mathrm{~V}$ DC linear actuator, with a stroke length of $100 \mathrm{~mm}$, and a gear ratio of $63: 1$, identical to that has been used in the napkin removal system. The actuator with the roller is mounted on a vertical support, on the rear side of the carriage, using a cantilever support element centrally positioned on the bottom surface of the rear support bar of the carriage, shown in Figure 2.10. The linear actuator presses and holds down the push roller on the napkin corner laying on the upstream conveyor end, until the napkin is carried far enough along the conveyor for its own weight to create the necessary friction with the conveyor surface to continue conveyance without extra hold-down force. The linear actuator is then signaled to return upward to its rest position, withdrawing the roller from the napkin. 


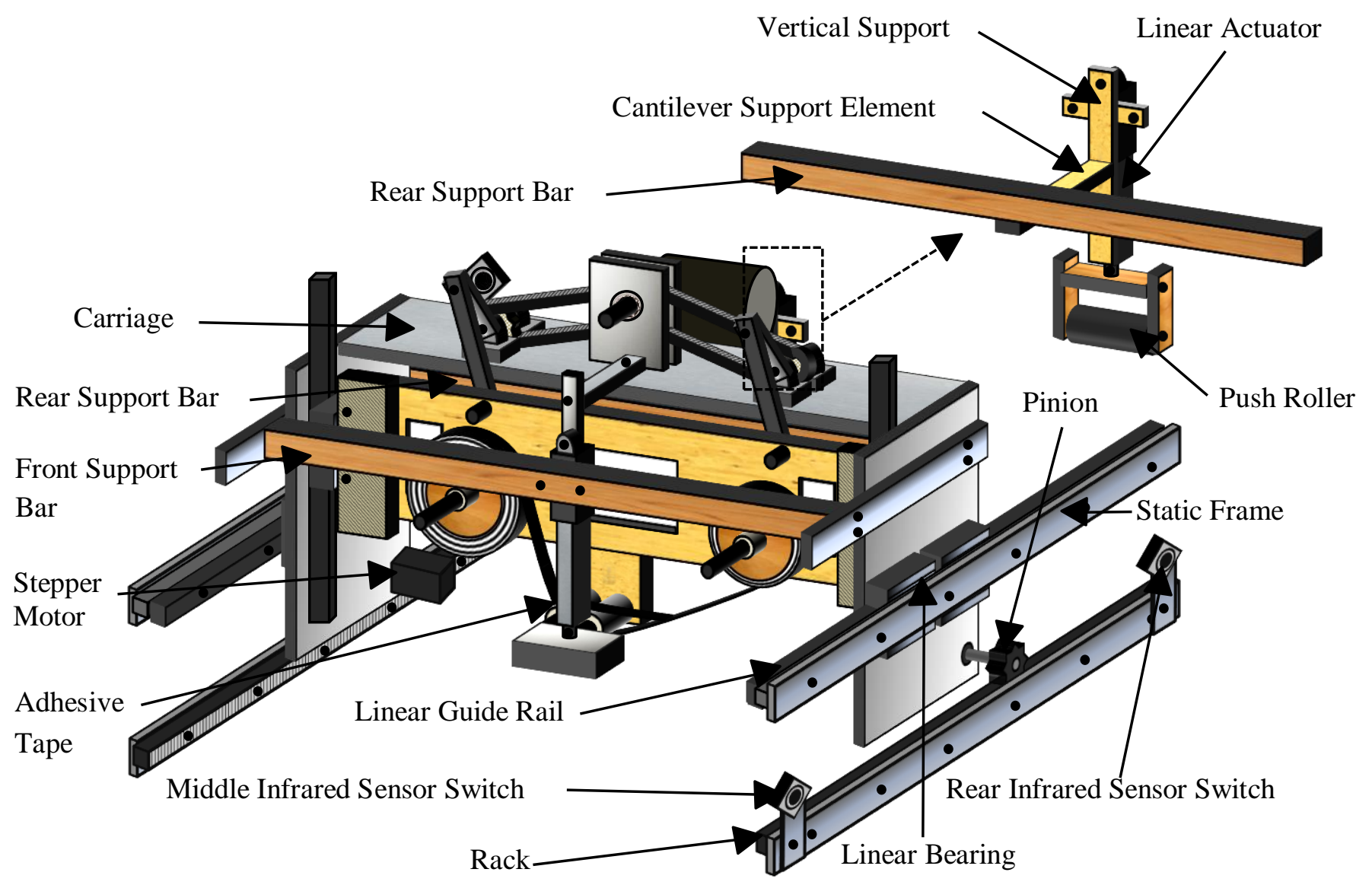

Figure 2.10: Napkin Engaging Configuration (Perspective View)

The conveyor is made of two pieces of neoprene belts that are placed next to each other and are joined to form continuous loops by metal clips on the ends. The belts run over two 2" rollers, located on both longitudinal ends of the conveyor, and the downstream roller is driven by a $12 \mathrm{~V}$ motor through a gearbox, as shown in Figure 2.11. The length and width of the active conveying surface have been judicially selected to accommodate the geometry of the napkin. Since the napkins used for the singulation process are 19" x 19" square napkins, each diagonal of a napkin is approximately 27 " in length. After allowing tolerance and space for drive support, the overall length and width of the conveyor are 34 " and 32 ", respectively. 


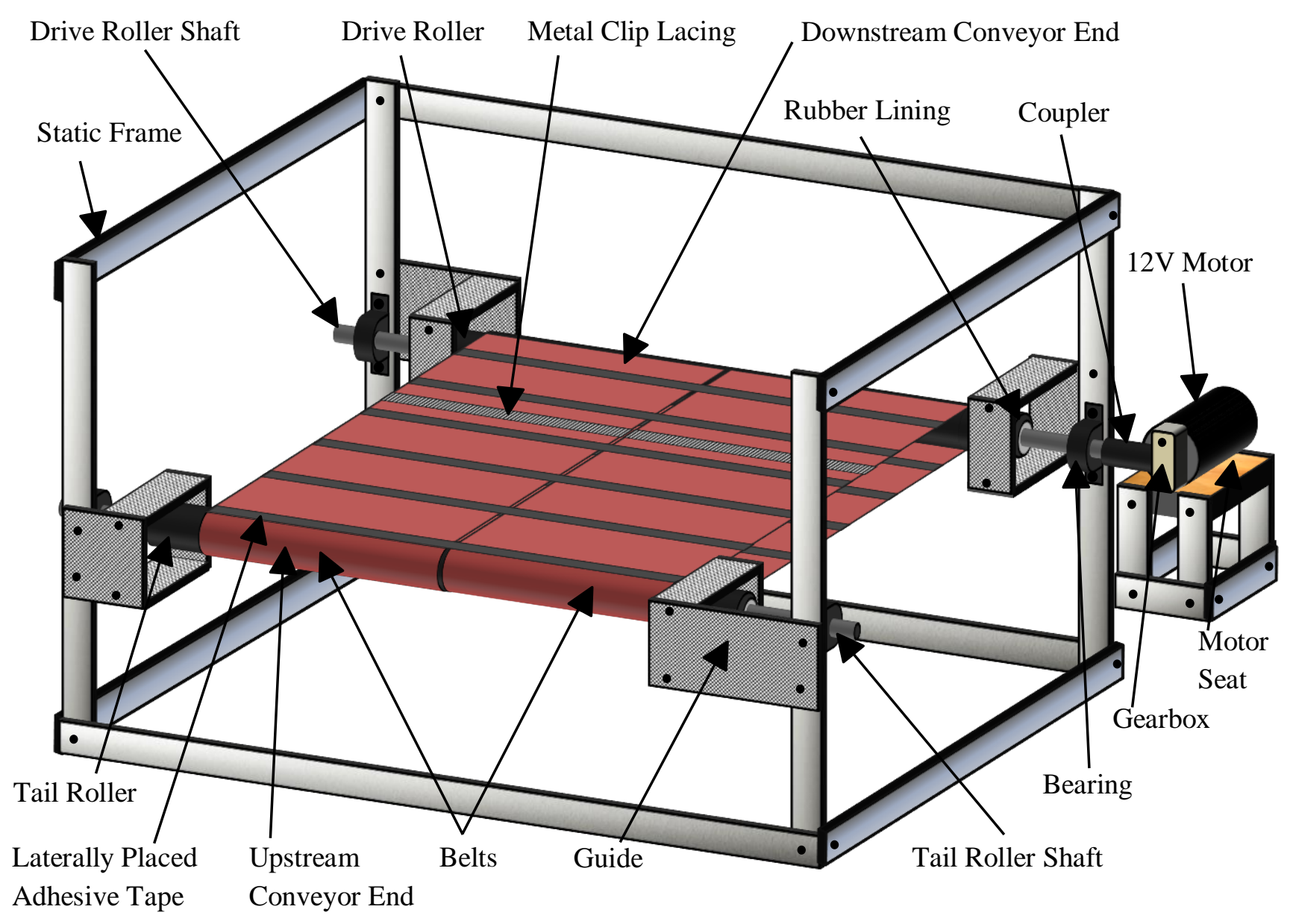

Figure 2.11: Conveyor Configuration (Perspective View)

Several problems were encountered during our initial testing on the previously designed conveyor system designed and constructed by Briley-Ford. First, as the conveyor consisted of two pieces of adjacently placed belts, the belts moved laterally away from each other over a few runs, generating a gap in the middle. As a result a napkin laying on the conveyor drooped into the gap, hampering a flat condition of a napkin, necessary for the silverware wrapping mechanism. Moreover, this gap also prevented the four-bar/roller mechanism from working properly because the wheel/roller could not provide necessary pressure for the napkin to engage with the conveyor. 
This problem was solved by laterally winding an adhesive tape around the belts at a plurality of locations, which maintained the belts acting as a single unit, as shown in Figure 2.11.

The belts of the conveyor were poorly tensioned, which caused noise, vibration and slippage of the belts on their rollers. To properly tension the belts, we initially moved the belt rollers further apart from each other to take up the belt slack. This slightly improved the belt tension, but did not eliminate the problem completely. Later we installed a take-up roller as shown in Figure 2.12.

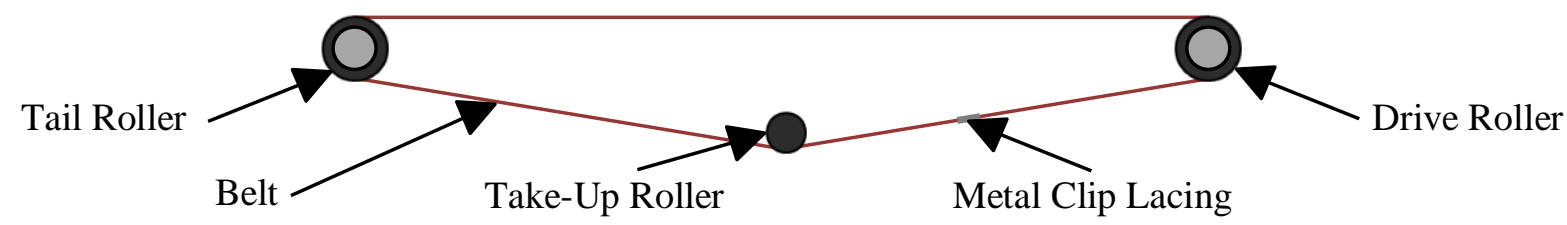

Figure 2.12: Take-Up Roller (Side View)

This helped tension the belts, but the metal clip lacings of the belts tended to catch on the take-up roller, which caused the drive roller motor to stall. As its disadvantage outweighed its advantage, we decided to drop this idea and looked for better alternatives. Finally we coated the drive and tail rollers with thick rubber linings on their outer surfaces, which improved belt performance significantly and reduced belt slippage to a tolerable degree.

The conveyor belts crept to one side after the conveyor had been running for a period of time. After investigation, we identified that the conveyor rollers were not perfectly aligned on the static frame with respect to each other. We, therefore, realigned the rollers, raised the roller drive motor seat elevation to better match the position of the drive roller, and also installed guides, as shown in Figure 2.11, which helped reduce creeping significantly. 
Another problem was slippage of the drive motor coupler on the drive roller shaft which caused noise, vibration, and interruption of conveyor motion. Initially we replaced the worn out set screws which held the coupler on the flat spot of the drive roller shaft. This solved the problem temporarily, but after several runs, the set screws became loose and the coupler slipped again. After investigation, we found that the threads on the coupler were stripped out, and so we pinned the coupler to the drive roller shaft as described earlier for the pinion drive motors.

In the previous design by Briley-Ford, the conveyor motor operated continuously during singulation process. This was not only power-inefficient, but also risky because it could burn out the motor if the drive roller was stalled. We, therefore, added a controller to the conveyor drive motor, which allowed the conveyor to operate only when a napkin was in place.

After the linear actuator with a push roller on its end was installed, and the conveyor problems were fixed, the system could convey a napkin along the conveyor successfully. A schematic diagram of this process is given in Figure 2.13. After the napkin removal system removes a napkin from the adhesive tape and places the napkin corner on the conveyor, the carriage rackand-pinion mechanism moves the carriage away from the conveyor in order to position the push roller right above the napkin corner, as shown in Figure 2.13(a). The middle infrared sensor switch is placed at a position so as to halt the carriage when the push roller center-line is aligned above the corner of the napkin. Then the conveyor is turned on and the linear actuator is extended. Upon full extension, the actuator presses and holds down the push roller on the napkin, which delivers necessary pressure between napkin and conveyor such that the conveyor can pull the napkin onto the belt and convey it, as shown in Figure 2.13(b). The slight flexible cantilever support helps absorb any vibration delivered by the conveyor during this process. When the napkin moves far enough for its own weight to adhere to the conveyor, the actuator is retracted and the push roller returns to its resting position. The conveyor motion is stopped when the napkin leaves the conveyor, ready for entry into a napkin wrapping system. 


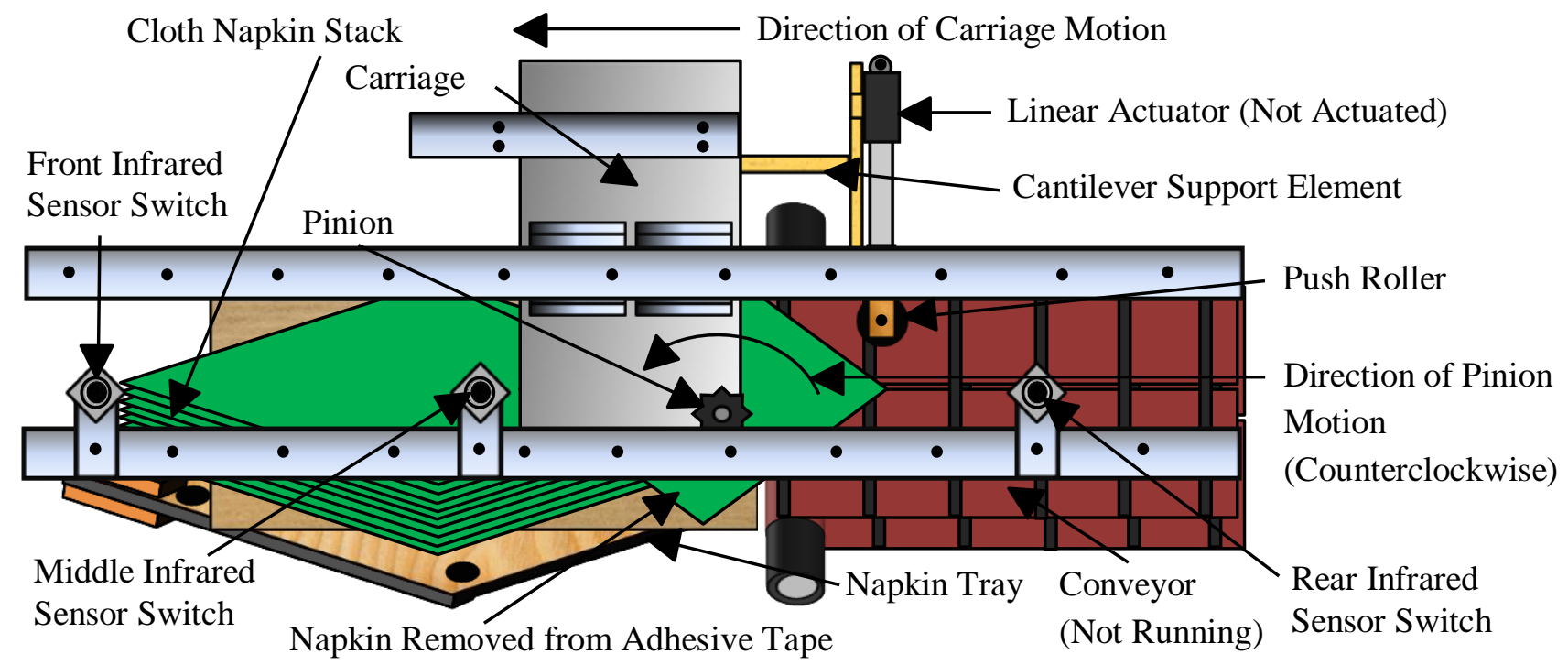

(a) Before Positioning Push Roller (Angled View from $45^{\circ} \mathrm{Up}$ from Right Side)

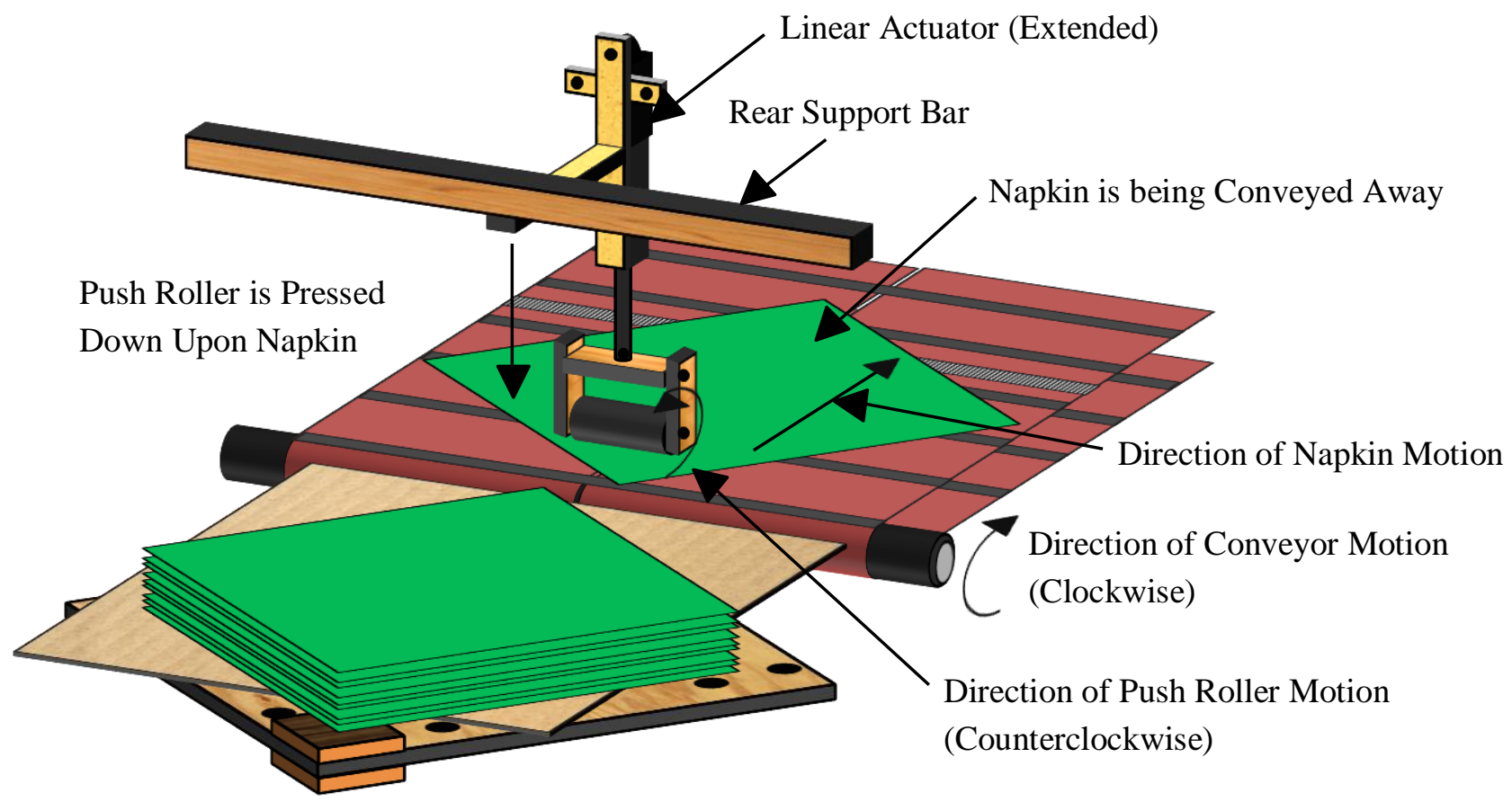

(b) After Positioning Push Roller (Perspective View)

Figure 2.13: Schematic Diagram of Napkin Engagement on Moving Conveyor 


\subsubsection{Design of System to Return Carriage to Resting Position}

After a napkin is fully conveyed, the carriage is returned to its original resting position to await the next napkin. This is accomplished using the carriage rack-and-pinion mechanism, which rolls the pinion gears along the racks until the front infrared sensor switch, positioned near the front portion of the setup, signals the control unit to stop the motion. A schematic view of this operation is shown in Figure 2.14.

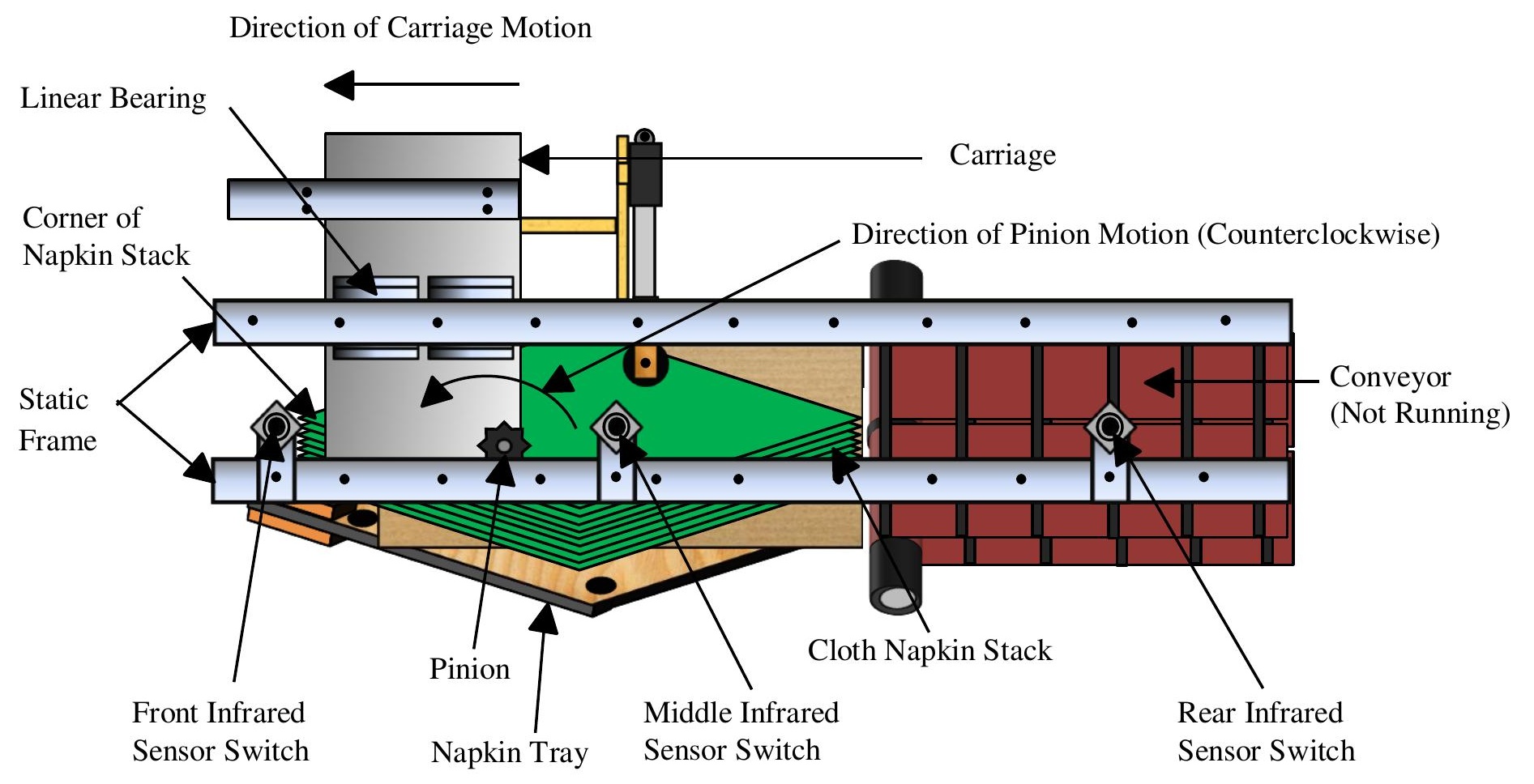

Figure 2.14: Schematic Diagram of Carriage Return (Angled View from $45^{\circ} \mathrm{Up}$ from Right Side) 
The position of the front infrared sensor switch is selected carefully such that when the carriage stops, the center-line of the adhesive tape is directly above the corner of the napkin stack, such that remaining napkins in the stack can be picked in following cycles of operation. The front sensor switch also serves another purpose at the very outset of the singulation process: when the singulation system is powered up for the first time, the front infrared sensor switch checks the position of the carriage. If the carriage is not at its resting position, the front infrared sensor switch signals the control unit, which then sends commands to the pinion drive motors to position the carriage at its desired resting position.

\subsubsection{Design of Napkin Tray Lifting System}

In the previous design by Briley-Ford, three lead screw stepper motors were used to lift a napkin tray containing napkin to compensate for decreasing stack height as napkins are removed from the top of the stack. This is necessary to maintain adequate contact pressure between the napkin and the adhesive tape. The motors were vertically mounted on a support structure with their lead screws pointed downward, as shown in Figure 2.15. Each lead screw threaded through a flanged nut and the nuts were fixed to a horizontally disposed napkin tray, made of a Masonite sheet, upon which the cloth napkin stack was placed. All three motors were actuated synchronously in an attempt to raise the napkin tray to maintain sufficient contact between the adhesive tape and the topmost napkin of the stack, after a few napkins had been removed. During our initial testing, we found that when the motors were actuated, the napkin tray leaned to one side and eventually bound up, restricting further vertical lifting. After investigation, we identified that different loading conditions existed at the points where the flanged nuts were attached to the napkin tray, such that the lead screws would not rotate equally when the motors were powered synchronously. 
As a result, the corners of the napkin tray rose by different amounts which tilted and eventually bound up the tray.

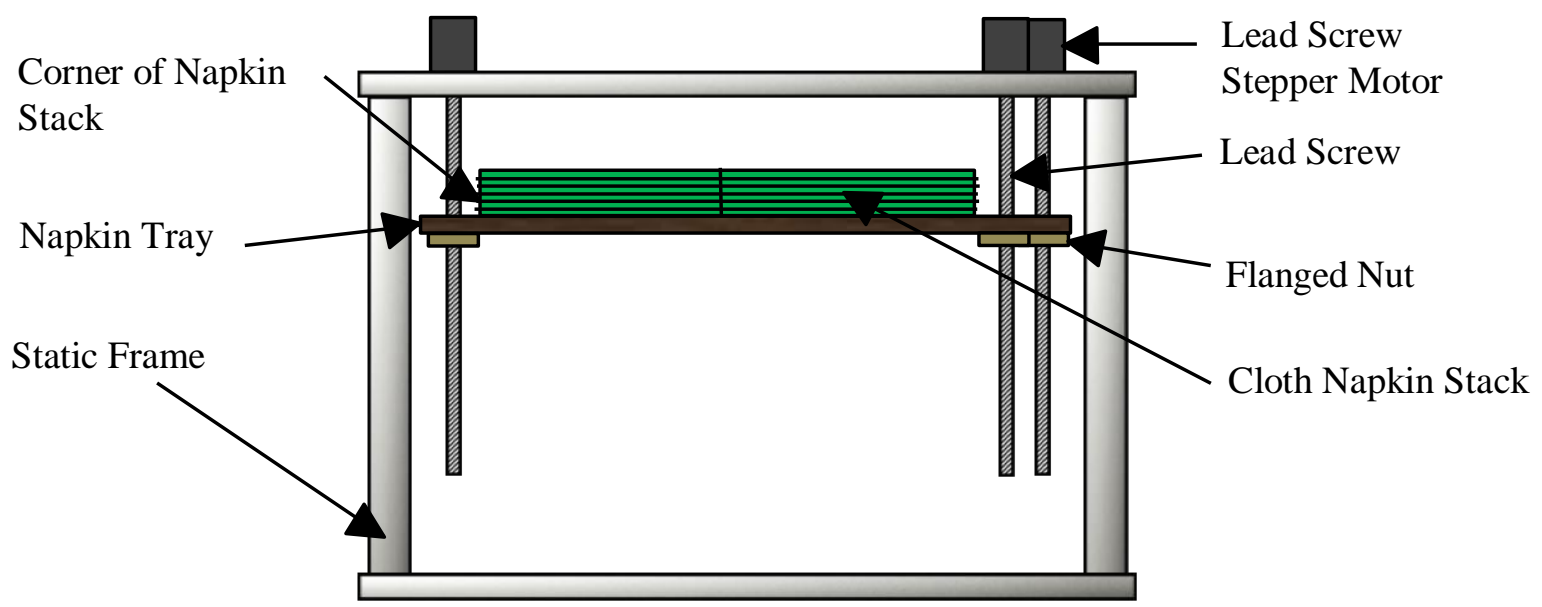

Figure 2.15: Previous Napkin Tray Lifting Configuration (Side View)

Initially we attempted to fix this problem by realigning the napkin tray and by lubricating the contact surfaces between the flanged nuts and the lead screws. As this did not solve the problem, we concluded that lifting the tray using three motors together was not a plausible solution, such that we investigated alternatives using only one lead screw stepper motor to raise the napkin stack. After considering several ideas for replacing the Briley-Ford tray lifting system, we selected the approach shown in Figure 2.16. 


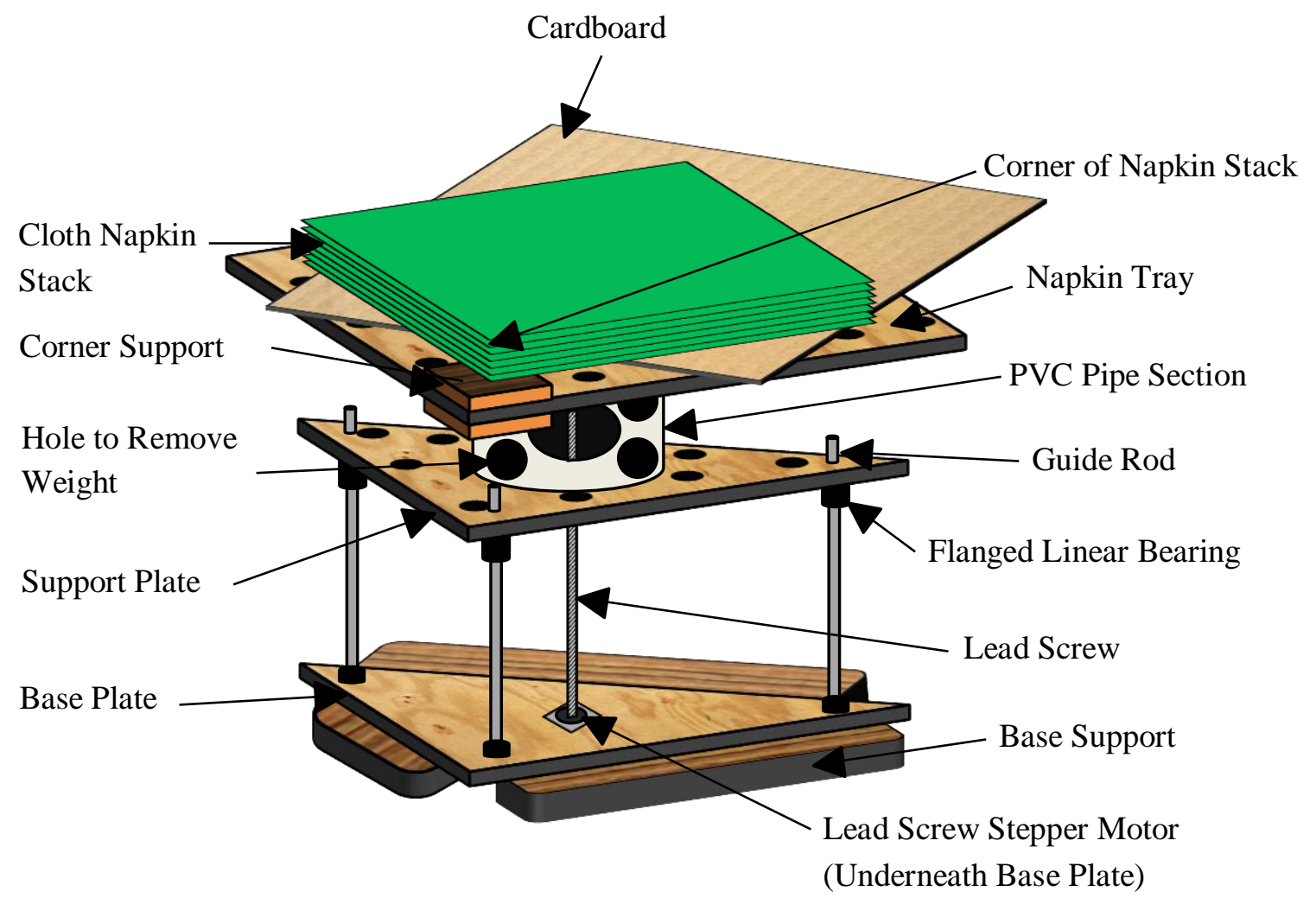

Figure 2.16: Napkin Tray Lifting Configuration (Perspective View)

The napkins are neatly stacked and are diagonally positioned on a napkin tray made of a 20 " $\mathrm{x}$ 20 " $\mathrm{x} 1 / 4$ " piece of plywood. This dimension of the napkin tray is selected so as to accommodate the geometry of the cloth napkins and the design of the conveyor. The tray is diagonally laid with one corner beneath the adhesive tape when the carriage is at resting position, and the opposite corner adjacent to the upstream end of the conveyor. Two corner supports are added to the front corner of the napkin tray to help the tray withstand repetitive stress exerted by the carriage slidercrank mechanism during napkin pick-up. As the napkin tray is diagonally positioned at the upstream end of the conveyor, a piece of cardboard is placed between the napkin stack and the 
napkin tray so as to facilitate smooth transition of the picked napkins from the napkin tray to the conveyor. A lead screw stepper motor threaded through a flanged nut is employed to lift the napkin tray. The motor is mounted upside down in a base plate with its open end of the lead screw passing through a support plate, disposed horizontally above the base plate and held in place by means of the flanged nut of the motor. The rotary motion from the motor is converted into linear motion by the lead screw, which helps raise and lower the support plate along three guide rods, mounted vertically on the base plate. A short section of PVC pipe, resting on the support plate, transfers the vertical motion of the support plate to the napkin tray without letting the lead screw interfere with the napkin tray. Several lightening holes are cut into the napkin tray, PVC pipe and the support plate to remove weight such that the load on the stepper motor is manageable.

After the old napkin tray lifting system was replaced with the new, the napkin tray could be raised reliably to accommodate the decreased stack height. A schematic figure of the napkin tray lifting mechanism is given in Figure 2.17. To raise the napkin tray, the lead screw stepper motor is actuated with the motor firmly fixed in the base plate and the support plate attached to the flanged nut of the lead screw motor, the rotary motion of the motor is converted into linear motion by the lead screw, which lifts upward the base plate, PVC pipe section, napkin tray, and support plate. After all the napkins have been removed from the napkin stack and conveyed away, the tray is returned to its resting position by rotating the motor in opposite direction. 


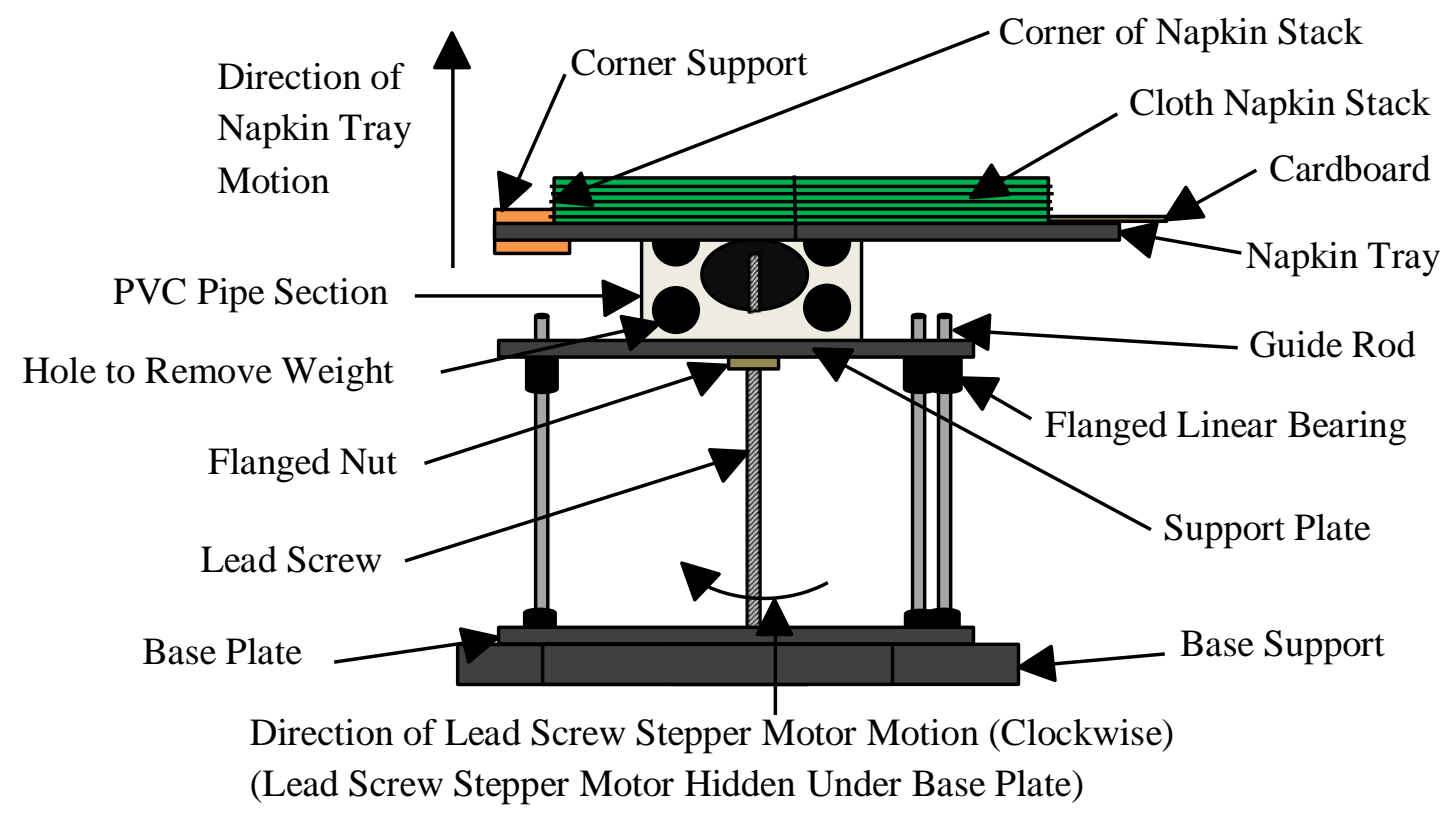

Figure 2.17: Schematic Diagram of Napkin Tray Lifting (Side View)

\subsubsection{Design of Adhesive Tape Renewal System}

After a few napkins have been picked up and delivered to the conveyor using the same area of adhesive tape, the tape loses its ability to adhere to new napkins due to collecting dirt, debris, napkin lint, and dust particles, such that a fresh adhesive area is required. A tape roll system consisting of one powered winding roller, two idler rollers, and one unwinding roller are mounted on the sliding plate of the carriage to serve this purpose. The unwinding roller has a roll of 1 " wide, special double-sided adhesive tape (adhesive area on both sides of the tape) manufactured by 3-M Corporation, which comes with a paper backing. The free end of the tape is pulled under the idler rollers and reeled back onto the powered winding roller together with the free end of the paper backing which is pulled above the idler rollers. The adhesive side of the tape in contact with the idler rollers helps prevent sideways creeping of the tape during tape renewal and the 
opposite side of the tape adheres to a napkin corner when the idler rollers are pressed onto the napkin stack by lowering the sliding plate using the carriage slider-crank mechanism. During the tape renewal process, the powered winding roller acts as a take-up reel and the unwinding roller acts as a supply reel. A $12 \mathrm{~V}$ motor positioned behind the sliding plate powers the winding roller, which places an unused area of the tape under the idler rollers. The motor is activated after a set number of napkin cycles by a signal from the control unit. Figure 2.18 depicts this process.

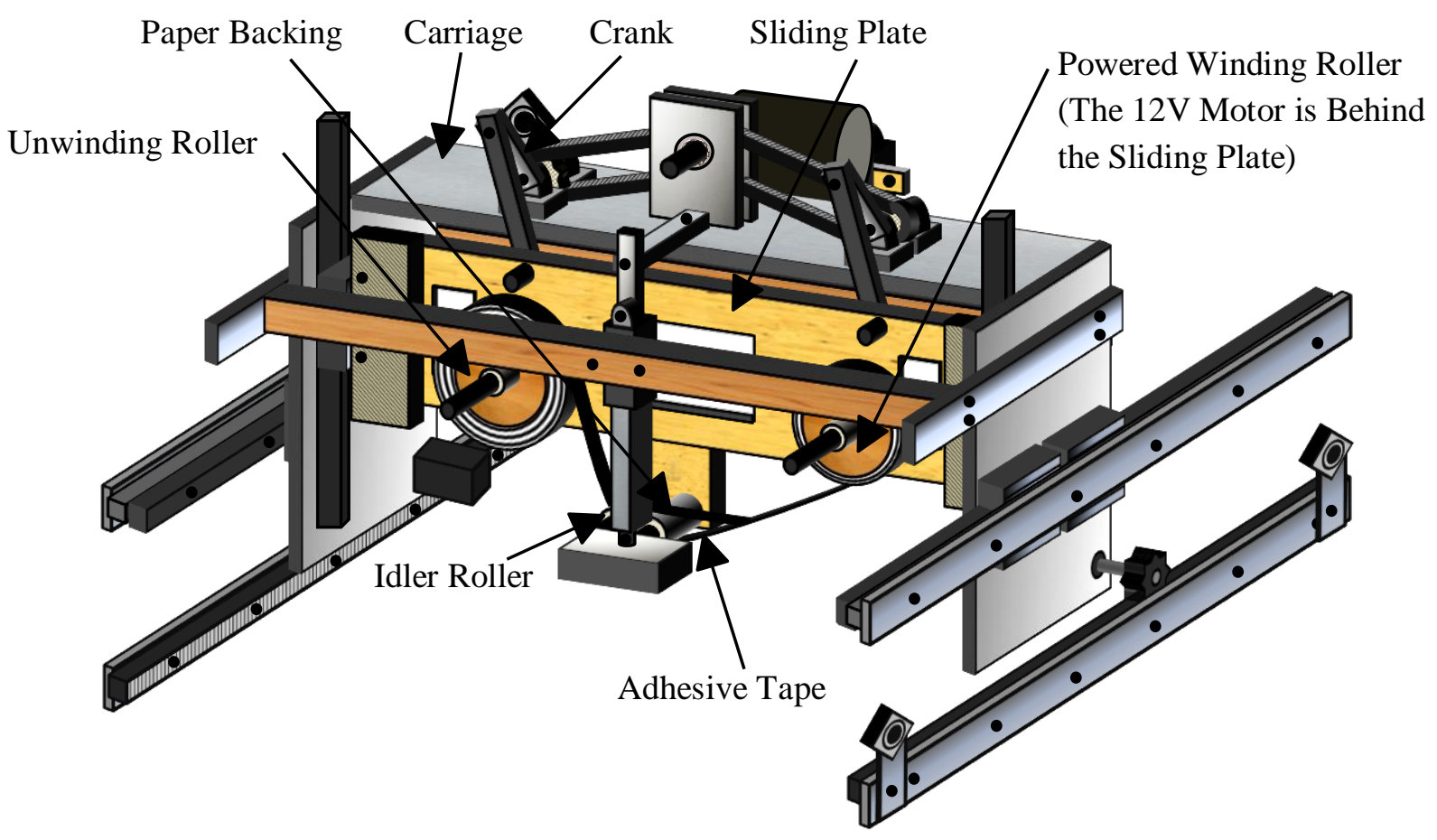

Figure 2.18: Tape Roll Configuration (Perspective View)

During initial testing, we identified a few problems which hampered the performance of the tape roll system. One of the problems was sideways creeping of the adhesive tape under the idler rollers when the tape was renewed. After investigation, we found that the winding roller, idler 
rollers and the unwinding roller were not aligned with one another on the sliding plate. This creeping reduced the effective adhesive surface area under the idler rollers, and eventually the tape slid off the idler rollers completely. We, therefore, repositioned and realigned the rollers, which reduced creeping to a tolerable limit.

We also encountered a problem with the driving motor of the tape roll system. The $12 \mathrm{~V}$ motor, which was coupled to the winding roller shaft behind the sliding plate, had an irreparably broken soldered tab, leaving the system non-operating. We, therefore, replaced the motor with a new one and also taped the soldered joints so as to prevent further breaking of the soldered tabs from fatigue, caused by frequent down and up motion of the sliding plate during napkin picking and napkin removal processes.

After the problems of the tape roll system were fixed, the system could renew the adhesive tape properly after a few cycles of operation. A schematic diagram of adhesive tape renewal mechanism is depicted in Figure 2.19. When the driving motor rotates the winding roller, the unwinding roller peels off a portion of the paper backing such that a new portion of tape is unwound in response to traction from the winding roller. This unwound portion of tape passes under the idler rollers and winds up on the winding roller together with the paper backing, replacing the old, used tape under the idler rollers with a new portion of tape. Thus the tape roll system renews the adhesive tape to maintain a tape strip sticky enough for successful continuation of the singulation process. 


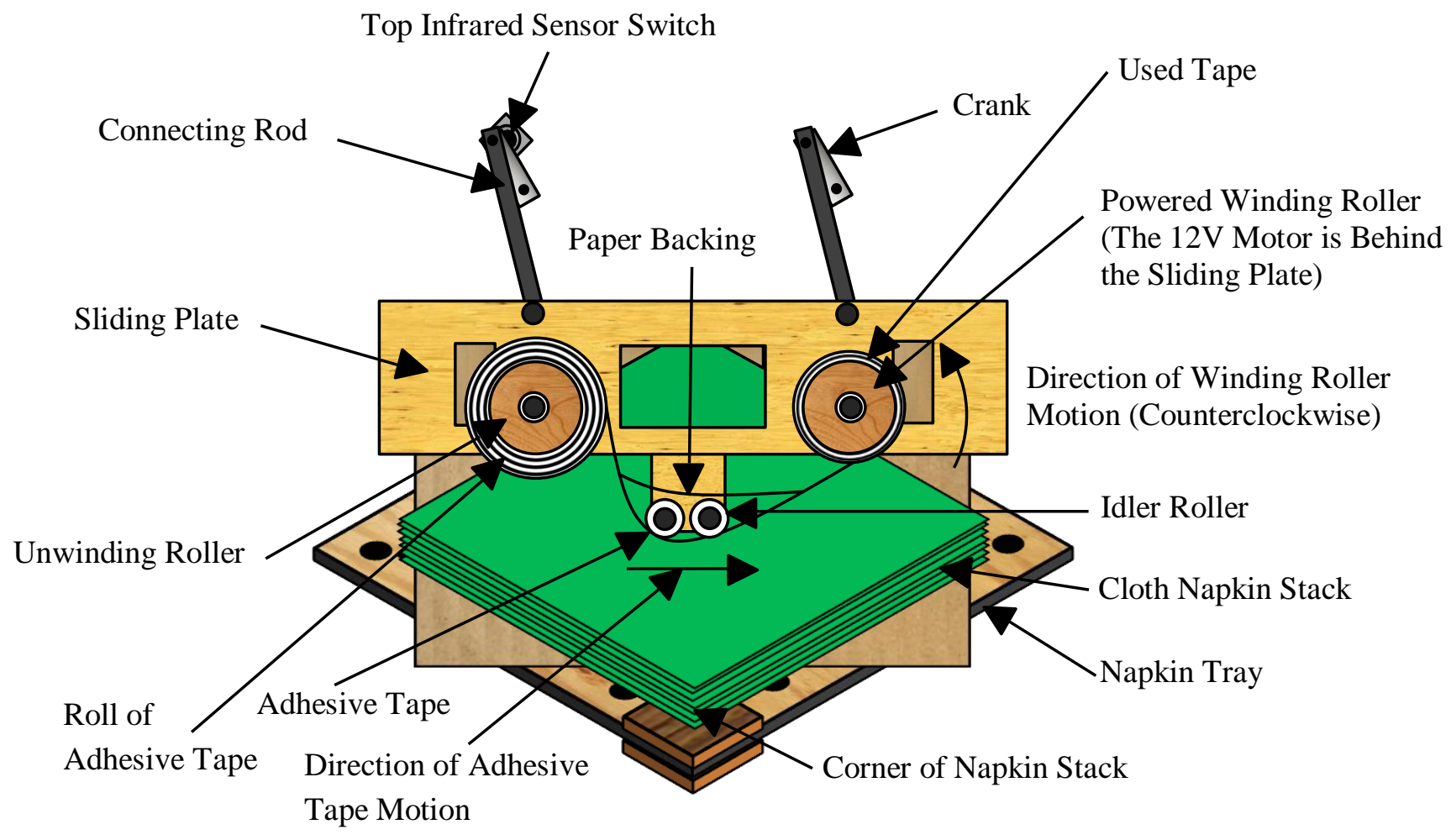

Figure 2.19: Schematic Diagram of Adhesive Tape Renewal (Front View)

A sketch of the complete cloth napkin singulation system is shown in Figure 2.20. In this chapter, we have presented a detailed analysis and design of the process and hardware we have used to design and construct a cloth napkin singulation system. A set of photographs of the apparatus with details and dimensions is given in Appendix B. In the next chapter, we present an in-depth discussion of the control system we developed to run various components of the napkin singulation system. 


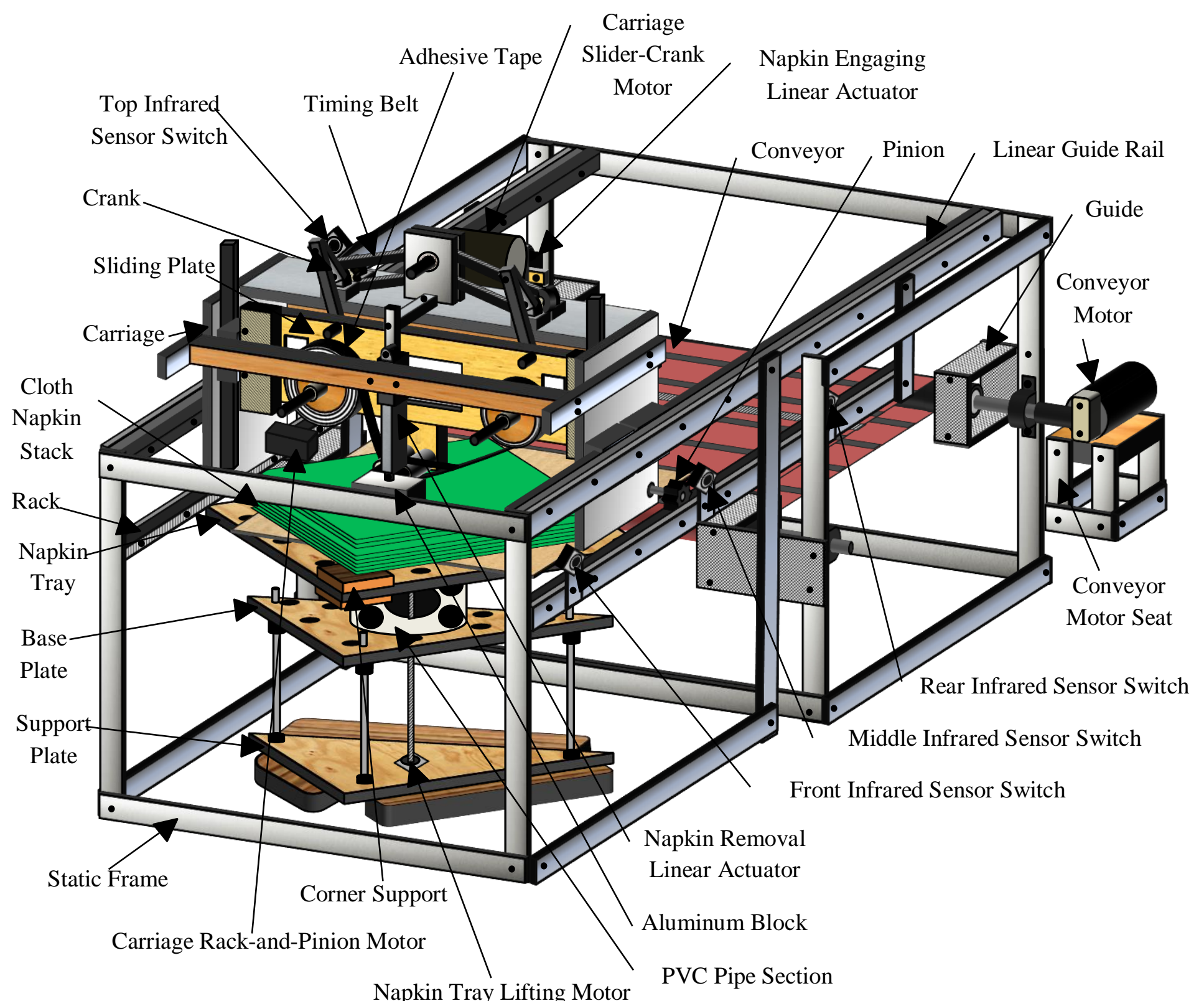

Napkin Tray Lifting Motor

(Hidden Under Base Plate)

Figure 2.20: Cloth Napkin Singulation System (Perspective View) 


\section{CHAPTER III}

\section{DESIGN OF CONTROL SYSTEM}

\subsection{Interface between Actuators, Sensors and Controllers}

To coordinate between different subsystems of the cloth napkin singulation system, a control system comprising actuators, sensors, controllers, and associated software was designed and implemented. The actuators are the output devices that receive commands from their driver controllers and deliver required motions during the singulation process. They include the $12 \mathrm{~V} \mathrm{DC}$ motor of carriage slider-crank mechanism, the two stepper motors of the carriage rack-and-pinion mechanism, the two $12 \mathrm{~V}$ DC linear actuators used in the napkin removing and engaging mechanisms, the $12 \mathrm{~V}$ DC motor operating the conveyor, the lead screw stepper motor for the napkin tray lifting system, and the $12 \mathrm{~V}$ DC motor used for tape renewal. The sensors are the input devices that send position feedbacks of different moving components to the main controller. They include the top, front, middle and rear infrared sensor switches, discussed in Chapter II. The controllers for the singulation system include different drivers for the actuators and a microcontroller, which acts as the CPU (Central Processing Unit) of the control system. The microcontroller operates in a stand-alone mode, interacting with all actuators and sensors, making controlling decisions, and implementing them. Two separate power supply units are used to meet the power demands for the control system components. 
In the following sections, we present details on each of these actuators, their drivers, the sensors, the power supply units, and the method in which they interface with the microcontroller. A detailed specification for each of these components is given in the Appendices.

\subsubsection{Microcontroller}

The microcontroller used in the cloth napkin singulation system to interact with the actuators and the sensors is the PIC18F4520, a microcontroller made by Microchip Technology Inc., and offered in a development kit from CCS, Inc. The prototyping board has a PIC18F4520 microcontroller with $30 \mathrm{I} / \mathrm{O}$ pins available through a simple plug configuration to connect to other electronic components. A schematic diagram of the pin configuration of the prototyping board is given in Figure 3.1. The board also features a potentiometer, an RS-232 level converter, a pushbutton, three LEDs, and an ICD (In-Circuit Debugger/Programmer) connector attached to the microcontroller (Not shown in the Figure 3.1). Both the digital and the analog pins of the microcontroller have been utilized in the control system. The digital pins are used to send commands to the actuator drivers, and the analog pins are used to receive analog voltage signals from the infrared sensor switches. The pins are connected to the respective components through a breadboard to allow for easy disconnection, if required. The prototyping board is supplied with $9 \mathrm{~V}$ through a $9 \mathrm{~V}$ AC adapter. A $5 \mathrm{~V}$ voltage regulator IC, built-in on the prototyping board, steps down the voltage to $5 \mathrm{~V}$ to supply the microcontroller and the sensors connected to the microcontroller with their operating voltage. The ground pin of the microcontroller is connected to the ground connections of the power supply units to serve as the COM terminal (Common Ground) of the entire control circuit. The development kit offers a C compiler, through which we generate .hex files for the software codes written in C programming language on a PC (Personal Computer). The .hex files are downloaded on the microcontroller from the PC using an ICD unit, 
provided in the development kit. The flash memory of the microcontroller helps erase previous code and reprogram the microcontroller any number of times required. The datasheet for the microcontroller and a detailed prototyping board layout are given in Appendix C.

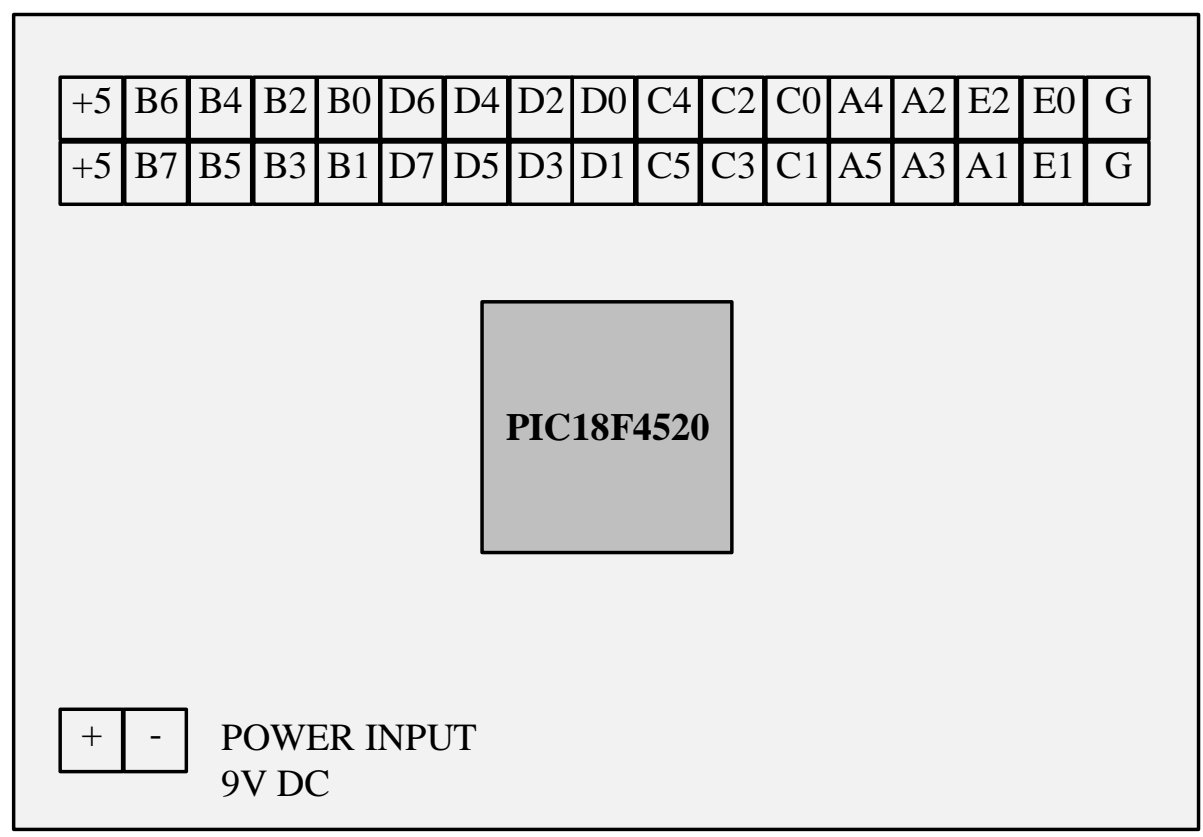

Figure 3.1: Schematic Diagram of Pin Configuration of PIC18F4520 Prototyping Board

\subsubsection{Control System for Carriage Slider-Crank Mechanism}

The 12V DC gear motor (PN01007) of the carriage slider-crank mechanism is controlled by a bidirectional PWM (Pulse Width Modulation) motor speed controller (BIDIR-115S) from Critical Velocity Enterprises, LLC. A schematic connection diagram of the controller is shown in Figure 3.2 . 


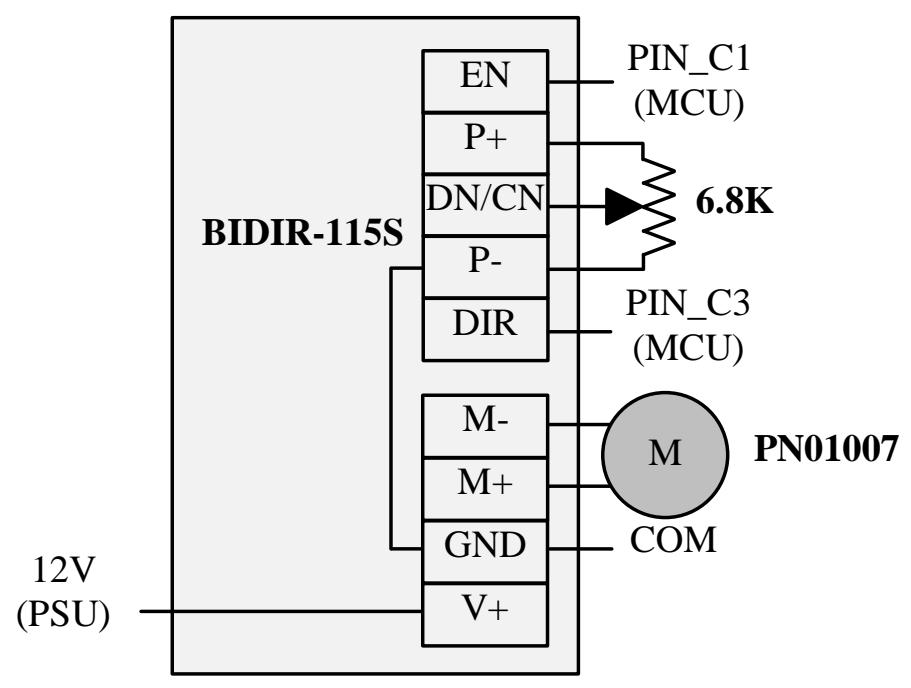

Figure 3.2: Schematic Connection Diagram for Carriage Slider-Crank Control System

The motor is connected between the M- and M+ pins of the controller. Since the driving motor of the carriage slider-crank mechanism is a $12 \mathrm{~V} \mathrm{DC}$ motor, the controller is supplied with $12 \mathrm{~V} \mathrm{DC}$ from the 12V DC PSU (Power Supply Unit) at the V+ pin, and the GND pin of the controller is connected to the COM terminal of the controller circuit. The voltage input is converted to $12 \mathrm{~V}$ DC pulses at the output by connecting a $6.8 \mathrm{~K}$ potentiometer between the $\mathrm{P}+$ and $\mathrm{P}$ - pins with its wiper connected to the center pin DN/CN of the controller. The P-pin is also shorted to the COM terminal. The wiper of the potentiometer has been adjusted so as to achieve desired speed during carriage slider-crank motion. The PWM output enable pin EN and the direction pin DIR of the controller are connected to the PIN_C1 and PIN_C3 of the MCU (Microcontroller Unit), respectively. Since the carriage slider-crank mechanism is needed to rotate in a single direction for our design, we have not used the direction reversing feature of the controller. For this mechanism, to activate the motor, the EN pin is made high while the DIR pin is kept low using the microcontroller. In order to stop the motor, the EN pin of the controller is brought low to turn 
off the motor, and the DR pin is immediately made high for a short period of time, which applies a brake to the motor. This helps stop the motor at a desired position. To determine the position of the motor after one full cycle is completed, the top infrared sensor switch (SEN0019), mounted on the top of the carriage, is utilized. A schematic connection diagram of the top infrared sensor switch is given in Figure 3.3.

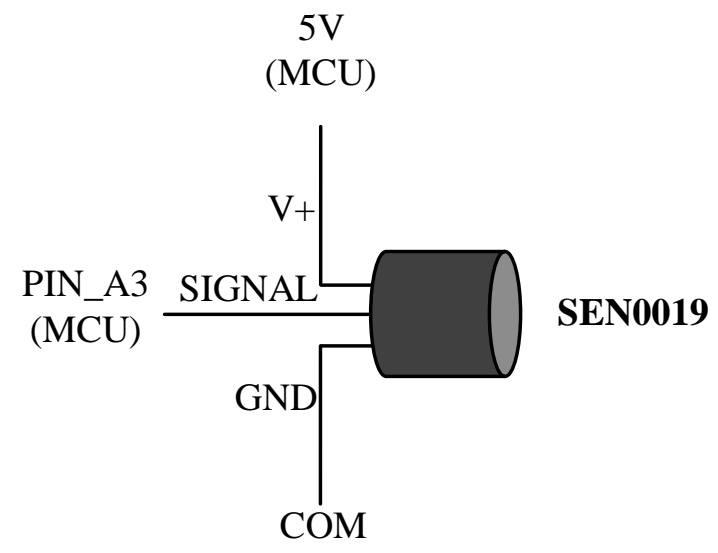

Figure 3.3: Schematic Connection Diagram for Top Infrared Sensor Switch

The $\mathrm{V}+$ pin of the sensor switch is supplied with $5 \mathrm{~V}$ from the MCU, and the GND pin is connected to the COM terminal of the circuit. The SIGNAL pin of the sensor switch, connected to the PIN_A3 of the MCU, delivers switching signal outputs to the microcontroller when objects in the vicinity of the sensor switch are detected. The signal remains high when there are no obstacles and becomes low when there are obstacles. After one complete cycle of the cranks, when the left crank passes the top infrared sensor switch to start a new cycle, the sensor switch detects the left crank, switching from high to low. As the main program polls the PIN_A3 of the microcontroller, it detects the change and stops the motor immediately. The datasheets for the 
carriage slider-crank motor, the bidirectional PWM motor speed controller, and the infrared sensor switch are given in Appendix D, Appendix E, and Appendix F, respectively.

\subsubsection{Control System for Carriage Rack-and-Pinion Mechanism}

The two stepper motors (KL23H276-30-8A) of the carriage rack-and-pinion mechanism, which together move the carriage along the rack gears to and from the conveyor, are connected to two micro stepping drivers (KL6050) from Automation Technology Inc. Figure 3.4 shows a schematic connection diagram of the controllers. The $+\mathrm{V}$ pin of each controller is supplied with 36V DC from a 36V DC PSU to power the connected stepper motor, and the GND pin of each controller is shorted to the COM terminal of the controller circuit. Each motor has 8 different colored wires: the Blue, Green, Brown and White wires are connected to the A+, A-, B+, and Bpins of the driver controller, respectively, while the Red/Yellow and Black/Orange wires are shorted together, respectively. This establishes a bipolar (series) connection of the motors with their driver controllers, which provides very good low speed torque required to reliably move the carriage along the racks. Each controller has 6 signal pins, among which two are pulse single pins, PUL+, and PUL-, two are direction signal pins, DIR+, and DIR-, and the remaining two are enable signal pins, ENA+, and ENA-. The PUL+ pins of both controllers are connected to the PIN_D5 of the MCU and the PUL- pins are connected to the COM terminal. The DIR+ pins of the controllers for the left and right stepper motors are connected to PIN_B1 and PIN_D7 of the MCU, respectively, and both DIR- pins are grounded. The ENA+ and ENA- pins of both controllers are left unconnected, which by default enable the controllers. A pulsing function written into the main program sends pulses to the PUL+ pins of the controllers, which actuates the motors to move the carriage to or from the conveyor. 


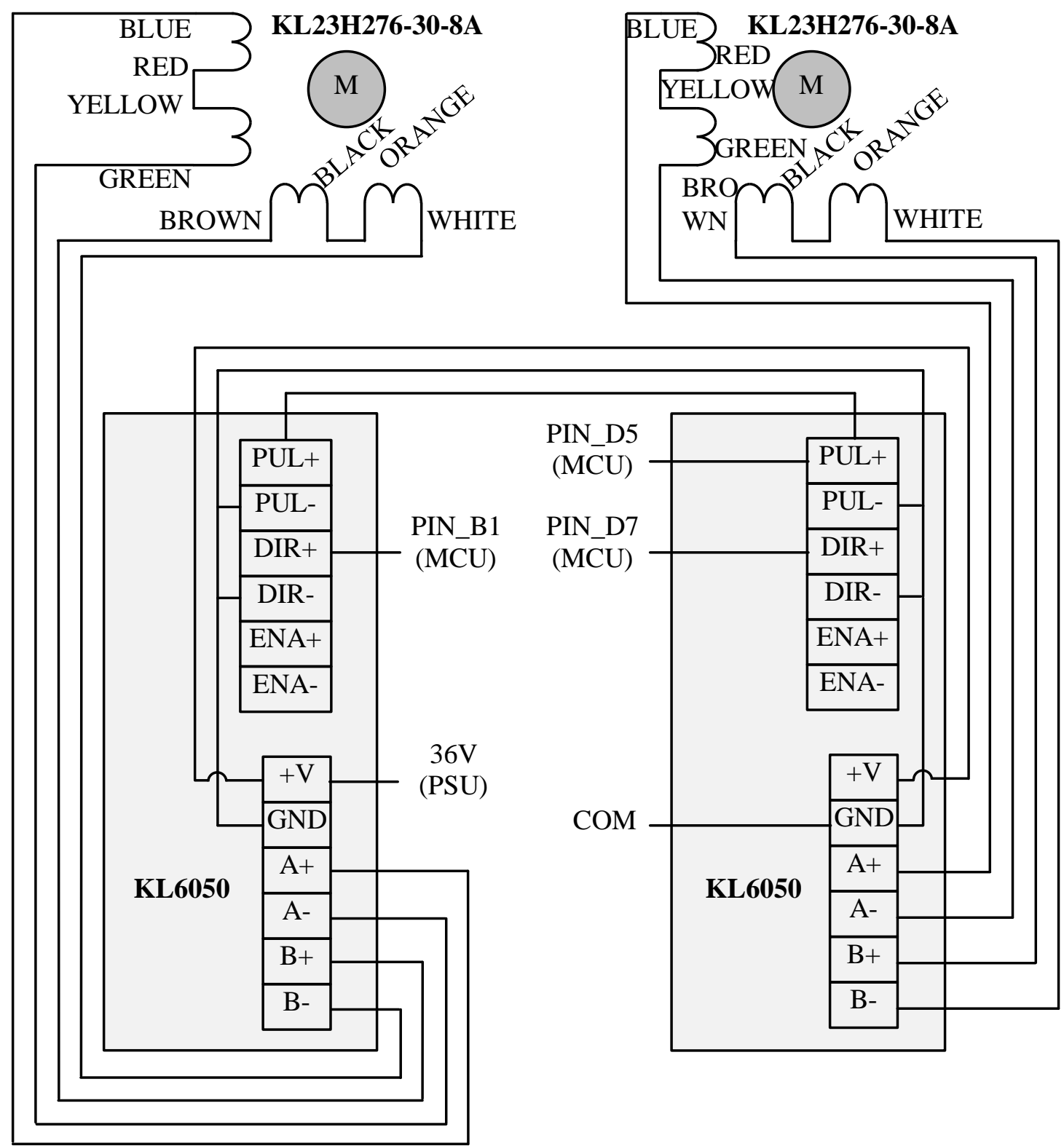

Figure 3.4: Schematic Connection Diagram for Carriage Rack-and-Pinion Control System

The desired speed of the carriage has been achieved by setting appropriate pulse width in the pulsing function. The direction of the carriage motion is controlled by the DIR+ pins of the controllers. Since the motors are placed on the two sides of the carriage, with motor bodies facing 
outboard, the DIR+ pins are inversely signaled to rotate the motors in opposite directions, which in turn move the carriage in the same linear direction. The carriage is stopped at the intended locations by stopping pulses at the PUL+ pins.

The front, middle, and the rear infrared sensor switches (SEN0019), placed on the static support frame, are used to trigger the controllers to stop the carriage when the carriage reaches in the sensor switches. Schematic connection diagrams of the sensor switches are given in Figure 3.5. Like the top infrared sensor switch, the V+ pins of the front, middle, and rear sensor switches are supplied with 5V DC from the MCU, and the GND pins are shorted to the COM terminal. The SIGNAL pins of the front, middle, and the rear sensor switches are connected to PIN_A1, PIN_E0, and PIN_A2 of the MCU, respectively. Upon detection of the carriage, the voltage signals from the sensor switches drop, which are sensed by the microcontroller. The microcontroller then ceases pulses at the PUL+ pins of the controller, stopping the carriage at the intended locations. The datasheets for the stepper motors, the micro stepping drivers, and the infrared sensor switches are given in Appendix G, Appendix H, and Appendix F, respectively. 


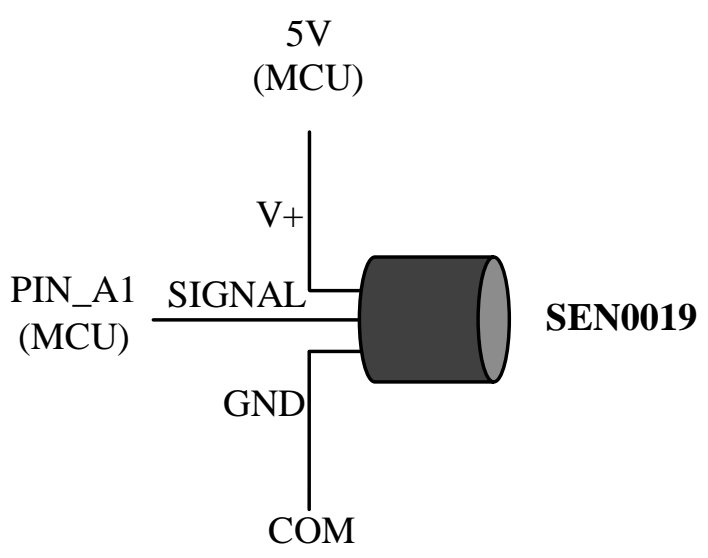

(a)Schematic Connection Diagram for Front Infrared Sensor Switch

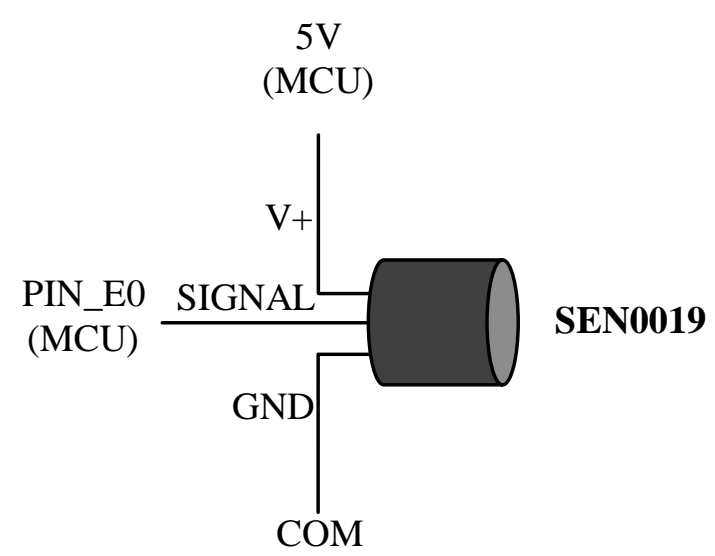

(b) Schematic Connection Diagram for Middle Infrared Sensor Switch

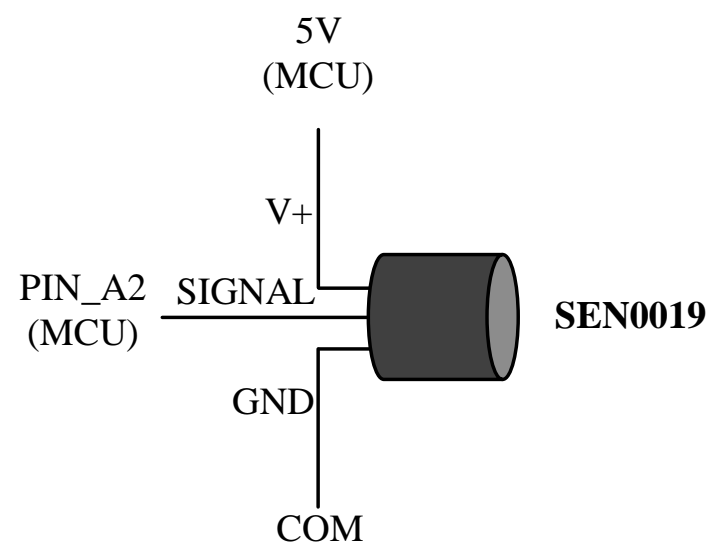

(c) Schematic Connection Diagram for Rear Infrared Sensor Switch

Figure 3.5: Schematic Connection Diagrams for Front, Middle, and Rear Infrared Sensor Switches 


\subsubsection{Control System for Napkin Removing and Napkin Engaging Linear Actuators}

The two 12V DC linear actuators with a stroke length of $100 \mathrm{~mm}$ and a gear ratio of 63:1 (L16100-63-12-P), which are used to remove a picked napkin from the adhesive tape and later to engage the removed napkin on the conveyor, are separately controlled by two linear actuator control boards (LAC) from Firgelli Technologies Inc. Schematic connection diagrams of the controllers are shown in Figure 3.6. Each of the linear actuators has 5 different colored wires, namely, Yellow, Black, Red, Purple, and Orange, which are sequentially connected to the 5 corresponding pins of actuator connector X2 on the control board. As the rated voltage for the linear actuators is $12 \mathrm{~V} \mathrm{DC}$, each actuator is supplied with $12 \mathrm{~V} \mathrm{DC}$ from the $12 \mathrm{~V}$ DC PSU at the VDC pin of control interface X6 on the control board. The GND pin of X6 for each controller is shorted to the COM terminal. The RC pins of X6 for napkin removing and napkin disengaging control boards are connected to the PIN_D6 and PIN_D4 of the MCU, respectively. These pins are used to send pulses to the connected actuators to activate them. A $2 \mathrm{~ms} 5 \mathrm{~V}$ DC signal pulse at the RC pin fully extends the connected actuator and a $1 \mathrm{~ms} 5 \mathrm{~V}$ DC signal pulse fully retracts the actuator. The remaining two input pins of X6, namely, IC, and, VC are left open and are not used by the control system. Since both actuators are needed to be fully extended for our design purposes, we have not used the position feedback capabilities of the actuators. The datasheets for

the linear actuators and the linear actuator control boards are given in Appendix I and Appendix $\mathrm{J}$, respectively. 


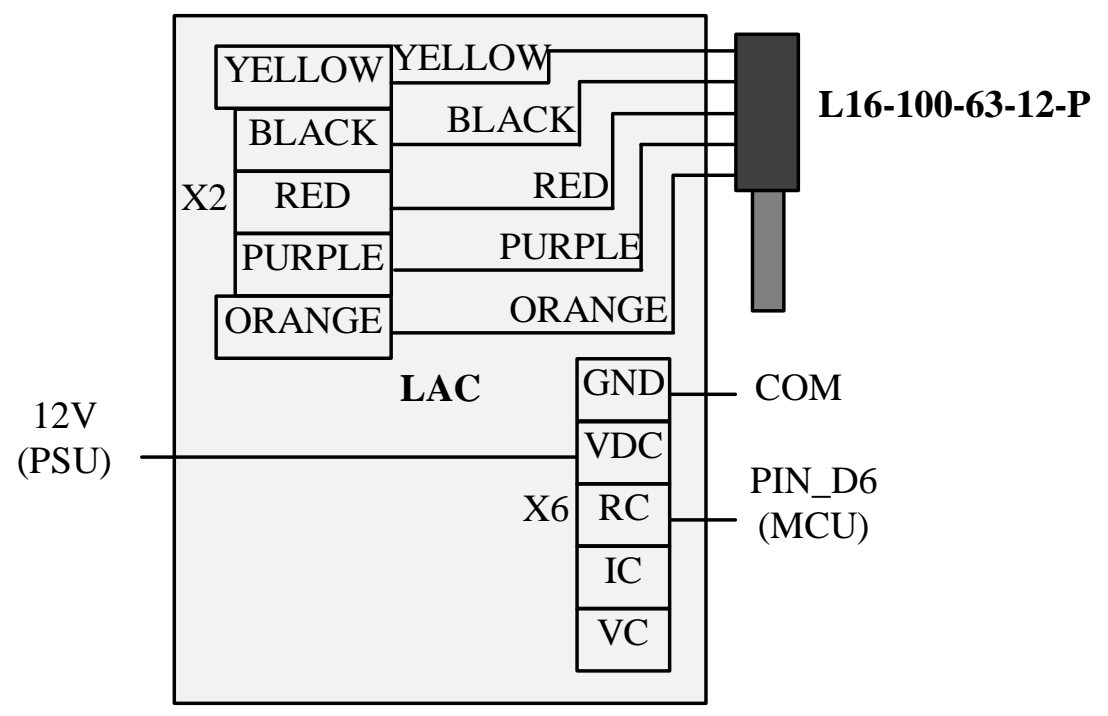

(a) Schematic Connection Diagram for Napkin Removing Linear Actuator Control System

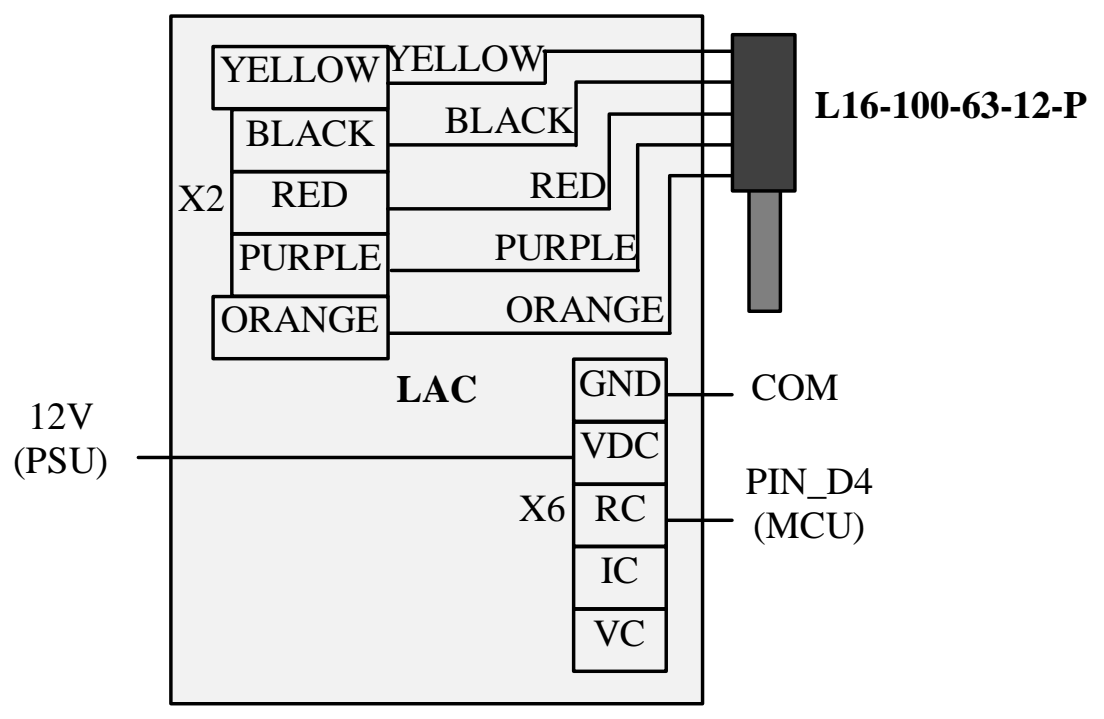

(b) Schematic Connection Diagram for Napkin Engaging Linear Actuator Control System

Figure 3.6: Schematic Connection Diagrams for Napkin Removing and Napkin Engaging Linear Actuators Control Systems 


\subsubsection{Control System for Conveyor}

The 12V DC gear motor (PN01007) used to drive the conveyor is identical to the one that has been used in the carriage slider-crank-mechanism. The motor is controlled by a DC-to-pulse width modulator (K8004) from Velleman, Inc. A schematic connection diagram of the controller is given in Figure 3.7.

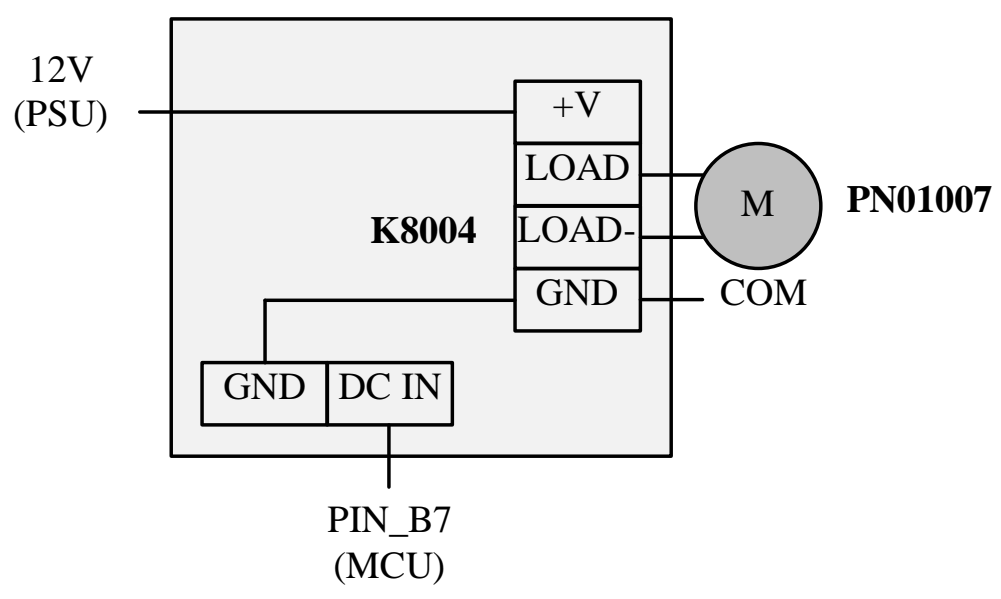

Figure 3.7: Schematic Connection Diagram for Conveyor Control System

The motor is connected between the LOAD+ and LOAD- pins of the controller. As the rated voltage for the motor is $12 \mathrm{~V} \mathrm{DC}$, the controller is supplied with $12 \mathrm{~V}$ DC by connecting the $+\mathrm{V}$ pin of the controller to the output voltage terminal of the $12 \mathrm{~V}$ DC PSU. Both the GND pins are shorted to the COM terminal. The motor is controlled by sending DC voltage signals at the DC IN pin of the controller, which is connected to PIN_B7 of the MCU. To run the conveyor, PIN_B7 is made high; by bringing the pin low, the conveyor is stopped. The controller converts the input $\mathrm{DC}$ voltage at the $+\mathrm{V}$ pin $(12 \mathrm{~V}$ here $)$ into a series of pulses, such that the pulse duration 
(duty cycle) is directly proportional to the value of the DC voltage applied at the DC IN pin of the controller. Since our design does not require variable speed for the conveyor, we apply a fixed voltage (Either $5 \mathrm{~V}$ or $0 \mathrm{~V}$ ) at the DC IN pin from the microcontroller to either run or stop the conveyor.

The minimum output voltage, maximum output voltage and output frequency required for our design have been adjusted using three potentiometers built-in on the controller, labeled RV1, RV2, and RV3 (Not shown in the Figure 3.7), respectively. The controller is a unidirectional motor controller. To change the direction of the motor rotation, the motor wires connected to the LOAD pins must be reversed, which is not required in our design, since the conveyor always runs in a single direction. The datasheets for the conveyor motor and the controller are provided in Appendix D and Appendix K, respectively.

\subsubsection{Control System for Napkin Tray Lifting Mechanism}

The control system for napkin tray lifting mechanism includes a lead screw stepper motor (E43H4C-12-007) and a bipolar stepper motor driver (K158) from DIY Electronics (HK) Ltd. A schematic connection diagram of the control system is given in Figure 3.8. 


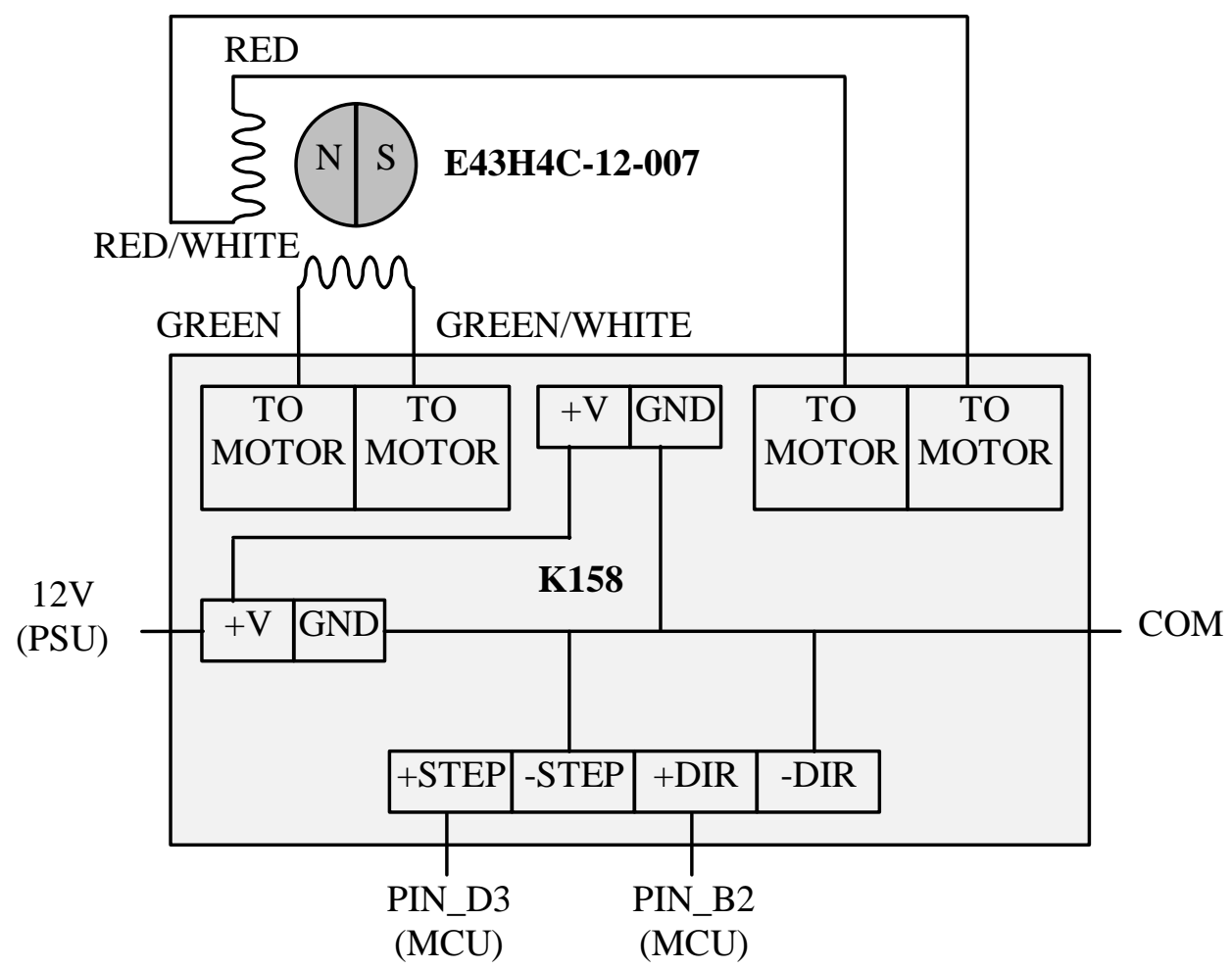

Figure 3.8: Schematic Connection Diagram for Napkin Tray Lifting Control System

The motor is a bipolar stepper motor with 4 wires of different colors, namely, Green, Green/White, Red, and Red/White, which are sequentially connected to the four corresponding TO MOTOR pins of the controller, as shown in the connection diagram. Since the rated voltage for the motor is $12 \mathrm{~V} \mathrm{DC}$, the $+\mathrm{V}$ pins of the controller is supplied with $12 \mathrm{~V} \mathrm{DC}$ from the $12 \mathrm{~V} \mathrm{DC}$ PSU and the GND pins are connected to the COM terminal. The controller has four control input pins, two are for step control, namely, +STEP, and -STEP, and the remaining two are for direction control, namely, +DIR, and -DIR. The +STEP and +DIR pins of the controller are connected to PIN_D3 and PIN_B2 of the MCU. Both the -STEP and -DIR pins are shorted to the COM terminal. To actuate the motor, pulses are sent to the +STEP pin for a given number of steps from the microcontroller. The direction of the tray motion is controlled by the DIR pins. A 
low signal from the microcontroller at the +DIR pin raises the tray and a high signal lowers the tray. The datasheets for the motor and the motor driver are given in Appendix L and Appendix M, respectively.

\subsubsection{Control System for Adhesive Tape Renewal Mechanism}

The 12V DC gear motor (MT-050) of the adhesive tape renewal system is controlled by a DC to pulse width modulator (K8004), identical to the one that has been used to control the conveyor motor. A schematic connection diagram of the controller is given in Figure 3.9.

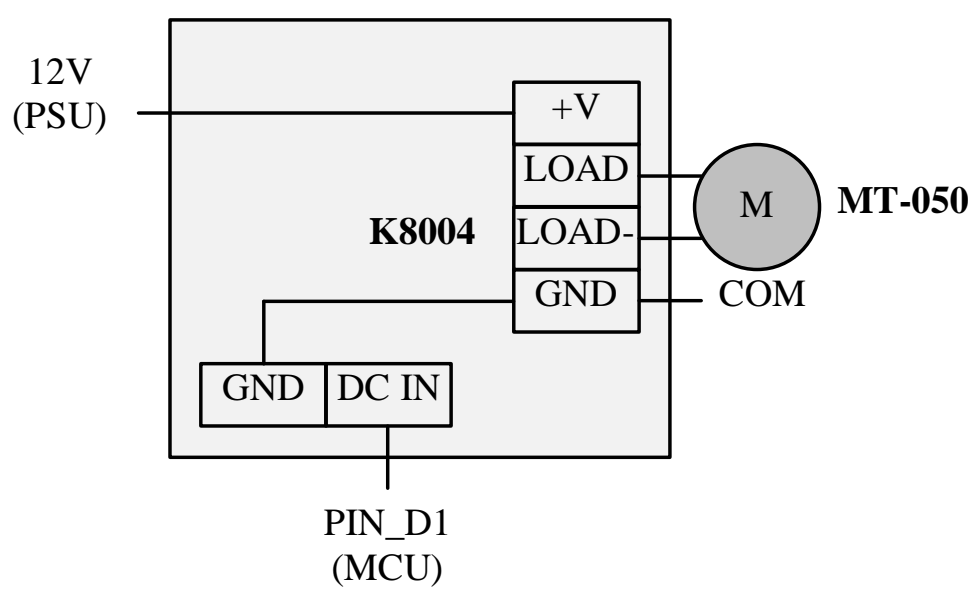

Figure 3.9: Schematic Connection Diagram for Adhesive Tape Renewal Control System

The motor is connected between the LOAD+ and LOAD- pins of the controller. The controller is supplied with $12 \mathrm{~V}$ from the $12 \mathrm{~V}$ PSU at the $+\mathrm{V}$ pin of the controller. The GND pins are shorted to the COM terminal. The DC IN pin of the controller in connected to the PIN_D1 of the MCU 
and is used to send high and low signals $(5 \mathrm{~V}$ or $0 \mathrm{~V})$ from the microcontroller. A high signal at the DC IN pin converts the source voltage (12V here) into a series of pulses at the motor terminals and thereby runs the motor. To stop the motor the PIN_D1 is brought low. The minimum output voltage, maximum output voltage and output frequency required for the system have been adjusted using three potentiometers built-in on the controller, labeled RV1, RV2, and RV3 (Not shown in the Figure 3.9), respectively. The datasheet for the motor and the controller is given in Appendix N and Appendix K, respectively.

\subsubsection{Power Supply Units}

Two different power supply units, one of $12 \mathrm{~V} \mathrm{DC}$, and the other of $36 \mathrm{~V} \mathrm{DC}$, are in place to power all the components of the control system. The 12V DC PSU (S-145-12) can output up to 12A, and the 36V DC PSU (HS-400-36) can output up to 11A. Schematic diagrams of the pin configuration of the power supply units are given in Figure 3.10. The rated power for the 12V DC PSU and the 36V DC PSU are 144W and 400W, respectively. The 36V DC PSU provides power only to the micro stepping driver for the carriage rack-and-pinion mechanism. All other

components are powered by the $12 \mathrm{~V}$ DC PSU. The datasheets for the power supply units are given in Appendix O. 


\begin{tabular}{|c|c|c|c|}
\hline \multicolumn{4}{|c|}{ S-145-12 } \\
\hline $\mathrm{L}$ & $\mathrm{N}$ & $\doteq|\mathrm{COM}| \mathrm{COM} \mid+\mathrm{V}$ & $+\mathrm{V}$ \\
\hline $\mathrm{AC}$ II & PU & $\begin{array}{l}12 \mathrm{~V} \\
\text { OUT }\end{array}$ & PUT \\
\hline
\end{tabular}

(a) 12V DC Power Supply Unit

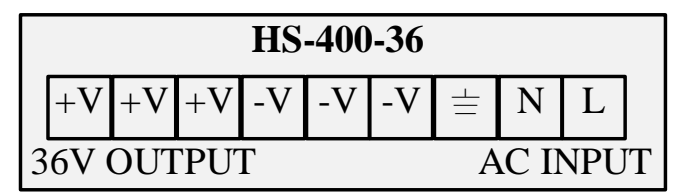

(b) 36V DC Power Supply Unit

Figure 3.10: Schematic Diagram of Pin Configuration of Power Supply Units

A schematic connection diagram of the complete control system is given in Figure 3.11. In the next section we discuss details of the software program controlling the microcontroller, which was written on a PC and later downloaded to the microcontroller. The microcontroller is used to communicate between different actuators, their driver controllers, and the sensors to perform the singulation process seamlessly and continuously for a given number of napkins in the napkin stack. 


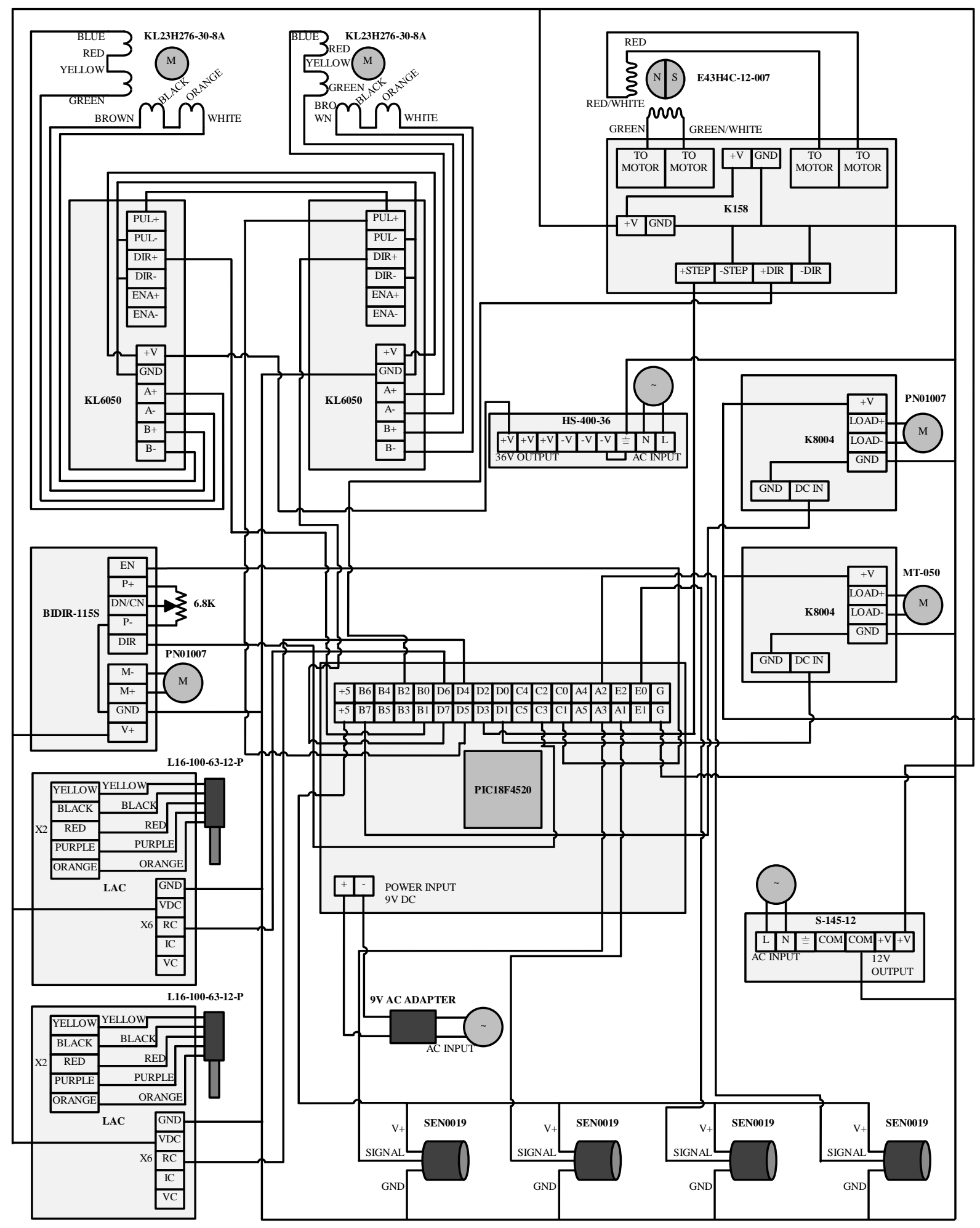

Figure 3.11: Schematic Connection Diagram of Complete Control System 


\subsection{Program for Cloth Napkin Singulation System}

A program written in the $\mathrm{C}$ programming language on a $\mathrm{PC}$ using the $\mathrm{C}$ compiler provided with the PIC18F4520 development kit is used to communicate with different components of the control system to perform the singulation process. The program was downloaded to the microcontroller using the ICD unit provided with the kit for programming and debugging. Once the microcontroller is programmed, it operates in a stand-alone mode, commencing and finishing the singulation process continuously for a given number of napkins. The actuators are run by their driver controllers upon receiving pulses or high/low voltage signals sent to them form the microcontroller by the program. The infrared sensor switches offer a non-contact method of providing position feedback of different moving objects in the singulation system to the microcontroller. The top infrared sensor switch provides position feedback of the left crank during carriage slider-crank operation, and the remaining three sensor switches provide position feedback of the carriage during carriage travel, which are used by the program in the microcontroller for decision making. The napkin removing and napkin engaging linear actuators have been mounted on the device in a way such that they are expanded or retracted completely during singulation process, such that their position feedback capabilities have not been used by the program. This has reduced the complexity of the code and also has resulted in saved memory and execution time. To better illustrate how the program executes, a flowchart for the entire singulation algorithm is given in Figure 3.12. The source code for the program is provided in Appendix P. 


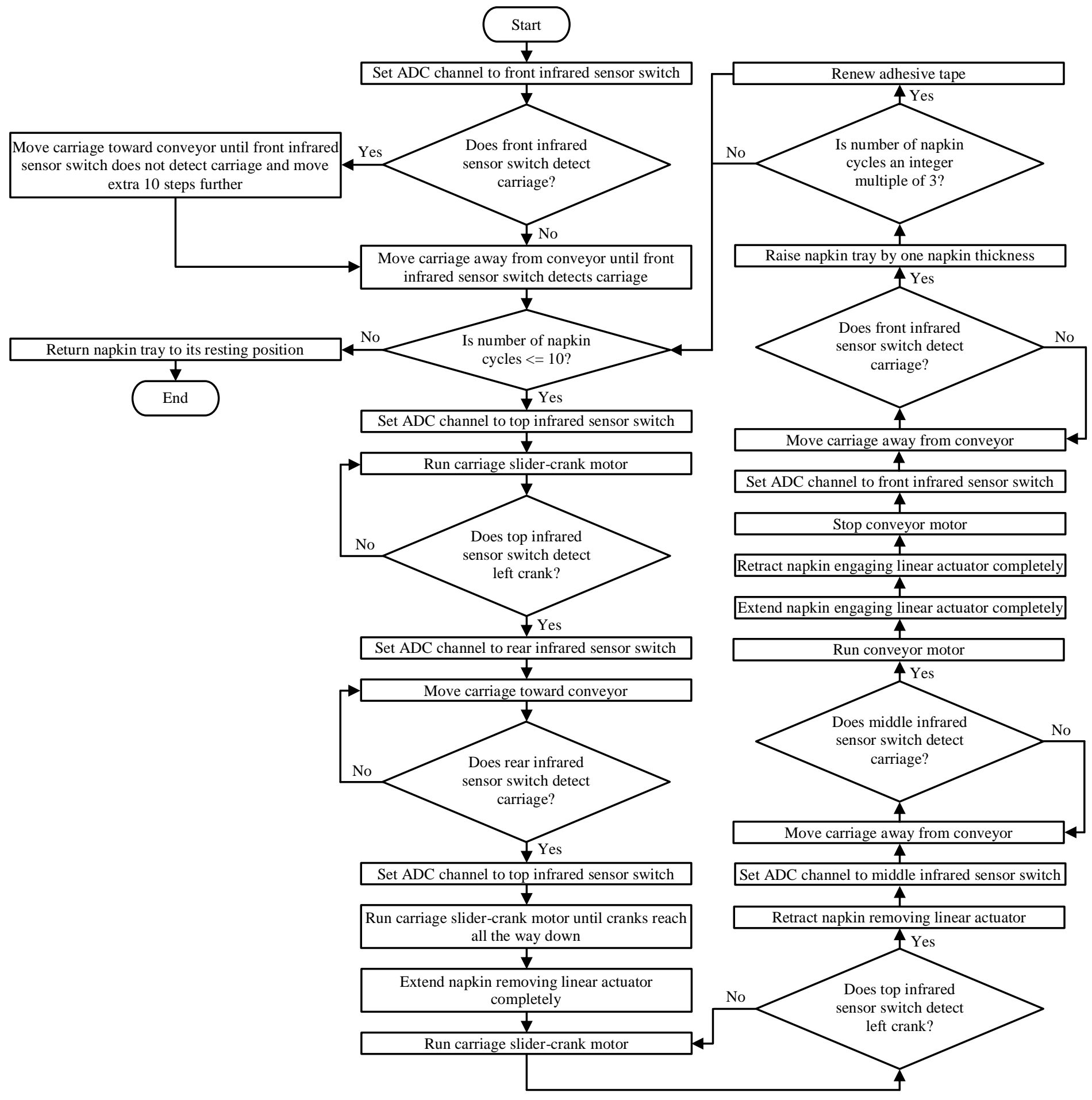

Figure 3.12: Flowchart for Cloth Napkin Singulation Algorithm 
In this chapter we have presented the details of the control system and how the program interfaces with different components to perform the singulation process. Results of different tests performed on the designed and constructed prototype cloth napkin singulation system are presented in the next chapter. 


\section{CHAPTER IV}

\section{EXPERIMENTATION AND RESULTS}

\subsection{Factors Considered for Experimentation}

After completing design and construction of the cloth napkin singulation system, it was tested for reliability and repeatability, and the results of the performance evaluation were recorded. These consist of singulation efficiency and unit singulation time as primary indicators of performance. Singulation efficiency is defined as 100 times the ratio of the total number of successfully singulated individual napkins placed on the moving conveyor by the system in a single test to the total number of napkins placed on the napkin tray in a stack at the outset of the test run. Unit singulation time is defined as the average time taken by the system to successfully singulate individual napkins in each test run. Before conducting tests on the overall performance of the system, we initially tested performances of the individual mechanisms and found that of all but three such mechanisms, worked consistently as intended in the design. The remaining three mechanisms, namely, the napkin picking mechanism, napkin removing mechanism, and mechanism for an engaging napkin on the conveyor, displayed occasional undesirable performances in the initial test runs, affecting the accuracy of the singulation system in repeated napkin cycles. Details regarding these undesirable performances and our approaches to resolve them are discussed in the following sections. 


\subsubsection{Performance of Napkin Picking Mechanism}

During our initial testing on the napkin picking mechanism, we discovered occasional picking of multiple napkins at a time by the adhesive tape when the carriage slider-crank mechanism was lowered onto the napkin stack. Figure 4.1 shows a photograph demonstrating this problem.

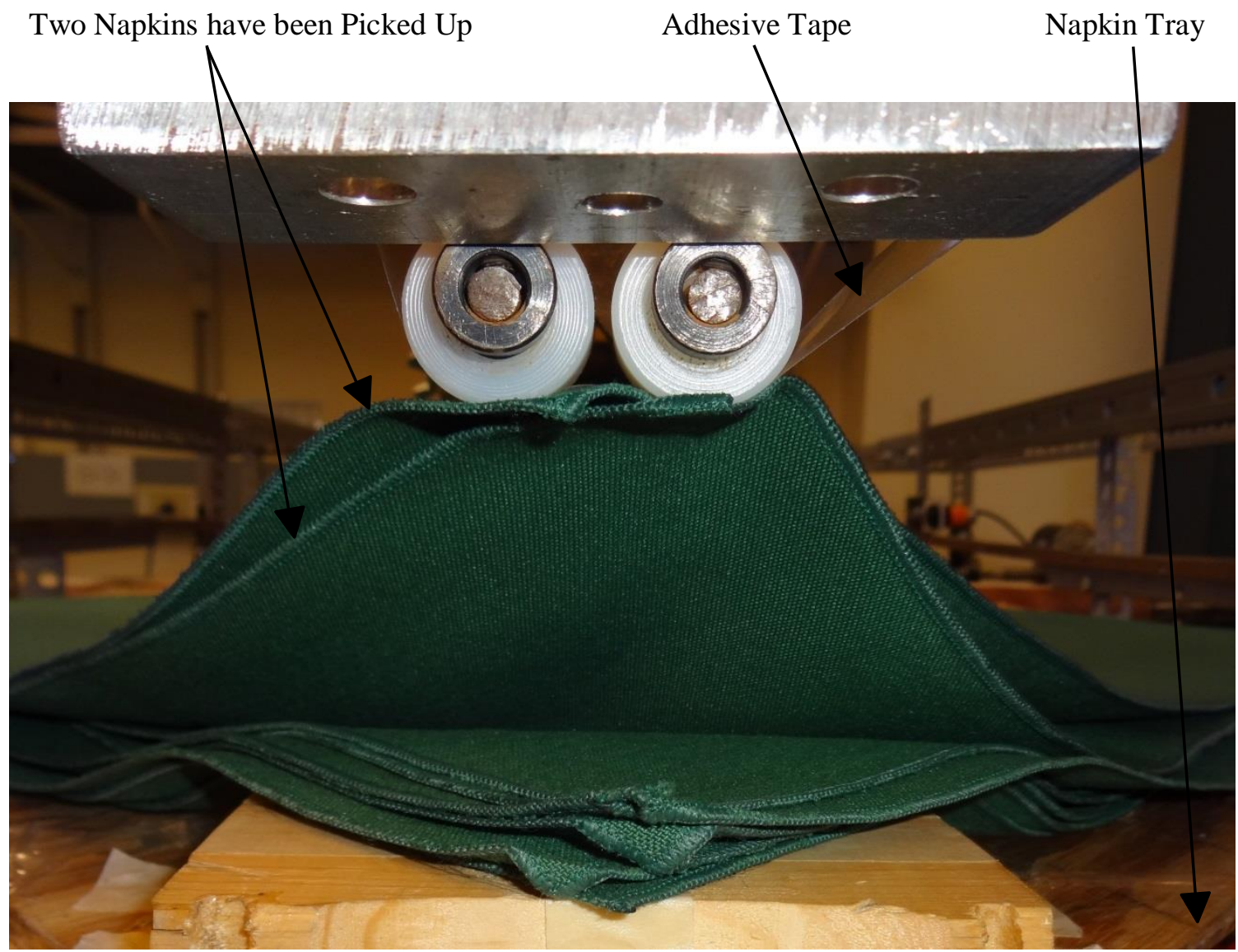

Figure 4.1: Picking of Multiple Napkins at a time by Adhesive Tape

After investigation, we discovered that this problem occurred only when napkins were not placed on the napkin tray in a neatly stacked pile. To avoid a napkin being singulated with its leading 
corner folded over on the moving conveyor, we need to engage the adhesive tape close to the napkin corner during pick-up. If the napkins are not neatly stacked, as shown in Figure 4.2(a), some corner portions of the next few napkins below the top in the stack become exposed to the adhesive tape, such that more than one napkin would stick to the tape. By placing the napkins in a neatly stacked pile on the napkin tray prior to the singulation process, as shown in Figure 4.2(b), we solved this problem completely in later test runs.

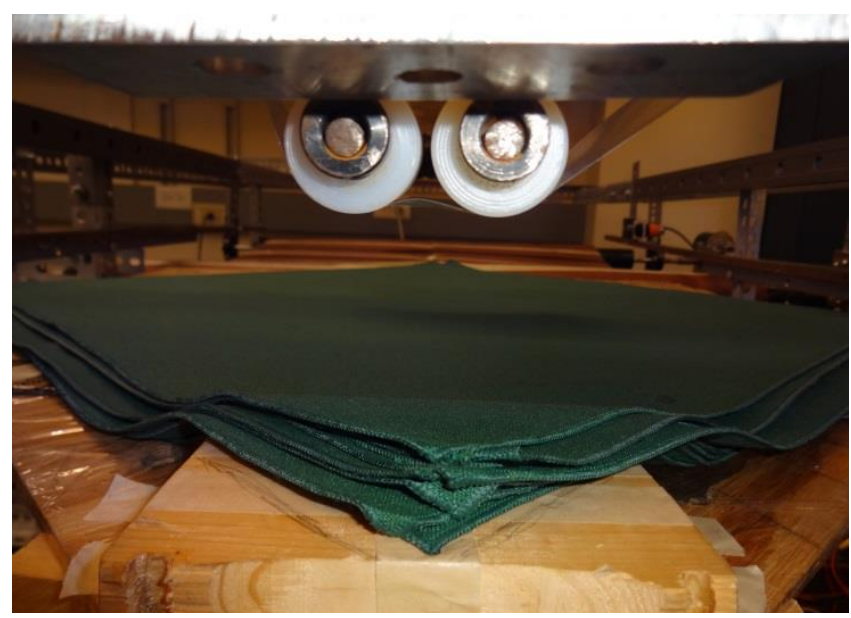

(a) Napkins are not neatly stacked

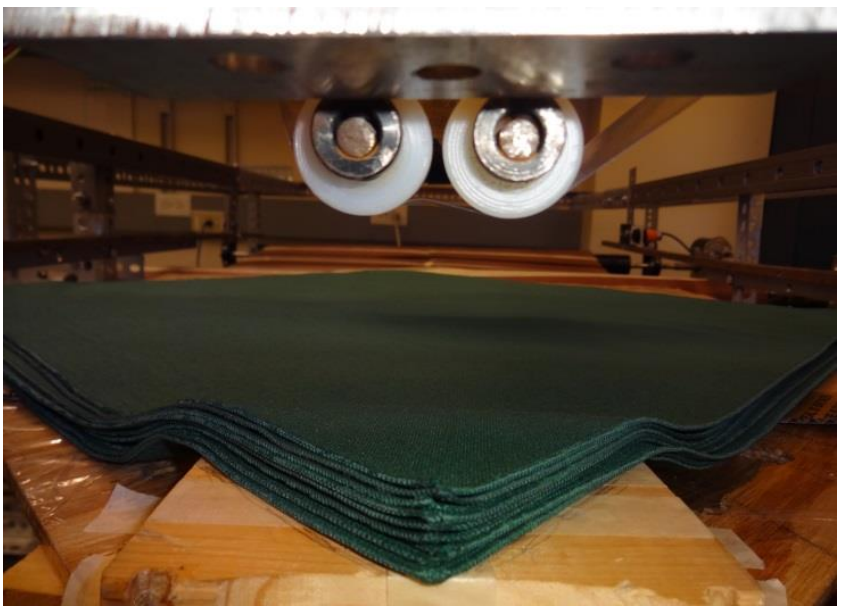

(b) Napkins are neatly stacked

Figure 4.2: Neatness of Stacked Napkins on Napkin Tray

\subsubsection{Performance of Napkin Removing Mechanism}

In rare occasions during our initial testing on the napkin removing mechanism, we discovered that the napkin removing linear actuator did not extend completely to press and hold the aluminum block attached to its end on the picked napkin, as shown in Figure 4.3. Complete 
extension is necessary so that the carriage slider-crank mechanism can disengage the adhesive tape properly from the napkin corner.

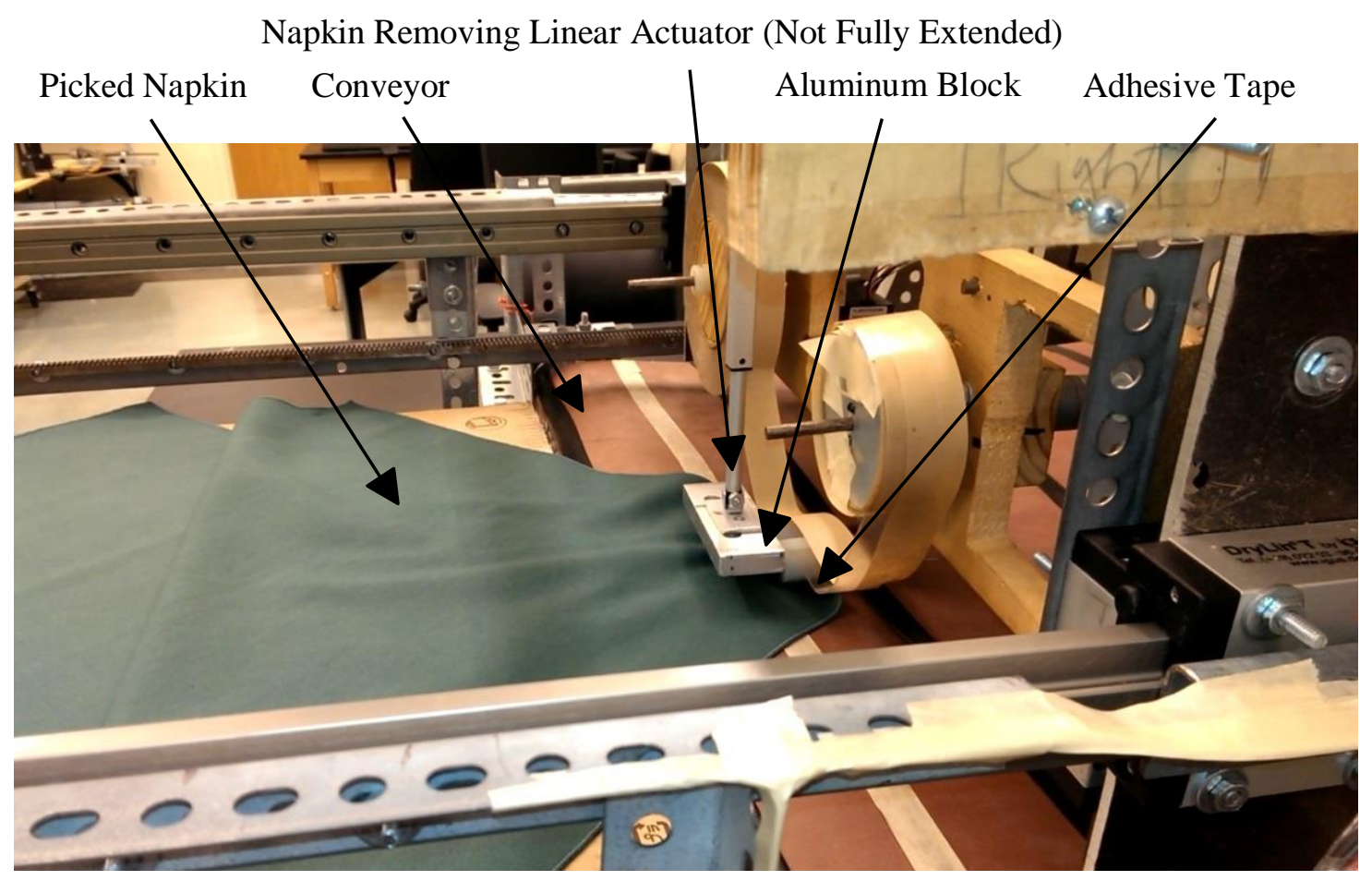

Figure 4.3: Partially Extended Napkin Removing Linear Actuator

After investigation, we found that during travels of the carriage to and from the conveyor, the connection between the linear actuator and its driver controller occasionally became loose, such that interruptions in communication between these two occurred. To make a good connection, we taped the connection joints, which mostly solved this problem. A permanent solution to this would be to solder the connection joints, given as a recommendation in the next chapter. 


\subsubsection{Performance of Mechanism to Engage Napkin on Conveyor}

During our initial test runs, we found that because of the abrupt surface area of the metal clip lacings of the conveyor, napkins were occasionally singulated with their trailing corners folded over on the moving conveyor, as shown in Figure 4.4(a). We covered the metal clip lacings with tape to reduce the abruptness, which reduced this problem considerably. A permanent solution would be to replace the metal clip lacings with a smoother connection method, mentioned as a recommendation in the next chapter. A photograph of a perfectly singulated napkin, laying on the moving conveyor, with none of its corners folded over, is given in Figure 4.4(b), which is the desired condition of a singulated napkin in our tests.

Trailing Corner of Napkin is Folded Over

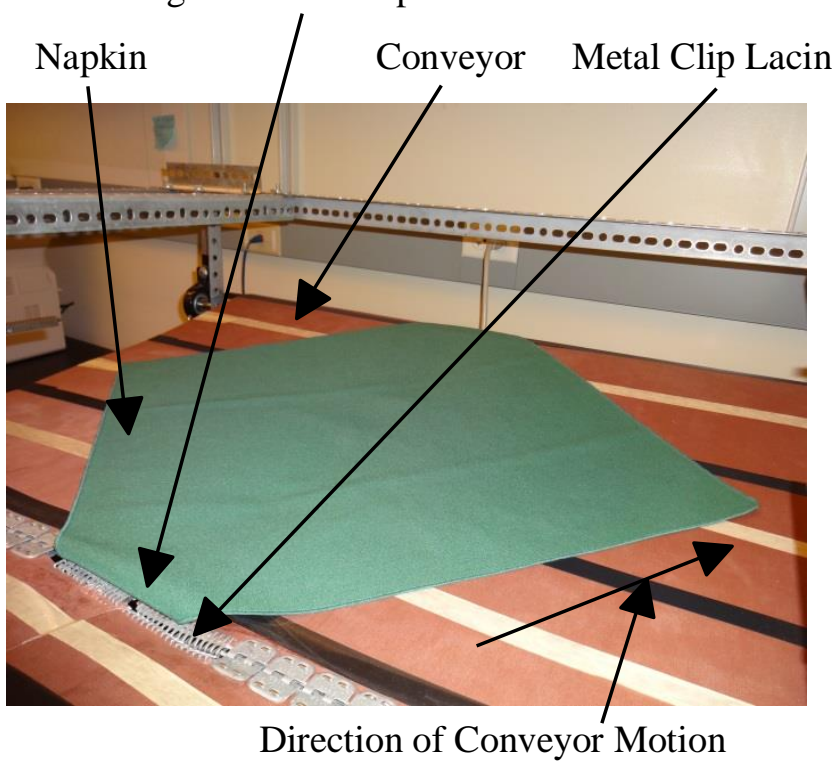

(a) Napkin with Trailing Corner Folded Over
Trailing Corner of Napkin is Not Folded Over

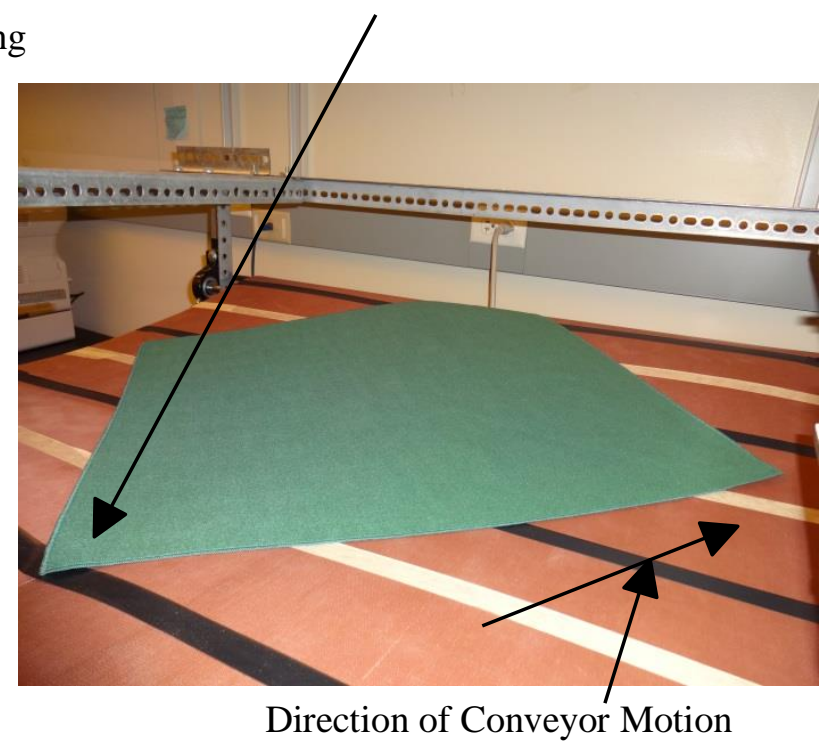

(b) Perfectly Singulated Napkin

Figure 4.4: Trailing Corner of a Singulated Napkin 


\subsection{Tabulation of Performance of Cloth Napkin Singulation System}

After completion of initial testing on the individual mechanisms, we evaluated the performance of the complete system. Like Jeyapalan (2005), we also used 10 napkins in each test run, and a total of 10 runs were conducted to evaluate the overall performance of the system. The results of the tests are tabulated in Table 4.1. Napkins are listed as successfully singulated, if they were placed on the moving conveyor by the system with none of their corners folded over, as shown in Figure 4.4(b). Napkins with any of their corners folded over together with napkins that failed to disengage from the adhesive tape because of the failure of the napkin removing mechanism are listed as unsuccessful results. Napkins unsuccessfully placed due to failure of the napkin removing mechanism were removed manually so as not to hinder the remaining singulation process.

Table 4.1: Performance of Cloth Napkin Singulation System

\begin{tabular}{|c|c|c|c|c|}
\hline Run No. & $\begin{array}{l}\text { Number of } \\
\text { Napkins } \\
\text { Processed }\end{array}$ & $\begin{array}{c}\text { Number of } \\
\text { Successfully } \\
\text { Singulated } \\
\text { Napkins }\end{array}$ & $\begin{array}{c}\text { Number of } \\
\text { Unsuccessful } \\
\text { Napkins }\end{array}$ & $\begin{array}{c}\text { Singulation } \\
\text { Efficiency }(\%)\end{array}$ \\
\hline 1 & 10 & 10 & 0 & 100 \\
\hline 2 & 10 & 10 & 0 & 100 \\
\hline 3 & 10 & 10 & 0 & 100 \\
\hline 4 & 10 & 9 & 1 & 90 \\
\hline 5 & 10 & 8 & 2 & 80 \\
\hline
\end{tabular}




\begin{tabular}{|c|c|c|c|c|}
\hline 6 & 10 & 10 & 0 & 100 \\
\hline 7 & 10 & 10 & 0 & 100 \\
\hline 8 & 10 & 10 & 0 & 100 \\
\hline 9 & 10 & 10 & 0 & 100 \\
\hline 10 & 100 & 9 & 1 & 96 \\
\hline
\end{tabular}

As can be seen from Table 4.1, the singulation efficiency has varied from $80 \%$ to $100 \%$ for individual test runs, and the overall average singulation efficiency for all of the test runs is $96 \%$, which is a $14 \%$ increase over the overall average singulation efficiency of $82 \%$, of Jeyapalan's (2005) singulator. Also Jeyapalan had to interleave the napkin stacks with vellum papers of the same size as the napkins at the beginning of the test runs, and had to manually remove each paper when one napkin was singulated, leaving the system un-automated and impractical for use. From Table 4.1, we note that our singulation system failed 4 times during the tests conducted, one failure was caused by the lack of a good connection between the napkin removing linear actuator and its controller, and the remaining three were singulated with their trailing corners folded over on the moving conveyor, caused by the abrupt surface area of metal clip lacings of the conveyor. However, these issues are resolvable by simple modifications, discussed in the next chapter.

To calculate the unit singulation time of the cloth napkin singulation system, we also recorded the time taken by the system in every napkin cycle during test runs. Total time taken by successful napkin cycles in each test run is listed in Table 4.2. 
Table 4.2: Time taken by Cloth Napkin Singulation System

\begin{tabular}{|c|c|c|c|}
\hline Run No. & $\begin{array}{c}\text { Number of } \\
\text { Successfully } \\
\text { Singulated Napkins }\end{array}$ & $\begin{array}{l}\text { Total Time taken by } \\
\text { System for } \\
\text { Successful Napkins } \\
\text { (sec) }\end{array}$ & $\begin{array}{l}\text { Unit Singulation } \\
\text { Time (min/napkin) }\end{array}$ \\
\hline 1 & 10 & 803 & 1.34 \\
\hline 2 & 10 & 804 & 1.34 \\
\hline 3 & 10 & 803 & 1.34 \\
\hline 4 & 9 & 723 & 1.34 \\
\hline 5 & 8 & 640 & 1.33 \\
\hline 6 & 10 & 802 & 1.34 \\
\hline 7 & 10 & 803 & 1.34 \\
\hline 8 & 10 & 803 & 1.34 \\
\hline 9 & 10 & 804 & 1.34 \\
\hline 10 & 9 & 721 & 1.34 \\
\hline Total & 96 & 7706 & 1.34 \\
\hline
\end{tabular}

As can be seen from Table 4.2, the unit singulation time has varied from $1.33 \mathrm{~min} /$ napkin to 1.34 min/napkin for individual test runs, and the overall average unit singulation time for all of the test runs is $1.34 \mathrm{~min} /$ napkin, i.e. on average each successful napkin cycle takes approximately $1 \mathrm{~min}$ 20 seconds. We could not compare this result to that of Jeyapalan's device, as he did not mention 
anything in his report regarding the time taken by his system during the napkin singulation or silverware wrapping process. However, our system could be made more time-efficient by adopting several modifications, discussed in the next chapter. 


\section{CHAPTER V}

\section{CONCLUSIONS AND RECOMMENDATIONS}

\subsection{Conclusions}

A large number of food service establishments reuse a limited inventory of silverware pieces, which are generally washed in commercial dishwashing machines after each use, separated into individual pieces from the washed batches, identified based on their types and orientations, inspected for cleanliness, grouped into sets of pieces based on their types, and then wrapped into singulated napkins to be used for further food serving. This research work is a part of a series of projects undertaken to automate these repetitive, time-consuming, and labor-intensive postdishwashing processes. In this study we have successfully designed and constructed a cloth napkin singulation system, capable of separating individual cloth napkins form a given stack and placing them on a moving conveyor to be delivered to a silverware wrapping system, which would then wrap sets of silverware pieces (e.g., a spoon, a soup spoon, a fork, and a knife in each set) in the singulated napkins to form wrapped arrangements to be used in place settings. Results obtained in the previous chapter demonstrate successful development of a cloth napkin singulation system that provides a high average singulation efficiency of $96 \%$, which is a $14 \%$ increase over the average singulation efficiency achieved by Jeyapalan (2005) with his napkin singulator. 
Also the singulation system developed in this study is completely automated, unlike Jeyapalan's singulator, which needed vellum papers to be interleaved with the napkin stack prior to the beginning of the singulation process and to be removed manually after each napkin was removed. The average unit singulation time achieved by our system is $1.34 \mathrm{~min} /$ napkin, which we have not been able to compare to that of Jeyapalan's device because of unavailability of similar data in his thesis. However, there is significant room for the improvement of the average unit singulation time by adopting several modifications, recommended later in this chapter.

\subsection{Contributions}

The core focus of this research has been design, development, construction and evaluation of a cloth napkin singulation system. The major contributions of this research are summarized in what follows.

- Development of a cloth napkin picking mechanism that utilizes an adhesive tape for picking one napkin at a time from a stack of napkins.

- Modification and performance enhancement of a mechanism that utilizes two pinion gears, rolling along two rack gears, to move a picked napkin toward a conveyor.

- Design, development and construction of a napkin removing mechanism to disengage a picked napkin from the adhesive surface near the upstream conveyor end.

- Design and construction of a mechanism to engage a picked napkin along the moving conveyor to pull the napkin completely off the stack to be conveyed to a silverware wrapping system.

- Fine-tuning of the conveyor system for smooth conveying of the singulated napkins.

- Design and construction of a napkin tray lifting system to accommodate the decreasing stack height during the singulation process. 
- Modification and improvement of the adhesive tape renewal system to renew the adhesive tape after several napkin cycles to ensure adequate adhesive surface area for proper picking of napkins.

- Design, development and implementation of a control system and control algorithm for establishing communication between all components of the system to execute the singulation process seamlessly for a given number of napkins.

\subsection{Recommendations}

The following recommendations are suggested for the enhancement of the cloth napkin singulation system.

- All of the connection joints between the electronic components of the system should be soldered. This would prevent occasional disconnection between the components and their drivers, resulting in a seamless operation during the singulation process. This would also resolve the occasional failure of the napkin removing linear actuator with the current apparatus.

- The majority of the average time taken by the system in each napkin cycle is spent during the travel of the carriage to and from the conveyor because of the slow speed of the driver stepper motors used in the carriage rack-and-pinion mechanism that moves the carriage. Replacement of the current stepper motors with higher speed motors would lower the average unit singulation time significantly, making the system more time-effective.

- Instead of using two conveyor belts placed side-by-side, a single belt should be used to avoid lateral shifting of the individual belts during conveyor running. Also, instead of joining the belt ends crudely using metal clip to form a continuous loop, a smoother connection method should be used. This would lessen resistance to conveyor movement 
over conveyor rollers, would increase the longevity of the belt material, and would also prevent the occasional singulation of napkins with their trailing corners folded over on the moving conveyor.

- A close-looped electronic system should be introduced using a calibrated infrared sensor switch pointed down at the napkin stack for precise lifting of the napkin tray to maintain good contact between the top napkin of the stack and the adhesive tape during napkin pick-up. 


\section{REFERENCES}

1. Ahmed, Ibrahim A.; Abueisheh, Ammar. "Device for wrapping a napkin about silverware and associated method", U.S. Patent - 7,210,279, May 1, 2007.

2. Akella, Venkatesh. "Silverware singulating system", M.S. thesis, School of Mechanical and Aerospace Engineering, Oklahoma State University, Stillwater, OK, December 2008.

3. Bareiss, Daman. "Napkin singulation", B.S. project, School of Mechanical and Aerospace Engineering, Oklahoma State University, Stillwater, OK, June 16, 2011.

4. Chitaveli, Rajashekar Reddy. "Silverware singulation system", M.S. thesis, School of Mechanical and Aerospace Engineering, Oklahoma State University, Stillwater, OK, December 2011.

5. Ford, Kelli (Nee Briley). M.S.M.E. Student, School of Mechanical and Aerospace Engineering, Oklahoma State University, Stillwater, OK, Spring 2010.

6. Gray, Charles Woodard; Brown, William Edward; Clanton, Dwight. "Apparatus and method for wrapping silverware within a napkin”, U.S. Patent - 6,023,913, February 15, 2000.

7. Hashimoto, Sachiko. "Separation of silverware for machine vision sorting and inspection", M.S. thesis, School of Mechanical and Aerospace Engineering, Oklahoma State University, Stillwater, OK, May 1995. 
8. Heilman, Rebecca A.; Heilman, Eric A.; LeBlanc, Andre. "Automatic utensil wrapping machine", U.S. Patent - 6,918,226, July 19, 2005.

9. Hoffman, Gerald T.; Lindahl, Glen T. "Utensil wrapping apparatus and method”, U.S. Patent 7,322,172, January 29, 2008.

10. Jeyapalan, Arul Selvam Simon. "Automated wrapping of silverware in a napkin”, M.S. thesis, School of Mechanical and Aerospace Engineering, Oklahoma State University, Stillwater, OK, December 2005.

11. Lavi, Payam. “Food service set assembly system”, U.S. Patent - 7,412,808, August 19, 2008.

12. Lolla, Sai Venu Gopal. "Identification and inspection of silverware using machine vision", M.S. thesis, School of Mechanical and Aerospace Engineering, Oklahoma State University, Stillwater, OK, May 2005.

13. Miano, Mario L.; Nelson, Kevin W. "Automated flatware and napkin assembling apparatus", U.S. Patent - 6,837,028, January 4, 2005.

14. Nagaraj, Shilpa. "Silverware sorting machine", M.S. thesis, School of Mechanical and Aerospace Engineering, Oklahoma State University, Stillwater, OK, August 2003.

15. Peddi, Ravi Vamshidhar. "Silverware sorting and orienting system", M.S. thesis, School of Mechanical and Aerospace Engineering, Oklahoma State University, Stillwater, OK, May 2005.

16. Rubin, Richard Howard. "Device for holding and dispensing utensils for wrapping apparatus", U.S. Patent - 7,513,089, April 7, 2009.

17. Sabpipatana, Lertrit. "Silverware sorting machine", M.S. thesis, School of Mechanical and Aerospace Engineering, Oklahoma State University, Stillwater, OK, May 2010. 
18. Sadabad, Ali asmari. "Silverware sorting machine", M.S. thesis, School of Mechanical and Aerospace Engineering, Oklahoma State University, Stillwater, OK, December 2011.

19. Vetsch, Kevin R. "Method and apparatus for folding a napkin around an eating utensil", U.S. Patent - 6,023,908, February 15, 2000.

20. Yeri, Sandeep. "Classification of silverware pieces using machine vision", M.S. thesis, School of Mechanical and Aerospace Engineering, Oklahoma State University, Stillwater, OK, May 2003. 
APPENDICES 
APPENDIX A

ABSTRACTS OF PATENTS 


\title{
1. U.S. Patent 6,023,908
}

Title: Method and apparatus for folding a napkin around an eating utensil

Inventors: Vetsch; Kevin R. (Kansas City, MO)

Family ID: 25342330

Appl. No.: 08/864,014

Filed: May 27, 1997

Published: February 15, 2000

\begin{abstract}
The present invention relates to a method and apparatus for rolling a napkin around silverware. The device comprises a housing having a conveyor belt system for advancing a napkin therethrough along a substantially horizontal path. As the napkin traverses said path, it contacts a folding belt which causes a corner of the napkin to be folded back onto itself. A knife, fork or other piece of silverware is delivered from storage bins in timed relation to the movement of the napkin to ensure placement thereon. The napkin and silverware then contact a rapidly moving rolling belt which rolls the napkin around the silverware. The rolled napkin and silverware are then transported out of the housing and on to an external holding bin.
\end{abstract}

\section{U.S. Patent 6,023,913}

Title: Apparatus and method for wrapping silverware within a napkin

Inventors: Gray; Charles Woodard (Tallahassee, FL), Brown; William Edward (Nashville, TN), Clanton; Dwight (Shelbyville, TN) 
Assignee: Mudd; Reginald M. (Lebanon, TN)

Family ID: 22694639

Appl. No.: 09/188,814

Filed: November 9, 1998

Published: February 15, 2000

\begin{abstract}
An apparatus and method for wrapping a napkin about silverware items into a wrapped arrangement involves a worktable within which is provided an upwardly-opening trough for accepting a napkin and silverware items positioned therein. The napkin is automatically placed over the opening of the trough in a spread condition and then silverware items are automatically directed onto the napkin so that the silverware falls to the bottom of the trough thereby positioning the napkin between the silverware and the bottom of the trough. A rotatable blade is positioned within the trough for automatically spinning the napkin and silverware items about the longitudinal axis of the trough until the napkin and silverware items are wound in a wrapped arrangement. The wrapped arrangement is thereafter removed from the trough in preparation of a subsequent napkin-wrapping operation.
\end{abstract}

\title{
3. U.S. Patent $6,837,028$
}

Title: Automated flatware and napkin assembling apparatus

Inventors: Miano; Mario L. (Fort Collins, CO), Nelson; Kevin W. (Fort Collins, CO)

Family ID: 33543960 
Appl. No.: 10/641,357

Filed: August 15, 2003

Published: January 4, 2005

\begin{abstract}
An apparatus that wraps dinner flatware in a paper napkin in an automated manner and secures it with a paper label is disclosed. The invention includes input hoppers for knives, forks, spoons, and napkins which are located on the front and top part of the unit. Additionally, a roll of paper napkins and a roll of securing paper labels are provided on top with their own automatic dispensing means. A plastic cover secures the entire top of the invention to protect it from dust and dirt as well as accidental contact during operation. Internal mechanisms then take one of each piece of flatware and fold and roll it in a napkin. The completed napkin unit then drops out the bottom of the invention, where it is collected for use. The invention is capable of processing up to 50 sets of flatware during one operating run. The use of the invention provides time and labor savings to restaurants and other eating establishments while producing rolled flatware secured in a paper napkin in fast and sanitary manner.
\end{abstract}

\title{
4. U.S. Patent 6,918,226
}

Title: Automatic utensil wrapping machine

Inventors: Heilman; Rebecca A. (Ponte Vedra Beach, FL), Heilman; Eric A. (Ponte Vedra Beach, FL), LeBlanc; Andre (Saskatoon, Saskatchewan, CA)

Family ID: 33552434

Appl. No.: 10/611,964 
Filed: July 3, 2003

Published: July 19, 2005

\begin{abstract}
The automatic utensil wrapping machine is an apparatus for wrapping a napkin around one or more utensils for use as a place setting. The apparatus comprises a housing, a support frame and an assembly of elements mounted to the support frame. The assembly of elements includes a napkin lifting station, a napkin wrapping station, a napkin transfer station, a utensil transfer station, and a napkin folding station. The apparatus wraps each napkin around a predetermined amount of utensils without the need for human contact. The napkins are wrapped by first positioning a stack of napkins on the lifting station, then individually transferring napkins from the lifting station to the wrapping station. The utensils are then transferred from the individual cartridges and placed onto the napkin. Two opposing corners of the napkin are then folded over and the napkin is subsequently wrapped around the utensils.
\end{abstract}

\title{
5. U.S. Patent 7,210,279
}

Title: Device for wrapping a napkin about silverware and associated method

Inventors: Ahmed; Ibrahim A. (Oklahoma City, OK), Abueisheh; Ammar (Oklahoma City, OK)

Family ID: 37991298

Appl. No.: 11/301,782

Filed: December 14, 2005

Published: May 1, 2007 


\begin{abstract}
A device includes isolated hoppers defining independent passageways converging downwardly towards a central and unitary area. A conveyor belt assembly is disposed subjacent to the hoppers, traverses the passageways, and travels along a linear path passing through the unitary area. A mechanism is included for depositing a napkin onto the conveyor belt. The napkin depositing mechanism is connected to the conveyor belt assembly and is spaced adjacent to one end portion thereof. A mechanism is included for simultaneously folding the napkin and horizontally stacking the eating utensils such that the napkin becomes folded about the eating utensils before being ejected from the simultaneous folding mechanism. A receiving conveyor belt assembly is disposed beneath the simultaneous folding mechanism for transporting the combined napkin and eating utensils. A storage bin is laid adjacent to the receiving conveyor belt and houses the combined napkin and eating utensils for transit.
\end{abstract}

\title{
6. U.S. Patent 7,322,172
}

Title: Utensil wrapping apparatus and method

Inventors: Hoffman; Gerald T. (Fort Wayne, IN), Lindahl; Glen T. (Churubusco, IN)

Assignee: Wrapmaster, Inc. (Fort Wayne, IN)

Family ID: 38748234

Appl. No.: 11/439,662

Filed: May 24, 2006

Published: January 29, 2008 


\begin{abstract}
An apparatus and method for wrapping a napkin around one or more utensils. The apparatus includes a wrapping area defining a trough dimensioned to receive one or more utensils. A utensil dispenser and napkin delivery mechanism may be provided to deliver the utensils and a napkin, respectively, to the trough. The apparatus may also include a wrapping mechanism that wraps the napkin around the utensils. In some cases, a tension mechanism may be included to selectively limit movement of the napkin during wrapping.
\end{abstract}

\title{
7. U.S. Patent 7,412,808
}

Title: Food service set assembly system

Inventors: Lavi; Payam (Oceanside, CA)

Assignee: Convenience Enterprises, Inc. (Oceanside, CA)

Family ID: 34830482

Appl. No.: 11/044,538

Filed: January 26, 2005

Published: August 19, 2008

\begin{abstract}
A device and method for assembling a food service set comprising at least one napkin wrapped around one or more utensils and secured by an adhesive band. The device includes a magazine subsystem including one or more magazines for containing and dispensing the at least one napkin, the one or more utensils, and the adhesive band. The device further includes an integrator
\end{abstract}


subsystem configured to integrate the at least one napkin, the one or more utensils, and the adhesive band together. A processor subsystem is configured to roll the at least one napkin around the one or more utensils and to secure the adhesive band around the at least one napkin. A receiver subsystem is configured for receiving the service set. A sterilization system is provided to sterilize the utensils prior to, or after, being assembled into a service pack.

\title{
8. U.S. Patent 7,513,089
}

Title: Device for holding and dispensing utensils for wrapping apparatus

Inventors: Rubin; Richard Howard (Fairfield, NJ)

Assignee: Rubin; Richard Howard (Fairfield, NJ)

Family ID: 33456594

Appl. No.: 11/854,983

Filed: September 13, 2007

Published: April 7, 2009

\begin{abstract}
Embodiments of the present invention provide for a wrapping apparatus and associated methods and a cassette device for holding utensils. The wrapping apparatus may include a first holder for holding first items to be wrapped. The wrap is placed on a rotating table when the rotating table is rotated into a first position. One of the first items to be wrapped is moved from the first holder onto the wrap on the rotating table when the rotating table is rotated to a second position. A wrapping mechanism then wraps the first item in the wrap.
\end{abstract}


APPENDIX B

DETAILED AND DIMENSIONED PHOTOGRAPHS OF CLOTH NAPKIN SINGULATION SYSTEM 


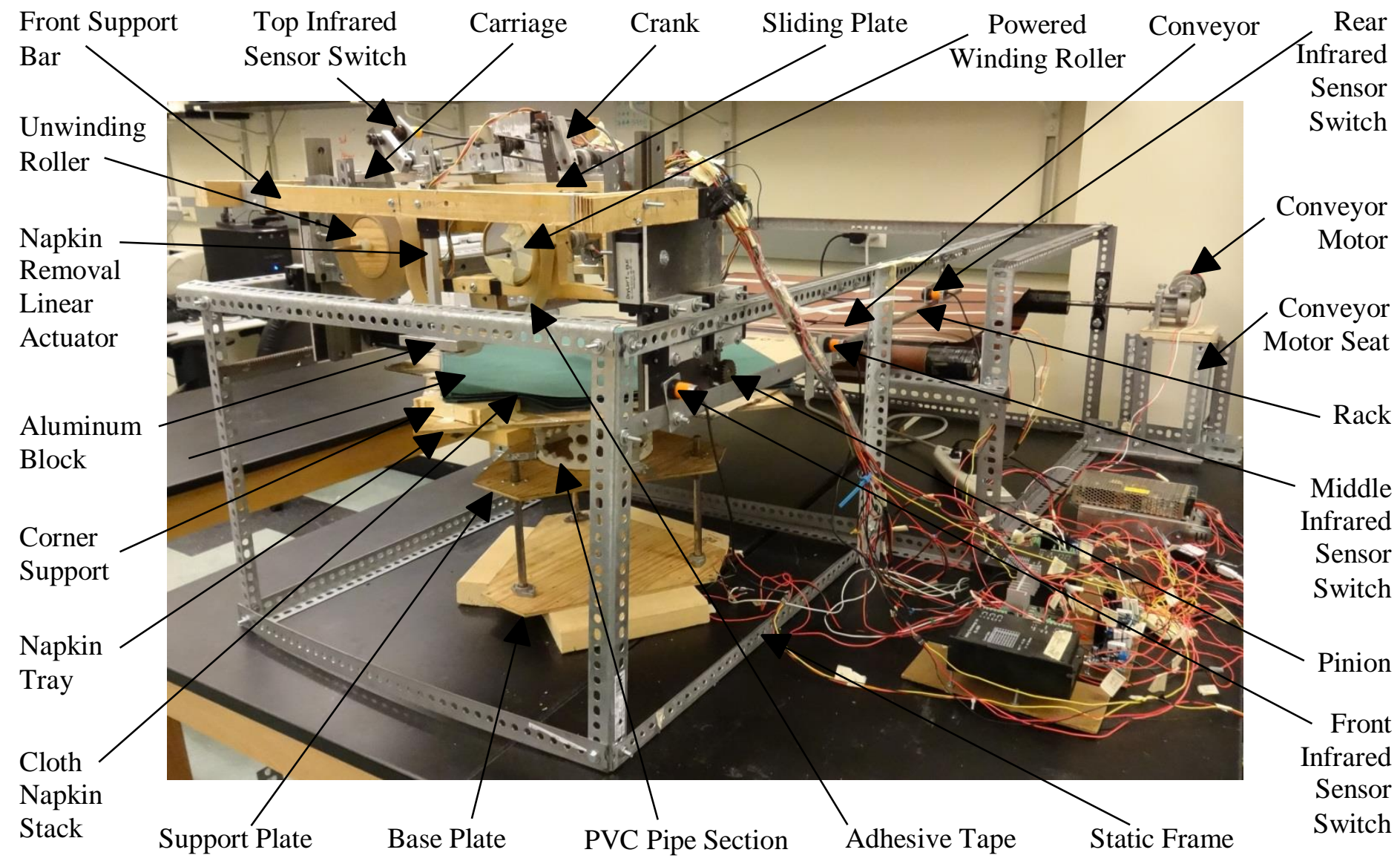

Figure B1: Detailed Perspective View of Cloth Napkin Singulation System Setup 


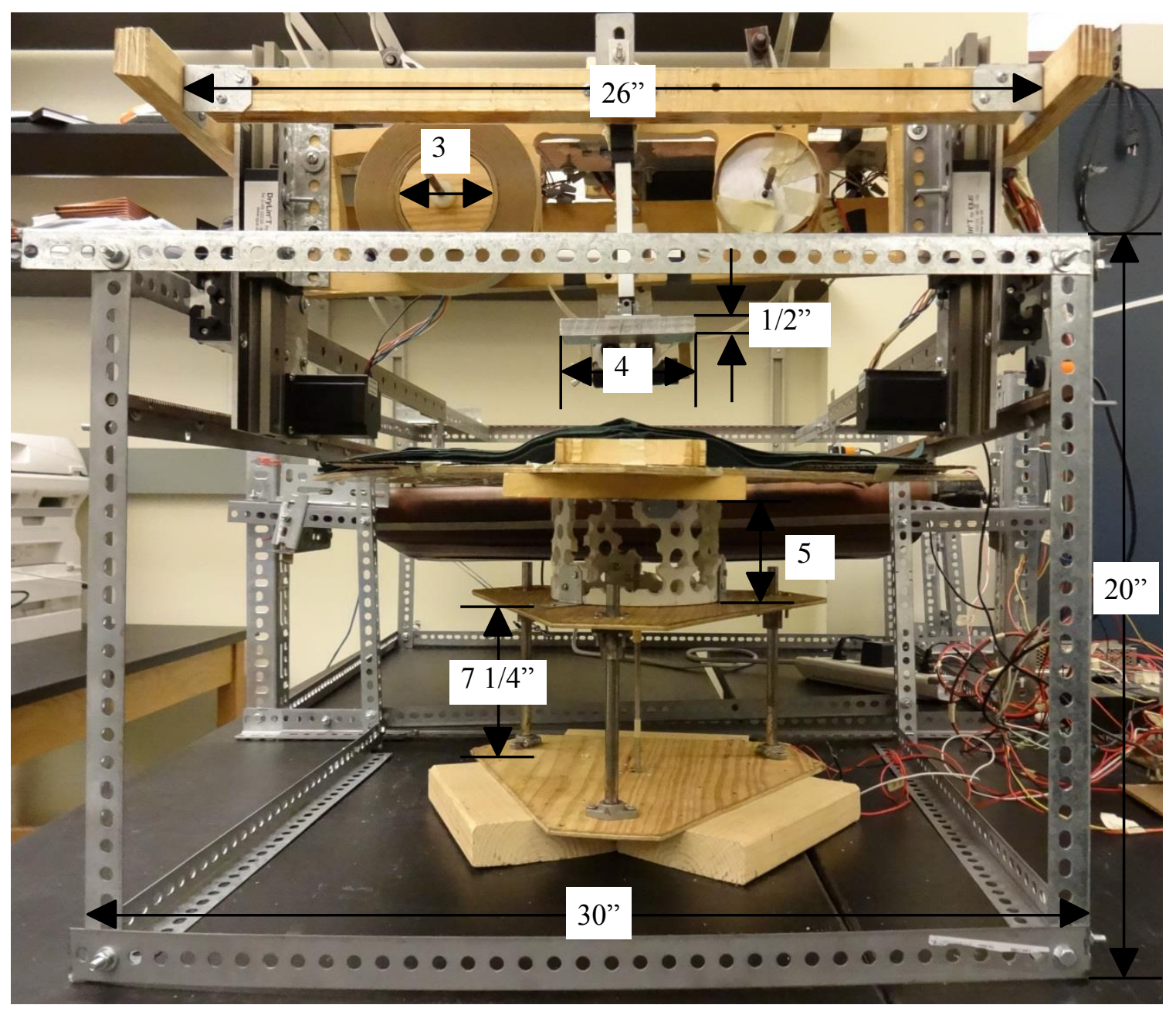

Figure B2: Dimensioned Front View of Cloth Napkin Singulation System Setup 


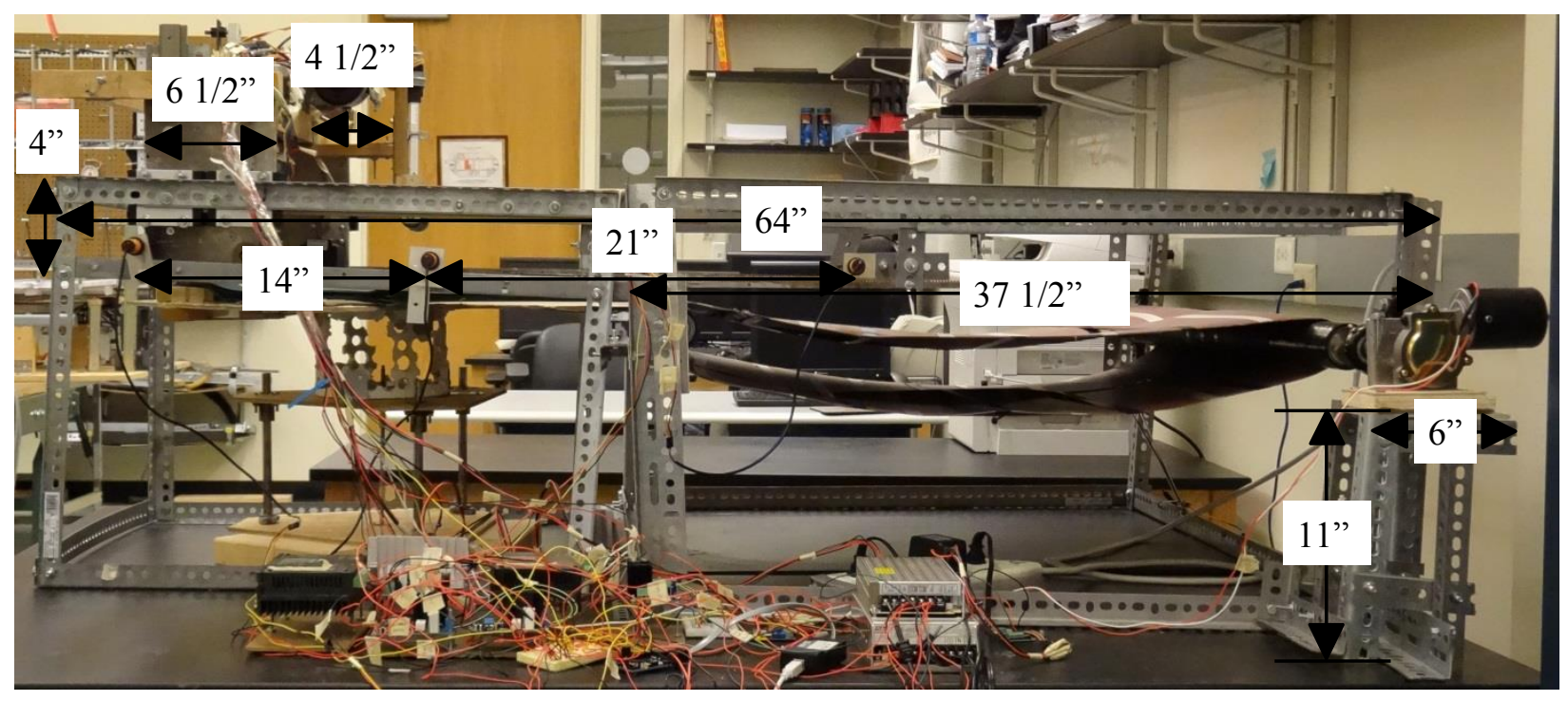

Figure B3: Dimensioned Side View of Cloth Napkin Singulation System Setup 


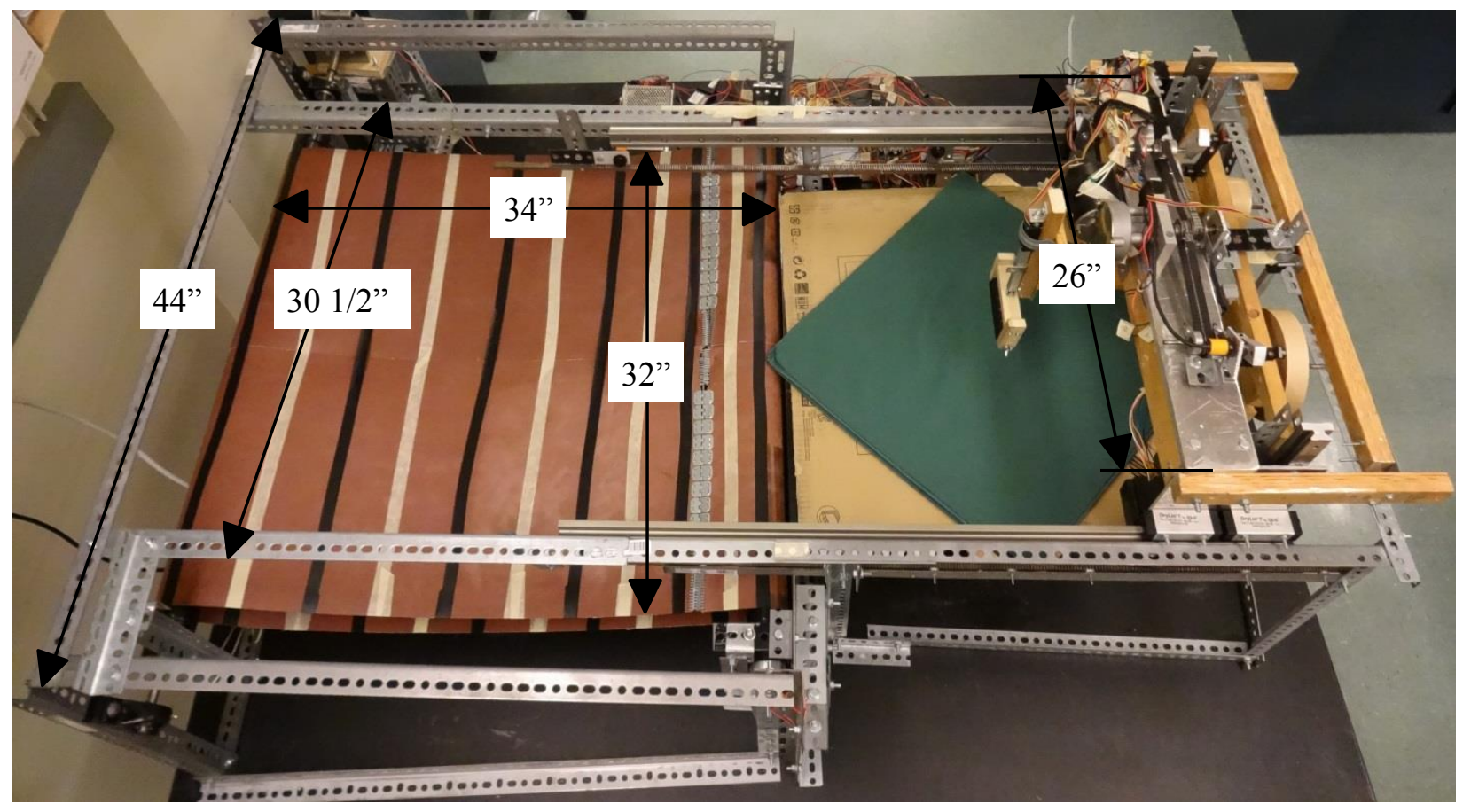

Figure B4: Dimensioned Top View of Cloth Napkin Singulation System Setup 


\section{APPENDIX C \\ DATASHEET FOR MICROCONTROLLER AND DETAILED PROTOTYPING BOARD LAYOUT}


Website:

http://ww1.microchip.com/downloads/en/DeviceDoc/39631E.pdf

MICROCONTROLLER (PIC18F4520) DATASHEET

\section{Niv \\ MICROCHIP PIC18F2420/2520/4420/4520}

\section{8/40/44-Pin Enhanced Flash Microcontrollers with 10-Bit A/D and nanoWatt Technology}

Power Management Features:

- Run: CPU on, Peripherals on

- Idle: CPU off, Peripherals on

- Sleep: CPU off, Peripherals off

- Ultra Low 50nA Input Leakage

- Run mode Currents Down to $11 \mu \mathrm{A}$ Typical

- Idle mode Currents Down to $2.5 \mu \mathrm{A}$ Typical

- Sleep mode Current Down to 100 nA Typical

- Timer1 Oscillator: $900 \mathrm{nA}, 32 \mathrm{kHz}, 2 \mathrm{~V}$

- Watchdog Timer: $1.4 \mu \mathrm{A}, 2 \mathrm{~V}$ Typical

- Two-Speed Oscillator Start-up

Flexible Oscillator Structure:

- Four Crystal modes, up to $40 \mathrm{MHz}$

- 4x Phase Lock Loop (PLL) - Available for Crystal and Internal Oscillators

- Two External RC modes, up to $4 \mathrm{MHz}$

- Two External Clock modes, up to $40 \mathrm{MHz}$

- Internal Oscillator Block:

- Fast wake from Sleep and Idle, $1 \mu$ s typical

- 8 use-selectable frequencies, from $31 \mathrm{kHz}$ to $8 \mathrm{MHz}$

- Provides a complete range of clock speeds from $31 \mathrm{kHz}$ to $32 \mathrm{MHz}$ when used with PLL

- User-tunable to compensate for frequency drift

- Secondary Oscillator using Timer1@ @ 32 kHz

- Fail-Safe Clock Monitor:

- Allows for safe shutdown if peripheral clock stops

Peripheral Highlights:

- High-Current Sink/Source 25 mA/25 mA

- Three Programmable External Interrupts

- Four Input Change Interrupts

- Up to 2 Capture/Compare/PWM (CCP) modules, one with Auto-Shutdown (28-pin devices)

- Enhanced Capture/Compare/PWM (ECCP) module (40/44-pin devices only):

- One, two or four PWM outputs

- Selectable polarity

- Programmable dead time

- Auto-shutdown and auto-restart
Peripheral Highlights (Continued):

- Master Synchronous Serial Port (MSSP)

module Supporting 3-Wire SPI (all 4 modes)

and ${ }^{2} \mathrm{C}^{\mathrm{TM}}$ Master and Slave modes

- Enhanced Addressable USART module:

- Supports RS-485, RS-232 and LIN/J2602

- RS-232 operation using internal oscillator

block (no external crystal required)

- Auto-wake-up on Start bit

- Auto-Baud Detect

- 10-Bit, up to 13-Channel Analog-to-Digital

(A/D) Converter module:

- Auto-acquisition capability

- Conversion available during Sleep

- Dual Analog Comparators with Input Multiplexing

- Programmable 16-Level High/Low-

Voltage Detection (HLVD) module:

- Supports interrupt on High/Low-Voltage Detection

Special Microcontroller Features:

- C Compiler Optimized Architecture:

- Optional extended instruction set designed to optimize re-entrant code

- 100,000 Erase/Write Cycle Enhanced Flash Program Memory Typical

- 1,000,000 Erase/Write Cycle Data EEPROM Memory Typical

- Flash/Data EEPROM Retention: 100 Years Typical

- Self-Programmable under Software Control

- Priority Levels for Interrupts

- 8 × 8 Single-Cycle Hardware Multiplier

- Extended Watchdog Timer (WDT):

- Programmable period from $4 \mathrm{~ms}$ to $131 \mathrm{~s}$

- Single-Supply $5 \mathrm{~V}$ In-Circuit Serial

Programming ${ }^{\mathrm{TM}}$ (ICSP ${ }^{\mathrm{TM}}$ ) via Two Pins

- In-Circuit Debug (ICD) via Two Pins

- Wide Operating Voltage Range: $2.0 \mathrm{~V}$ to $5.5 \mathrm{~V}$

- Programmable Brown-out Reset (BOR)

with Software Enable Option

\begin{tabular}{|c|c|c|c|c|c|c|c|c|c|c|c|c|}
\hline \multirow[b]{2}{*}{ Device } & \multicolumn{2}{|c|}{ Program Memory } & \multicolumn{2}{|c|}{ Data Memory } & \multirow[b]{2}{*}{$1 / 0$} & \multirow[b]{2}{*}{$\begin{array}{c}10-B i t \\
A / D(c h) \\
\end{array}$} & \multirow{2}{*}{$\begin{array}{l}\text { CCPI } \\
\text { ECCP } \\
\text { (PWM) }\end{array}$} & \multicolumn{2}{|c|}{ MSSP } & \multirow{2}{*}{ 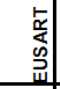 } & \multirow[b]{2}{*}{ Comp. } & \multirow[b]{2}{*}{$\begin{array}{l}\text { Timers } \\
\text { 8/16-Bit }\end{array}$} \\
\hline & $\begin{array}{c}\begin{array}{c}\text { Flash } \\
\text { (bytes) }\end{array} \\
\end{array}$ & $\begin{array}{l}\text { \# Single-Word } \\
\text { Instructions } \\
\end{array}$ & $\begin{array}{r}\text { SRAM } \\
\text { (bytes) } \\
\end{array}$ & \begin{tabular}{|c|}
$\begin{array}{c}\text { EEPROM } \\
\text { (bytes) }\end{array}$ \\
\end{tabular} & & & & SPI & \begin{tabular}{|c|} 
Master \\
$I^{\prime} \mathrm{C}^{\text {TM }}$ \\
\end{tabular} & & & \\
\hline PIC18F2420 & $16 \mathrm{~K}$ & 8192 & 768 & 256 & 25 & 10 & $2 / 0$ & Y & $\mathrm{Y}$ & 1 & 2 & $1 / 3$ \\
\hline PIC18F2520 & $32 \mathrm{~K}$ & 16384 & 1536 & 256 & 25 & 10 & $2 / 0$ & Y & Y & 1 & 2 & $1 / 3$ \\
\hline PIC18F4420 & $16 \mathrm{~K}$ & 8192 & 768 & 256 & 36 & 13 & $1 / 1$ & Y & Y & 1 & 2 & $1 / 3$ \\
\hline PIC18F4520 & $32 \mathrm{~K}$ & 16384 & 1536 & 256 & 36 & 13 & $1 / 1$ & Y & $\mathrm{Y}$ & 1 & 2 & $1 / 3$ \\
\hline
\end{tabular}




\section{PIC18F2420/2520/4420/4520}

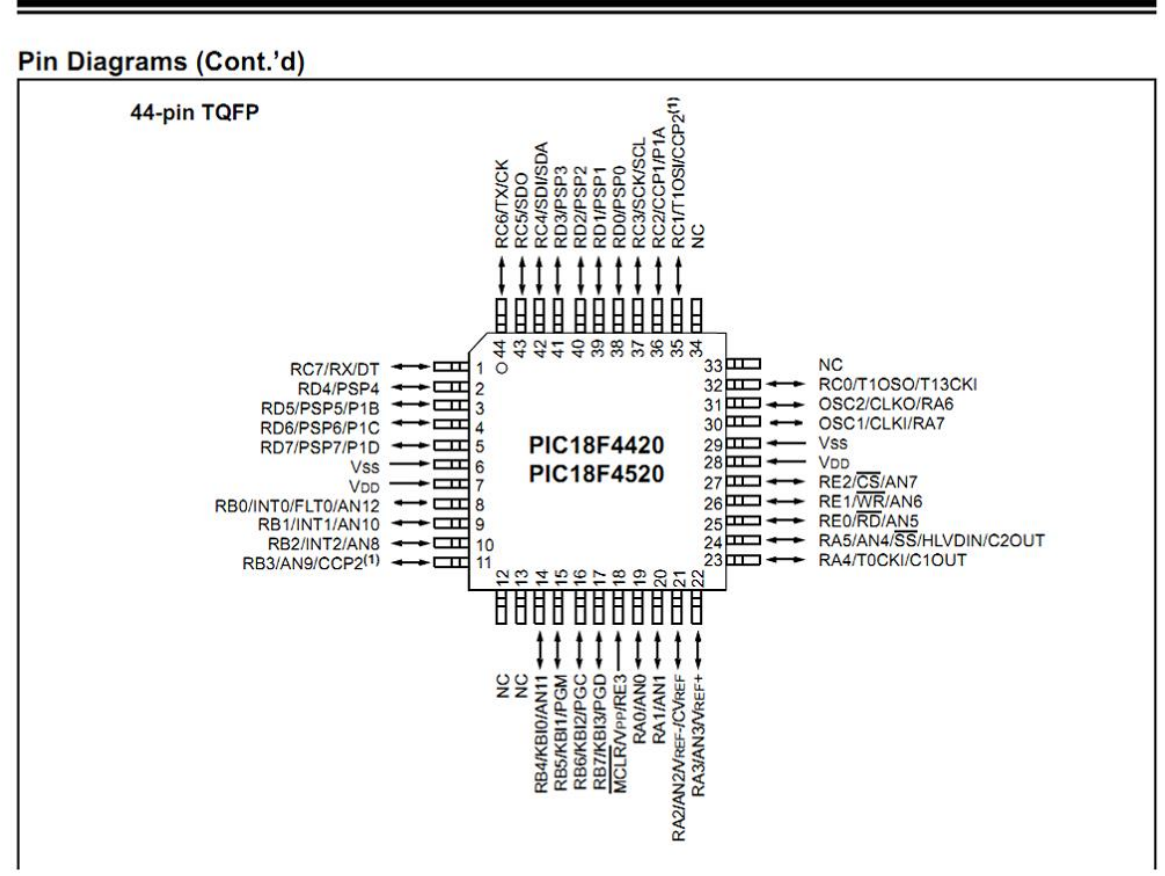


Website:

http://www.ccsinfo.com/pdfs/product_PDFs/4520_board.pdf PIC18F4520 PROTOTYPING BOARD LAYOUT

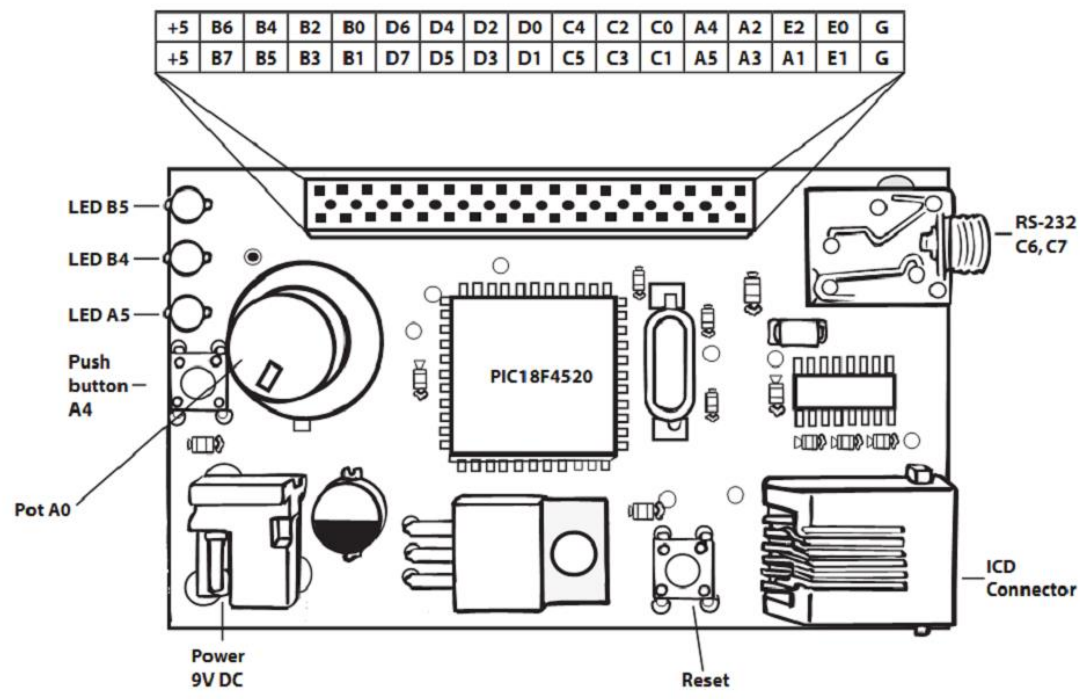


APPENDIX D

DATASHEET FOR CARRIAGE SLIDER-CRANK AND CONVEYOR MOTORS 
Website:

http://store01.prostores.com/servlet/wondermotor/the-17/Electric-Gear-Motor-12v/Detail

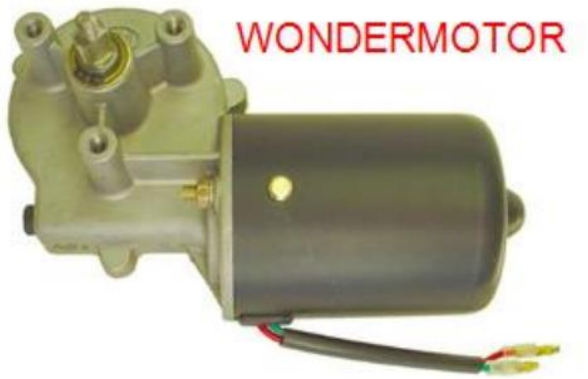

PN01007 12V DC Reversible Electric Gear Motor 50 RPM

\section{Specifications:}

This is a brand new electric gear motor that has extremely high torque to handle many heavyload applications. The specifications are listed below:

Rated Voltage: $13.5 \mathrm{~V}$ DC

Rated Speed: 50 RPM

Rated Load: 60 Watts

Rated Torque: $11.5 \mathrm{~N}-\mathrm{m}(8.5 \mathrm{ft}-\mathrm{lb})$

Mounting: M6 screw holes

Shaft: $10 \mathrm{~mm}$ shaft with 2 flats where flat to flat is $6.6 \mathrm{~mm}$ and threaded end to fit a $\mathrm{M} 6$ tightening nut

Dimension: The gear motor is measured to be 7 " long and motor itself has a diameter of $2.5^{\prime \prime}$

MPN: PN01007

Manufacturer: Wondermotor 


\section{APPENDIX E}

DATASHEET FOR BIDIRECTIONAL PWM MOTOR SPEED CONTROLLER FOR CARRIAGE SLIDER-CRANK MECHANISM 
Website:

http://criticalvelocity.com/products/datasheets/bidir-115.pdf

\section{Critical Velocity \\ BIDIR-115(S) Speed Controller}

\section{Amp Bidirectional PWM Motor Speed Controller BIDIR-115 and BIDIR-115S}

The BIDIR-115(S) PWM controller allows you to control the speed and direction of a motor using any potentiometer from $1-30 \mathrm{k}$. Use of PWM and low on-resistance MOSFETs allows for high efficiency control with minimal power loss.

\section{Absolute Maximum Ratings:}

\begin{tabular}{|l|c|c|}
\hline Parameter & Max & Units \\
\hline Continuous Output Current & 15 & $\mathrm{~A}$ \\
\hline Instantaneous Output Current & 20 & $\mathrm{~A}$ \\
\hline Continuous Input Voltage & 30 & $\mathrm{~V}$ \\
\hline
\end{tabular}

Warning - operating at or above the absolute maximum ratings may damage your controller or your equipment under control.

Operating Parameters:

\begin{tabular}{|l|c|c|c|c|}
\hline Parameter & Min & Typical & Max & Units \\
\hline Input Voltage & 10 & 12 & 26 & $\mathrm{~V}$ \\
\hline Continuous Output Current & -- & -- & 15 & $\mathrm{~A}$ \\
\hline Digital Logic Input Low Level & 0 & -- & 1.5 & $\mathrm{~V}$ \\
\hline Digital Logic Input High Level & 3.5 & -- & 5 & $\mathrm{~V}$ \\
\hline Digital Input Capacitance & -- & 0.1 & -- & $\mathrm{uF}$ \\
\hline Analog Voltage Input & 0.0 & -- & 5.0 & $\mathrm{~V}$ \\
\hline Potentiometer Total Resistance & 1 & 10 & 30 & $\mathrm{k} \Omega$ \\
\hline Soft Start from Disabled Mode, Ramp Rate* & -- & 100 & -- & $\% / \mathrm{s}$ \\
\hline PWM Frequency & 150 & 200 & 250 & $\mathrm{~Hz}$ \\
\hline Quiescent Current Drain & 70 & 75 & 80 & $\mathrm{~mA}$ \\
\hline Temperature & -40 & 25 & +60 & ${ }^{\circ} \mathrm{C}$ \\
\hline
\end{tabular}

* on BIDIR-115S models

Pin-out:

\begin{tabular}{|l|l|l|}
\hline Pin Label & Function & Active H/L \\
\hline P- & Lower pin of potentiometer (GND) & -- \\
\hline Center & Wiper of potentiometer & -- \\
\hline P+ & Upper pin of potentiometer (5V) & -- \\
\hline DIR & Direction & $\begin{array}{l}\text { L = forward } \\
\text { H = reverse }\end{array}$ \\
\hline EN & $\begin{array}{l}\text { PWM output enable } \\
\text { (internal pull-up) }\end{array}$ & $\begin{array}{l}\text { H = enable } \\
\text { L = disable }\end{array}$ \\
\hline M- & Negative output to LOAD & -- \\
\hline M+ & Positive output to LOAD & -- \\
\hline GND & Ground from power Supply & -- \\
\hline V+ & Positive Power Supply & -- \\
\hline
\end{tabular}




\section{Analog Control Mode}

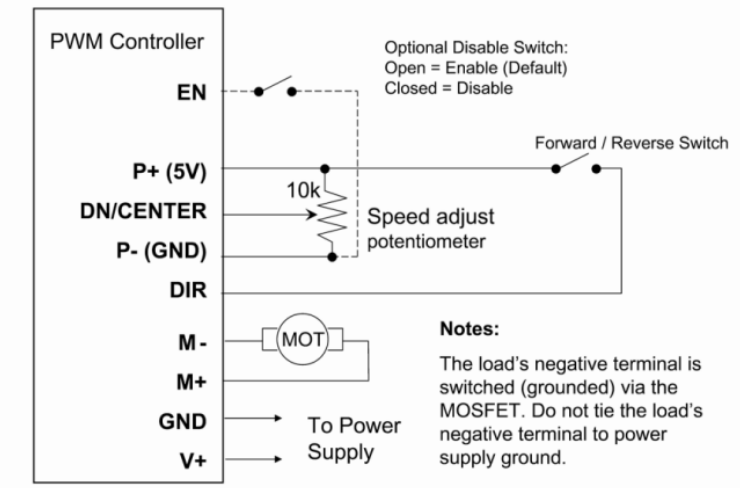

Figure 1: Connection Diagram

\section{Operation:}

A potentiometer of $1 \mathrm{k}-30 \mathrm{k}$ can be used to control the pulse width. Alternatively, a varying voltage ( 0 $-5 \mathrm{~V}$ ) level applied between the CENTER and POT- pins can be used as well. The voltage input is converted to a pulse width at the output $(0-100 \%)$.

There is a built-in dead-band for potentiometer operation that sets the duty cycle to:

$0 \%$ for any voltage level $<0.10 \mathrm{~V}$.

$100 \%$ for any voltage level $>4.90 \mathrm{~V}$.

This dead-band along with digital filtering ensures smooth and reliable operation even with dirty potentiometers.

\section{Output Enable:}

The output is enabled by default and is internally pulled up. Bringing the EN pin low immediately brings the PWM output to $0 \%$. Allowing the pin to return to high re-enables the PWM output at the previous duty cycle.

\section{Direction:}

A switch can be connected between the DIR input and P+ to reverse the direction of the motor. Ensure that the motor is completely stopped before reversing direction. The controller enters a braking mode for about 1 second after the direction input is received before reversing. The onboard fuse protects the motor in the event of an accidental reverse when the motor is still rotating. Replace only with a fuse of the same type and rating.

In applications where this delay is not necessary, it can be disabled. To disable the delay, connect a $1 \mathrm{k}$ resistor between $\mathrm{EN}$ and $\mathrm{P}+$, and a $4.7 \mathrm{k}$ resistor between $\mathrm{EN}$ and $\mathrm{P}$-. This disables the delay. The controller's EN pin can still be used, but the voltage on the EN pin should be around 4 volts at startup to disable the delay. 


\section{Critical Velocity}

\section{Soft Start (on BIDIR-115S models only):}

The output is automatically ramped up back to the original PWM level at a rate of $100 \%$ per second when the controller is switched from disabled to enabled. This reduces the stress placed on power supplies and mechanical linkages as motors come back up to speed.

\section{Application Notes:}

The controller automatically puts the motor into braking mode when power is removed. Please be aware that if the motor is still spinning when the power is removed, the motor will brake suddenly.

This controller is not reverse-polarity protected. Ensure that it is wired correctly before applying power. Always turn off the power supply before making any changes to the wiring.

PWM controllers switch currents at high frequencies to vary the average power to the load. This switching can cause undesirable RF interference. To minimize such interference, it is recommended to twist the input V+ and Ground wire pair as well as the Out+ and Out- wire pair. Please see application note $\mathrm{AN}-100$ for more tips on reducing noise.

Ensure that the controller has adequate air flow for proper cooling. If operating for extended periods of time in high temperature environments, a cooling fan may be necessary.

Use the shortest possible wiring between the load and controller, and between the controller and the power source. Ensure that the cables carrying the load current are adequately sized. If the wiring from the power source to the controller is more than 12 inches long, a $2200 \mathrm{uF} 50 \mathrm{~V}$ filter capacitor should be connected to the V+ and GND terminals of the PWM controller. Inadequate power supply filtering or other causes leading to a high impedance path to the power supply will result in higher losses in the filter capacitor and wiring, and may damage the load and/or controller.

The heat sink on the controller is electrically live. Do not connect anything to the heat sink, and do not use it as a mounting location. Use only the holes provided on the board itself for mounting.

\section{0-Day Limited Warranty:}

Subject to the provisions described below, CRITICAL VELOCITY ENTERPRISES, LLC ("Critical Velocity") warrants this product to be free from defects in material and workmanship for thirty (30) days from the date of purchase by the original consumer. If any part is found to be defective during the provided you: (1) return the failed product to Critical Velocity with shipping prepaid, and (2) provide Critical Velocity with proof of the original date of purchase. Repaired or replacement products will be returned to you with shipping charges prepaid.

Replacement products may be refurbished or contain refurbished materials. If Critical Velocity, by its sole determination, is unable to repair or replace the defective product, it will refund the purchase price of the product. This warranty does not apply if, in the judgment of Critical Velocity, the product fails due to damage from shipment, handling, storage, accident, abuse or misuse, or if it has been used or maintained in a manner not conforming to product manual instructions or has been modified in any way. Repair by anyone other than Critical Velocity will void this warranty. The maximum liability of Critical Velocity under this warranty is limited to the purchase price of the product covered by the warranty.

EXCEPT AS SPECIFICALLY PROVIDED IN THIS AGREEMENT OR AS REQUIRED BY LAW, THE WARRANTIES AND REMEDIES STATED ABOVE ARE EXCLUSIVE AND IN LIEU OF ALL OTHERS, ORAL OR WRITTEN, EXPRESS OR IMPLIED. ANY AND ALL OTHER WARRANTIES, INCLUDING IMPLIED WARRANTIES OF MERCHANTABILITY, FITNESS FOR A PARTICULAR PURPOSE AND NONINFRINGEMENT OF ANY PATENT, COPYRIGHT OR OTHER INTELLECTUAL PROPERTY RIGHT ARE EXPRESSLY EXCLUDED. CRITICAL VELOCITY SHALL NOT UNDER ANY CIRCUMSTANCES BE LIABLE FOR ANY SPECIAL, INCIDENTAL, INDIRECT OR CONSEQUENTIAL DAMAGES, INCLUDING WITHOUT LIMITATION, DAMAGES RESULTING FROM USE OR MALFUNCTION OF THE PRODUCTS, LOSS OF PROFITS OR REVENUES OR COSTS OF REPLACEMENT GOODS, EVEN IF CRITICAL VELOCITY IS INFORMED IN ADVANCE OF THE POSSIBILTTY OF SUCH DAMAGES.

UNLESS EXPRESSLY APPROVED IN WRITING BY AN AUTHORIZED CRITICAL VELOCITY REPRESENTATIVE, CRITICAL VELOCITY PRODUCTS ARE NOT RECOMMENDED, AUTHORIZED OR WARRANTED FOR USE IN MILITARY, AIR CRAFT, SPACE, LFE SAVING OR LIFE SUSTAINING PROPERTY OR ENVIRONMENTAL DAMAGE.

[http://www.criticalvelocity.com] 


\section{APPENDIX F \\ DATASHEET FOR TOP, FRONT, MIDDLE AND REAR INFRARED SENSOR SWITCHES}


Website:

http://www.dfrobot.com/wiki/index.php/Adjustable_Infrared_Sensor_Switch_\%28SKU:SEN0019\%29

ADJUSTABLE INFRARED SENSOR SWITCH (SKU:SEN0019)

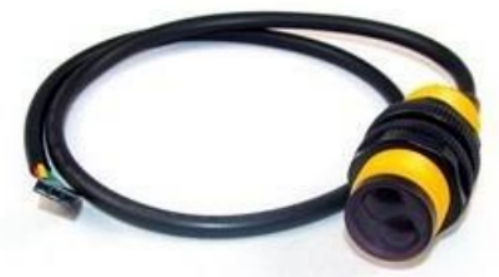

Adjustable Infrared Sensor Switch (SKU:SEN0019)

\section{Contents}

- 1 Overview

- 2 Specification

- 3 Pinout

- 4 Connection Diagram

- 5 Sample Code

\section{Overview}

The DFRobot Adjustable Infrared Sensor Switch is a set of transmitter and receiver in one of the photoelectric switch sensor. The detection distance can be adjusted according to the demand. The sensor has a detection range of $3-80 \mathrm{~cm}$. The DFRobot Adjustable Infrared Sensor Switch is small, easy to use, inexpensive, easy to assemble and can be widely used in robot to avoid obstacles, interactive media, industrial assembly line, and many other occasions. The switching signal output differs in accordance to the obstacles. It remains high when no obstacles and remains low when there are obstacles. There is a bright light behind the probe to detect the scope of $3 \mathrm{~cm}-80 \mathrm{~cm}$.

\section{Specification}

- Adjustable detection range, $3 \mathrm{~cm}-80 \mathrm{~cm}$

- Small, easy to use/assemble, inexpensive

- Useful for robot, interactive media, industrial assembly line, etc

- Power supply: 5V

- Current: $100 \mathrm{~mA}$ 
- Dimension: 45 × $18 \times 18 \mathrm{~mm}$

Pinout

- Red - V+

- Yellow - Signal

- Green-GND

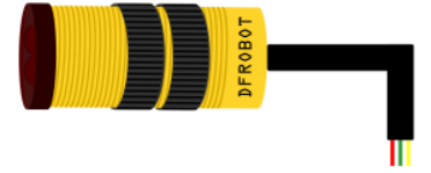

Infrared Sensor Switch

Connection Diagram

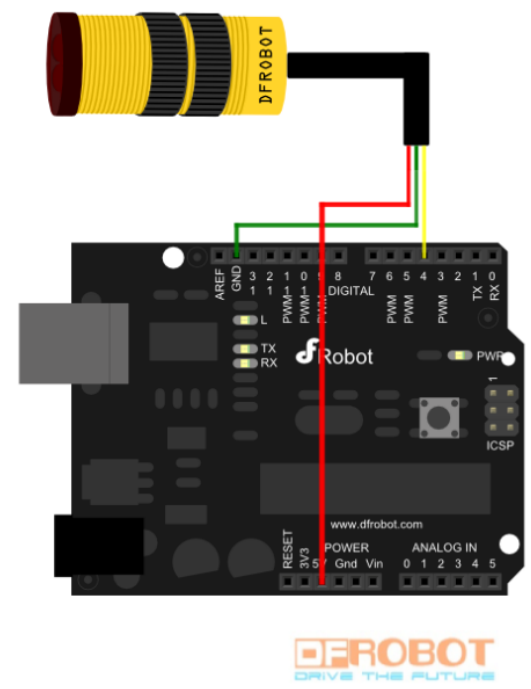

Analog sensor connection diagram 


\section{Sample Code}

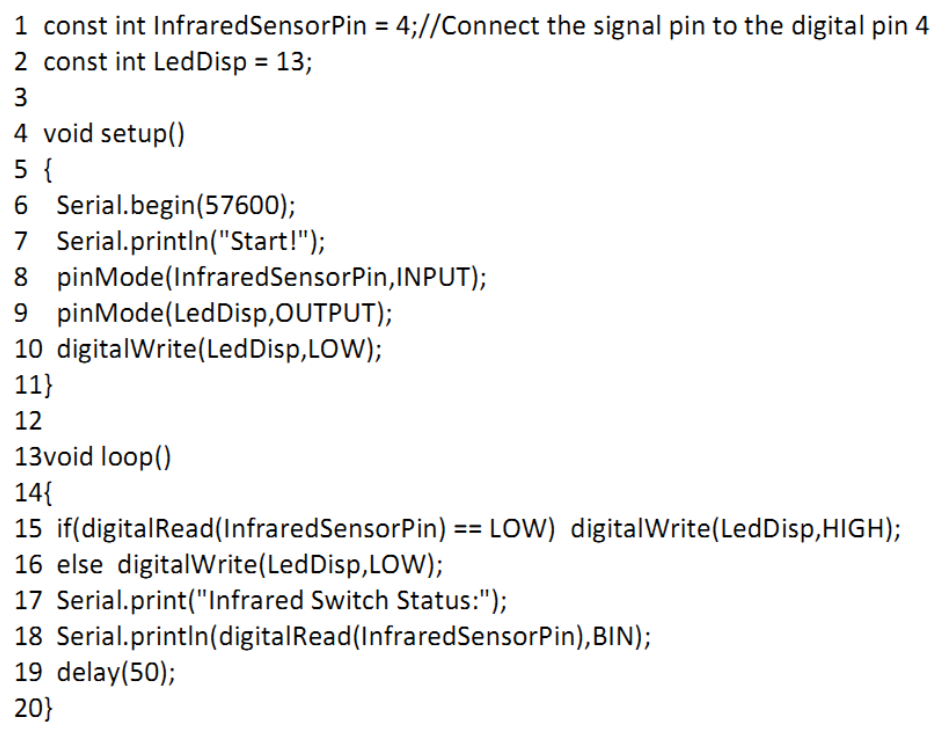


APPENDIX G

DATASHEET FOR CARRIAGE STEPPER MOTORS 
Website:

http://www.kelinginc.net/KL23H276-30-8A.pdf

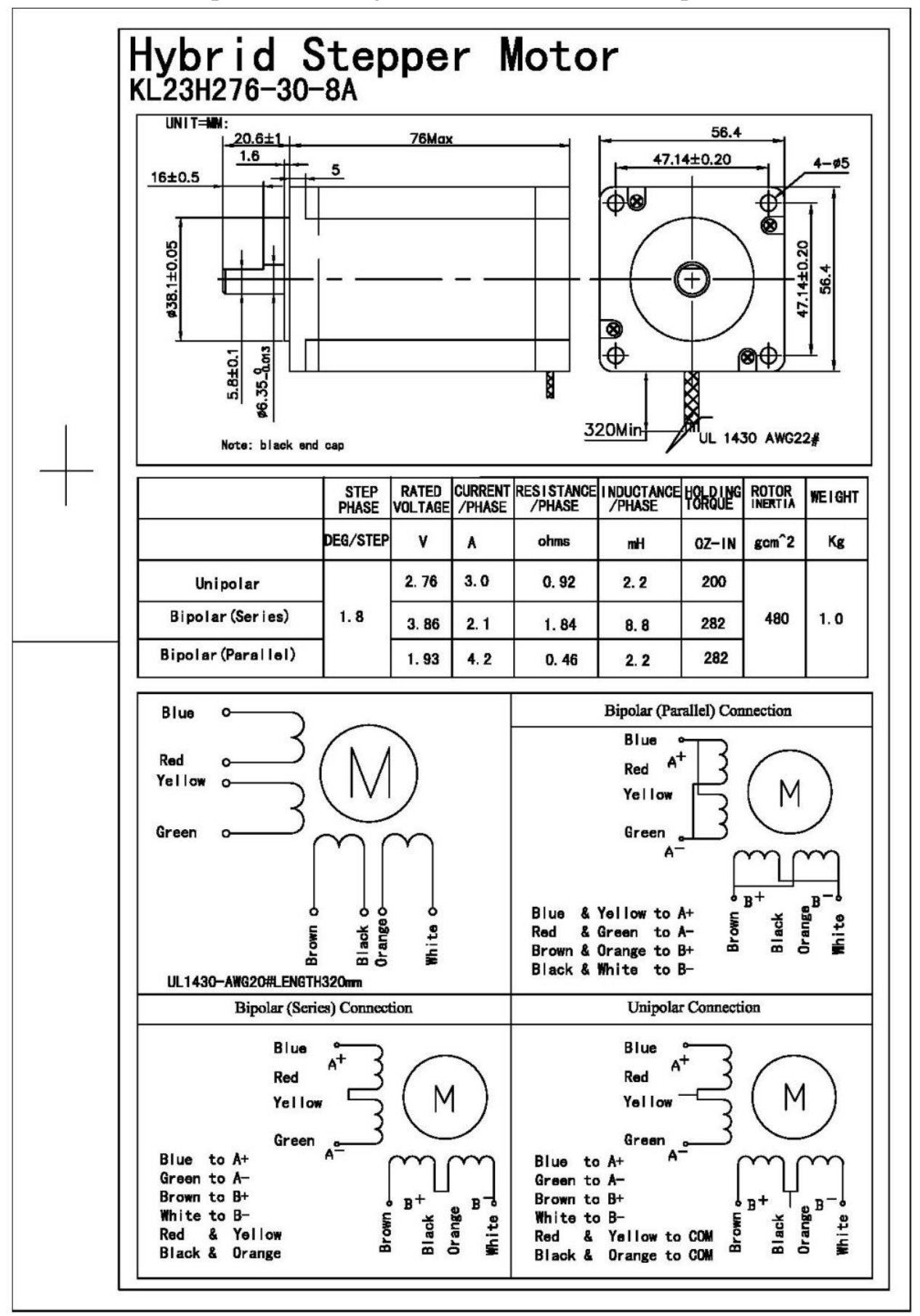


Website:

http://www.kelinginc.net/KL23H276-30-8AT.pdf TORQUE SPEED CURVE

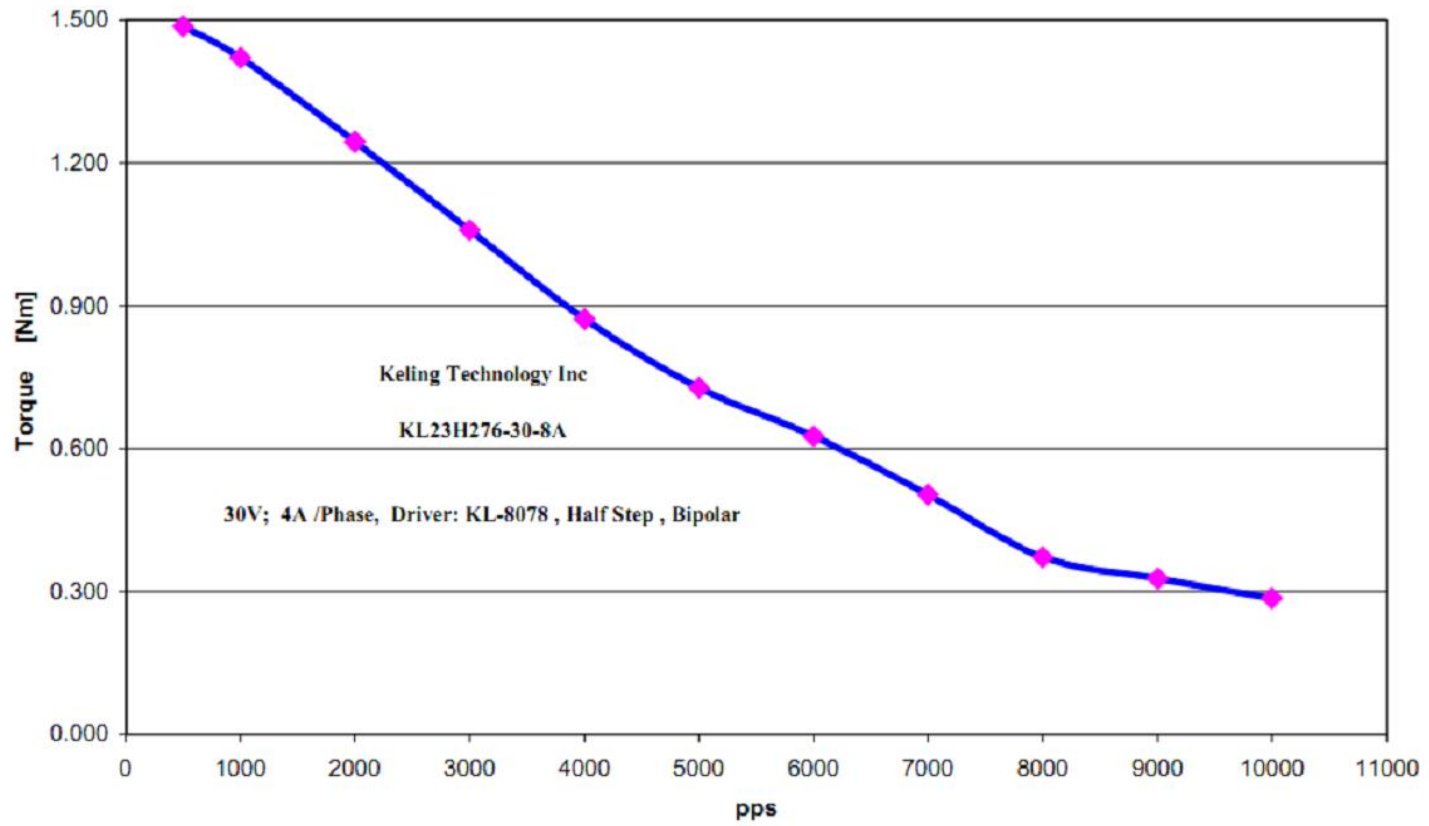


APPENDIX H

DATASHEET FOR MICRO STEPPING DRIVERS FOR CARRIAGE RACK-ANDPINION MECHANISM 
Website:

http://www.kelinginc.net/kl-6050.pdf

\section{Microstepping Driver KL6050}

\section{Applications}

Suitable for a wide range of stepping motors of Nema 17,23 and 34, and usable for various kinds of machines, such as $X-Y$ tables, labeling machines, laser cutters, engraving machines, and pickplace devices. Particularly useful in applications with low vibration, high speed and high precision are desired

\section{Electric Specifications $\left(\mathrm{T}_{\mathrm{j}}=25^{\circ} \mathrm{C}\right)$}

\begin{tabular}{|c|c|c|c|c|}
\hline \multirow{2}{*}{ Parameters } & \multicolumn{5}{|c|}{ KL6050 } \\
\hline Output current & Min & Typical & Max & Unit \\
\hline Supply voltage & 1.5 & - & 5.0 & $\mathrm{~A}$ \\
\hline Logic signal current & 20 & 48 & 60 & $\mathrm{VDC}$ \\
\hline Pulse input frequency & 7 & 10 & 16 & $\mathrm{~mA}$ \\
\hline Isolation resistance & 0 & - & 100 & $\mathrm{KHz}$ \\
\hline
\end{tabular}

Mechanical Specifications (Unit: mm, 1 inch=25.4 mm)
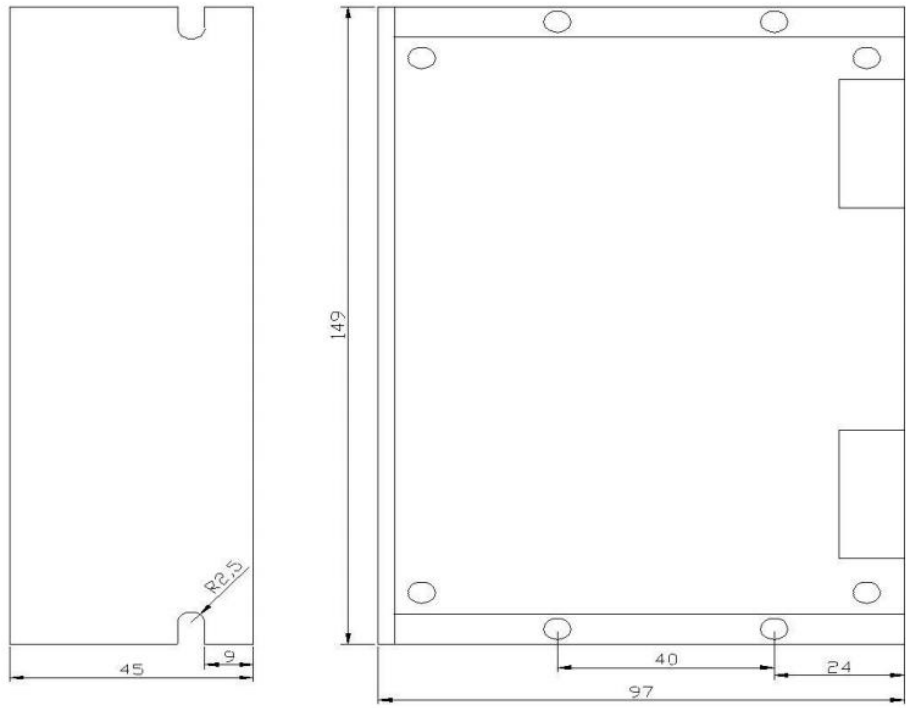

Figure 1: Mechanical Specifications 


\section{Pin Assignment and Description}

Control Signal Connector P1 pins

\begin{tabular}{|c|c|}
\hline Pin Function & Details \\
\hline PUL $+(+5 V)$ & \multirow{2}{*}{$\begin{array}{l}\text { Pulse signal: In single pulse (pulse/direction) mode, this input represents pulse } \\
\text { signal, effective for each rising or falling edge (set by inside RI3\&R14): } 4-5 \mathrm{~V} \\
\text { when PUL-HIGH, 0-0.5V when PUL-LOW, In double pulse mod, } \\
\text { (pulse/pulse), this input represents clockwise (CW) pulse, effective for higl } \\
\text { level or low level (set by inside R13\&R14). For reliable response, pulse widtl } \\
\text { should be longer than } 1.2 \mu \text { s. Series connect resistors for current-limiting wher } \\
+12 \mathrm{~V} \text { or }+24 \mathrm{~V} \text { used. }\end{array}$} \\
\hline PUL-(PUL) & \\
\hline $\mathrm{DIR}+\mathrm{C}$ & \multirow{2}{*}{$\begin{array}{l}\text { DIR signal: In single-pulse mode, this signal has low/high voltage levels, } \\
\text { representing two directions of motor rotation; in double-pulse mode (set by } \\
\text { inside R31\&R32), this signal is counter-clock (CCW) pulse, effective for high } \\
\text { level or low level (set by inside R13\&R14). For reliable motion response, DIR } \\
\text { signal should be ahead of PUL signal by } 5 \mu \text { s at least. } 4-5 \mathrm{~V} \text { when DIR-HIGH. } \\
0-0.5 \mathrm{~V} \text { when DIR-LOW. Please note that motion direction is also related to } \\
\text { motor-driver wiring match. Exchanging the connection of two wires for a coil } \\
\text { to the driver will reverse motion direction. }\end{array}$} \\
\hline DIR-(DIR) & \\
\hline $\mathrm{ENA}+(+5 \mathrm{~V})$ & \multirow{2}{*}{$\begin{array}{l}\text { Enable signal: This signal is used for enabling/disabling the driver. High level } \\
\text { (NPN control signal. PNP and Differential control signals are on the contrary. } \\
\text { namely Low level for enabling.) for enabling the driver and low level for } \\
\text { disabling the driver. Usually left UNCONNECTED (ENABLED). }\end{array}$} \\
\hline & \\
\hline
\end{tabular}

\section{Power connector P2 pins}

\begin{tabular}{|c|c|}
\hline Pin Function & Details \\
\hline GND & DC power ground. \\
\hline$+V$ & $\begin{array}{l}\text { DC power supply, } 20-60 \mathrm{VDC} \text {, Including voltage fluctuation and EMF } \\
\text { voltage. }\end{array}$ \\
\hline$A+, A-$ & Motor Phase A \\
\hline $\mathrm{B}+, \mathrm{B}-$ & Motor Phase B \\
\hline
\end{tabular}

\section{Microstep Resolution Selection}

Microstep resolution is specified by 4 DIP switches as shown in the following table:

\begin{tabular}{|c|c|}
\hline Microstep & sW4 \\
\hline $1 / 2$ & 1 \\
\hline $1 / 8$ & 0 \\
\hline
\end{tabular}

Current Setting

\begin{tabular}{|c|c|c|c|}
\hline Current & SW1 & SW2 & SW3 \\
\hline 1.5 & 0 & 0 & 0 \\
\hline 2.0 & 1 & 0 & 0 \\
\hline 2.5 & 0 & 1 & 0 \\
\hline 3.0 & 1 & 1 & 0 \\
\hline 3.5 & 0 & 0 & 1 \\
\hline 4.0 & 1 & 0 & 1 \\
\hline 4.5 & 0 & 1 & 1 \\
\hline 5.0 & 1 & 1 & 1 \\
\hline
\end{tabular}

Notes: Due to motor inductance, the actual current in the coil may be smaller than the dynamic current settings, particularly under high speed condition. 


\section{Typical Connections}

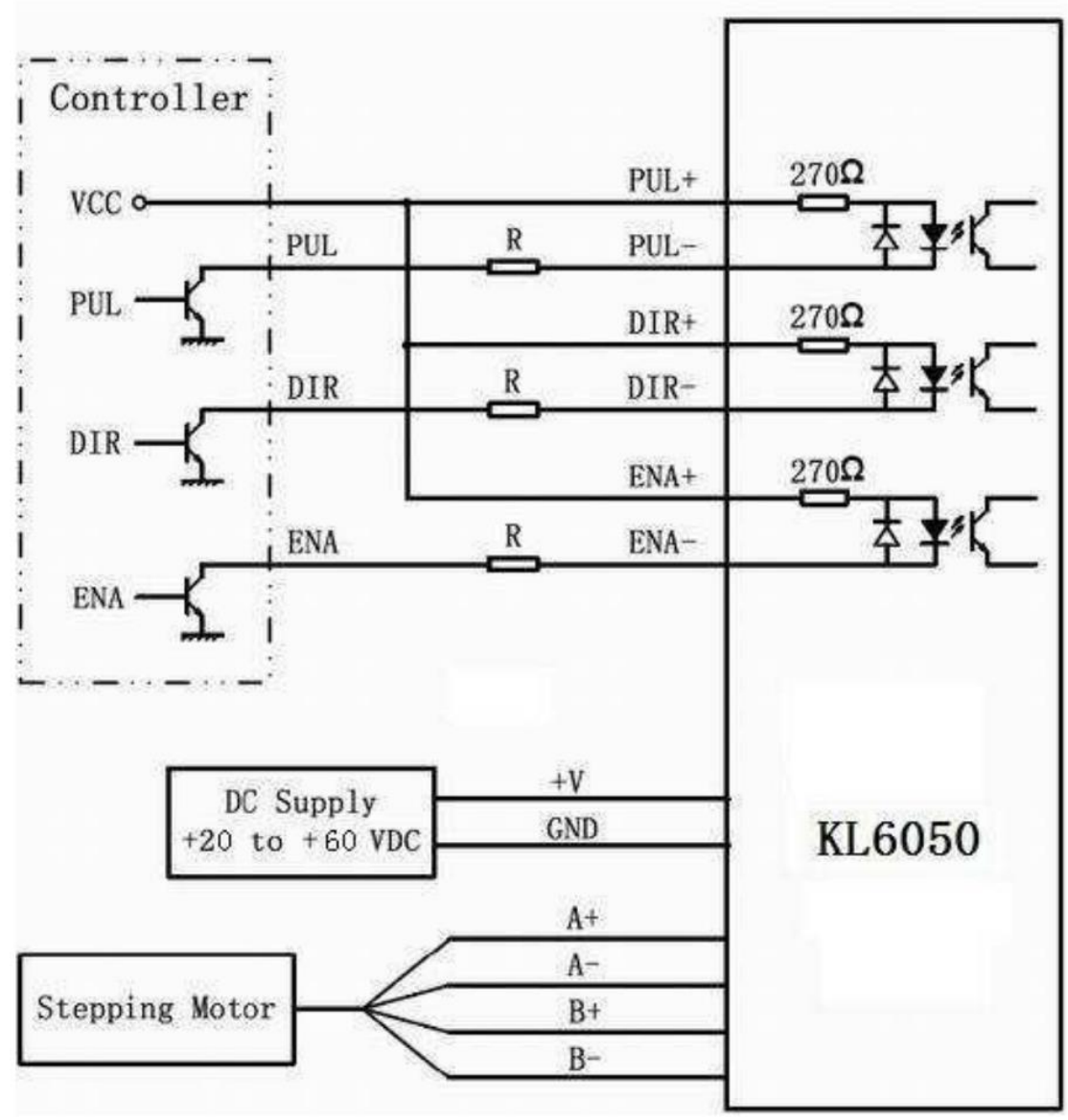

Figure 2: Typical Connections 
APPENDIX I

DATASHEET FOR LINEAR ACTUATORS FOR NAPKIN REMOVING AND NAPKIN ENGAGING MECHANISMS 


\section{Website:}

http://www.firgelli.com/Uploads/L16_datasheet.pdf

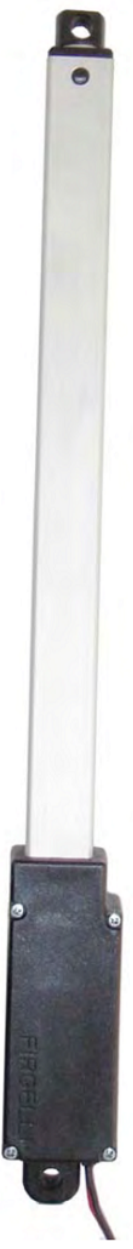

\section{Miniature Linear Motion Series · L16}

Firgelli Technologies' unique line of Miniature Linear Actuators enables a new generation of motion-enabled product designs, with capabilities that have never before been combined in a device of this size. These linear actuators are a superior alternative to designing your own push/pull mechanisms.

The L16 actuators are complete, self contained linear motion devices with position feedback for sophisticated position control capabilities, or end of stroke limit switches for simple two position automation. Driving them couldn't be easier, simply apply a DC voltage to extend the actuator, and reverse the polarity to retract it. Several gear ratio's are available to give you varied speed/force configurations.

\begin{tabular}{|c|c|c|c|}
\hline \multicolumn{4}{|l|}{ L16 Specifications } \\
\hline Gearing Option & $35: 1$ & $63: 1$ & 150:1 \\
\hline Peak Power Point & $50 \mathrm{~N} @ 16 \mathrm{~mm} / \mathrm{s}$ & 75N@10mm/s & $175 \mathrm{~N} @ 4 \mathrm{~mm} / \mathrm{s}$ \\
\hline Peak Efficiency Point & 24N@24mm/s & 38N@15mm/s & 75N@7mm/s \\
\hline Max Speed (no load) & $32 \mathrm{~mm} / \mathrm{s}$ & $20 \mathrm{~mm} / \mathrm{s}$ & $8 \mathrm{~mm} / \mathrm{s}$ \\
\hline Max Force (lifted) & $50 \mathrm{~N}$ & $100 \mathrm{~N}$ & $200 \mathrm{~N}$ \\
\hline Back Drive Force & $31 \mathrm{~N}$ & $46 \mathrm{~N}$ & $102 \mathrm{~N}$ \\
\hline Stroke Option & $50 \mathrm{~mm}$ & $100 \mathrm{~mm}$ & $140 \mathrm{~mm}$ \\
\hline Mass & $56 \mathrm{~g}$ & $74 \mathrm{~g}$ & $84 \mathrm{~g}$ \\
\hline Positional Accuracy & $0.3 \mathrm{~mm}$ & $0.4 \mathrm{~mm}$ & $0.5 \mathrm{~mm}$ \\
\hline Max Side Load (extended) & $40 N$ & $30 N$ & $20 N$ \\
\hline Feedback Potentiometer & $9 \mathrm{k} \Omega \pm 30 \%$ & $18 \mathrm{k} \Omega \pm 30 \%$ & $25 \mathrm{k} \Omega \pm 30 \%$ \\
\hline Electrical Stroke & $48 \mathrm{~mm}$ & $98 \mathrm{~mm}$ & $138 \mathrm{~mm}$ \\
\hline Input Voltage & \multicolumn{3}{|c|}{ 0-15 VDC. Rated at 12VDC. } \\
\hline Stall Current & \multicolumn{3}{|c|}{ 650mA @ 12V } \\
\hline Operating Temperature & \multicolumn{3}{|c|}{$-10^{\circ} \mathrm{C}$ to $+50^{\circ} \mathrm{C}$} \\
\hline Lifetime @ Peak Eff. Pt. & \multicolumn{3}{|c|}{20,000 strokes, $20 \%$ Duty Cycle } \\
\hline Audible Noise & \multicolumn{3}{|c|}{$57 \mathrm{~dB} @ 45 \mathrm{~cm}$} \\
\hline Ingress Protection & \multicolumn{3}{|c|}{ IP-54 } \\
\hline Mechanical Backlash & \multicolumn{3}{|c|}{$0.2 \mathrm{~mm}$} \\
\hline Limit Switches & \multicolumn{3}{|c|}{ Max. Current Leakage: $8 \mathrm{uA}$} \\
\hline
\end{tabular}

Basis of Operation

The L16 is designed to push or pull a load along its full stroke length. The speed of travel is determined by the load applied. (See the Load Curves). When power is removed the actuator will hold its position, unless the applied load exceeds the backdrive force. Stalling the actuator for short periods will not cause damage, however repeated stalling will shorten the life of the actuator.

Ordering

Small quantity orders can be placed directly online at www.firgelli.com. Each actuator ships with two mounting brackets and \#8-32 mounting hardware. The cable length is approximately $300 \mathrm{~mm}$ and connector is a $0.1^{\prime \prime}$ pitch female socket connector.

Firgelli Technologies Inc.

1550 Mileva Lane

Victoria, BC V8N 2V5

Canada
1 (206) 347-9684 phone 1 (888) 225 -9198 toll-free 1 (206) 347.9684 fax sales@firgelli.com www.firgelli.com 


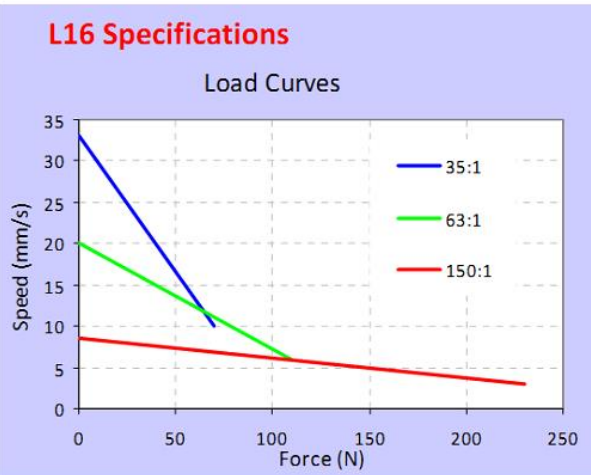

Model Selection

The L16 has 3 configuration choices: Stroke, Gear Ratio and Controller. L16 options are identified according to the following model numbering scheme:

\section{L16-SS-GG-VV-C} feature

$$
\text { options }
$$

SS: Stroke GG: Gear reduction ratio (refer to load curves above) VV: Voltage

C: Controller

\section{$50,100,140(\mathrm{~mm})$}

$35,63,150$

(lower ratios are faster but push less force, and vice versa)

12 (DC volts)

P Potentiometer Feedback

$S$ Limit Switches

\section{L16 Controller Options}

Option S - End of Stroke Limit Switches

WIRING: (see next page for pin numbering)

1 (red) - Actuator Motor Power

2 (black) - Actuator Motor Power

The $-\mathrm{S}$ actuators have limit switches that will turn off power to the motor when the actuator reaches within $1 \mathrm{~mm}$ of the end of stroke. Internal diodes allow the actuator to reverse away from the limit switch. The limit switches cannot be moved. While voltage is applied to the motor power pins the actuator extends. Reverse the polarity and the actuator retracts. This can be accomplished manually with a DPDT switch or relay, or using an $\mathrm{H}$-Bridge circuit. The $-\mathrm{S}$ model cannot be used with the $\mathrm{CIB}$ control board.

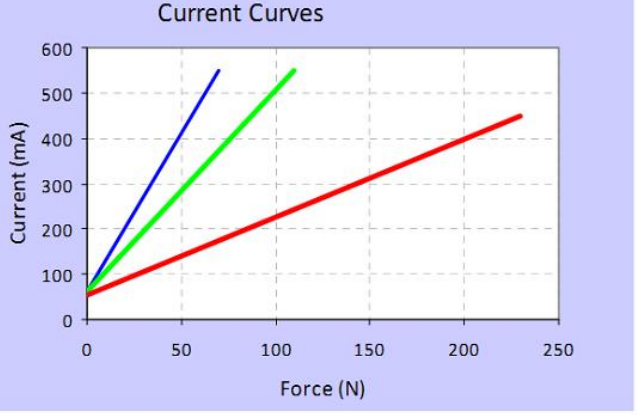

Option P - Potentiometer Position Feedback

WIRING: (see next page for pin numbering)

1 (orange) - Feedback Potentiometer negative reference rail

2 (purple) - Feedback Potentiometer wiper

3 (red) - Actuator Motor Power

4 (black) - Actuator Motor Power

5 (yellow) - Feedback Potentiometer positive reference rail

The -P actuators have no built in controller, but do provide an analog position feedback signal that can be input to an external controller. While voltage is applied to the motor power pins $(3 \& 4)$ the actuator extends. Reverse the polarity and the actuator retracts. This can be accomplished manually with a DPDT switch or relay, or using an H-Bridge circuit. Position of the actuator stroke can be monitored by providing any stable low and high reference voltage on pins $1 \& 5$, then reading the position signal on pin 2 . The voltage on pin 2 will vary linearly between the two reference voltages in proportion to the position of the actuator stroke.

The L16 -P actuators can be used as a linear servo by connecting the actuator to a microcontroller such as the $\mathrm{CIB}$ control board offered by Firgelli. This control board reads the position signal from the L16, compares it with your input control signal then commands the actuator to move via an onboard $\mathrm{H}$-bridge circuit. The $\mathrm{CIB}$ allows any one of the following control inputs: Analog 0-5V or 4-20mA, or Digital 0$5 \mathrm{~V}$ PWM or $1-2 \mathrm{~ms}$ standard RC. The RC input effectively transforms your L16 into a linear servo which is a direct replacement for any common hobby servo used in RC toys and robotics. Refer to the CIB datasheet for more details.

Special Notes:

Currently in development are the RC versions of the L16 .

\section{CFfirgelli}

Firgelli Technologies Inc.

1550 Mileva Lane Victoria, BC V8N 2V Canada
1 (206) 347-9684 phone 1 (888) 225-9198 toll-free 1 (206) 347.9684 $\mathrm{fax}$ 


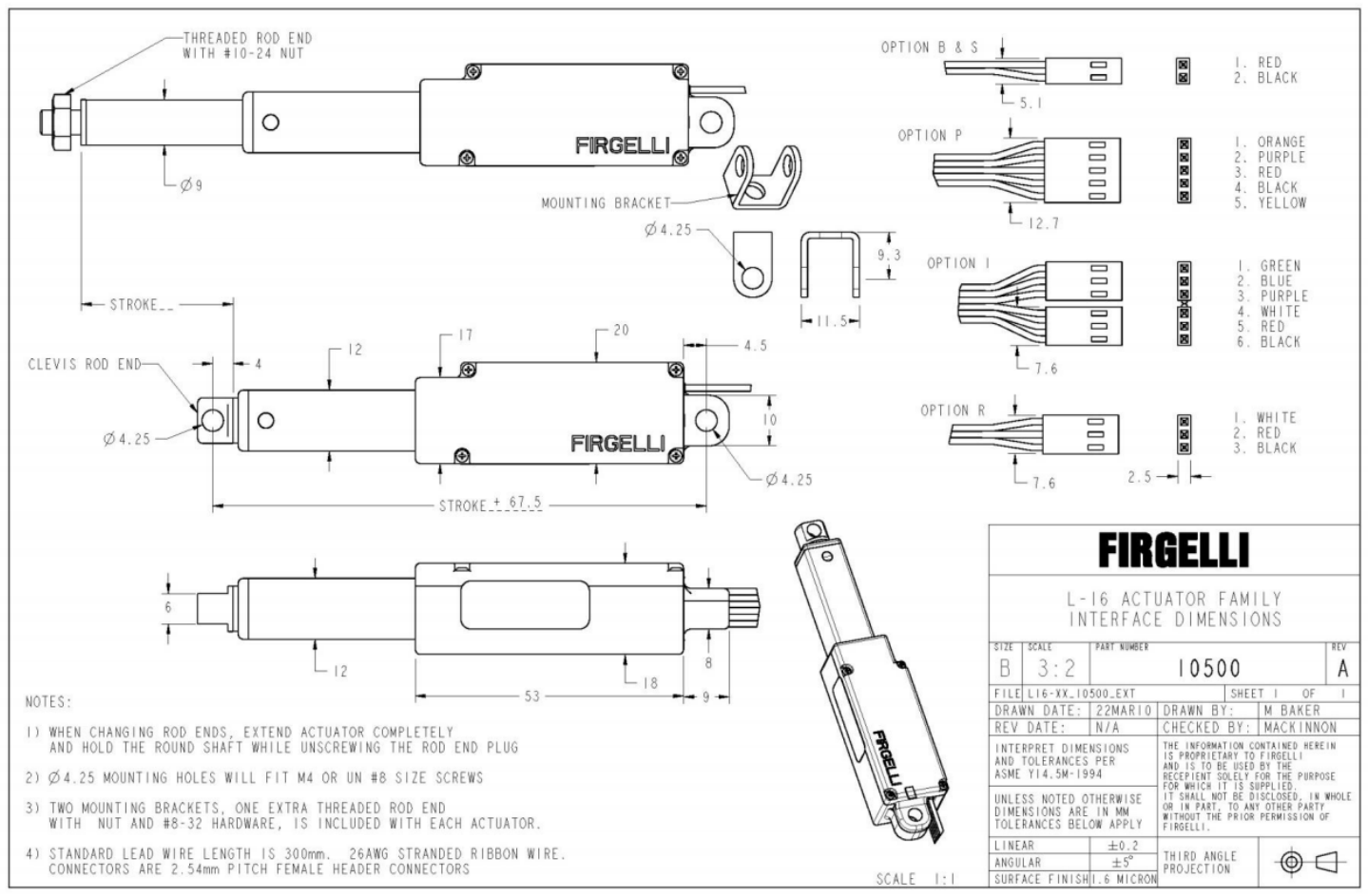


APPENDIX J

DATASHEET FOR LINEAR ACTUATOR CONTROL BOARDS FOR NAPKIN REMOVING AND NAPKIN ENGAGING MECHANISMS 


\section{Website: \\ http://www.firgelli.com/Uploads/LAC_Datasheet.pdf LAC・ Firgelli Linear Actuator Control Board}

\begin{abstract}
The Linear Actuator Control Board is a stand-alone closed-loop control board specifically designed for Firgelli actuators. The LAC greatly simplifies designs by saving the development time, cost, and processor overhead associated with direct motor control. As little as 1 digital or analog output is required for position control. Supported input signals include USB, Voltage, Current, RC Servo, and PWM. Firgelli's motor control IC uses a software based algorithm to optimize position and speed control. This makes the LAC compatible with a wide range of actuators, using only the default settings. Firgelli's Advanced Configuration Program allows full customization of actuator response. A stall detection feature provides a great increase in actuator life for applications that may briefly exceed the rated force.
\end{abstract}

The LAC can be operated as both an interface board, or as a stand alone controller with the addition of an external potentiometer and power supply.

(Accessory kit and housing sold separately)

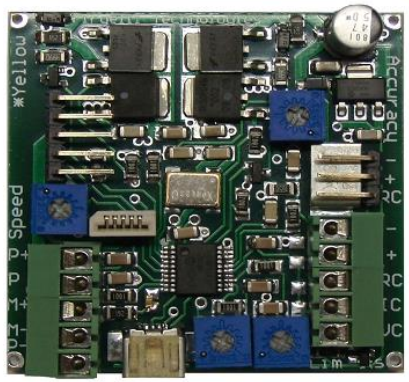

\section{Specifications \\ Control input modes \\ Controller \\ Compatible actuators Analog: 0-3.3 V, 4-20 mA \\ 10-bit Dual Sample Rate Quasi PD \\ PQ12 Actuators with position feedback, 6 or 12 volts \\ L12-P Actuators with position feedback, 6 or 12 volts L16-P Actuators with position feedback, 12 volts Larger Actuators such as FA-PO-xxx-xxx, 12 or $\mathbf{2 4}$ volts \\ Dimensions $50 \mathrm{~mm} \times 50 \mathrm{~mm}$ (excluding battery holder) \\ Power 5-24 VDC, 4 Amps peak current at $10 \%$ duty cycle \\ Operating environment -10 to $+70^{\circ} \mathrm{C}$ at $10-80 \%$ relative humidity}

\section{Operation}

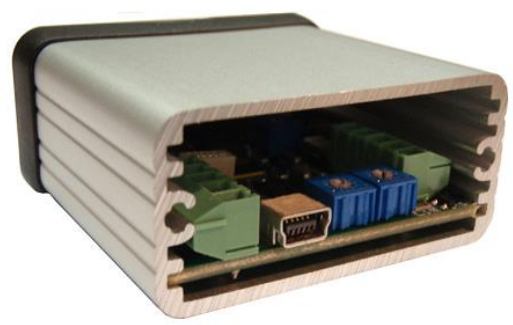

When the LAC is powered up, it will repeatedly scan for an input signal that is valid under any of the five supported interface modes (see reverse for External Connections Detail illustration). When a valid signal is first detected, the actuator will self-configure to the corresponding interface mode, and all other interface modes and input leads are disabled until the actuator is next powered on. The sensitivity or accuracy of the actuator control algorithm can be set by adjusting the "Accuracy" trim potentiometer. Turning clockwise will allow the actuator to move in smaller increments and be more accurate. However, due to the differences in actuator types this may cause jittery or unstable behaviour. If this occurs, consider using the USB configuration program to more finely tune the controller for your application. Each time a control potentiometer is adjusted, power must be cycled to the LAC board prior to the new settings taking effect. Adjusting the "Speed" potentiometer will set the maximum actuator speed. The two "Limits" potentiometers allow user settable digital limit switches. These set the minimum and maximum acceptable positions. Control inputs that exceed these limits will cause the actuator to position to the limit.

Firgelli Technologies Inc.

580 Starling Lane

Victoria, BC, V9E $2 A 9$

1 (206) 347-9684 phone

1 (888) 225-9198 toll-free

1 (206) 347-9684 fax 
External Connections Detail

\author{
X1 PQ12 actuator connector \\ 5 pin, $1 \mathrm{~mm}$ Pitch FPC connector \\ X2 L12-P/L16-P actuator connector \\ Pin Function \\ 1 Potentiometer Reference Negative (yellow) \\ Motor Terminal (black) \\ 3 Motor Terminal (red) \\ 4 Potentiometer Feedback (wiper) (purple) \\ 5 Potentiometer Reference Positive (orange) \\ X3 Radio control receiver connector \\ Pin Function \\ 1 Ground (black) \\ 2 Power (red) \\ 3 Control (white) \\ X4 Large actuator connector \\ Pin Function \\ 1 Potentiometer Reference Positive (white) \\ 2 Potentiometer Feedback (wiper) (yellow) \\ 3 Motor Terminal (red) \\ 4 Motor Terminal (black) \\ 5 Potentiometer Reference Negative (blue) \\ NOTE: If the actuator moves to one end \\ then stops, swap pins 3 and 4 to change \\ the motor direction. \\ X5 Universal Serial Bus (Male Mini-B)

$\begin{array}{cl}\text { Pin } & \text { Function } \\ 1 & \text { N/C } \\ 2 & \text { Data } \\ 3 & \text { Data } \\ 4 & \text { N/C } \\ 5 & \text { Ground }\end{array}$

\section{Control Modes}

0-3.3 V Interface Mode: This mode allows an actuator to be controlled with just a battery, and a potentiometer to signal the desired position to the actuator - a simple interface for prototypes or home automation projects. The desired actuator position (setpoint) is input to the LAC on connector X6 pin 5 as a voltage between ground and $3.3 \mathrm{~V}$. The set-point voltage must be held on pin 5 to reach and maintain the desired actuator stroke position. The wiper pin of an external potentiometer connects to X6 pin 5. Pins 1 and 5 of $X 4$ can be used as the 3.3V Reference. The other two potentiometer pins connect to these. When a Potentiometer is not used, ensure the control signal ground is connected to LAC ground.

RC Servo Interface Mode: This is a standard hobby-type remotecontrol digital servo interface, compatible with servos and receivers from manufacturers like Futaba ${ }^{\mathrm{TM}}$ and $\mathrm{Hi}_{\mathrm{T}} \mathrm{Tec}^{\mathrm{TM}}$. The desired actuator position is input to the LAC on connector X6 pin 3 as a positive 5 Volt pulse-width signal. A $1 \mathrm{~ms}$ pulse commands the controller to fully retract the actuator, and a $2 \mathrm{~ms}$ pulse signals full extension. Connector X3 can also be used for the RC contro signal, and uses the standard 3 pin $0.1^{\prime \prime}$ spacing typical on most hobby servo receivers. Do not connect power to both X6 and X3 at the same time (If the supply voltages differ, large currents will flow).
P1 Speed Control

Sets maximum actuator speed

CW Faster

CCW Slower

P2 Limit Controls

Left Potentiometer controls Retract Limit

CW Maximum Stroke

Right Potentiometer controls Extend Limit

CW Maximum Stroke

P3 Sensitivity adjustment

CW Smaller dead-band

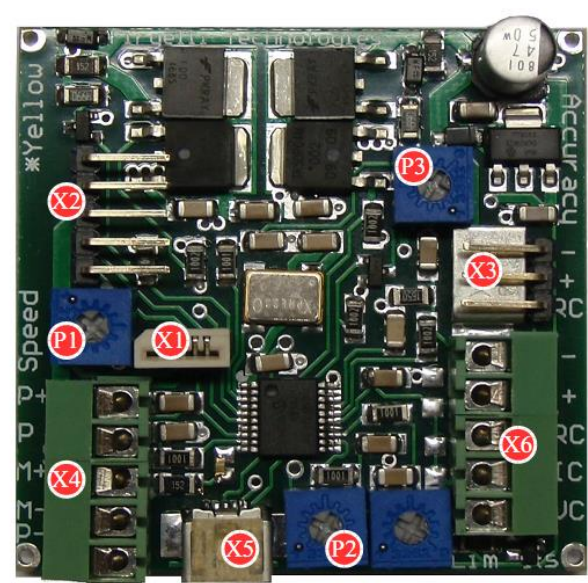

Connector Pins numbered from Top to Bottom or Left to Right

4-20 mA Interface Mode: This mode is compatible with PLC devices typically used in industrial control applications. The desired actuato position (set-point) is input to the LAC on connector X6 pin 4 as a current between $4 \mathrm{~mA}$ and $20 \mathrm{~mA}$. The set-point current must be held on pin 4 to reach and maintain the desired actuator stroke position.

PWM Mode: This mode allows control of the actuator using a single digital output pin from an external micro controller. The desired actuator position is encoded as the duty cycle of a 3.3 Volt, $1 \mathrm{kHz}$ square wave on LAC connector X6 pin 5, where the percent duty cycle sets the actuator position to the same percent of full stroke extension. $100 \%$ duty cycle represents full extension, and $0 \%$ duty cycle represents full retraction. This input is $5 \mathrm{~V}$ tolerant, however the \% duty cycle range will differ.

USB Mode: This mode allows control of the actuator using a Computer. In addition advanced settings allow fine control over the controller response. Default settings can be reverted to, using the reset command. When custom settings are turned on, $\mathrm{P} 1, \mathrm{P} 2$, and $\mathrm{P} 3$ are ignored. These settings will be saved even when power is cycled. This allows custom configuration for all inputs even when USB is not connected. Details of the DLL are given in a separate document so that custom programs can be created by the customer. An example Labview program is available for download. The Dynamic Link Library(DLL) allows Programming in many windows languages including Labview. 
APPENDIX K

DATASHEET FOR DC TO PULSE WIDTH MODULATOR FOR CONVEYOR AND ADHESIVE TAPE RENEWAL MECHANISM 
Website:

http://www.vellemanusa.com/downloads/0/illustrated/illustrated_assembly_manual_k8004_rev3.pdf Total solder points: 82

\section{Dc to Pulse Width Modulator}

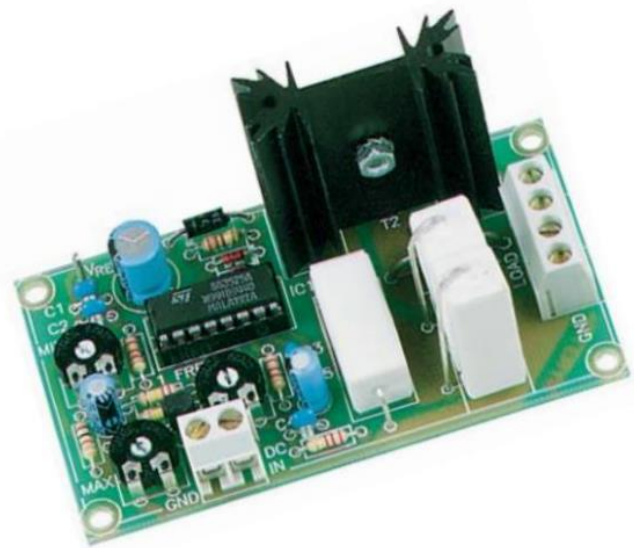

\section{$K 8004$}

Allows very efficient control of DC motors, heaters or lights.

\section{Features:}

$\square$ PWM range: 0 to $100 \%$.

$\square$ PWM frequency: 100 to $5000 \mathrm{~Hz}$ adjustable.

$\square$ Minimum PWM offset: 0 to $20 \%$ adjustable.

Adjustable sensitivity: 2.5 to $35 \mathrm{VDC}$

$\square$ Short circuit protection.

$\square$ Overload protection: $6.5 \mathrm{~A}$

\section{Specifications:}

- Power Supply: 8 to 35VDC unregulated

- Supply current (No load): $35 \mathrm{~mA}$ typ

- Efficiency: better than $90 \%$ at full load

- Dimensions (wxdxh): $85 \times 48 \times 45 \mathrm{~mm}$ 


\section{Test}

- Connect the supplied $4 \mathrm{k} 7$ resistor between the + and - points of the load.

- Connect the Vref point to the DC input.

- Set preset RV3 to the middle of its adjustment range.

- Connect a DC voltage between 8 and $35 \mathrm{~V}$ with the points $+V$ and GND.

- Measure between the + and - points of LOAD with a voltmeter (set to read DC voltage)

- If everything goes well then the voltage on the output can be adjusted with RV2.

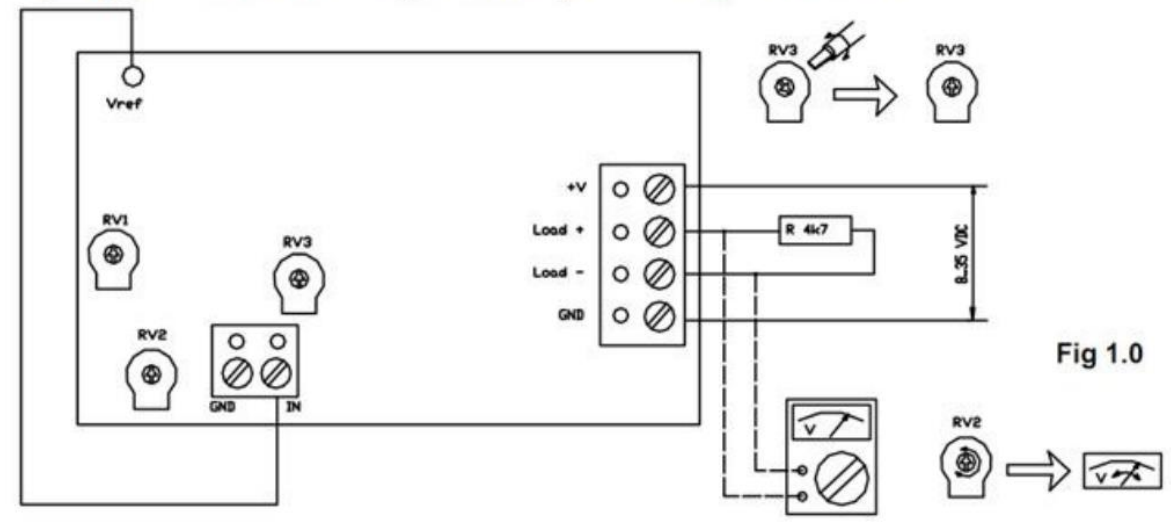

\section{Different configurations}

Fiqure A:

Standard configuration, use a separate control voltage.

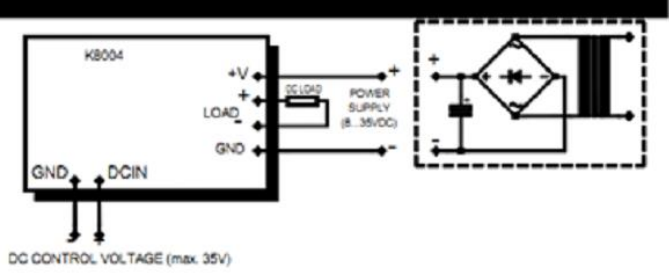

F Figure B:

Connection to one of the analogue outputs of the K8000 interface card. If DAC1 is used then the circuit can be controlled with the demo program, "dimmer".

The circuit can also be tested with the test program of the K8000.

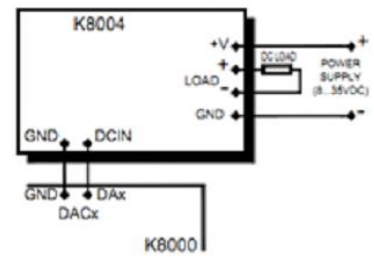

D Figure C:

Internal reference voltage used as control voltage.

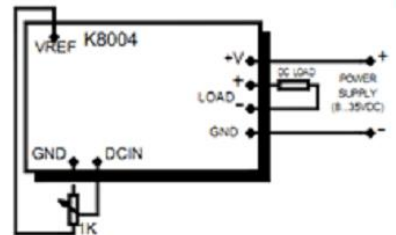




\section{Setting up}

- RV1: setting the minimum output voltage.

Set the control voltage to zero (perhaps by disconnecting it). An initial pre-voltage can then be adjusted using preset RV1. This is especially useful with motors (in order to overcome mechanical resistance) and with halogen lamps (in order to pre-heat the filament).

- RV2: setting the maximum output voltage.

Set the control voltage to the maximum voltage that you are going to use. The maximum output voltage can be adjusted with the preset, RV2 (useful for limiting motor speed or light intensity).

- RV3: setting the output frequency.

If an irritating noise can be heard in the load, then it can be resolved by adjusting the output frequency. The normal position of this preset is the middle of its range. 
APPENDIX L

DATASHEET FOR NAPKIN TRAY LEAD SCREW STEPPER MOTOR 
Website:

http://www.haydonkerk.com/LinearActuatorProducts/StepperMotorLinearActuators/LinearActuatorsHy brid/LinearActuatorPartNumbers/tabid/205/Default.aspx

\section{PART NUMBER CONSTRUCTION}

\section{Hybrid Stepper Motor Linear Actuators}

For Haydon Kerk Motor Series 21000, 28000, 28000 Double Stack, 35000,35000 Double Stack,

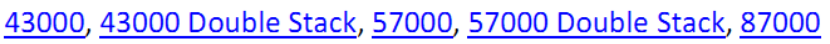

Example Part Number: E43H4N-05-900

$\begin{array}{lllllllll}\underline{E} & \underline{4} & \underline{H} & \underline{4} & \underline{N} & - & \underline{05} & - & \underline{900}\end{array}$

PART NUMBER DESIGNATIONS FOR HYBRID STEPPER MOTOR LINEAR ACTUATORS

Prefix

(only when using the following)

$\mathrm{E}=$ External

$\mathbf{E}$

$\mathrm{P}=$ Proximity Sensor

$\mathrm{S}=$ Home Switch

$\mathrm{T}=$ High Temp

\section{Style}

$\mathbf{F}=1.8^{\circ}$ Non-captive

$\mathbf{H}=1.8^{\circ}$ Captive

$\mathbf{H}=1.8^{\circ}$ Captive (use "E" prefix for "External")

$\mathrm{J}=0.9^{\circ}$ Non-captive

H $\quad \mathbf{K}=0.9^{\circ}$ Captive

$\mathbf{K}=0.9^{\circ}$ Captive (use "E" prefix for "External")

$\mathbf{L}=1.8^{\circ}$ Double Stack, Non-Captive

$\mathbf{M}=1.8^{\circ}$ Double Stack, Captive

$M=1.8^{\circ}$ Double Stack (use "E" prefix for

"External")

Code ID*

Resolution Travel/Step

Example:

$\mathrm{N} \quad \mathrm{N}=$ travels .00012 -in per step

> Single Stack: Refer to chart

> Double Stack: Refer to chart
Series

Number

Designation

$21=21000$

$4328=28000$

$35=35000$

$43=43000$

$57=57000$

$87=87000$

Coils

4 = Bipolar (4 wire)

$46=$ Unipolar (6 Wire)

$\mathbf{G}=$ Integrated Programmable

Drive

Voltage

Examples:

$0505=5 \mathrm{VDC}$

$12=12 \mathrm{VDC}$

Custom V Available 


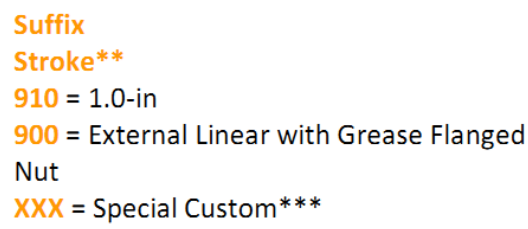

* Refer to Travel/Step chart on motor series product page by clicking product number above

**Refer to Stroke chart on Captive motor series product page

*** Special part numbers for custom screw lengths and design options will require an issued 3 digit suffix number. Please contact our sales or applications engineering department for assistance

EXAMPLES

E43H4N-05-900 = External linear actuator, 43000 series, 1.8 degree, Bipolar coils, .00012 -in travel per step, 5 volt DC.

43H4N-05-910 $=43000$ series, 1.8 degree captive linear actuator, Bipolar, .00012-in travel per step, 5 volt DC, 1.0-in stroke. 
Website:

http://www.haydonkerk.com/LinearActuatorProducts/StepperMotorLinearActuators/LinearActuatorsH ybrid/tabid/73/Default.aspx

\section{SELECTION OF LINEAR ACTUATOR PROTOTYPES}

Linear Actuator Types: Captive, External, and Non-Captive

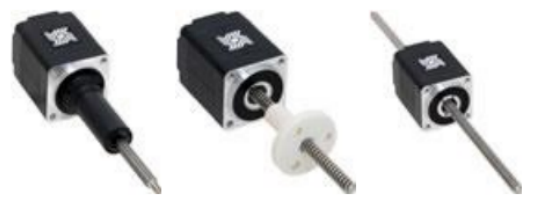

Haydon Kerk Motion Solutions offers a full range of linear actuators from size 8 to size 34 in a wide range of force outputs. All stepper motor linear actuators can be customized for application specific needs.

Series
RESOURCES

" Wiring Diagram

" Stepping Sequence

"Step Movement - Hybrids

" Step Movement - Hybrid Double Stack

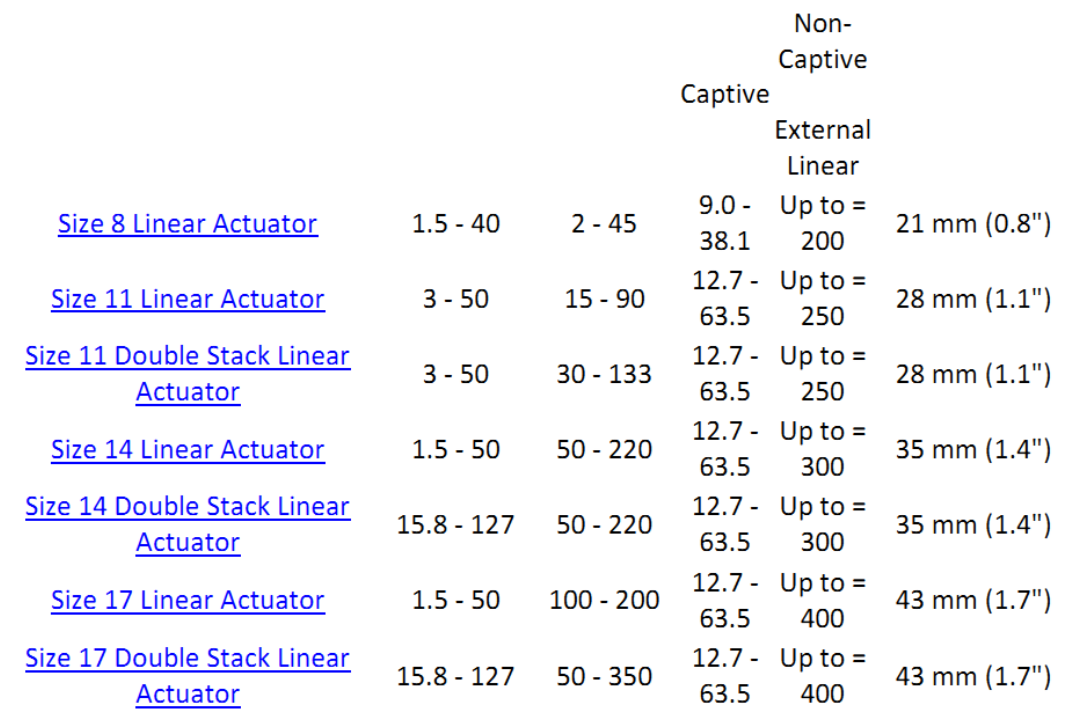




\begin{tabular}{|c|c|c|c|c|c|}
\hline Size 23 Linear Actuator & $4-50$ & $300-880$ & $\begin{array}{c}12.7- \\
63.5\end{array}$ & $\begin{array}{c}\text { Up to }= \\
500\end{array}$ & $57 \mathrm{~mm}\left(2.3^{\prime \prime}\right)$ \\
\hline$\frac{\text { Size } 23 \text { Double Stack Linear }}{\text { Actuator }}$ & $12.7-127$ & $150-880$ & $\begin{array}{c}12.7- \\
63.5\end{array}$ & $\begin{array}{l}\text { Up to }= \\
500\end{array}$ & $57 \mathrm{~mm}\left(2.3^{\prime \prime}\right)$ \\
\hline Size 34 Linear Actuator & $12.7-127$ & $400-2200$ & $\begin{array}{c}12.7- \\
63.5\end{array}$ & $\begin{array}{l}\text { Up to }= \\
500\end{array}$ & 87 mm (3.4") \\
\hline
\end{tabular}

HAYDON HYBRID LINEAR ACTUATORS: WIRING DIAGRAM Hybrid Actuator Wiring Diagram
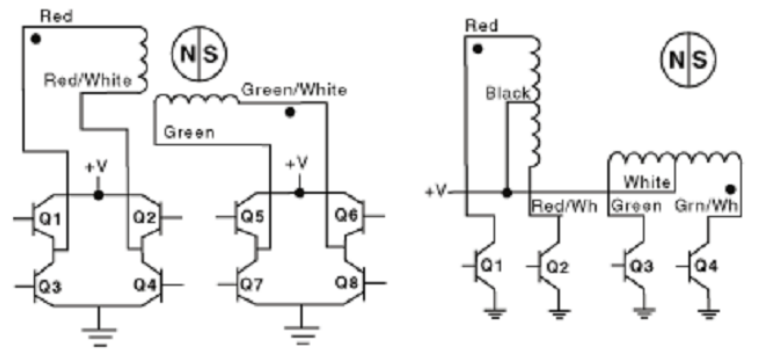

HAYDON HYBRID LINEAR ACTUATORS: STEPPING SEQUENCE

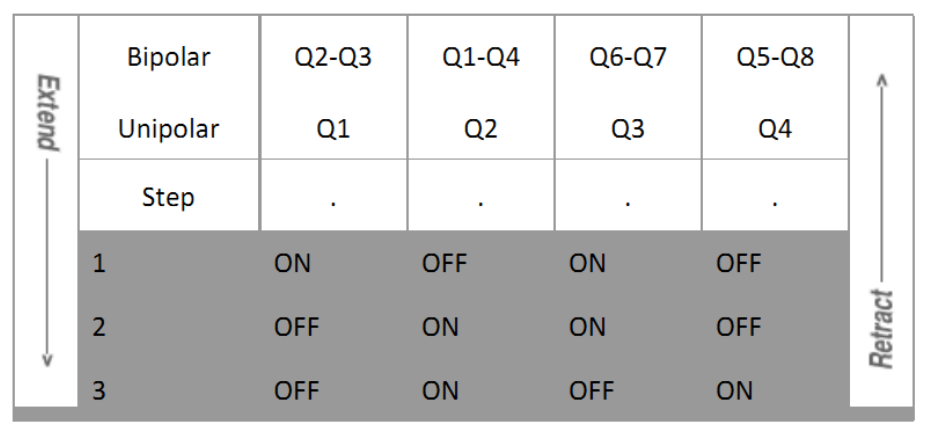




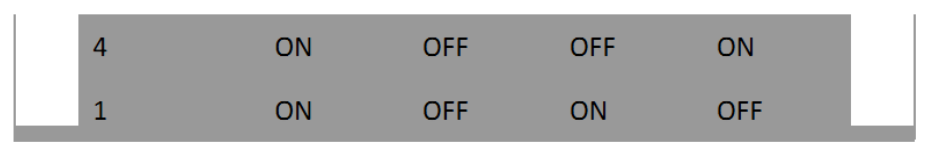

LINEAR TRAVEL PER STEP CHART - HYBRIDS STEPPER MOTOR LINEAR ACTUATOR

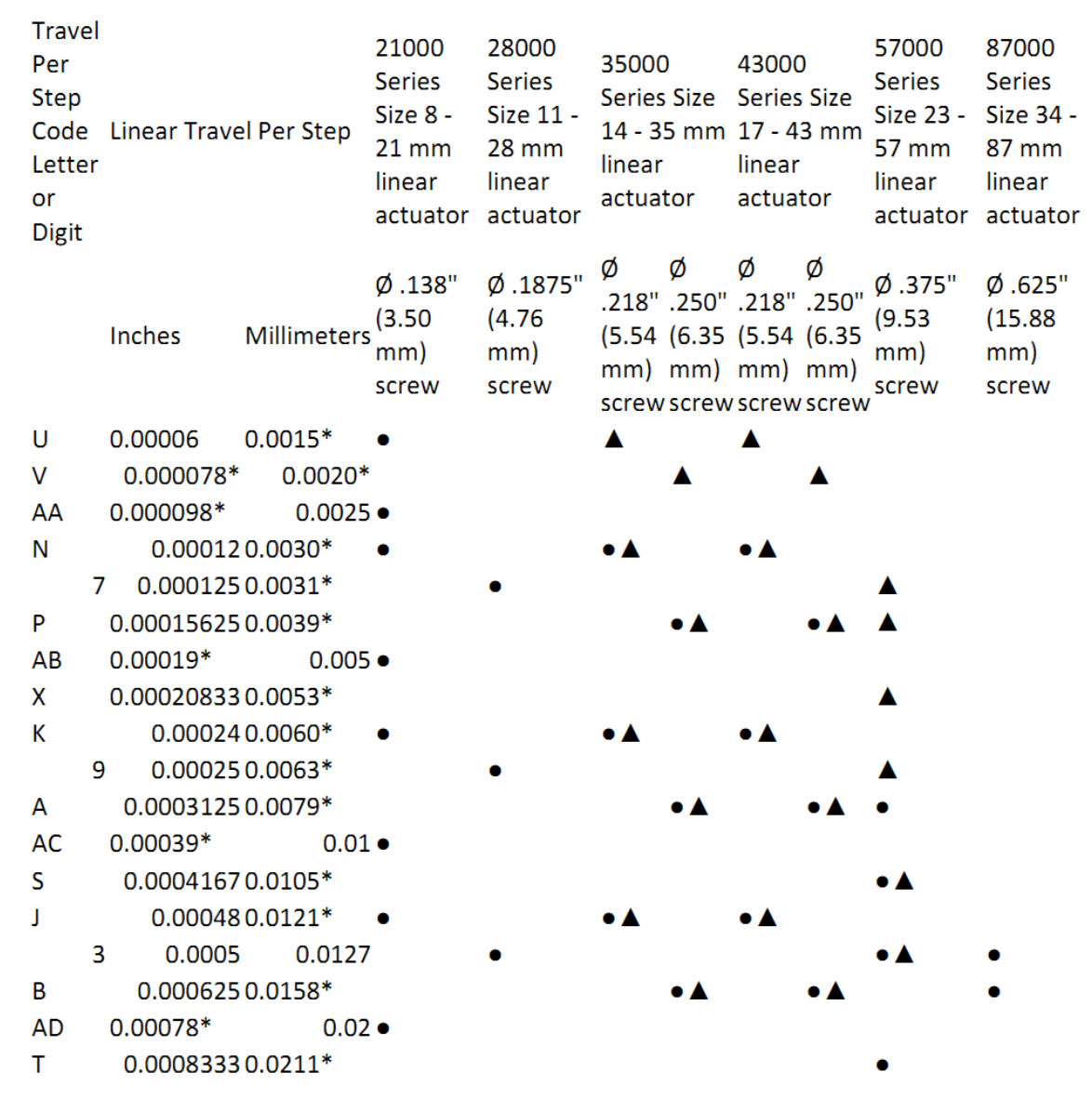




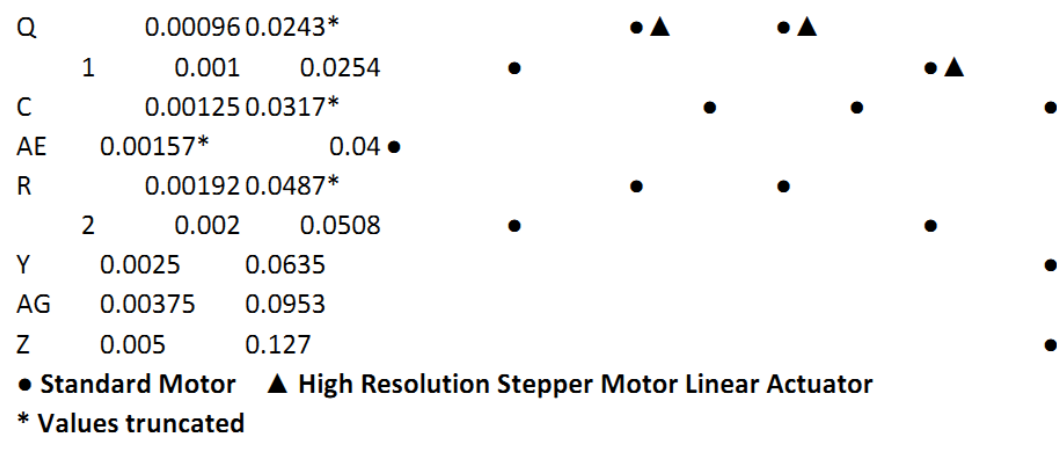

LINEAR TRAVEL PER STEP CHART - HYBRID DOUBLE STACK STEPPER MOTOR LINEAR ACTUATOR

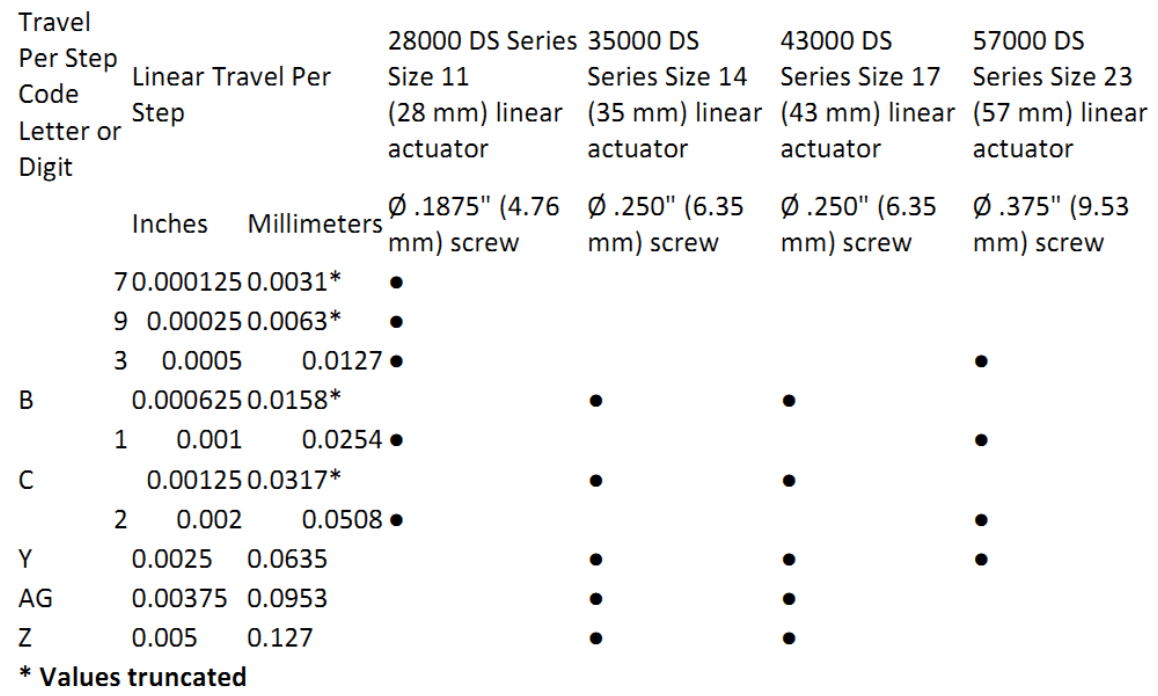


APPENDIX M

DATASHEET FOR BIPOLAR STEPPER MOTOR DRIVER FOR NAPKIN TRAY LIFTING MECHANISM 


\section{Website: \\ http://www.kitsrus.com/pdf/k158.pdf \\ K158. BI-POLAR STEPPER MOTOR DRIVER}

This kit will drive a bi-polar stepper motor driver using externally supplied $5 \mathrm{~V}$ levels for steping and direction.

These usually come from software running in a computer.

Google 'Stepper Motor Software' and will see a range of controller freeware available. Also go to

http://www.metalworking.com/

http://www.kellyware.com/

http://www.thegallows.com/stepster.htm

http://www.stepperworld.com/

http://www.ams2000.com

Construction. Follow the overlay on the PCB. Add the lowest height components first - the resistors and diodes. Note there are seven links to add to the board. For the six short links use offcuts from the resistor legs. For the longer link we have provided a $1 \frac{1}{2}$ " of tinned copper wire. There are 4 pins you can place in the DIR and STEP positions if you wish to use the pins.

We have assumed that the operation of stepper motors is known to you. If not google the topic and also see our Kits 109,113 and 179.

Operation. Attach a bi-polar stepper motor to the TO MOTOR terminals. Power to the Kit can be the same or different depending on the stepper motor being driven.

The DIRection and STEP inputs are opto-isolated by the 4 N25 IC's.

DIRection. This is controlled by a $0 \mathrm{~V}$ or $5 \mathrm{~V}$ applied between the pins.

STEP. A $5 \mathrm{~V}$ to $0 \mathrm{~V}$ transistion between the pins will step the motor one position. The step direction will be according to the voltage applied to the DIRection pins.

$9 \mathrm{~V}$ was used. The STEP and DIRection negative input pins were tied together and connected to system ground.

Resistors 5\%, 1/4W, carbon

150R brown green brown R9 R10 R15 R16

$\mathrm{IK}$ brown black red

R1 R2

$2 \mathrm{~K} 2$ red red red

R7 R8 R13 R14

$10 \mathrm{~K}$ brown black orange

R3 R4

$12 \mathrm{~K}$ brown red orange

R5 R6 R11 R12

$100 \mathrm{uF} / 35 \mathrm{~V}$ ecap

$10 \mathrm{uF}$ mini ecap

$100 \mathrm{uF} / 63 \mathrm{~V}$ ecap

$1 \mathrm{~N} 4148$ diode

104 mono

$\mathrm{C} 1$

$104 \mathrm{n}$

4013 IC

4030 IC

$4 \mathrm{~N} 25 \mathrm{IC}$

BC547B transistors

IRFZ44

MTP2955

6 pin IC socket

14 pin IC socket

2 pole terminal block

C4

D1 - D8

inned copper wire

$\mathrm{K} 158 \mathrm{PCB}$

\section{$\mathrm{ICl}$}

IC2

IC3 IC4

IC5

All the power inputs were connected together. The CLOCK was connected to STEP, and the RESET was connected to DIRection. Pushing the CLOCK button then advanced the motor one notch. Pressing CLOCK with the RESET button also depressed and pressed down advanced the motor one notch the other way.

Software does the same thing but using a PC.

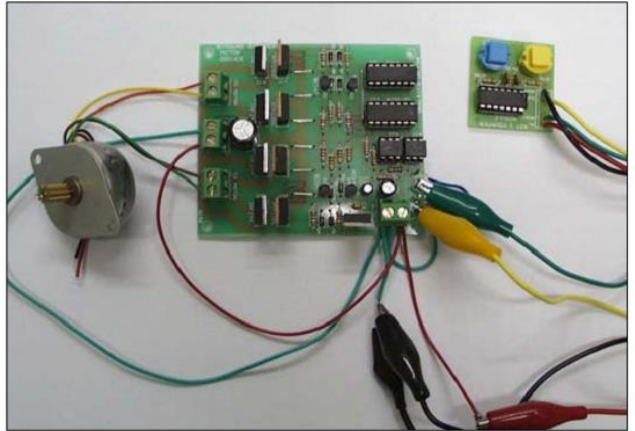

The full color photo can be downloaded from http://www.kitsrus.com/ing/k158 l.jpg

This kit is based on a kit from Oatley Electronics, Australia. It is adapted here with permission.

You can read about about other stepper motor kits:

http://www.kitsrus.com/pdf/k109.pdf

http://www.kitsrus.com/pdf/k113.pdf

$\underline{\text { http://www.kitsrus.com/pdf/k179.pdf }}$

(Documentation march 30, 2003.)

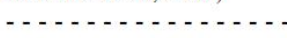

We used the debounced Counter Module of our Kit 1 to

test Kit 158. You can get the schematic for it here http://www.kitsrus.com/pdf/k1.pd

The unipolar stepper motor is connected as a bipolar motor (the 2 center wires of the 6 wire motor are unused.) 
K158. BI-POLAR STEPPER MOTOR DRIVER

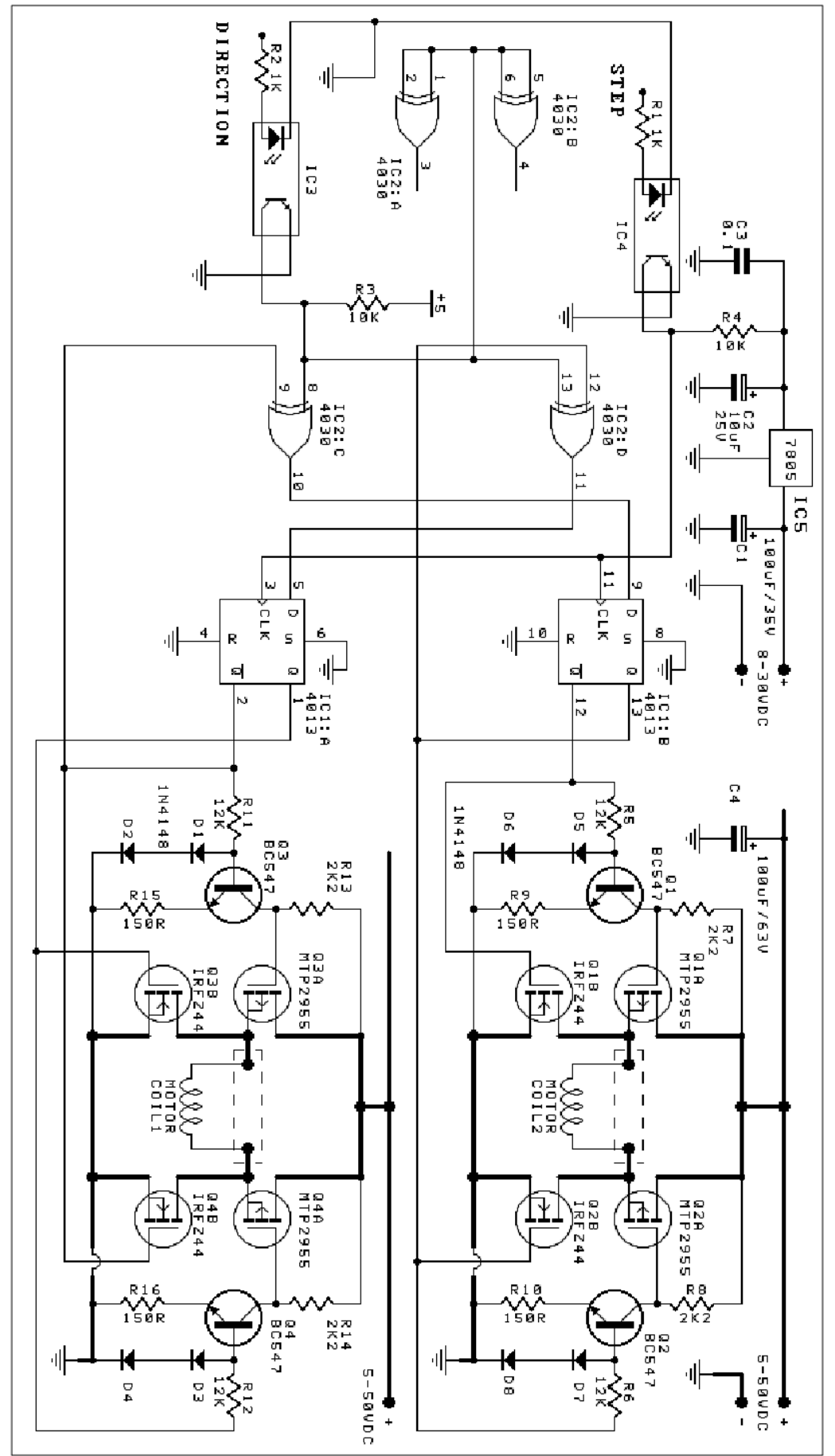


APPENDIX N

DATASHEET FOR ADHESIVE TAPE RENEWAL MOTOR 
Website:

http://www.batteryspace.com/prod-specs/3840.pdf

DC Motor: High Torque Mini 12V DC Gear Motor, 50 rpm

for Hobby Projects

\section{(Part\# MT-050)}
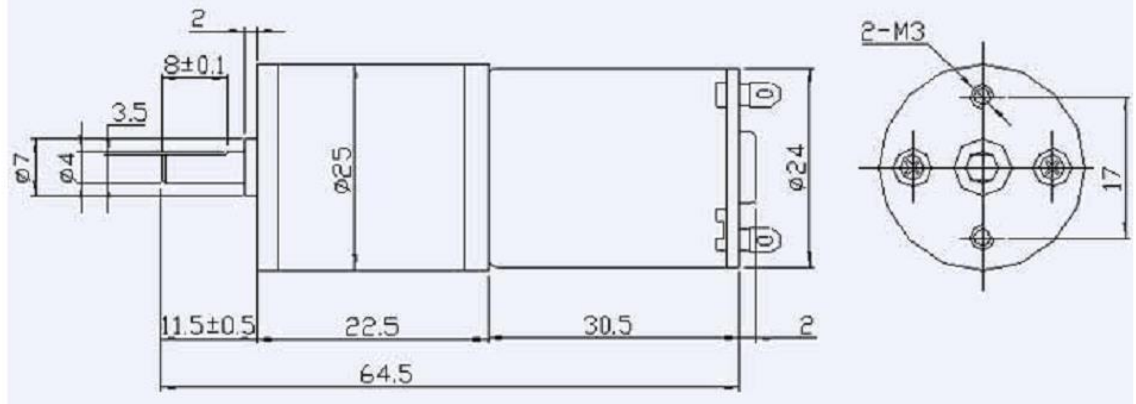

Motor Spec (Model\# 25GA370D12, i = 1:56)

1. Voltage: $12.0 \mathrm{VDC}$

2. Output Speed: 50 RPM

3. No-Load output current: $=<50 \mathrm{~mA}$

4. Rotation Output: $\mathrm{CW} / \mathrm{CCW}$

5. Noise: No Gear Noise

6. Stall output: : Slip Gear, Broken Gear is no allowed

7. Output shaft of the axial clearance: $=<0.1 \sim 0.3 \mathrm{~mm}$, Horizontal clearance requirement $=<0.05$

\section{Electrical Spec}

1. No-Load Speed: 3000 RPM

2. No-Load Current: $=<40 \mathrm{~mA}$

3. Rotation: $\mathrm{CW}$

4. Motor\#: 370 


\section{APPENDIX O}

\section{DATASHEETS FOR POWER SUPPLY UNITS}


Website:

http://www.meanwell.com/search/s-145/S-145-spec.pdf

POWER SUPPLY UNIT (12V)

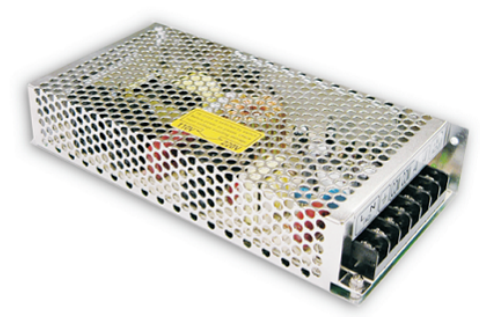

Features:

- AC input range selectable by switch

- Protections: Short circuit / Overload / Over voltage

- Cooling by free air convection

- $100 \%$ full load burn-in test

- Fixed switching frequency at $25 \mathrm{KHz}$

- LED indicator for power on

- Made in China for low cost

- High reliability

- 1 year warranty

\begin{tabular}{|c|c|c|c|c|c|c|c|c|}
\hline MODEL & & S-145.5 & S-145-7.5 & S-145-12 & S-145-15 & S-145-24 & S-145-27 & S-145-48 \\
\hline \multirow{11}{*}{ OUTPUT } & DC VOLTAGE & $5 \mathrm{~V}$ & $7.5 \mathrm{~V}$ & $12 \mathrm{~V}$ & $15 \mathrm{~V}$ & $24 \mathrm{~V}$ & $27 \mathrm{~V}$ & $48 \mathrm{~V}$ \\
\hline & RATED CURRENT & $25 \mathrm{~A}$ & $18 \mathrm{~A}$ & $12 \mathrm{~A}$ & $9.6 \mathrm{~A}$ & $6 \mathrm{~A}$ & $5.3 \mathrm{~A}$ & $3 A$ \\
\hline & CURRENT RANGE & 0 25A(30A max.) & $0 \sim 18 \mathrm{~A}(21 \mathrm{~A}$ max. $)$ & $0 \sim 12 \mathrm{~A}(14 \mathrm{~A} \max$. & 0 9.6A(11A max.) & $0 \sim 6 \mathrm{~A}(7 \mathrm{~A}$ max. $)$ & $0 \sim 5.3 \mathrm{~A}$ & $0 \sim 3 A$ \\
\hline & RATED POWER & $125 \mathrm{~W}$ & $135 \mathrm{~W}$ & $144 \mathrm{~W}$ & $144 \mathrm{~W}$ & $144 \mathrm{~W}$ & $143.1 \mathrm{~W}$ & $144 \mathrm{~W}$ \\
\hline & RIPPLE \& NOISE (max.) Note.2 & $100 \mathrm{mVp}-\mathrm{p}$ & $120 \mathrm{mVp}-\mathrm{p}$ & $120 \mathrm{mVp}-\mathrm{p}$ & $120 \mathrm{mVp}-\mathrm{p}$ & $150 \mathrm{mVp} \cdot \mathrm{p}$ & $200 \mathrm{mVp}-\mathrm{p}$ & $240 \mathrm{mVp} \cdot \mathrm{p}$ \\
\hline & \begin{tabular}{|l|} 
VOLTAGE ADJ. RANGE \\
\end{tabular} & $4.5 \sim 5.5 \mathrm{~V}$ & $6 \sim 8.3 \mathrm{~V}$ & $10.6 \sim 13.2 \mathrm{~V}$ & $13.2 \sim 16.5 \mathrm{~V}$ & $21 \sim 28 \mathrm{~V}$ & $24.5 \sim 29.5 \mathrm{~V}$ & $43.2 \sim 52.8 \mathrm{~V}$ \\
\hline & VOLTAGE TOLERANCE Note.3 & $\pm 2.0 \%$ & $\pm 1.0 \%$ & $\pm 1.0 \%$ & $\pm 1.0 \%$ & $\pm 1.0 \%$ & $\pm 1.0 \%$ & $\pm 1.0 \%$ \\
\hline & \begin{tabular}{|l|l} 
LINE REGULATION \\
\end{tabular} & $\pm 0.5 \%$ & $\pm 0.5 \%$ & $\pm 0.5 \%$ & $\pm 0.5 \%$ & $\pm 0.5 \%$ & $\pm 0.5 \%$ & $\pm 0.5 \%$ \\
\hline & LOAD REGULATION & $\pm 0.5 \%$ & $\pm 0.5 \%$ & $\pm 0.5 \%$ & $\pm 0.5 \%$ & $\pm 0.5 \%$ & $\pm 0.5 \%$ & $\pm 0.5 \%$ \\
\hline & SETUP, RISE TIME & \multicolumn{7}{|c|}{$100 \mathrm{~ms}, 50 \mathrm{~ms}$ at full load } \\
\hline & HOLD UP TIME (Typ.) & \multicolumn{7}{|l|}{$24 \mathrm{~ms}$ at full load } \\
\hline \multirow{6}{*}{ INPUT } & VOLTAGE RANGE & \multicolumn{7}{|c|}{$88 \sim 132 \mathrm{VAC} / 176 \sim 264 \mathrm{VAC}$ selected by switch $\quad 248 \sim 370 \mathrm{VDC}$} \\
\hline & FREQUENCY RANGE & \multicolumn{7}{|c|}{$47 \sim 63 \mathrm{~Hz}$} \\
\hline & EFFICIENCY (Typ.) & $78 \%$ & $80.5 \%$ & $80.5 \%$ & $81 \%$ & $83.5 \%$ & $85 \%$ & $83.5 \%$ \\
\hline & AC CURRENT (Typ.) & $2.6 \mathrm{~A} / 115 \mathrm{VAC}$ & $1.3 \mathrm{~A} / 230 \mathrm{VAC}$ & & & & & \\
\hline & INRUSH CURRENT (Typ.) & COLD START 32 & & & & & & \\
\hline & LEAKAGE CURRENT & $<3.5 \mathrm{~mA} / 240 \mathrm{VAC}$ & & & & & & \\
\hline \multirow{4}{*}{ PROTECTION } & \multirow{2}{*}{ OVERLOAD } & \multicolumn{7}{|c|}{$125 \sim 165 \%$ rated output power } \\
\hline & & \multicolumn{7}{|c|}{ Protection type: Shut down o/p voltage, re-power on to recover } \\
\hline & 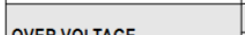 & $5.6 \sim 6.8 \mathrm{~V}$ & $8.6 \sim 10 \mathrm{~V}$ & $13.8 \sim 16.2 \mathrm{~V}$ & $17.3 \sim 20.3 \mathrm{~V}$ & $29 \sim 32 \mathrm{~V}$ & $31.05 \sim 36.45 \mathrm{~V}$ & $55.2 \sim 64.8 \mathrm{~V}$ \\
\hline & OVER VOLTAGE & \multicolumn{7}{|c|}{ Protection type : Shut down o/p voltage, re-power on to recover } \\
\hline \multirow{5}{*}{ ENVIRONMENT } & WORKING TEMP. & \multicolumn{7}{|c|}{$-10 \sim+60^{\circ} \mathrm{C}$ (Refer to "Derating Curve") } \\
\hline & WORKING HUMIDITY & \multicolumn{7}{|c|}{$20 \sim 90 \%$ RH non-condensing } \\
\hline & STORAGE TEMP., HUMIDITY & \multicolumn{7}{|c|}{$.20 \sim+85^{\circ} \mathrm{C}, 10 \sim 95 \% \mathrm{RH}$} \\
\hline & TEMP. COEFFICIENT & \multicolumn{7}{|c|}{ $\pm 0.03 \% / \mathrm{C}\left(0 \sim 50^{\circ} \mathrm{C}\right)$} \\
\hline & VIBRATION & \multicolumn{7}{|c|}{$10 \sim 500 \mathrm{~Hz}, 2 \mathrm{G} 10 \mathrm{~min} .11$ cycle, $60 \mathrm{~min}$. each along $X, Y, Z$ axes } \\
\hline \multirow{5}{*}{$\begin{array}{l}\text { SAFETY \& } \\
\text { EMC }\end{array}$} & SAFETY STANDARDS & \multicolumn{7}{|c|}{ Design refer to UL 1012} \\
\hline & WITHSTAND VOLTAGE & \multicolumn{7}{|c|}{ I/P-O/P:1.5KVAC I/P.FG:1.5KVAC O/P.FG:0.5KVAC } \\
\hline & ISOLATION RESISTANCE & \multicolumn{7}{|c|}{ I/P-O/P, I/P-FG, O/P-FG:100M Ohms / 500VDC / $25^{\circ} \mathrm{C} / 70 \%$ RH } \\
\hline & EMC EMISSION & \multicolumn{7}{|c|}{ Compliance to EN55022 (CISPR22) Class B } \\
\hline & EMC IMMUNITY & \multicolumn{7}{|c|}{ Compliance to IEC801-2,3,4, light industry level, criteria A } \\
\hline \multirow{3}{*}{ OTHERS } & MTBF & $286.7 \mathrm{~K}$ hrs min. & MIL-HDBK-217F & $\left(25^{\circ} \mathrm{C}\right)$ & & & & \\
\hline & DIMENSION & \multicolumn{7}{|c|}{$199^{*} 98^{*} 38 \mathrm{~mm}\left(L^{*} W^{*} H\right)$} \\
\hline & \begin{tabular}{|l|} 
PACKING \\
\end{tabular} & \multicolumn{7}{|c|}{$0.71 \mathrm{Kg} ; 30 \mathrm{pcs} / 22.5 \mathrm{Kg} / 1.22 \mathrm{CuFT}$} \\
\hline NOTE & \multicolumn{8}{|c|}{$\begin{array}{l}\text { 1. All parameters NOT specially mentioned are measured at } 230 \mathrm{VAC} \text { input, rated load and } 25^{\circ} \mathrm{C} \text { of ambient temperature. } \\
\text { 2. Ripple } \& \text { noise are measured at } 20 \mathrm{MHz} \text { of bandwidth by using a } 12^{\prime \prime} \text { twisted pair-wire terminated with a } 0.1 \text { uf } \& 47 \text { uf parallel capacitor. } \\
\text { 3. Tolerance : includes set up tolerance, line regulation and load regulation. }\end{array}$} \\
\hline
\end{tabular}


- Mechanical Specification

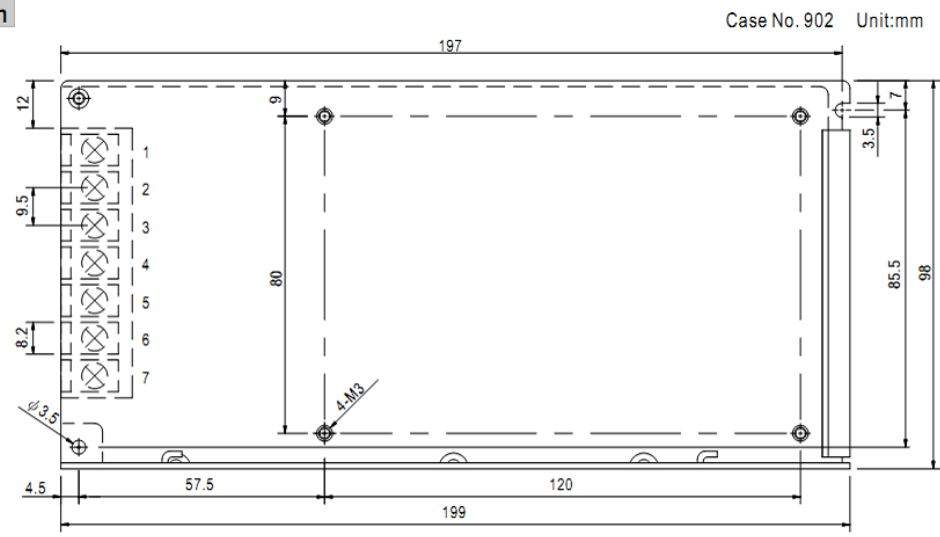

Terminal Pin No. Assignment \begin{tabular}{|l|l|}
\hline Pin No. & Assignment \\
\hline &
\end{tabular}
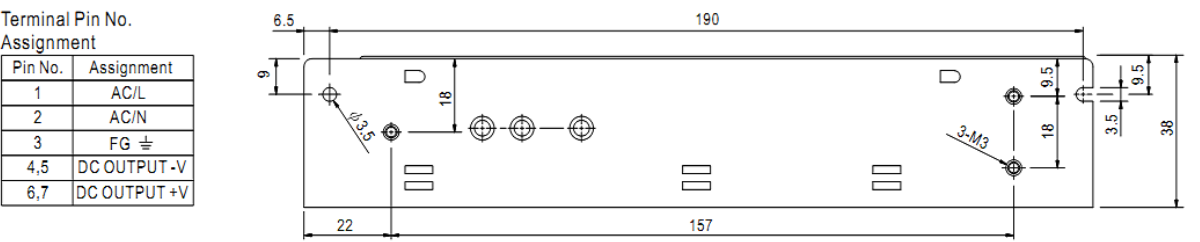

Block Diagram

fosc : $25 \mathrm{KHz}$
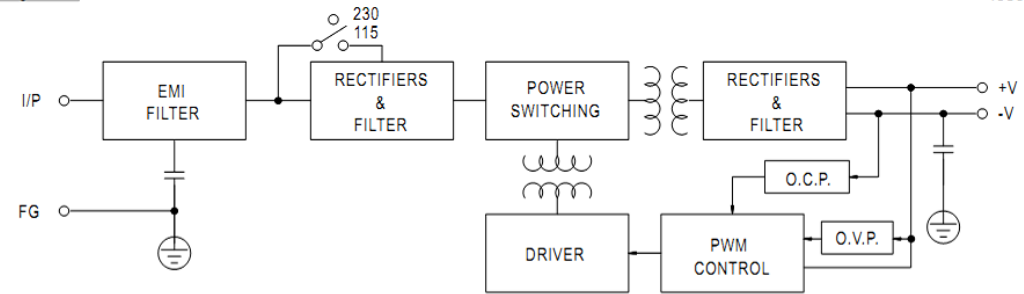

Derating Curve

Static Characteristics (24V)
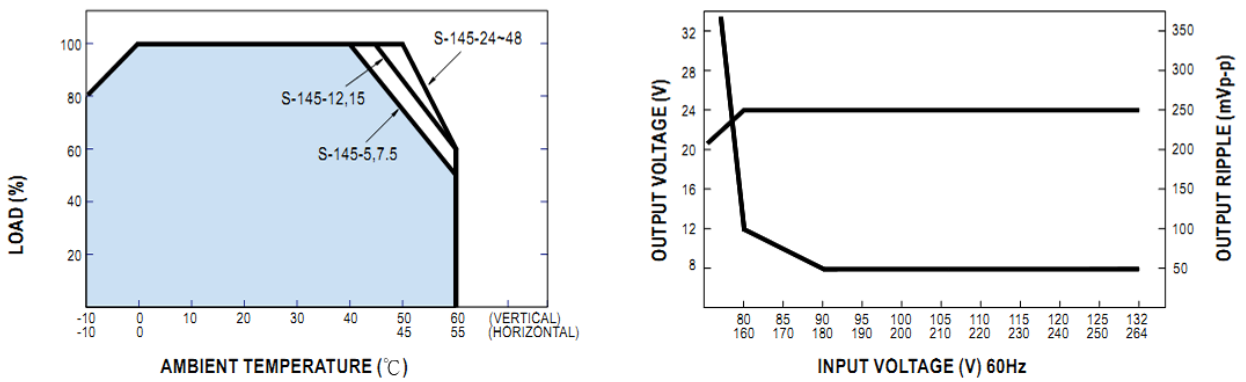


\title{
Website: \\ http://www.hspower.net/en/ProductView.asp?ID=104\&SortID=93 POWER SUPPLY UNIT (36V)
}

\author{
Model : HS-400W \\ Power : 400W \\ Voltage : $12,24,36,48 \mathrm{~V}$ \\ Number of outputs : Single Output \\ Manufacturers : South china starlight electronics co.,ltd,guangzhou

\section{Q Information} \\ 400W Single output switching power supply seriesAC/DC \\ Features : \\ $\diamond$ Full RangeACInputVoltage \\ $\diamond$ Built-inEMIFilter \\ $\diamond 100 \%$ Loaded with high-temperature aging \\ $\diamond$ DCOutputVoltage Adjustable \\ $\diamond$ Short circuit, overload protection $\quad$ Size : $215 * 115 * 50$ \\ InputVoltage------------88 132VAC/176 264VACSwitching Converters \\ Input Frequency----------------------------------47 63HZ

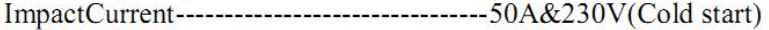 \\ Establishment, increased retention time-------500 ms,50ms, $16 \mathrm{~ms} \& 230 \mathrm{VAC}$ \\ Overload value-------------110\% 200\%Rated output power, Automatic recovery

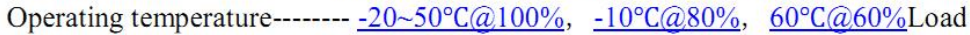 \\ Safety Standards------oetGB4943 \\ Pressure-----------Input to output, Input-to-ground1.5KVAC\&1Minutes \\ Interface Type--------------------------9P/9.5mmTerminal spacing \\ Weight---o-

\begin{tabular}{|c|c|c|c|c|c|c|}
\hline Code & Model & Voltage & Current & Accuracy & Ripple & Efficiency \\
\hline 1077 & HS-400-12 & $12 \mathrm{~V}$ & $33 \mathrm{~A}$ & $\pm 1 \%$ & $120 \mathrm{mV}$ & $80 \%$ \\
\hline 1078 & HS-400-24 & $24 \mathrm{~V}$ & $16.7 \mathrm{~A}$ & $\pm 1 \%$ & $240 \mathrm{mV}$ & $82 \%$ \\
\hline 1079 & HS-400-36 & $36 \mathrm{~V}$ & $11 \mathrm{~A}$ & $\pm 1 \%$ & $360 \mathrm{mV}$ & $82 \%$ \\
\hline 1080 & HS-400-48 & $48 \mathrm{~V}$ & $8.3 \mathrm{~A}$ & $\pm 1 \%$ & $480 \mathrm{mV}$ & $83 \%$ \\
\hline
\end{tabular}

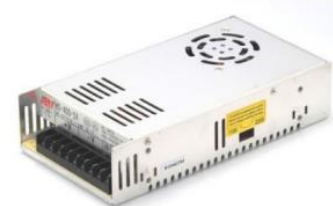




\section{APPENDIX P}

SOURCE CODE FOR CLOTH NAPKIN SINGULATION PROGRAM 


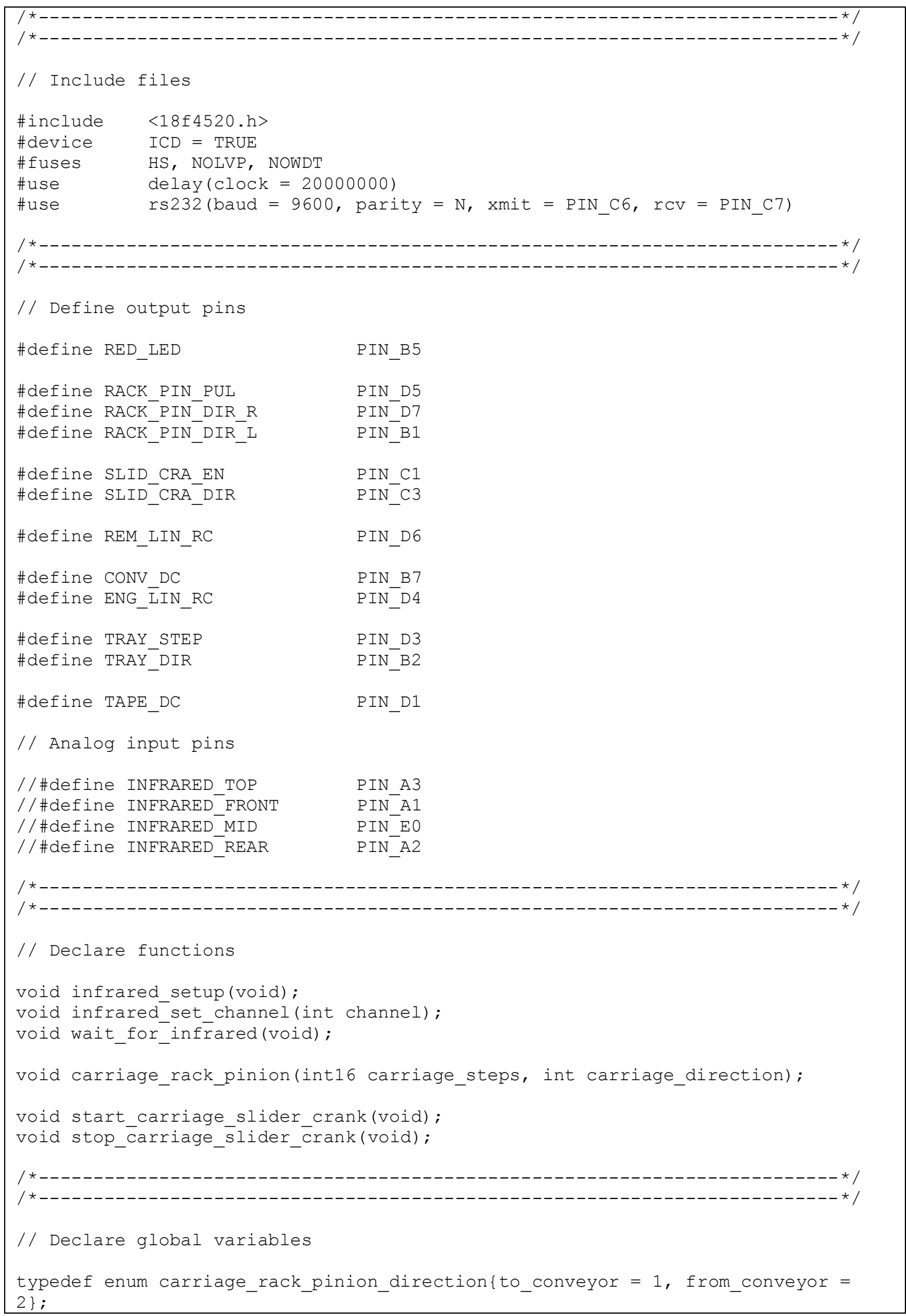




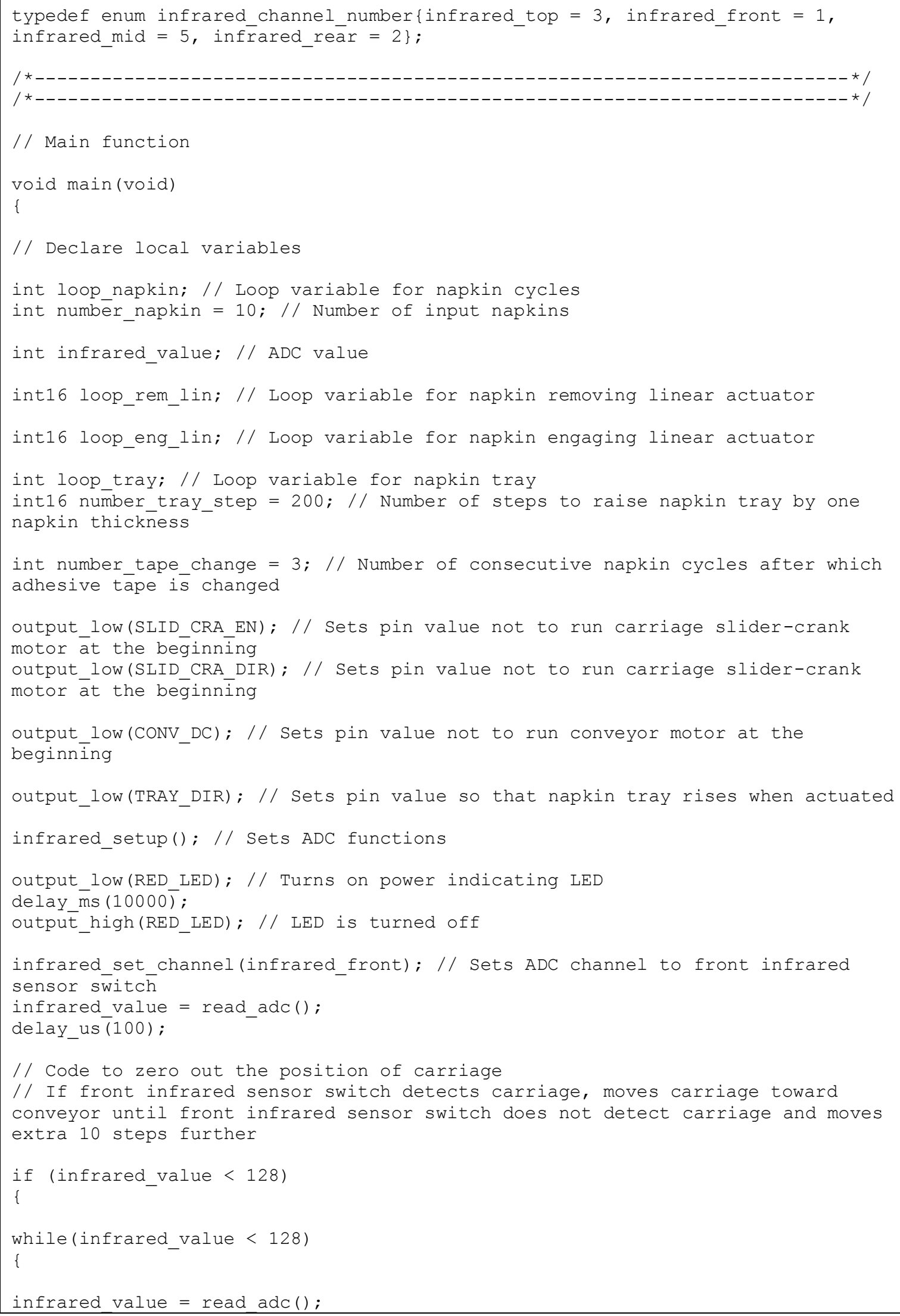




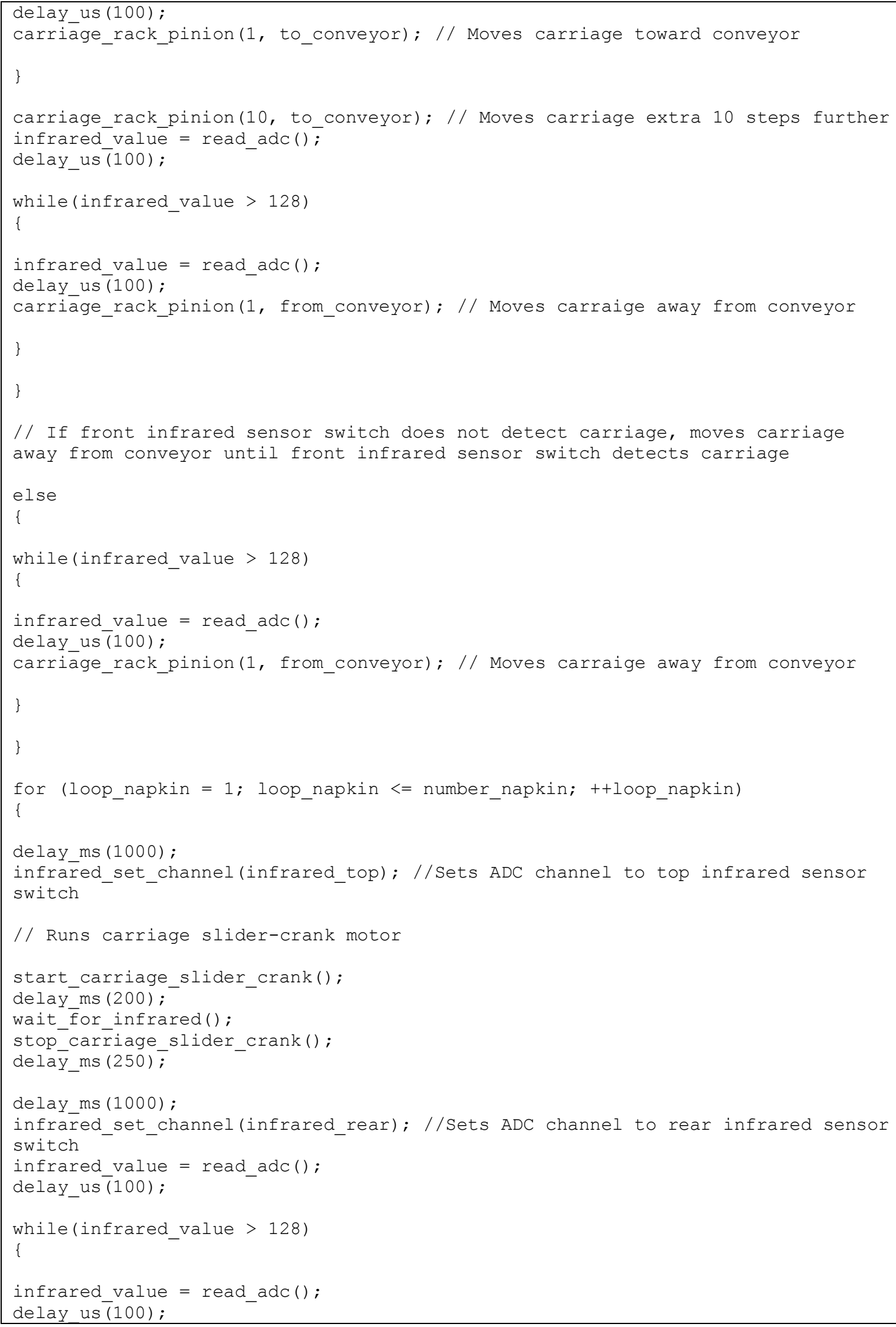




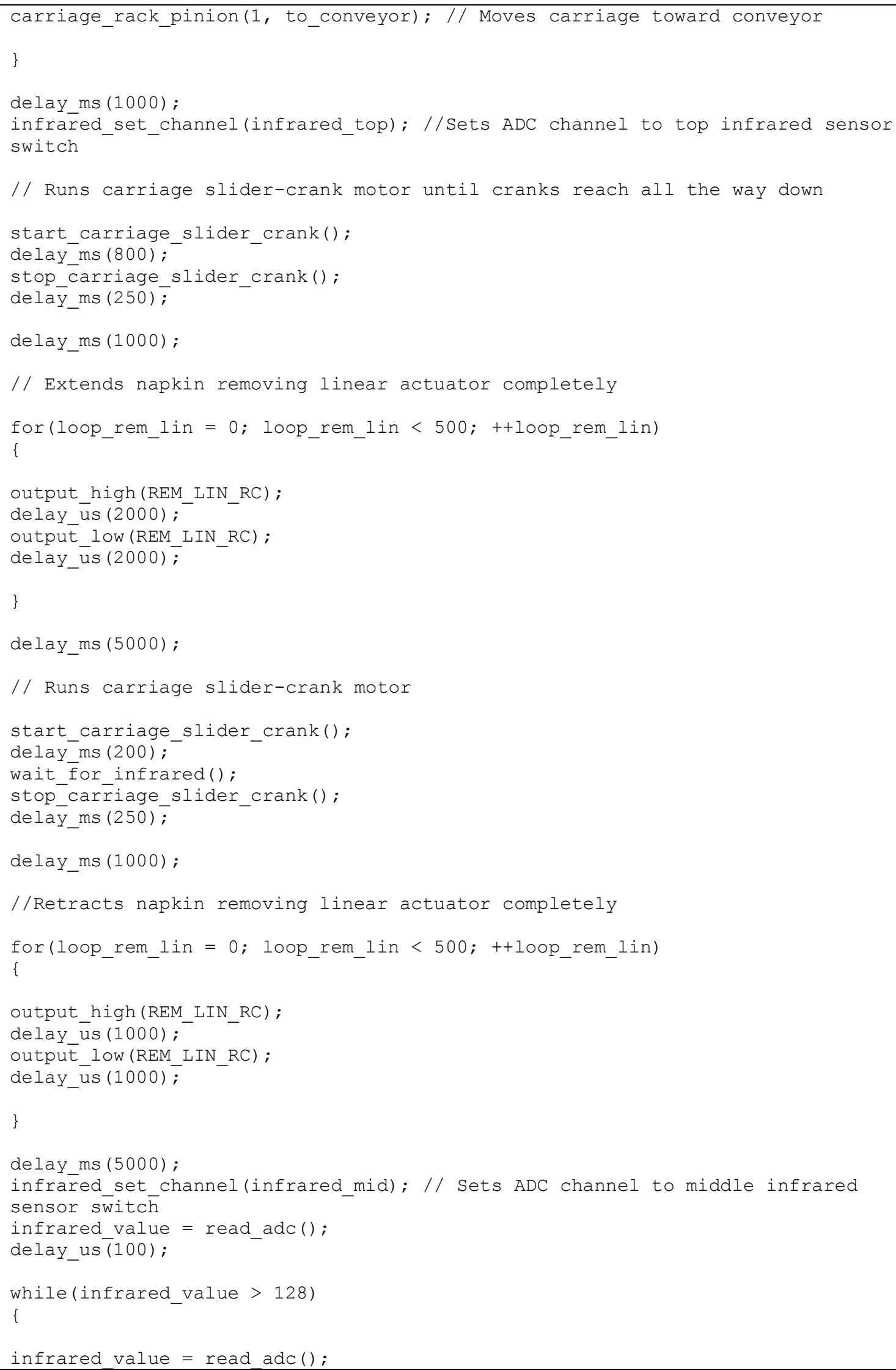




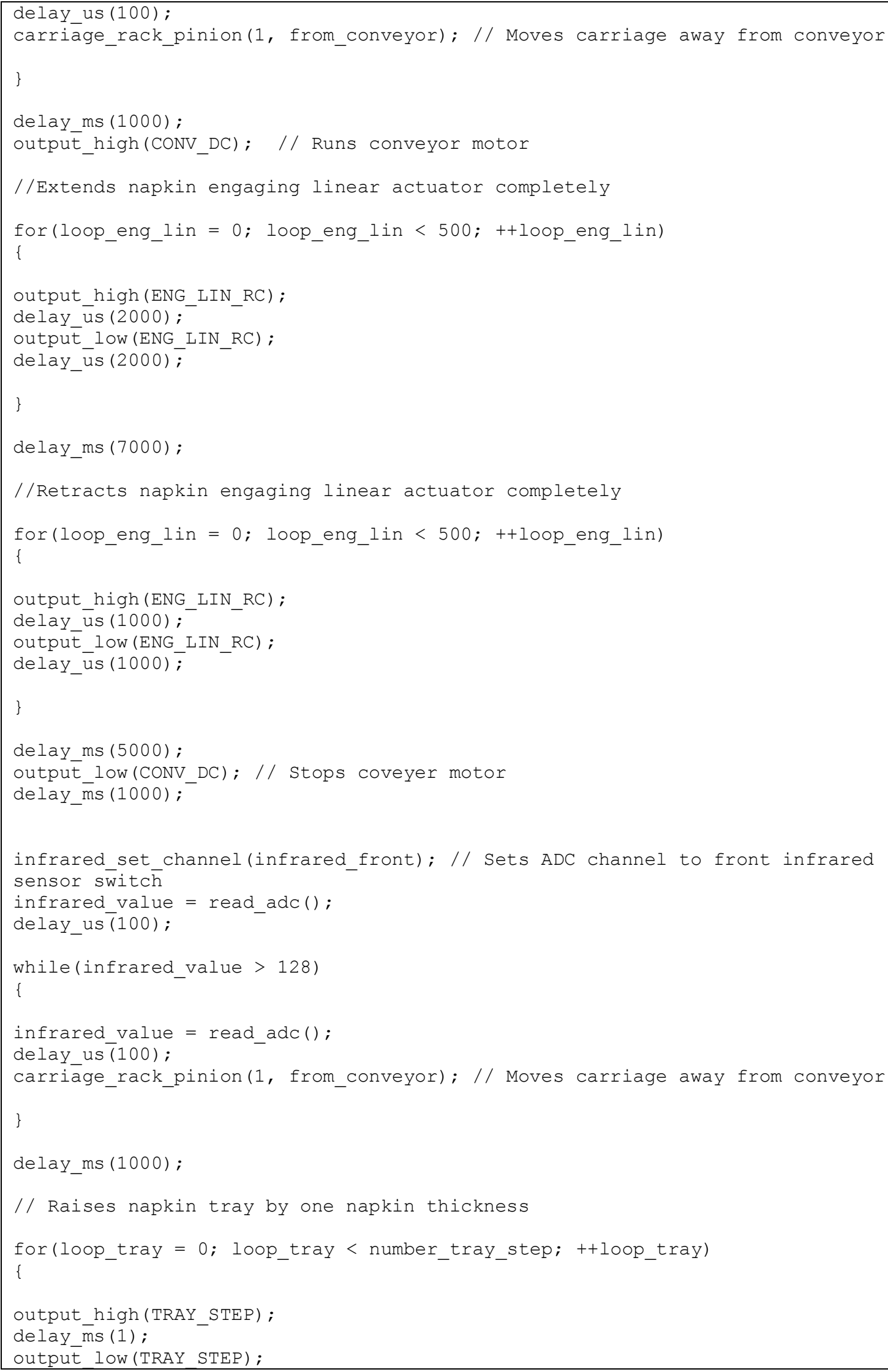




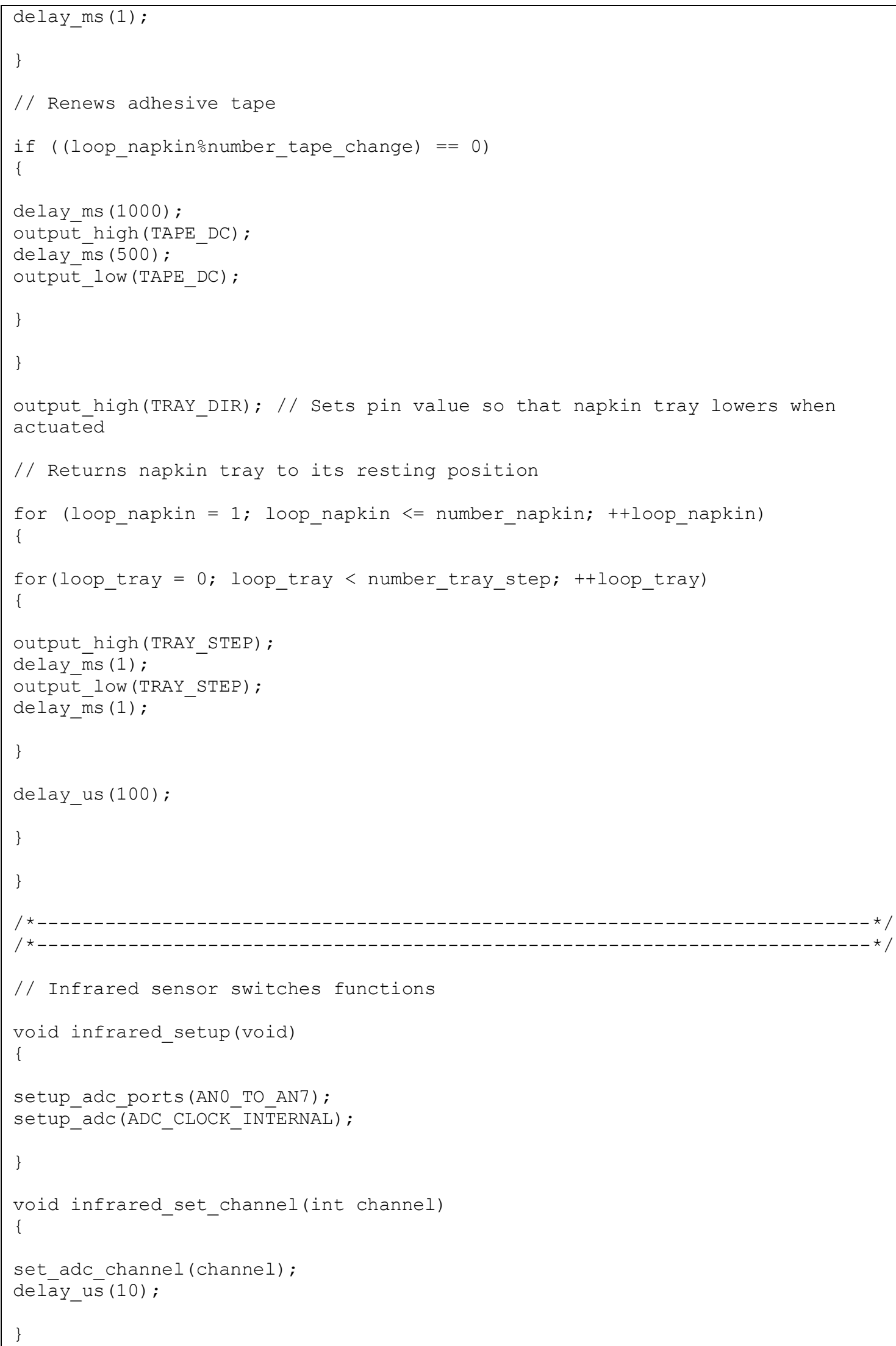




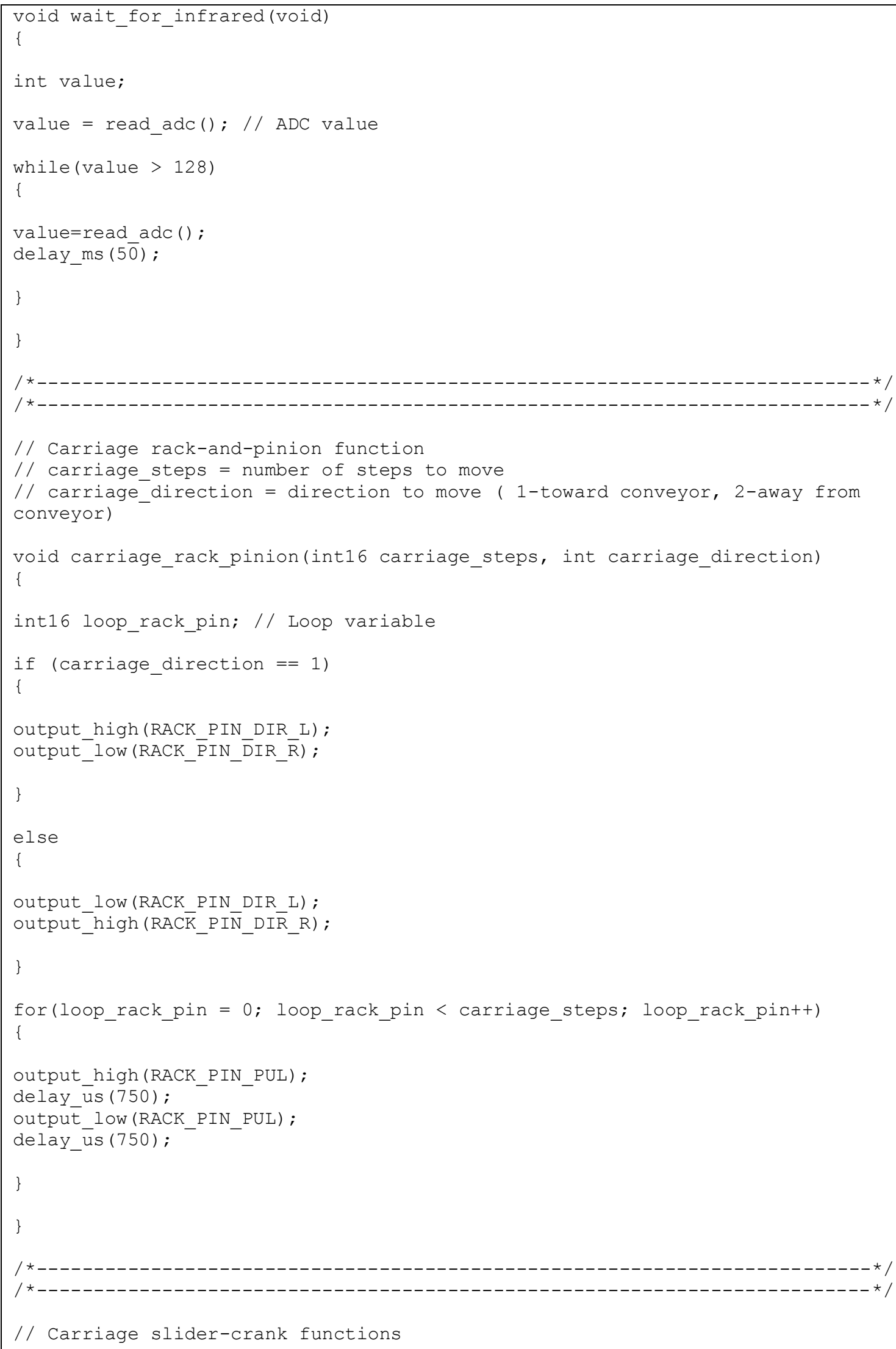




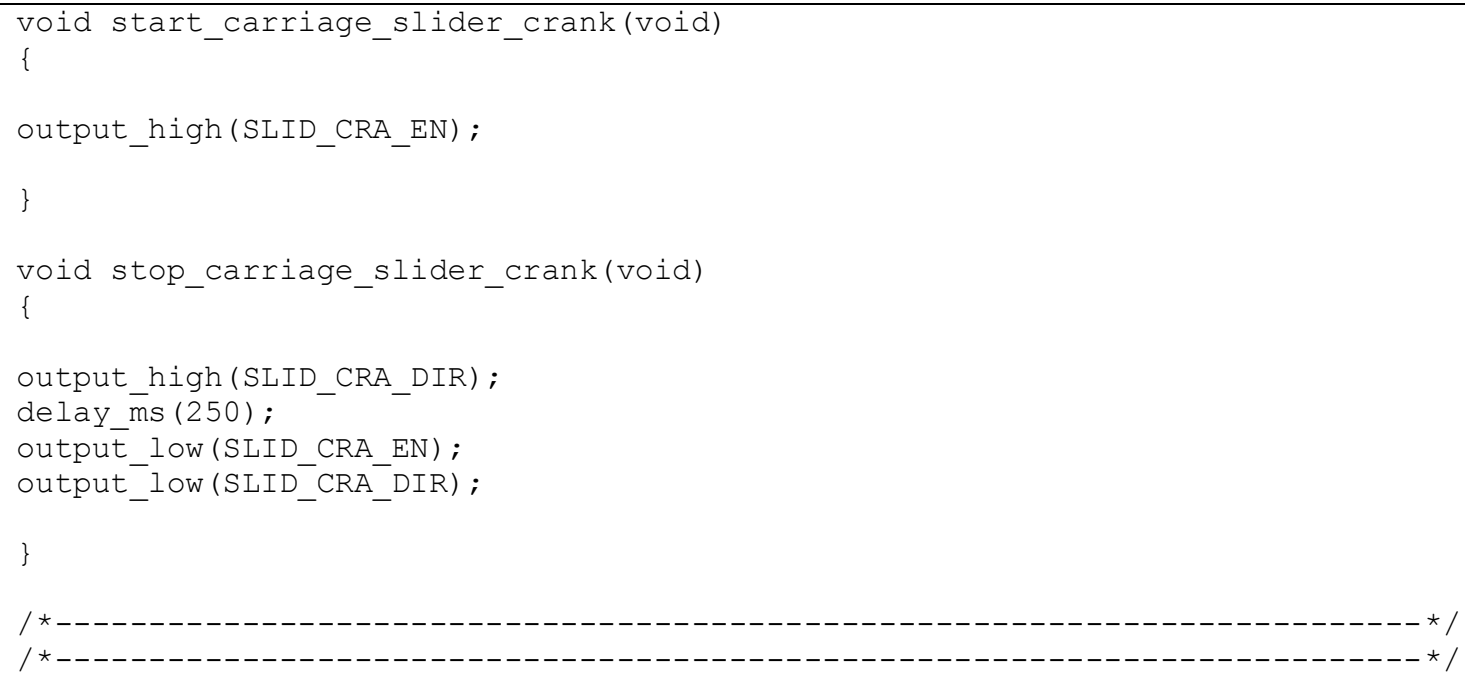


VITA

Shuvra Banik

Candidate for the Degree of

Master of Science

Thesis: CLOTH NAPKIN SINGULATION SYSTEM

Major Field: Mechanical and Aerospace Engineering

Biographical:

Education:

Completed the requirements for the Master of Science in Mechanical and Aerospace Engineering at Oklahoma State University, Stillwater, Oklahoma in December, 2013.

Completed the requirements for the Bachelor of Science in Mechanical Engineering at Bangladesh University of Engineering \& Technology, Dhaka, Bangladesh in 2011.

Experience:

Graduate Teaching Assistant, School of Mechanical and Aerospace Engineering, Oklahoma State University, Stillwater, Oklahoma from August, 2011 to December, 2013.

Industrial Intern, 210 MW Siddhirganj Thermal Power Station, Dhaka, Bangladesh from April, 2010 to May, 2010. 